\title{
Resource allocation and knowledge production : studies in the economics of university research
}

Citation for published version (APA):

geuna, A. (1998). Resource allocation and knowledge production : studies in the economics of university research. [Doctoral Thesis, Maastricht University]. Universiteit Maastricht. https://doi.org/10.26481/dis.19980625ag

Document status and date:

Published: 01/01/1998

DOI:

10.26481/dis.19980625ag

Document Version:

Publisher's PDF, also known as Version of record

\section{Please check the document version of this publication:}

- A submitted manuscript is the version of the article upon submission and before peer-review. There can be important differences between the submitted version and the official published version of record.

People interested in the research are advised to contact the author for the final version of the publication, or visit the DOI to the publisher's website.

- The final author version and the galley proof are versions of the publication after peer review.

- The final published version features the final layout of the paper including the volume, issue and page numbers.

Link to publication

\footnotetext{
General rights rights.

- You may freely distribute the URL identifying the publication in the public portal. please follow below link for the End User Agreement:

www.umlib.nl/taverne-license

Take down policy

If you believe that this document breaches copyright please contact us at:

repository@maastrichtuniversity.nl

providing details and we will investigate your claim.
}

Copyright and moral rights for the publications made accessible in the public portal are retained by the authors and/or other copyright owners and it is a condition of accessing publications that users recognise and abide by the legal requirements associated with these

- Users may download and print one copy of any publication from the public portal for the purpose of private study or research.

- You may not further distribute the material or use it for any profit-making activity or commercial gain

If the publication is distributed under the terms of Article $25 \mathrm{fa}$ of the Dutch Copyright Act, indicated by the "Taverne" license above, 


\section{Resource Allocation and Knowledge Production:}

Studies in the Economics of University Research 



\section{Resource Allocation and Knowledge Production:}

Studies in the Economics of University Research

\section{PROEFSCHRIFT}

ter verkrijging van de graad van doctor aan de

Universiteit Maastricht, op gezag van de Rector Magnificus, Prof. dr. A.C. Nieuwenhuijzen Kruseman, volgens het besluit van het College van Decanen, in het openbaar te verdedigen op donderdag 25 Juni 1998 om 14:00 uur

door

Aldo Geuna 


\section{Promotores:}

Prof dr. P.A. David

Prof. dr. W.E. Steinmueller

\section{Beoordelingscommissie:}

Prof. dr. L. Soete (woorzitter)

Prof dr. R. Cowan

Prof. dr. P. Llerena (Université Louis Pasteur, Strasbourg I)

A revised version of this thesis entilled "The Economics of Knowledge Production: Funding and the Structure of University Reseanch" is forthcoming from Edward Elgar in 1998. 


\section{Acknowledgements}

A short story is required to explain how a few events which occurred over the last six and a half years have shaped this thesis. In 1990, during my final year of study in mangement engineening, a confrontation on the future of Italian universities erupted between the Ministry of University and Scientific and Technological Research (MURST) and uniwersity students. Central to this debate was the issue of the changes in university funding structure and the development of university-industry relationships. What was especially puzzling was the fact that the various opinions expressed did not seem to rest on any solid analytical background.

In September 1991, following the advice of Professor Cristiano Antonelli, I started a Masters course in Economics at the Universita di Torino. In the spring of the following year, Cristiano introduced me to Professor Paul David, who was then visiting Torino for six months. Paul worked on what would become the new economics of science. I had the chance of being his research assistant and in this way, became familiar with a field of economic research relevant to the analysis of university research behaviour and funding. My interest in the evolution of the Italian university system found its natural utterance in this field of economic research. One year later I joined MERTT to write a Ph.D. thesis, under the supervision of Paul David, on university research behaviour. In 1994 Professor Ed Steinmueller joined MERIT and thereby became my co-supervisor. Thanks to his and Paul's guidance, this dissertation has been realised. This thesis is the result of a premistent interest as well as a series of events that have shaped its development. It could not have been possible without the stimulit, discussions and advice of Cristiano, Ed and Paul.

Most of the research for this thesis has been carried out at MERIT, although 1 completed it during my fellowship at BETA, Université Louis Pasteur (Strasbourg I). I would like to express my gratitude to all the people working in these two research 
centres for their direct and indirect support. Particular thanks for their comments and advice go to: Anthony Arundel, Karin Kamp, Marc Ledoux, Ivo de Loo, Stéphane Malo, Myriam Mariani, Benoit Simon, Luc Soete, Bart Verspagen, Katy Wakelin and Thomas Ziesemer.

Of course, other people outside MERTT and BETA have also contributed to the realisation of this thesis. I am particularly obliged to: Giuseppe Catalano, Alfonso Gambardella, Walter Garcid-Fontes, Diana Hicks, the colleagues at the Center for Higher Education Policy Studies (CHEPS) and various officials of the Commission of the European Communities.

In the course of the past few years, different institutions financially supported my research. I gratefully acknowledge the post-graduate fellowship of the Politecnico di Milano and the TMR Marie Curie fellowship of the Commission of the European Communities. Part of the research has been financed via the Human Capital and Mobility Programme of the Commission of the European Communities and the STOA programme of the European Parliament.

Writing a thesis is a very long process and sometimes you just do not see the end anymore. In such moments, but also in moments of happiness, the presence of Clarien, Karin, Katy, Marcello, and Stéphane has been extremely important for me.

Finally, I want to thank my parents for having taught me the importance of studying and having supported me in the process of learning. 


\section{Table of Contents}

1. Introduction 1

1.1. The Context of the Research 2

1.2 Research Questions and Overview of the Thesis 9

\section{Part I: A Theoretical and Historical Framework}

2. The Economics of University Research Behaviour

2.1 Modelling Approaches to University Behaviour 19

2.2 Resource Allocation to University Research 30

2.3 Empirical Implications 41

3. An Evolutionary Account of European Universities 45

3.1 The Birth of the University 49

3.2 The Recovery and German Transtormation 58

3.3 The Expansion and Diversification 67

$\begin{array}{lll}3.4 & \text { Conclusions } & 74\end{array}$

Appendix 1: Tables $\quad 77$ 


\section{Part II: Allocation of Funds and University Research}

4. Contemporary European Universities:

Relationships among Age, Size and Research Output

4.] The European Higher Education System

4.1.1 Contemporary European Universities $\quad 89$

4.2 Clusters of European Universities

96

4.3 Conclusions

102

Appendix 1: Research Performance Indicators 106

Appendix 2: Tables

\section{Allocation of Funds and Research Output:} The Case of British Universities

5.1 The Evolution of the Funding Structure of British Universities 112 5.1.1 The Aggregate Situation

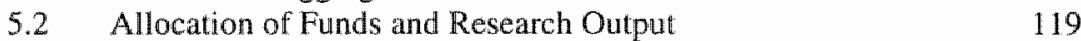

$\begin{array}{ll}5.2 .1 \text { Cluster analysis } & 120\end{array}$

5.2.2 An Analysis of the Changing Membership of Clusters 126

$\begin{array}{ll}5.3 \text { Conclusions } & 131\end{array}$

Appendix 1: List of Universities 134

\section{Part III: EU Funding of University Research}

\section{University Participation in Community Framework Programmes}

6.1 The Participation of higher Education Institutions in Community Framework Programmes

6.2 An Interpretative Framework

6.3 Determinants of University Participation in EU R\&D Co-operative Projects

6.4 An Econometric Test of the Determinants of University Participation

6.5 Conclusions 
7. EU and National University Research Funding: The BRITE-EURAM Programme

7.1 The BRITE-EURAM Innovation System 174

7.1.1 The BRITE-EURAM Research Programmes 177

7.2 University Participation in BRITE-EURAM 181

7.3 The Participation of UK Universities in BRITE-EURAM 185

7.4 Conclusions 191

Appendix 1: Network Formation and the Main Hub $\$ 93$

Appendix 2: Telephone Interviews and Questionnaire $\$ 97$

\section{Part IV: Summary and Conclusions}

8. Conclusions

Annex A: Data Sources

Bibliography 



\section{Introduction}

Attributing an economic significance to knowledge is not a novel idea. In 1776. Adam Smith wrote that "A man educated at the expense of much labour and time to any of those employments which require extraordinary dexterity and skill, maty be compared to one of those expensive machines" (p.1 18, Book I), thereby laying a basis for what was to eventually become known as 'human capital.' Since then various scholars have built on this notion." In particular, during the 1960s human capital theories gained intellectual pre-eminence and political influence. Starting in the same period, but from a different perspective, the comprehensive work of Fritz Machlup on the production and distribution of knowledge ${ }^{2}$ offered insights and stimulated a wave of academic studies on the economic significance of knowledge. ${ }^{3}$ The relevance of knowledge and learning in the process of economic development has been analysed from two perspectives. On the one hand, human competence, as well as the process of acquisition and the use of it, is considered to be at the core of economic development throughout history. On the other hand, the production, distribution and use of knowledge is seen as the paradigm for modern economic growth. ${ }^{4}$

\footnotetext{
'See, among others, Becker $(1962 \mathrm{a}, 1975)$ and Schultz (1960). For al recent critical anallysis see Griliches (1996).

2 The breath of his approach can be appreciate when one reads the definition of knowing and knowledge the has given in the preface of Knowledge: Its Creation, Distribution, and Economic Significance: "my concept of knowing and knowledge are unusually wide. I do not confine mysell to scientific on technological or verified or practical or intellectual knowledge. Anything that people think they know I include in the universe of knowledge" (1982, p.xjii).
}

${ }^{3}$ See, among others, Elliason at al. (1990), Von Hippel (1988) and Lundvall (1992). For a recent analysis of the so-called knowledge-based economy see Foray and Lund wall (1996).

"For the original exposition of this argument see Kuznets (1966). 


\section{Introduction}

By the 1980 s and early 1990 s, the central relevance of knowledge in the process of economic development has become widely recognised. Both neomclassical endogenous growth models and recent approaches of the economics of science and technological change have thus used the cancepts of production and distribution of knowledge to explain economic growth. Conceptualisations such as the knowledgebased economy, the leaming economy and more generally the knowledge-based society have all sprung from the cross-fertilisation of economics, history and sociology. Common to all the studies, albeit at different levels, is the concern with the "sites" where knowledge is created and from which it is transmitted." The main institutional sites where scientific and technological knowledge are generated are uniwersities, firms, public research agencies, and private research centres. Due to the presence of externalities and spillovers, as well as to the development of specific transfer mechanisms, the knowledge created at a specific site in the system tends to percolate, ${ }^{6}$ athough neither immediately nor completely, to other sites and to interact with learning processes that are taking place elsewhere in the system. ${ }^{7}$

\subsection{The Context of the Research}

While the study of the production and use of knowledge in industries has developed giving rise 10 disciplines such as the economics of technological change and the economics of innovation, the economic analysis of the process of knowledge production in the university is still in its infancy. In this original work on American

\footnotetext{
s Thamsmitied is used with a broad connotation meaning both the transfer and distribution of knowledge inside and outside the "site" of production.

It does not exist a preordaned sequence in the percolation. The process can be depicted as an interchange of knowladge among the warious sites and not as a one way transmission.

7 There exists a large body of liberature dealing with the analysis ot the diffusion of knowledge across differen institutions, See, among others. Aroma and Gambardella (1990), Cohen and Levinthal (1989), von Hippel (1988), Jafie (1989), Mansfield (1991, 1995). Nelson and Rosemberg (1994), Puvitt (1993) and Rosenberg (1994).

Fon Fin overview of the main themes of the economics of innovation and technological change see Dosi ef ah. (1988) and Freman and Soete (1997).
} 


\section{Introduction}

universitics, Veblen (1918) proposed economic explanations of the institutional behaviour of universities, focusing particularly on the introduction of business principles into university policy. After this seminal work, the understanding of the behaviour of universities has been mainly of concern to sociologists and historians. From the $1960 \mathrm{~s}$ onwards, economists, with the development of human capital theories, again focused their research effort on the university. But, despite this new interest, it was mainly the educational aspects that were taken into account, leaving aside the analysis of the overall behaviour of the institution. While this research endeavour led to the development of the economics of education, it did not equally promote the development of the economic of university-based research.?

In the same period, the two articles of Nelson (1959) and Arrow (1962) laid some of the foundations of the economics of science. Together these two papers have underscored the fact that, due to the properties of non-excludability and non-rivalry in consumption characterising scientific knowledge, the creator cannot fully appropriate the knowledge produced. Moreover, as marginal costs of duplicating scientific knowledge are very low, scientific knowledge can be characterised as a "public good.' Furthermore, it is argued that, due to the 'public goods' nature of scientific knowledge, the producer cannot capture the benefits stemming from the production of new knowledge and therefore market forces remain inadequate in delivering the socially optimal level of scientific research. As a result of this market failure, private investment is socially insufficient and the state has a legitimate role in laking responsibility for the support of an important part of scientific research.

The economics of science ${ }^{10}$ was concerned mainly with the analysis of the behaviour of the individual researcher, considering only marginally the issues related to the institution where the research is carried out (Dasgupta and David, 1987).

\footnotetext{
See Blaug (1970) for an introduction to the economics of education and a review of the fiterature.

${ }^{113}$ For a critical presentation of the man thematic of the economics of science see the two recent survey articles of Stephan (1996) and Diamond (1996), and the survey on the new economics of science by David, Foray and Steinmueller (1998). For examples of current research see the special insule of the Revue d'Economie Industrielle edited by Callon and Foray (1997).
} 


\section{Introduction}

Throughout the 1980s and 1990s, attention has increasingly been devoted to the institutional analysis. A number of these studies focused on the understanding of university behaviour" giving rise to what can be defned as the "economics of university." Most of them originate from, and refer to an Anglo-American context. Recently, especially in countries such as the USA, the United Kingdom and Australia, market forces and government simulated marker actions (via performance-based funding systems) have significanty influenced the behaviour of universities (Massy, 1996). These changes towards a stronger market orientation of the higher education systems stimulated the development of scholarly works on the economics of university.

The university systems of the highly industrialised countries are going through a period of profound modification. Although the changes vary from country to country, they are driven by the same forces and have similar overall aims. After the Second World War the various higher education systems witnessed an impressive growth in the numbers of students and staff, and in the levels of expenditures. For example, the number of students in the EU countries increased from about one million in 1960 to circa nine million in 1990 . In the same period, the gross enrolment ratio -i.e. total enrolment, regardless of age, divided by the population of the age group 20-24-grew from less than $10 \%$ to around $30 \%$, depending on the EU country. "This rapid growth was also connected with a rise in society's expectations for economic returns. These two phenomena have led to counteracting pressures on the institutional organisation and roles played by the university. Examples of the tensions characterising contemporary universities are: (1) incompatibility between the demands of elite and mass higher education; (2) friction between curiosity-driven

\footnotetext{
"For examples of recent studies see Adams and Griliches (1996), Baldwin (1996), Cave, Dodsworth and Thompson (1992), Garwin (1980), Geuna (1998a, 1997). Hare and Wyatt (1988, 1992), Hoenack and Collins (1990), James (1986, 1990), Johnes (1988, 1992, 1996), Mansfield and Lee (1996), and Massy (1996). Also relevant to the understanding of university bethaviour are some of the works developed within the framework of the "national system of innowation"; see, among others, Edquist (1997), Lundvall (1992) and Nelson (1993).

12 For the amalysis of the expansion and diversification of the thigher education system of the $\mathbb{E U}$ countries see Sedion 3.3 .
} 


\section{Introduction}

research enterprise and targeted research; (3) different impact of private and public financing; and (4) conflicts between the free advancement of the knowledge frontier and nesearch driven by the need of the society. From the early 1980 s onwards, policies and priorities of universities have been increasingly influenced both by the quest for rellevance of university research to national needs and by the pressure for accountability and cost reduction.

One of the most pertinent indications of the ongoing change can be found in the increased interactions between university and industry. During the 1980 s the share of higher education expenditure on research and development (HERD) financed by business enterprises showed positive growth rates in all the EU countries. ${ }^{13}$ Universities contribute to knowledge inputs of industry in three major ways. First, industry receives inputs from universities in the form of trained individuals. Although these individuals may require further training, university education lays the foundations for the following more specialised industrial training. " Second, knowledge produced at universities and disseminated through publications is used as input in the process of knowledge creation that takes place in industry. Third, universities are increasingly involved in co-operative research and development (R\&D) projects with industry. Although these collaborations are of various types, ${ }^{15}$ they are all characterised by an exchange of knowledge among participants, with the university usually in the role of the most important supplier of knowledge. The intensilication of interactions between universily and industry owes much to the following four interrelated factors: (1) the development of science such as molecular

\footnotetext{
If For the aralysis of the flnancial sources of higher education expenditures on reseanch and development in the EU countries in the 19805 and early 1990 s see Section 4.1 . It is important 10 underscore here that the share of HERD financed by business enterprises had constant and in some cases, decreasing growh rates in the early 1990 s.

14 It is mot uncommon that training and retrainitg of the workforce is realised in collaboration with unversities. Increasingly, universities are supplying highy specialised teaching services focused on industrial needs.

15 A large body of literature hats been devoted co the analysis of university-industry conoperations, For the andysis of the dilferent types of linkages sea, among others, Blume (1987), Mallemat al (1991) and $\mathrm{OECD}(1990,1984)$. For a recent surwey including the analysis of the use public research by industry at the European level, see Arundet ef al (1995). For an analysis focused on the US context: see, among others. Etzowitz (1997), Geiger (1993) and Nelson and Rosenberg (1994).
} 


\section{Introduction}

biology, material science and computer science ${ }^{16}$ characterised by high levels of applicability and shorter time between the phase of exploratory research and the possibility of industrial development spurring the interactions between industry and university: (2) an increasing budget stringency, forcing universities to seek external sources of income, and thereby fostering them to carry out research work financed by industry; (3) the growing scientific and technological content of industrial production and certain forms of services such as health care making university knowledge more valuable to industry; (4) policies aiming at raising the economic returns of public financed research stimulating the interaction between university and industry with the goal of increasing the transfer of knowledge from the university.

Governmental push for increasing co-operation between university and. industry is just one of the outcomes of the process of re-examination and modification of the rationale for resounce allocation to university, and in particular to university research. "The model of university research funding developed after the Second World War related academic quality to the level of funding. The increase in public funding was grounded on the premise that the proportional rise of academic quality (for both teaching and research) would foster the welfare of society. Crucial to this view are the following two assumptions. First, the transfer of knowledge from basic research to commercialisation is seen as linear process. In this linear model, basic research (mainly carried out at the university) leads to applied research and development and then to commercialisation. ${ }^{18}$ Second, knowledge is a public good with important positive externalities and hence there is the need for public funding to reach a sacially optimum level of investment. ${ }^{19}$

\footnotetext{
16 See Blume (1990) for an analysis of the characteristics of what he defines transfer sciences.

17 Tot a recent analysis of public funding of university basic research see Wood (1995).

$1 \%$ For a clear andysis of gowemmental expectations from scientific research generated by the successful use of scientific discoveries made during the wher Geiger (1993; Chapter I and Chapter 2). For an early formulation of the rationale used to justify the public support of science see Bush $(1945)$.

19 As education is characterised by positive externalities a simitar reasoning is allso applicable.
} 


\section{Introduction}

In the post World War II rationale, resource allocation to universities, as compared to other public funded sectors such as health care, was mainly based on an ex-ante judgement of research promises and thereby was influenced by the priorities of the academic community. Two main reasons justified the self-determination of priorities by the university community. First, as the research output (and the value of education) is difficult to measure the people in the best position to evaluate it are the practitioners, that is the academic staff. Second, the strong conviction that the intermal social organisation of the university was the most appropriate means for managing university activities supported the claim of autonomy in the definition and control of university behaviour.

On the basis of these premises the post World War II rationale for resource allocation to universities relied on a research funding approach whereby the government was funding the research that was considered by the academic community most worthy -i.e. through the peer review process. In return, scientists were producing new knowledge that, due to its 'public goods' nature, would enter into other knowledge production processes within and outside the university.

A more direct intervention of government in the guidance of the research enterprise in universities started in the mid 1970s. From the early 1980 s onwards a transition from the post World War II rationale for scientific funding to what can be referred as the 'competitive approach' to university research behaviour and funding took place. As pointed out above, governments have put increasing pressures on universities to focus their research on national economic prionities. Moreover, funding of science has shifted from a period of continuous budgetary expansion 10 one of constant or shrinking budgets. ${ }^{20}$ Policies aimed at concentration and selectivity of research funds and, more generally, at a higher level of accountability and cost reduction have been implemented. What lies behind such resource allocation policies

\footnotetext{
31 See Zmon (1994) for the arallysis of science in a 'steady state.' See Section 4.1 for the andysis of values and intensities of HERD in the EU counties it the 1980 s and early 1990 s. Among the industrialised countries Japan is the only one that has committed itself to increase in a substantal way the retative level of public funding for aniversity based scientific research.
} 


\section{Introduction}

is the assumption that it is possible to implement an ex-post evaluation of university performance via market forces or simulated market actions. In this framework, consumers, such as students, govermment, and other organisations, buy the services supplied by universities giving in this way a direct evaluation of their output.

In Europe the UK system based on exwost institutional accountability for performance quality is a clear example of the new market steering approach. Although direct competition is not permitted, government attempt to simulate market actions by adjusting its demand of university services in rellation to absolute or relative institutional performance ${ }^{21}$ (Massy, 1996). Other European countries, such as The Netherlands, have started to implement similar approaches to university funding. ${ }^{22}$ National policies aimed at concentration and selectivity of research funds may be further reinforced by the European Union (EU) research actions. The four Framework Programmes of the Commission of the European Communities for the support of R\&D co-operative projects, discussed later in this thesis, ${ }^{23}$ have been characterised by a highly competitive approach to research funding. Universities have increasingly taken part in these $R \& D$ co-operative projects, becoming in the Forth Framework Programme the largest single type of institution both in terms of the number of times they participated in an EU-funded $R \& D$ co-operative project and in terms of funds received.

A debate on the advantages and drawbacks of the new rationale for resource allocation to universities is currently taking place primarily in the fields of science and technology policy, and higher education studies. ${ }^{24}$ One of the aspects that merits

\footnotetext{
2 A series of adminstrative measures have had to be created to enable the evaluation of performance.

${ }^{22}$ For the description, of the changes in the Dutch higher eduction system see Maassem, Govedegebur and Westerheijen (1993) and Van Vught 1991,1997 . Van Vught (1997), for instance, suggests that the new govetnthent strategy towards higher edtertion in The Netherfands is the outome of both government planing and market-coordination.

2) See Chapter 6 and Chapter 7 for the analysis of university participation in EU Framework Programmes.

24 For examples of works analysing the cries of the post-war rationale tor public support of science see Dill (1997), Guscon and Keniston (1994), Shapley and Roy (1985), Sommer (1995), Vawakova (1998)
} 


\section{Introduction}

special attention is the analysis of the intended and unimtended consequences ${ }^{25}$ of the market approach on the medium to long term horizon. In particular, the absence of a systematic understanding of the operation of the university as an economic and social institution raises the possibility that unintended consequences may flow from the ongoing changes.

\subsection{Research Questions and Overview of the Thesis}

The universities of the EU countries in the early 1990 s are the subjects of inquiry in this thesis. The impacts of the changes in the rationale for university funding on university research behaviour, and on the structure of the university system, are the specific questions to be studied. Considerable attention will be paid to the changing opportunities and constraints facing European universities. The first part of this work formulates a behavioural approach to university research, and an historical characterisation of 'European University' as the typical unit. On the basis of these, Part Two analyses the relationships between the allocation of funds and the organisation and development of university research activity, whereas Part Three is devoted to the detailed study of EU-funded university research.

The overall aim of this thesis is to investigate the unintended consequences of the changes in the rationale for resource allocation to universities. In particular, the existence and the impact of unintended consequences on the policies and priorities of universities are studied. In doing so, two other related subjects of a specific nature will be addressed. First, the connections between resource allocation and scientific research productivity are examined. This analysis is carried out both for the total population of unversities in the EU countries and, in a more detailed way, for the

Ziman (1994), The debate transcends the academic circle, as illustrated by the recent survey of The Econonist (1997).

25 For a recent analysis of the intended and unintended consequences of the new market sterting approach for the Austral han higher education see Meek and Wood (1997). 


\section{Introduction}

"old" universities of the UK. Particular attention is given to the understanding of the possible influences of an increased dependence on industrial funding upon the conduct of university research. Second, competitive research funding is influenced by the existence of cumulative and self-reinforcement phenomena and, in particular, by the so-called Matthew effect. ${ }^{26}$ The impact of these phenomena is studied for the participation of universities in EU-funded R\&D co-operative projects.

The thesis is thus organised into four main parts. The first proposes a theoretical and historical framework for the analysis of European Universities. The second considers the relationships between allocation of funds and university scientific research productivity. The third analyses different aspects of $\mathrm{EU}$ funding of university research. Finally, the fourth presents the overall conclusions of the dissertation.

Part One consists of two chapters. The first, Chapter Two, considers universities as socio-economic institutions influenced by opportunities and constraints. These non-profit institutions have a multiplicity of objectives and decision-makers that cannot be reduced to an unique objective function. Hence an utility-maximising approach cannot be used to study their behaviour. One way to study their behaviour is to anallyse the response of the institution to environmental changes. The Chapter presents an economic approach to university research behaviour that focuses on how constraints and opportunities imposed by the regulatory framework and market conditions shape the behaviour of the institution. The analysis of the relationships between inputs and outputs, and more specifically, between diversified funding sources and research outputs provide insights relevant for the understanding of university research behaviour. The approach is further

26 For the original definition of the Mathew effect in the sociology of science see Merton (1968). Merton $(1968,1973)$ and some of his students, see for example Cole and Cole (1973) and Zuckerman (1977). suggested that the organisation and resource allocation structure of science tend to reward stuccessful individuals and groups with access to means that increase their probability of being successful in the future. For an early analysis of the relationships between scientific productivity and cumulative effect see De Solla Price $(1963,1976)$. For an economic analysis of the Matthew effect and its implication for resource allocation see Arora and Gambardella (1997), Dasgupta and David (1987, 1994) and David (1994). 


\section{Introduction}

developed in the second section where the implications for university research behaviour of the changes in the rationale for university research funding are analysed. The objectives, research allocation mechanisms, and implicit assumptions of the competitive approach to university behaviour and funding are examined. This analysis underscores the importance of considering the possibility that the existence of diversified non ca-ordinated competitive funding sources, supporting different incentive settings and constraints, gives rise to unintended outcomes some of which may have perverse long-term consequences.

Chapter Three presents an historical analysis of European universities. Focusing on university contribution to social purpose and on the governance and organisation of the institution, it describes the pach of evolution of the typical institution, delineating the presence of continuity within change. It shows that the historical evolution of the European universities has led to the creation of routines and expectations that may influence their capacities and possibilities of responding to current changes. The aim of the chapter is to develop a systematic empirical grounding for taking the "European University" as the unit of analysis in the dissertation.

Part Two considers the relationships between resource allocation and scientific research productivity of universities at different levels of detail. It is divided into twio chapters. The first, Chapter Four, provides a description of the total population of universities in the EU courtries in the period 1981-1993. It begins with an aggregate analysis of the research funding structure of higher education institutions and of the scientific publications" oulput. ${ }^{27}$ Next, focusing on the universities active in 1992, a methodology is developed for describing the university system in terms of its main characteristics, such as size of the university and research output. Here the objective is to identify the existence of well-defined clusters of institutions that have similar features. The analysis of the characteristics of the

\footnotetext{
27 Appendix 1: Research Pertormance Indicators provides a defailed analysis of the drawbacks characterising research output indicators.
} 


\section{Mntroduction}

institutions included in the different groups points to a clear polarisation of the university system. Two extreme configurations have thus been identified. One accounts for the new post-war universities of small size with low research output and low scientific research productivity. The other includes institutions founded early that are large in size, high in research output and high in scientific research productivity.

Chapter Four forms a background for the following chapter, which considers the same issues within the context of a single country's university system, permitting a more detailed specification of both the funding patterns and research outputs. Chapter Five is devoted to the analysis of the changing relationships between the allocation of funds and research output for the "old' UK universities in the period 1989-1993, that is the institutions other than the former polytechnics. After a description of the evolution of the funding structure of UK universities, the methodology developed in the previous chapter is applied to the data pertaining to the initial and terminal years of the period considered in order to examine the impact on university research output of the intervening changes in the funding structure. Particular attention is given to the movements of institutions among the different clusters. By considering the changes in the scientific research productivity and in the funding structure of the universities that changed their profile of research activity and other characteristics, the existence of distinctive relationships between funding and research output is explored. Chapter Five also considers in some detail the specific impact of an increased industrial funding on the conduct of university research.

Part Three analyses several specific aspects of EU funding of university research. The participation of universities in research networks formed through EU. funded $R \& D$ co-operatiwe projects is a central subject in the analysis, which is carried out in the Part's two chapters at different levels of detaill. The furst of them, Chapter Six, considers the participation of universities in projects financed under the first three Framework Programmes of the European Commission. After an overview of the main characteristics of the research and technological development (RTD) Programmes financed by the European Commission, an interpretative hypothesis is 


\section{Introduction}

put forward, explaining the participation in EU-funded R\&D projects in terms of information signalling and cumulative and self-reinforcement mechanisms. The hypothesis is then tested using the data-set for the total population of universities in the EU countries in 1992, which was introduced in Chapter Fonr. An econometric model is developed to test for the relevance of university size, scientific research productivity, and other fixed factors on two independent variables: 1) the probability that a uniwersity will joining an EU-funded R\&D co-operative project; 2) the number of times a university will participate in such co-operative projects. The results indicate that the probability of taking part in an EU-funded R\&D project depends primarily on the scientific research productivity of the university. The main factors explaining the frequency of university participation include scientific research productivity, size, and differences among countries and scientific fields.

Chapter Seven extends the analysis to the interactions between EU and national university research funding. The chapter is focused on the participation of UK institutions into the two BRITE-EURAM programmes funded in the Second and Third. Framework Programme. The relationships between EU and national university funding are studied considering both the deliberate action of government in response to EU funding and the unintended consequences related to the existence of two overlapping sources of funds. Sixteen departments accounting for $55 \%$ of the participation of "old' universities in the BRITE EURAM programmes have been surveyed. The questionnaire has been complemented with interviews to the heads of the departments. The survey addresses the changes in the funding structure of the department in the period 1990-1993 and the situation in 1994. The aim of the survey and interviews is to identify the presence (or absence) of positive or negative dependence between EU and national sources of funds in terms of cumulative and self reinforcement phenomena and substiution effects. Chapter 7 presents also a detailed analysis of both institutional participation and network structure of the BRITE-EURAM programmes. 


\section{Introduction}

Finally, in Part Four, Chapter Eight presents the overall conclusions of the dissertation. This last chapter offers a synthesis of the themes discussed throughout the thesis. It also supplies a discussion over the overall implications of the competitive approach to university behawiour and funding on the medium to long term horizon. On the basis of this further avenues of research are put forward. 


\section{PART I}

A Theoretical and Historical Approach 


\section{The Economics of University Research Behaviour}

The analysis of university behaviour has been mainly the concern of scholars in the field of social studies of science. Economic approaches to explain university behaviour have been developed only recently. From the early 1960 s onwards, on the basis of human capital theories, the economic literature focused on specific features and contributions of higher education. Nonetheless, this research endeavour was mainly concerned with the analysis of student demand, with the study of the rate of return to and redistributive effects of higher education, and with cost and economies of scale in higher education. ${ }^{\prime}$ University behaviour and its determinants were only marginally considered. ${ }^{2}$ From the 1980 s onwards an increasing number of economists has focused its research efforts on the understanding of uniwersity behaviour and on the process of knowledge production in the university. ${ }^{3}$

Universities are socio-economic institutions whose economic behaviour is influenced by external opportunities and constraints. As other non-profit institutions,

\footnotetext{
For an introduction to the economics of education see Blaug (1970). For an analysis of educational benefits see, among others, Carnoy and Marenbach (1975) and Hansen (1970). For a survey of the studies on costs and economies of scale in higher education see Brinkman and Leslie (1986) and Hoenack (1990). For recent studies of economies of scale and scope in higher education irnstitutions see, for example, Cohn, Rhine and Santos (1989) and Gläss, Mckillop and Hyndman (1995).

2 For examples of early works considering university behaviour and university production see Culyer (1970), James (1978) and Nerlove (1972).

"See, among others, Adams and Griliches (1996), Baldwin (1996), Cave, Dodsworth and Thompson (1992), Garvin (1980), Geuna (1998a 1997), Hare and wyatt (1988, 1992), Hoenack and Collins (1990), James (1986, 1990), Johnes (1988, 1992, 1997), Mansfield and Lee (1996), and Massy (1996).
} 


\section{The Economics of University Research Behaviour}

they have multiplicity of objectives depending on the tasks they accomplish, the organisation they have, and their status as public or priwate institutions. The definition of the overall objectives of universities is an arduous task. Also, reducing the complexity of the unversity to a stylised model requires considering at least three main groups of actors shaping the definition to the objectives. They are: the government that finances a large part of university budget, the academic staff that produces the various outputs of the institution, and the administrative personnel that, together with the academic staff, manages the university. The relationships among these three main actors are characterised by principal agent type of situations which shape the definition of university objectives. Thus, overall objectives of universities are defined by the interactions between the sociall goals determined by government, the aims of university academic staff and the ams of university administrative personnel. Moreover some objectives are socially but not economically relevant, nonetheless they are important in driving university behaviout. "Therefore, a "closed" definition of the multiple, and sometimes conflicting, objectives of the university in a general objective function is inappropriate.

This chapter develops an economic approach to university behaviour paying particular attention to university research. Here the focus is mainly on the university as a producer of knowledge, educational aspects are only considered in relation to research. Even in this more limited domain, university behaviour is the result of the interaction between the multiple, and sometimes conflicting, objectiwes of the institution and external constraints and opportunities imposed by the regulatory framework and market conditions. The behaviour of European universities is studied by examining their response to changes in their environment. In particular, the implications for university research behaviour of the new rationale for resource allocation based on an ex-post exaluation of university research performance via market forces or simulated market actions is analysed.

\footnotetext{
"European universicies are in large majority public institutions; hence the framework developed here will devote particular attention to the behaviour of public universities.
} 
The Chapter is divided in three sections. The first, after a brief review of the utility-maximising approach to university behaviour, sets out the framework employed in the dissertation to analyse university research behaviour. (Section 2.1). In Section 2.2 the framework is further developed considering the unintended consequences of the competitive approach to university research behaviour and funding. Finally, the last section explains how the proposed approach to the analysis of university behaviour is employed in the subsequent parts of the thesis.

\subsection{Modelling Approaches to University Behaviour}

Universities are social and economic institutions. They are social institutions as regards the norms, incentives and organisational structure on which their behaviour is based. $^{5}$ They are economic institutions in so far as they are organisations that transform a set of inputs into outputs with value added depending on costs and revenues. Depending on the different importance given to the social and economic aspects of the institution, university behaviour has been analysed from three broad perspectives. First, models of university behaviour focusing on the organisational features of the institution ${ }^{6}$ have been developed using a sociological approach. Second, historical accounts of the social evolution of the university have been carried out on the basis of an institutional perspective. They have studied how the structure and governance of universities have changed in response to modification in their external environment. ${ }^{7}$ Finally, works with an economic perspective have modelled university behaviour as the result of purposive actions shaped by the competitive enviromment. The utility maximising approach has been used to analyse the economic

\footnotetext{
$\$$ See Chapter 3 for an historical account of European unwersties that highlights tho ewolution of noms, incentives fond orgamisationat structure charderising these institutions along their history.

"Four main organisational models have ben proposed, they are: 1) the collegial model; 2) the bureaucratic model: 3) the political model; and 4) the or sanised atarchy model (Charwin, 1980).

"See, among others, Geiger (1985, 1993), Kerr (1995) and Wittrock (1993).
} 
features of universities and the behavioural implications of different cost and revenue structures. 8

The analysis conducted here focuses on university economic behaviour. After discussing the main limitations of the utility-maximising approach to university behaviour, an altemative approach that relies also on the institutional perspective will be presented.

\section{The Unility-Maximising Approach}

Like other economic organisations, universities are influenced by opportunities and constraints. Howewer, unlike business institutions they do not have stockholders claiming for the surplus generated by the organisation. Universities do not distribute a monetary residual, like other non-profit institutions they do not follow a profitmaximising rule, but tend to spend all revenues within the organisation. ${ }^{9}$ On the basis of the non-profit behaviour several recent contribution to the literature have employed the framework of utility maximisation to explain different aspects of university behaviour. For example, James (1990), building on her previous works, ${ }^{10}$ models the university as a non-profit organisation maximising an objective function for the entire institution. She assumes that faculty and administrators have an "... identical teamobjective function (which can therefore be termed the institution's objective) and, moreover, that everyone is affected in similar ways by its arguments." Hence, the university maximises an objective function subject to the break-even constraint that

Her an arly atilily-maximising view of the university see Culyer (1970). For a prestige-maximising view of the universily see Garvin (1980); for a multi-product (baching and research) wtility maximising approach see. Hane and Wyat (1992) and Jam (1990) for an atility-maximising approfeh focused on uniwersity aninistrators see Kesselrin wa strein (1986).

"Given the mon-protit chatscter of the uniwers we the revente of the institution cannot be claimed either by the stockholders or by its actorkers. He vever, like employees in a marnagerial firm (see, for example, Williamson, 1967) academic staff may extract rents through discretionary expenditure or shirking (Cave, Dodsworth and Thompson, 1992).

10 Ses James (1978. 1986) for a theoretical and empirical analysis, mainly focused on instruction, of the nomprofit behwiour of public and private universities and colleges. See aiso James and Neuberger (1981) for a view of the university department as a non-profit labour co-operative. For a review of the economics of nom-protit organisations see Janes and Rose Ackerman (1986). 
all the resources generated are used in the production of teaching and research. She considers prestige and faculty-worker satisfaction as the overall objectives of the university. These can be expressed in terms of intermediate objectives. She assumes that research, graduate training, undergraduate training, student quality and teaching load enter into the university"s objective function. "The objective function depends positively on research, presence of graduate students and student quality because these increase the prestige of the university. Similarly, high student quality and small classes (especially graduate classes) increase the satisfaction of faculty. Finally, the revenues of the university depend on the number of students (especially undergraduate) accepted.

An utility-maximising approach to university behaviour, such as the one proposed by James, rests on three main assumptions. First, the multiple, and sometimes conflicting, objectives of the university are reduced to an overal objective function. Faculty and administrators have an identical team-objective function and are affected in similar way by all outputs. Moreover, it is assumed that there are no conflicts between government goals and university aims, so that the latter are perfectly consistent with the former. Second, it is assumed that the university is facing a competitive market for education and research. Third, to develop a marginal analysis it is assumed that the system under study is in long-run equilibrium.

These assumptions are questionable, even for the puposes of approximating institutional behaviour. Assuming that faculty and administrators have a common objective function and that this objective function is consistent with the social goals imposed upon the uniwersity is an oversimplification for the following reasons.

First, the growth of universities in the post-war period brought a process of bureaucratisation of the institution." Contemporary universities are complex

\footnotetext{
"For the administrative, organisational and structural changes following the expansion of the universily sector in the European countries in the 1960s and 1970 s see, for example, Daalder and Shils (1982). See also Gellen (1993) and Neave and Van Vught (1991) for an analysis of the most recent changes.
} 
organisations run by administrators with participation from faculty. The increased diversification of the services provided by universities, such as the transfer of technology and patenting of innowations, have further augmented the relevance of the management staff. In this context assuming that the prestige enjoyed by the institution, as is usually done, is its overall aim does not recognise that faculty members and administrators have different and conflicting preferences and goals. For example, while the formers are affected by academic reputation, the latter are influenced by the growth of the institution and thus they have preference for income generating actiwities.

Second, different and conflicting objectives also characterise faculty members. Due to the zero-sum nature of the allocation process across departments or centres, and due to the existence of negative externalities and free-rider situations $i . e$. the action of a department raises the cost associated to another department- the objectives of university units can be conflicting (James, 1990; Massy, 1996). With the increased commercialisation of university research the existence of different priorities. among faculty members is becoming more evident at two different levels. On the one hand, a divide is forming between researchers in more utillitarian disciplines and scholars of the less marketable disciplines, such as the humanities. Faculty members are affected by different incentive structures and consequently they are forming different preference profiles. On the other hand, a new academic figure is developing, that of faculty members mainly involved in research contracts. These research scientists are primarily inwolved in sponsored research and they are not responsible For graduate and undergraduate education. Hence, the goals of research scientists may different from those of other members of the faculty (Cohen and Florida, 1996). ${ }^{12}$

Third, as will be discussed in Section 2.2, new purposes for higher education have been defined in the last ten years -e.g. to produce knowledge that serves the need of the economy. Universities are reacting to these changes adapting their

\footnotetext{
${ }^{12}$ Carnegie Mellon University has recognised this new academic figure, creating a new career track for them (Cohen and Floridn, 1996).
} 


\section{The Economics of University Research Belawiour}

behaviour to the new needs, nonetheless, due to the presence of routines and expectations in the behaviour of the university, the adaptation requires a significant amount of time and the outcomes are not secure. Hence, particularly in a period of evolution in the role that the university is supposed to accomplish in society, the objectives of the institution may diverge from those of the funding agency (the government).

The second assumption on which the utility-maximising approach to university behaviour rests is the existence of a competitive market for education and research. While this assumption may be an approximation for the university system of the US, it does not hold in the European context. Although recent years have witnessed the first steps in the development of quasi-rnarkets ${ }^{13}$ for education and research, the university systems of the EU countries tend to be characterised, on the one hand, by low levels of market competition for education, and, on the other hand, by an increasing market competition for uniwersity research. ${ }^{14}$

Finally, the ongoing changes in the structure and organisation of European universities are sufficiently relevant and the adjustment times are sufficiently lengthy -e.g. time required to change the composition of tenure faculty-- that it is highly unlikely that the system under study is in equilibrium. Hence, marginal analysis is not the most appropriate tool for examining the changes.

The intrinsic shortcomings of the utility-maximising approach to university behaviour, especially when applied to a context different from the one of the US, affect the use of its predictions. On the one hand, some insights, such as the presence of cross-subsidisation among revenue-generating activities and utility-generating activities, allow a better understanding of university behaviour. On the other hand,

\footnotetext{
13 For an analysis of the introduction of quasi-markets into the delivery of public services see, for example, Broadbent and Laughlin (1997). Glennerster (1991). Hughes, Griffiths and McHale (1997) and Le Grand (1991).

14 The British university systent is the one with the clearest market orientation.
} 
however, the identification of a mix of inputs and outputs maximising a single objective function for the institution is not useful for analysing the behaviour of institutions that do not have a clearly defined objective function, and are also going through a period of profound change.

\section{An Industrial Economics Approach to University Behaviour}

The focus here is on European universities. ${ }^{15}$ The large majority of universities in the EU countries are public institutions, financed in large part by the state, with approximately pre-defined pay scales, and student costs almost completely covered by the state. These characteristics differentiate them from many universities in the US, particularly the private institutions. ${ }^{16}$ The behaviour of European universities can be better understood as the result of the interaction between the multiple, and sometimes conflicting, objectives of the various professional groupings within the institution the academic and business branches of the administration, the faculty members of various departments and research centres) and the changing constraints and opportunities externally imposed by the regulatory framework and market conditions. Shifting alignments of constituencies within, as well as outside, the university shape both the process and the outcomes of university decision-making.

Moreover, there is no well-defined "bottom line" in the operation of the nonprofit university whether it is public or privately funded; university outputs are only valued subsequent to their production and, even then, in an highly approximate way by the array of communities of interest -i.e. the state apparatus, the tax-paying public, the academic professions, the graduates, industrial sponsors and clients, atc. Hence, university decision-takers in the pursuit of manageable processes and viable outcomes are especially likely to adopt simple decision making procedures and

\footnotetext{
is To thevelop an economic approach to university behariour requires the implicit hypothesis that a well-defined institution called university exists. This issue is dealt with in the next chapter which develops an systematic basis for the "European University" as a unit of anallysis in this thesis.

tw of the 160 institutions recognised in Palombara (1991) as universities in the USA, one third are private.
} 
operating rules. These procedures and nules are the result of interactions among the incentive structures of the various actors taking part in university production and university organisation. In turn, the incentive structures are affected by the external environment and by the internal resource allocation mechanisms.

Given this general description of university behaviour, two research paths can be followed. Neither proceeds on the assumption that the institution is usefully characterised as a consistent utility-maximising "agent." The first examines the response of universities to changes in the regulatory framework and market conditions, focusing on the effect of alteration in the relevant incentives and constraints governing their behaviour; the second studies internal resource allocation mechanisms that affect the profile of the institution, recognising that there is structural heterogeneity within the population of institutions of higher education. These two approaches together provide the basis on which to develop an empirically implementable theory of university operation.

At this stage, it is important to clarify whether the subject of analysis is the single institution, or the ensemble of institutions whose behaviour can be characterised by some distributional statistics. In the first case, the theoretical framework to be used would be the one of the representative agent. However, even if the shortcomings of the utility-maximising approach to university behaviour described above were not important, the diverse characteristics and activities pursued by universities and the existence of sub-markets in which universities operate heavily constrain the usefulness of the representative agent approach. ${ }^{17}$ In the second case, where the ensemble is explained but not the individual institution, a statistical mechanic approach can be applied to account for the behaviour of a distribution of universities in same space (described by ranges of variables such as teachers per student, researchers per student, size of facully, etc. ). ${ }^{18}$ This framework, focusing on

\footnotetext{
${ }^{17}$ For a critical analysis of the representative agent model see Kiman (1992).

${ }^{\prime \prime}$ For an introduction to statistical mechanics approaches applied at the analysis of the growth of firms see Steind (1965). For a critical survey of the literature see Sutton (1997).
} 
population averages, acknowledges the high level of heterogeneity within the university system. It accounts for the dynamic of the system wia well specified details at the micro level such as the existence of heterogeneous opportunity set or diversified response capabilities. Thus, it seems to be the most suited framework to develop a theory of university operation and, in particular, of its response to environmental changes.

This thesis does not tackle the task of elaborating a formal model along such lines. ${ }^{19}$ Instead, it will draw from an informal exploration of this approach some general insights that can guide empirical inquiry. One practical reason for proceeding in this way resides in the prohibitive data requirements needed to test a full structural model of university behaviour, especially one that considers the distinct actors and internal conflicts through whose resolution university actions emerge. At present, the available statistics on resotirce allocation and the cost structure of European universities do not allow for the implementation of empirical studies at the level that would be required to test detailed behavioural hypotheses.

How can the response of universities to modifications in their environment be analysed? A study of the relationship between inputs and outputs can offer insights about the response of the university to changes in the regulatory framework and market conditions. It must be acknowledged, however, that defining and measuring university inputs and outputs is not a trivial task. First of all, the definition of an input

\footnotetext{
19 A promising approach would appera the one that sought to integrate the following two streams of literature. On the one hand, behavioural theories of the firm can be fruitfully applied to model the individual organisational behaviour as boundedly rational (satisficing), in which systematic responses to viability or threatening changes in external constraints are predictable (Cyert and March, 1963; Simon, 1955). On the other hand, the statistical approach to the theory of market demand provides a useful framework to model the aggregate bethaviour. This approach makes minimal assumptions, of the sort that requires the agentiorganisation to operate within a reasonably light inter-temporal budget constraint; assimes that there is a positive probability that at least one agent/organisation will visit every point in the opportunity ser; and replaces the von Neuman-Morgenstem axioms with stochastic dominance axioms on the way the changes in the total resource availability distribution will be related to changes in the distribution of expenditures upon each of the activities in the consumption basket, in the application presently contemplated, the agentshorganisations 'activity-basket' (Becker, 1962b; Fildenbrand, 1989; Sanderson, 1974).
} 
or an output is controversial. For example, in some cases research incomes are included among the inputs while in other cases they are part of the outputs. ${ }^{20}$ Also, assuming that it is possible to identify university inputs and outputs, the measurement has to take into account both their quantity and their quality. The value measurement is especially difficult for the outputs because, due to their non-market characteristics, prices cannot be used as a measure of the value that the consumer associates with the purchased good.

To reduce the degree of complexity this study focuses onlly on university research production. The main limitation of this partial analysis is that it will make it difficult to assess the indirect effects of behavioural changes in the production of research. For example, questions such as whether a rise in research quality is a complement or a substitute for educational quality cannot be evaluated here. Nonetheless, considering only university research production allows one to use available statistics as partial indicators of inputs and outputs. The relationship between inputs and outputs can be expressed in term of research productivity -i.e. the ratio of output to input. Clearly, given the multiplicity of research inputs and outputs, and their qualitative and multidimensional character, research productivity represents only an approximation of the relationship between inputs and outputs.

The saciology of science and more recently scholars from the fields of science and technology studies, bibliometric studies, and the new economics of science have developed theoretical and empirical studies on scientific research productivity. Starting with the works of Lotka (1926) and De Solla Price (1963). most of these investigations focused on the scientific research productivity of the individual scientist considering the research productivity of the department or research centre only in a few cases. ${ }^{21}$ However, there is no overall agreement on which indicator (set

\footnotetext{
2/i See, among others, Hate and Wyat (1988) for a criticism of to the use of research incomes as a research performance indicator.

${ }^{21}$ Purticularly during the 1980 s, and early 1990s, a considerable number of studies on the research output of universities departments have been produced in the field of bibliometric studies. Among others see Carpenter et al. (1988), Moed et al. (1985) and Nederhof and Noyons (1922).
} 
of indicators) is best suited for measuring the quantity, impact, quallity, and utility of the research. ${ }^{22}$ Publication counts, citations analysis and peer review are the three methods that are usually applied to evaluate research performance. ${ }^{23}$ Each has its own limitations. For example, publication counts are mainly a measure of the quantity of the research; citations analysis requires a costly and time-consuming methodology that, at the current level of development, is not optimal for the analysis of university research productivity; peer review is based on a subjective and not very systematic judgement of the research output.

Despite the above limitations it is important to assess the response of available measures of research productivity to changes in university environment. In particular, while most of the literature has examined scientific research productivity at the level of the individual researcher or at the level of the department, here the subject of analysis is the entire institution. ${ }^{24}$ New incentives originating from the changes in the regulatory framework and market conditions affect the behaviour of the university in general, and its scientific research productivity in particular. The focus at the institutional level endorses the use of less detailed output indicators than those employed at the level of the individual researcher or at the level of the department. However, when considering the institution as a whole, it is possible to have an account of the modification in the inputs that is a direct consequence of the environmental changes. Hence, even using incomplete research output indicators, the scientific rescarch productivity of the university can be expressed in different ways depending on the inputs considered.

\footnotetext{
${ }^{22}$ For an early work on fhe difficulties involved in constructing research pertionnance indicators see Martin and Irwine (1983). For references and further discussion see, for example, Cave et al. (1997: Chapter 4), and van Raan (1988).

${ }^{23}$ See Appendix 1: Resource Performance Indicators in Chapter 4 for the analysis of the difficulties and drawbacks in using these indicators.

2 A number of studies analysing university research productivity have recently appeared; see, among others, Johnes (1988, 1992) and Johnes and Johnes (1993). Of particular interest is the work of Adams and Griliches (1996). Using data on 40 American universities for the period 1981-1989, they study the relationship between research output and uniwersity $\mathbb{R} \& D$ expenditures.
} 
Among the various inputs, a crucial role is played by the competitive and noncompetitive research funding sources. The changes in the regulatory framework and the consequent increase of competition in the market for university research have given rise to the development of a funding system for university research based on diversified competitive funding sources. On top of the less competitive general government research funds, ${ }^{25}$ universities receive an important share of their research funding through competitive sources. A substantial advance in current understanding of university behaviour can be made by considering the inpact of diversified funding sources for university research on the research subsystem engaged by this funding. The diversified funding sources can complement or substitute each other, in both cases they affect the outputs and the incentive structure of the university, thus determining its behaviour. In addition, a detailed analysis of the relationships between diversified funding sources and output indicators allows one to obtain insights for the understanding of the whole university system.

This approach to the analysis of the response of the university to changes in its environment allows one to analyse three main issues. First, the push towards a more competitive university research funding may cause, among other possible consequences, an increase in scientific agglomeration and a shorter time horizon for the evaluation of the research output. Both phenomena are characterised by an unclear balance between advantages and disadvantages. Second, the existence of competitive research funding sources may give rise to diverse incentive structures that, due to their conflicting character, may induce distortions in university research behaviour. Third, the existence of important ctimulative and self reinforcement phenomena in the process of scientific production may be exacerbated by the increasingly competitive character of university research funding and by the existence on non co-ordinated competitive funding sources. In general, the ongoing changes in

\footnotetext{
25 Especially in the UK, but also in other European countries, the general research grant from the government is also awarded via competitive criteria. The Research Assessment Exercise allows the distribution of government funds depending oin the pass performance of the institution. See Chapter 5 for the analysis of the funding structure of the British uniwersity system.
} 
university environment are characterised by important indirect effects and it is highly unlikely that those were ever intended by policy makers. The next section discusses in more detail these issues in relation to the re-examination and modification of the rationale for resource allocation to university.

\subsection{Resource Allocation to University Research}

This section will analyse the implications for university behaviour of the changes in the rationale for university research funding. In particular, it will be highlights how the existence of diversified competitive funding sources supporting different incentive settings and constraints may create important unintended consequences. The objectives, resource allocation mechanisms, and the implicit assumptions of the new rationale will be analysed. On the basis of this analysis, it will be shown that the potential advantages of the competitive approach may be counterbalanced by longterm disadvantages arising from unintended outcomes of the new rationale.

University income can be subdivided into four main sources: general government grants, specific government grants, own funds, and sale of academic services. In Europe by far the most important source of university funds are the incomes from the various govermment sources. ${ }^{26}$ The responsibility for financing universities varies in the various EU countries. Depending on the country it can be mainly the responsibility of the central government (Austria, Finland, Denmark, France, Italy, Ireland, The Netherlands, UK), mainly of regional government (Belgium, Germany), or shared between central and regional government (Spain) (OECD, 1995). Chapter 4 shows the subdivision of sources of financing of Higher Education Expenditures in R\&D. For most of the countries considered, government funds are responsible for more than three-quarters of total expenditure. Only Greece, Ireland and the UK have lower shares of about $60 \%$ in 1993.

\footnotetext{
26 For an analysis of the main issues relevant to the understanding of higher education funding mbchanisms se OECD (1990t).
} 
General government funds to universities are funnelled through three differant channels: 1) incremental funding, 2) formula funding, and 3) contractual funding. ${ }^{2}$ In the first, funds are allocated on the basis of historical expenditures with incremental resources made available for the development of new activities. This funding mechanism has been the dominant one in the expanding university systems until the early 1980 s (OECD, 1990b). In formula funding the budget of the institution is determined by some form of assessment of the actual institutional expenditures per student enrolled or expected to be enrolled. These funds are combined with general research funds according to a ratio of government funding for teaching compared to resertrch, e.g. a $60: 40$ split. Research funds can also be determined by a formula system that allows a distribution of the funds in a selective way on the basis of the research record. Contractual funding is applied via tender schemes. Public funding agencies issue targets in terms of student numbers or research and the various institutions apply to obtain the funds to carry out the specified tasks. There are different forms of contracting depending on the existence of fixed limits for the availability of funds, and on the level of specification for the activity. In the case of limited funds and tightly specified targets the universities have to compete with each other for the resources.

Although in the various EU countries there exists a high level of diversity in the mix of the different funding systems, the most recent years have seen an increasing reliance upon formula and contractual funding (OECD, 1990b). This move towards an indirect control of university behaviour via financial incentives is the result of the process of re-examination and modification of the rationale for resource allocation to universities.

\footnotetext{
${ }^{27}$ In some countries, stch as the UK, the government pays the large majority of tuition feess to universities. Currently, a debate on the opportunity of increasing the contribution of students, and their families, is taking place in all the EU countries. To the extent that this thesis emphasises mainly tuniversity research, this issue will not be dealt with here. For a clarifying analysis of the introduction of income-contingent charges for higher education in Australia see Chapman (1997). For the current debate in the UK see National Committee of Inquiry into Higher Education (1997).
} 
The new rationale for university research funding can be referred to as the competitive approach to university research behaviour and funding. Two main features characterise it. First, the university is required to support aims that are intended to enhance national economic development and the strengthening of competitiveness. Second, to obtain this result, and to increase the short-term efficiency of the institution, the government makes increasing use of competitive mechanisms for resource allocation developing a market-oriented approach to university research funding.

\section{The Role of the University in the New Rationale for Resource Allocation}

A new governmental vision of the role of the university characterises the competitive approach to university research behaviour and funding. The following can be considered the principal social goals for the university system as defined by the government: 28

1. To perpetuate the reproduction of existing levels of knowledge.

2. To improve the critical reasoning capabilities and specific skills of individuals.

2.1. As an input into their public and private work activity.

2.2. As an inpul into the development of a democratic, civilised, inclusive society.

3. To increase the knowledge base.

3.1. Pursuing knowledge for its own sake.

3.2. Pursuing knowledge and its application for the creation of wealth.

4. To serwe specific training and more general research support needs of the knowledge-based economy at the local, regional and national levels.

The first two aims correspond to the traditional role of the university as an institution for the preservation and the transmission, through education, of knowledge, culture and social walues. The third social goal, although referring to the traditional role of the university as a site where knowledge is produced through

\footnotetext{
${ }^{28}$ See, among others, National Committee of Inquiry into Higher Education (1997).
} 


\section{The Economics of University Research Behaviour}

scholarship and research, defines the action of the university in a broader sense. Scholarship and research should be pursued at the university for the production of knowledge for its own sake and for the production of a stock of useful knowledge that might be applied at other sites to produce benefits for society. Moreover, university research should also aim at the direct production of applied knowledge for the creation of wealth. Finally, the fourth social goall attributes a new role to the university. Universities are seen as direct actors in the process of economic development. In this new role, the university has to satisfy the knowledge needs, in terms of teaching and research, for the economic development at the local, regional and national levels.

Two streams of thought are at the basis of the competitive approach to university research behaviour and funding. On the one hand, on the basis of the laissez-faire philosophy, and due to the process of globalisation and the resulting increased international competition a large number of politicians and industrialists began perceiving the contribution of universities to wealth creation and national competitiveness as insufficient. In this view, public funding of university research has to give more concrete and direct returns. Hence, university research would have to reflect more the scientific and technological needs of the society, and universities would have to co-operate with firms, becoming the suppliers of applied knowledge which can be readily transformed into innovation to increase the competitiveness of national industries. ${ }^{29}$

On the other hand, the increased complexity of scientific research and the development of cross-field research, such as in the case of information technologies and molecular biology, underscores the relevance of knowledge production based on cross-disciplinary and cross-institutional collaborations. On the basis of this observation, it has been claimed that the nature of the scientific investigation process is changing from the search for new knowledge (on the basis of the old one) in a

\footnotetext{
${ }^{29}$ For a criticism of this view on the contribution of uniwersity to the welfare of society see Vavakova $(1998)$.
} 
single discipline to a process of search that cuts across disciplines, institutions and methods. ${ }^{30}$ As a consequence, the university ceases to be the leading player in the process of knowledge creation, but it is only one of the possible sites where knowledge is produced (Gibbons et al., 1994). In this view, the structure of the university is not suited to the new process of scientific discovery and therefore, without radical structural changes, it cannot claim the current level of public resources.

Before turning to the analysis of the characteristics of the market steering approach to university research funding, one more observation on the role of the university is required here. A process of knowledge production characterised by an increasing number of actors, and by blurred boundaries between them, still needs to have a formal or informal institution where knowledge is certified. If a transfer of knowledge among the various sites has to be achieved there is a need for a validation of the flow of knowledge. In the so-called new nature of scientific investigation private actors are having an important role in the generation of knowledge. If this is the case there will be an increased propensity to extract private benefit and consequently a higher level of secrecy. In this context a university characterised by its traditional incentive structure that favours the open disclosure of new knowledge and its verification would stand as the best-suited site for the certification of knowledge produced in other more private environments. This is not a novel role for the university. In the early nineteenth century the renewal of the university was characterised by the reception of the methodologies and social organisation of the scientific research carried out in the eightheenth century societies and academies. ${ }^{31}$ One of the crucial role played by, for example, the Royal Society and the Académie Royale des Sciences was the one of institutional sites where new knowledge was

\footnotetext{
3n This view of a changing process of scientific discovery is highly controversial; the analysis of the debate is however beyond the scope of this thesis (for a brief discussion see Section 3.3). For an analysis supporting this view see, among others, "Gibbons el al. (1994); for a criticism of the approach see, for example. David, Foray and Steinmueller (1998) and Pestre (1997).
}

${ }^{31}$ See Section 3.2 for a description of the evolution of the university in the early nineteenth century. 
confronted and verified. The renewed universities also took over this aspect of the social organisation of scientific mesearch.

If social welfare rises with an increase in the production and diffusion of knowledge there is a need for knowledge certification. In this way, verified knowledge can diffuse more effectively and enter in other processes of production of basic and applied knowledge. ${ }^{32}$ Thus, in a more diffuse knowledge production process the university with its traditional incentive structure that favours the open disclosure of new knowledge and its verification plays a crucial role as a site for knowledge certification.

\section{The Competitive Approach}

The competitive approach to university research behaviour and funding is based on an indirect control of university research behaviour via financial incentives. To succeed in drawing university research behaviour toward the accomplishment of new objectives and to increase the short-term efficiency of the institution quasi-market incentive schemes are applied. The clearest example of the competitive approach is the market-steering model developed in the UK. To implement this model two paths are followed. First, due to budget constraints and competition for funds from other public funded sectors, the overall contribution from the government to the total research incomes of universities is reduced or maintained unchanged in nominal terms. ${ }^{33}$ This strategy is pursued not only to stimulate cost-minimising behaviour in the universities, but also to create incentives for the development of research actiwities that could find funding support from non-governmental sources such as

\footnotetext{
${ }^{32}$ In the absence of certification the 'quality' of knowledge must be ascertained more directly which raises transaction costs and moral hazard risks. In addition, it creates the potential for quasi-fents. accruing to the new 'gatekeepers' or intermediaries brokering this knowledge.

3. See Section 4.1 for the analysis of the changes in Higher Education Expenditures in R\&D during the 1980 s and early 1990s. The budget cuts in the UK system were so important that the 1996 forecast of the Higher Education Funding Council for England reports hat 77 (or nearly 55\%) of English HEIs were expected to be in deficit by the end of $1999 / 2000$ (quoted from The National Committee of Inquiry into Higher Education, 1997 , p.263).
} 
firms and foundations. Second, a reallocation between government sources of funds is implemented with a decrease of general government grants and an increase of specific government grants. A larger allocation of resources through specific grants allows the government to develop policies aimed at a more purpose-directed allocation of research effort, and at the creation of quasi-market incentive structures that permit indirect control of uniwersity research behawiour.

The core of the new resource allocation system resides in an ex-post evaluation of universily research performance via market forces or simulated market actions. First, most of the non-governmental sources of university research funding, especially industrial funding, are characterised by a high level of competition and by a continuous short-term evaluation of research outputs. Second, specific government grants are allocated through competitive mechanisms, such as tenders with specific targets and limited budgets, on the basis of the past performance of the applicants, and they are subject to repeated evaluation of the outputs. Finally, an increasing share of general government grants is granted through simulated market actions such as the case of limited research funding allocated to the universities in proportion to their previous research performance. The expected consequences of these mechanisms of resource allocation are on the one hand, a higher degree of concentration and selectivity of research funds and, on the other hand, a higher level of accountability and cost reduction for the whole university system.

The resounce allocation to university research pursued in the competitive approach to university behaviour and funding stands on the following main assumptions. First, that it is possible to correctly evaluate the quality of the research output. Second, that is possible to identify the most promising research avenues. Third, that cost reductions can be obtained without lowering the quality of the output. Fourth , due to the existence of scale and scope economies the concentration of scientific capabilities increases the research output of the system. Fifth, the administrative costs, for both government and universities, linked to the implementation of a competitive system are low compared to the cost saving. 


\section{The Unintended Consequences of the New Rationale for Resource Allocation}

It is not the aim of this section to discuss each one of these five assumptions. Here the methodological approach, as developed in the previous section, will be applied to explain why the negative unintended consequences of the new rationale for resource allocation may prevail ower its predicted advantages in the long run. More specifically, the analysis will focus on the following four issues: 1) excessive concentration of resources, 2) disproportionate incentives for a short-term foreseeable research endeavour, 3) conflicting incentive structures, and 4) exacerbation of the impact of cumulative and self reinforcement phenomena present in the process of scientific production. The empirical studies presented in Part II and Part III of this thesis quantify the presence and importance of these unintended consequences.

One of the aims of the allocation of government funds via the simulation of market conditions is to obtain higher concentration and selectivity of research funds which permits the exploitation of economies of scale and scope present in the research production process, and orient the research towards the needs of society. The existence of uncoordinated competitive sources of research funds may result in negative unintended consequences that may offset the potential positive effects of the competitive approach. This would occur both at the national level, due to the existence of diversified competitive national sources of funds, and at the European level, due to the existence of national and EU funding sources. For example, due to its competitive character industrial funding will tend to be mainly funnelled towards the top universities ${ }^{34}$ which via simulated market actions also receive the largest share of public funding. An overlapping of the increased industrial funding with an expanded competitive public funding may create an excessive concentration of resources.

\footnotetext{
34 Arora and Gambardella (1997) show that due to an information externality problem firms have lower incentives than public agencies to fund scientists and institutions of uncertain scientific capabilities.
} 
An excessive concentration of research resources may have three main unintended consequences. First, the trends towards increasingly selective funding will reduce the availability of nom-competitive public funds -i.e. funds allocated in a proportional way. The allocation of resources not on the basiss of merit enables human resources and research institutions to express their potential, and hence allows the public agency to collect information about research potential. Competitive allocation mechanisms, concentrating the funds in few highly productive institutions, do not produce this information. Thus, the selective funding approach, although efficient in the short term (the most productive universities are the ones that receive the largest share of money), may have negative long-run effects for society because only a reduced fraction of human resources and research institutions is able to realise its potential.

Second, the possible advantages connected with the geographical concentration of scientific capabilities, and the localisation of a large part of research in a few universities may be offset by the negative externalities imposed on the universities marginalised by this process. For example, the currency of knowledge that researchers have at an institution with scance or no resources to carry on fundamental research will tend to become stale or obsolete preventing them from teaching and carrying out targeted research in an effective way for social needs (Dresch, 1995). Third, universities, with very low research receipts from the government are pushed to rely more heavily on industrial funding. Being then in a weakened financial situation, they find themselves in an asymmetric bargaining relationship with industry that they may be unprepared to manage effectively. This situation may lead to the involvement of a large amount of universities' scarce resources in routine contract research for industry. Researchers, technicians and scientific instrumentation of these universities are thus employed to develop a type of research that mainly gives private returns to the firms. However, the process will lead to universities pricing access at marginal cost, and consequently, average costs will not be covered for universities which have excess capacity $-i$. the costs of the institutional and research infrastructure, such as the library, are only partially covered 
depending on the share of overheads. Moreover, it is highly unlikely that these universities, given their weak bargaining position, will be able to account for the real opportunity costs of the involvement of their scance resources in contract research for industry. Hence, this activity may result in a form of public subsidy for particular industries for a kind of research that firms would otherwise have had to finance on a full-cost basis.

The push towards tighter interactions between university and industry, with the aim of possibly fostering state economic development, and the use of ex-post evaluation of university research performance via market forces or simulated market actions may create disproportionate incentives for a short-term foreseable research endeavour. In fact, university research is incited to respond to the short-term concerns of industry, and, in addition, the ex-post evaluation approach tends to focus on the recent quantifiable outputs of the institution, without taking into account work in progress or plans for long-term projects. As a result the following unintended consequences may arise. First, projects with a long-term horizon will be less likely to be performed. The competitive approach creates disincentives for researchers to be engaged in this type of project as they do not present quantifiable outputs at the time of evaluation. Hence, with this incentive structure, application-oriented short-term research will substitute for long-term research in the university research activity portfolio, dismantling what was the core activity and the source of comparative advantage for the uniwersity. Second, given the resource allocation mechanisms, industrial funding and public funding based on ex-post evalluation of university research performance will not provide the research funds for screening new scientific paradigms and developing new risky research programmes. The lack of incentives for path breaking, and consequently more risky research, decreases the probability of scientific innovation, ${ }^{35}$ potentially reducing the new knowledge base from which new technological innowations can emerge.

\footnotetext{
${ }^{35}$ For the analysis of the process of scientific innovation see Kuhn (1970) and Lakatos (1970).
} 
Different competitive research-funding sources create diverse incentive structures. Unversity researchers, and in general, wniversity institutions face different incentives and constraints depending on the source of funds upon which they rely. However, the research activities carried out at the university cannot be easily allocated to the sources of funds, hence university behaviour is the result of the interaction among the warious incentives and constraints. In the case in which the incentive structures lead to conflicting behaviours, for example relative to the secrecy and applicability of research results, tensions would characterise the organisation of university research. Moreover in certain cases the impact of the various incentive structures is proportional to the support provided, while in others it can be more or less important. In the former instance, university behaviour is driven towards accomplishing diverse aims depending on the weight of the various incomes in the total research budget of the university. In the latter instance, the incentives associated with a subsidiary source of funds may dominate university research behaviour distorting the role played by the university and thus reducing the social benefits of the allocation of public resources to university research. This case is more probable when general government research funds are fully utilised. In fact, new research activities should be supported by other competitive funds, hence the incentive structure stimulated by these funds may have an impact on university research behaviour disproportionate to the amount of resources supplied (OECD, 1990b).

The increased competitive character of university research funding, and the existence of diversified non co-ordinated competitive funding sources, may exacerbate the importance of the cumulative and self reinforcement phenomena present in the process of scientific production. Since the seminal work of Merton on the so-called Matthew effect (1968) it has been recognised that the organisation and resource allocation structure of science tends to reward successful individuals and grotups with access to means that increase their probability of being successful in the future. The new economics of science ${ }^{36}$ has elaborated this concept in terms of path-

\footnotetext{
${ }^{36}$ For the building blocks of this mew theoretical approach to the organisation of scientiffe production, see Dassupta and David (1987, 1994) and David (1994).
} 
dependence and self-reinforcing mechanisms. ${ }^{37}$ The reputation of a researcher (group) derives in some measure from prior success, but this may be due to good luck and not to 'real' innate abilities. On the one hand, a lucky researcher may have an early success that feeds the subsequent performances putting her on a high productivity path. On the other hand, an unlucky but possibly talented researcher may have problems in seeing her work published, leading to decreasing means for further research and to reducing self-motivation that will drive ber onto a low productivity path. The same mechanisms are applicable to group as well as individuals.

In this situation, competitive allocation mechanisms based on ex-post accountability not only give a biased evaluation of real talent, but also, due to their mechanistic accounting, tend to reinforce the virtuous and vicious circles described above. Moreover, the existence of diversified non co-ordinated sources may further reinforce the cumulative process. ${ }^{38}$ In fact, on the one hand, the concentration of public funding in few institutions through competitive resource allocation augments the probability of attracting other competitive research funds for these universities, and, on the other hand, decreases the attractiveness of the less supported institutions to external prowiders of funds. As pointed out above, this latter type of university will be pushed to carry out routine contract research to attract money from industry, this in turn may lead to a reduction in the quality of scientific output which will further reduce the probability of attracting research funds targeted to high-quality research.

\subsection{Empirical Implications}

The available empirical economic studies of the university research subsystem have been mainly based on the utility-maximising model. Consequently their analysis

\footnotetext{
"7. Fon the original definition of path-dependence see Arthtur (1988) and David (1985).

Although it is possible to imagine some form of co-ordination that would rediuce the negative unintended consequences of a diversified funding sources structure, co-ordination failures are likely al both national and European levels.
} 
focuses principally on the identification of the most efficient combination of inputs and outputs. The approach to university research behaviour developed in this Chapter puts particular emphasis on the incentives and constraints created by the changing funding rationale. To test the behavioural hypotheses presented above requires timeseries data at the institutional level that are not available at the cross-country level in Europe. Nonethelless some of the implications of these hypotheses can be tested by using cross-section data at a specific moment of time, while others can be verified for a single country or a particular type of competitive funding. The empirical studies presented in Part II and Part III are, thus, an attempt to evaluate the presence and importance of the unintended consequences resulting form the competitive approach to university behaviour and funding.

As pointed out above, the various $\mathrm{EU}$ countries implement different approaches to public university research funding, forming a continuum of possible funding configurations. On the one hand, countries such as the $\mathrm{UK}$ tend to rely more heavily on mission-oriented policies (selective policies), on the other hand, in countries such as Italy proportional allocation policies (distributive policies) are still dominant. Nonetheless, the most recent years have witnessed an increasing orientation of public policies towards the competitive approach in all the EU countries. The UK system based on an expost instiutional accounting for performance quality is the university system with the most evident market orientation, and hence, may serve as a model for emulation by other European systems.

Throughout the thesis, the UK university funding system will be used as the reference case for two main reasons. First, the insights from the Btitish experience can allow an evaluation of the intended and unintended consequences of the new competitive approach to university behaviour and funding, that, although preliminary and limited, can offer valuable lessons for the shaping of the funding system in all the EU countries. Second, the availability of panel data on the funding structure and on 
the scientific research output for the "old" British universities allows one to test specific behavioural thypotheses. ${ }^{39}$

One of the most important mechanisms on which the competitive research funding approach is based is the use of contractual funding via tender schemes. European universities compete for research contracts at the national and EU level. In the course of the four Framework Programmes of the Commission of the European Communities for the support of R\&D co-operative projects universities have increasingly taken part into these projects. In a context of reducing public funding of university research the existence of a new competitive source of funds may have important effects on the researcla activities of European universities. The analysis of university participation in co-operative R\&D projects funded by the European Commission, and the interactions of this funding source with national sources allows one to study how universities respond to diversified non co-ordinated competitive sources of research funds ${ }^{40}$

\footnotetext{
${ }^{39}$ For the analysis of the changing rellationships between the allocation of furds and scientific research output in the British university system see Chapter 5 .

${ }^{40}$ For the analysis of EU funding of university research see Part III. Chapter 6 and Chapter 7.
} 
The Economics of University Research Behaviour 


\section{An Evolutionary account of European Universities}

In the previous chapter it was illustrated that an increasing number of scholars of economics and policy-oriented studies have recently carried out research on the different aspects of university behaviour. In most of these studies the university is treated as a single type of organisational entity despite significant differences in the institutions labelled as universities. On the one hand, this is a general problem with economic thought that tends to treat heterogeneous institutions as homogeneous organisations - -e.g. the use of the term firm to describe all profit-seeking business organisations.. On the other hand, this is an acute problem in the definition of university as noted by Rothblatt and Wittrock $(1993$, p. 1):

\footnotetext{
"the problem of defining university hias long preoccupied politicians, planners, reformers, academics, theologians, philosophers, historians, and linterateurs. They have often found the task impossible. So much has this been the case, especiaily since the eighteenth century, that universities are now subsumed under a broader if less romantic category called higher education"."
}

Still, to understand the ongoing changes in the structure, role and goals of the university, a better definition of the contemporary European university is needed. Referring to the university as a group of institutions, sub-group of the class 'higher education institutions" does not add much clarity to the debate. Rothblatt and Wittrock (1993, pp.3-4), among others, consider the higher education institution ambiguous definition: 


\title{
An Evolutionary Account of European Universities
}

\begin{abstract}
"Higher education ... is wery likely a neologism of the last century. It was, and remains, imprecise. Nations do not defime 'higher' in the same way, just as they do not define 'lower' education in the same way. Academic work deemed appropriate for a school in one country is inappropriate in another, and courses of study pursued at college or university in one nation are located in an "upper secondary" or "post-compulsory sector' in another."
\end{abstract}

The term 'higher education institutions' is not suatable for identifying a particular kind of organisation. This term encompasses groups of institutions that differ by country of origin and period of time considered. Therefore, the university cannot usefully be described merely as a sub-group of "something" that cannot be defined. Ir would be better simply to describe the attributes of the subclass itself.

After the Second World War the university went through a process of rapid growth and diversification. The number of students, number of researchers and the level of financing have more than quadrupled in the thirty years between the early $1950 \mathrm{~s}$ and the late 1970 s. The elite pre-war institution has become a mass institution, mostly, but not only, concerned with research and teaching. New universities and new kinds of higher education institutions, with different structures, roles and goals, have been established. This process of increasing diversification makes the task of precisely defining the university problematic if not impossible.

In 1992 the total number of Higher Education Institutions (HEIs) in the EU ${ }^{2}$ countries was of approximately 1429 (IAU 1991, 1993). Looking at the official national classifications, it is possible to subdivide them in 379 Universities and 1050 Post Secondary Institutions (PSIs). Nonetheless when one considers the

\footnotetext{
1 Higher education institutions are institutions that offer education programmes at the tertiary level -i.e. programmes classified as eirher ISCED (Intermational Standard Classification for Education) level 5. 6 ar 7. For the definition of tertiary education and 1SCED classification see the Glossary of OECD (1995; pp. 366-369).

2 This count does not include Austria, Finland Luxembourg, and Sweden.

3 To calculate the number of PSIs has been used an estimate of the PSIs in the UK. For the selection criteria of the 379 institutions classified under the class universities see Chapter 4, Section 4.1.1.
} 
International Standard Classification for Education (ISCED), the difference between uniwersities and PSIs becomes less clear (see Table I for students'subdivision). ISCED level 5 -i.e. education at the tertiary level, first stage, of the type that leads to an award not equivalent to a first university degree-- is usually offered by PSIs, but sometimes also by universities. ISCED level 6 --i.e. education at the tertiary level, first stage, of the type that lleads to a first university degree or equivalent-- is usually supplied by both universities and PSIs. Finally, ISCED level $7-i, e$ education at the tertiary level, second stage, of the type that leads to a post-graduate university degree or equivalent-- is usually the domain of universities, but sometimes PSIs also offer Master degrees and Ph.D. degrees. Thus, degrees granting specialisation do not seen relevant for justifying a division between universities and PSIs.

Table 1: Students by ISCED level of programme

\begin{tabular}{|c|c|c|c|c|}
\hline & $\begin{array}{l}\text { Tertiary Level } \\
\text { Non Umiversity } \\
\text { Equivalent }\end{array}$ & $\begin{array}{c}\text { Tertiary Level } \\
\text { University or } \\
\text { Equivalent }\end{array}$ & $\begin{array}{c}\text { Tertifury Level } \\
\text { Post-graduate } \\
\text { Degree }\end{array}$ & All Levels \\
\hline$B-1990$ & 123,970 & 136,664 & 15,614 & 276,248 \\
\hline D - 1990 & 22,843 & 120,125 & \# & 142,968 \\
\hline$F-1990$ & 454,055 & $1,065,600$ & 179,283 & $1,698,938$ \\
\hline$C-1990$ & 220,802 & $1,578,592$ & + & $1,799,394$ \\
\hline Cr-11989 & 77,159 & 117,260 & - & 194,419 \\
\hline $1-1991$ & 10,378 & $1,474,719$ & 48,105 & $1,533,202$ \\
\hline $\operatorname{Tr}=1990$ & ก. & ma & n. & 90,296 \\
\hline $\mathrm{N1}-1990$ & 252,346 & 181,795 & 8,653 & 442,794 \\
\hline$P-1990$ & - & 182,032 & 3.730 & 185,762 \\
\hline S-1989 & 366 & $1,143,080$ & 25,695 & $1,169,141$ \\
\hline UK - 1990 & 383,026 & 706,089 & 169,073 & $1,258,188$ \\
\hline TOTAL & $1,544,950$ & $6,705,962$ & 450,160 & $8,791,340$ \\
\hline
\end{tabular}

Source: Unesco Statistical Yearbook (1993).

+: The ligure is included in the fugure of Level $6 ;-\therefore$ Magnitude is either negliguble or zero; * It exciudes the students of distant learning institutions.

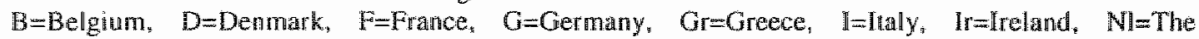
Netherlands, $P=$ Pontugal, $S=S p a i n, U K=$ United Kingdom. 
When knowledge creation and transmission aspects -i.e. norms, incentives and organisational structure of the "open science" kind of research-- are put at the core of the analysis, a subdivision is still possible. Nevertheless, as highlighted at the end of the Section 3.3, the most crucial dilferences in research orientation, independence in the pursuit of new knowledge and avalability of funds are between a restricted group of elite research-intensive universities and a cluster of uniwersities and PSIs, and not between uniwersities and PSIs. The offucial distinction between universitues and PSIs is, in general , a precarious one and therefore not useful.

The institutional stability, or inertia, of the university historically has led to a slow process of incremental institutional innovation. This process of institutional change can be depicted as a continuous series of adjustments to a changing enviromment. Unless a profound and disruptive change impelled by shifts in the external socio-political environment of the organisation takes place, the roles played, rules followed, and aims to be accomplished can be traced back to the historical development of the institution. Highly diversified modem universities are the result of this process of evolution. The historical and sociological analysis of university development has highlighted a few main features --e.g. the independence from external powers of the medievall university, the pursuit of knowledge for its own sake of the nineteenth century university-- that have characterised the university throughout its history. Some of these attributes are still present, with different degrees of importance, in contemporary universities.

Contemporary European Universities are the product of about 800 years of evolution." Their current standing is the result of a series of historical events. Hence an historical approach is required to fully understand the characteristics of this pecular institution. Focusing on university contribution to social purpose and on the

\footnotetext{
"For an analyical history of the encrgence of the instututions of "open science" see David (1997a); for the role played by norms, incentives and organisational structure in the creation of knowledge see Dasgupta and David $(1987,1994)$.

"Together with the Roman Catholic Church the university is the oldest institution with a continuous history in the Western wonld.
} 


\section{An Evalutionary Account of European Uniwersities}

governance and organisation of the institution, this chapter will try to highlight the path of evolution of the institution, delineating the presence of continuity within change. On the basis of the evidence put forward by the historical analysis of university development it will be maintained that the roles played, rules followed, and aims to be accomplished of contemporary universities find their roots in the medieval traditions, in the approach to scientific discovery developed by the scientific societies of the late eighteenth century, in the nineteenth century German model and in the post-war 'endless frontier' ideal.

Broadly speaking, one can subdivide the historical development of the university into four phases. First, the birth of the university: the period of time between the late twelfth and the early sixteenth century that witnessed the birth and development of a unique institution that would have assumed the name of Universitas Magistrorum et Scholarium or Studium Generale. Second, the decline period that runs from the second half of the sixteenth century up to the end of the eighteenth century. Third, the recovery and German transformation, from the early nineteenth century up to the Second World War. ${ }^{7}$ Fourth, the expansion and diversification, from the end of the Second World War up to the end of the 1970s. Probably, we are now entering a fifth phase that can be called the institutional reconfiguration of the university. This chapter provides an analysis of first, third and fourth phase.

\subsection{The Birth of the University}

The university is essentially a European creation. During the Middle Ages, between the twelfth and thirteenth centuries, in some European towns (mostly in Italy and

\footnotetext{
6 The "endless frontier' ideal is associated with the report to President Roosewell tidled "science The Endless frontier" by Vannevar Bush (1945).

7 A more detailed division is offered by Bjorn Wittrock (1993) who subdivides the recovery and German transformation into two sub-phases: the resurtection of the university (1800-1850) and the rise of the research-oriented university $(1850-1939)$.
} 
France) a peculiar institution of higher education developed to a level of organisational and educational complexity to be consider the ancestor of the modern university. For more than three thousand years the development of various ciwilisations has gone with the flourishing of higher learning. Nonetheless, only the medieval higher education institution, known as studium generale, "*..employing regular teaching staff, offering specific courses of higher studies ... and granting certificates of accomplishment in the form of generally recognised diplomas or degrees" (Rudy, 1984, p.14), showed a continuity through time that enables one to consider it as the predecessor of the modern university. In particular, Paris and Bologna are often considered as home of the oldest universities.

The origins of the university of Paris ${ }^{9}$ are to be found in the ecclesiastical and priwate schools that flourished in the twelfth century. The former were schools of theology, the most important being the school of Notre-Dame with its chancellor who operated under the authority of the bishop. The latter were schools of arts which, although private, were under the direct control and exaction of the chancellor of Notre-Dame. Due to the rapid growth in the number of students and masters, a proliferation of new schools and a disciplinary confusion occurred. The danger of loosing control over the subjects being taught convinced the bishop and the chancellor to accept the formation of an autonomous guild of masters. This "university" was responsible for the organisation of curricula, examinations, and faculties' distinction in a way that respected the "classification and hierarchies upon which Christian knowledge had raditionally been based." Nonethelless, the compromise between the bishop and the atutonomous guild of masters was fragile. In subsequent times, the direct intervention of the Pope or of the King ${ }^{10}$ was required to

\footnotetext{
Bologna chirms to be the furst, dating its foundation in 1088. However, dilferent investigations into we histony of medieval andersties have failed to produce any evidence in support of this claim (Rilegg, 1992; Rastudall, 1936).

The following deseription of the unversites of Paris and Bologna draws particularly heavily upon Verger (1992a), bur see also Rastudall (1936) and Cobban (1975).

wo The Empire and the Papacy were struggling to assume the jurisdiction over the new education institution, thus they were avelable to support the "university" one against the other.
} 
settle such disputes. The confrontation reached the point of the cessatio (moving the institution out of the town) in 1228, when the nembers of the arts faculties withdrew from Paris. Three years later, Pope Gregory $\mathrm{DX}$ issued a bull granting full chartered rights to the university, and the whole institution was reassembled. Due to the importance of art and theology, the students were mainly clerict and/on young students, thus the only members of the university to enjoy all of the rights and prerogatives were the teachers and the masters."

Bologna had a long tradition in the teaching of law. At the start of the twelfth century the law schools developed into a 'university' (guild) and acquired international prestige. After some years other subjects developed to the level of complexity that allowed the creation of other "university' organisations that were then associated with the one of law. Among the professional courses, it was medicine and not theology that flourished. Especially in the case of law and medicine, the students where generally adults from high social class. Coming from different European regions, they went to Bologna to specialise in a professional career. Consequently, the university of Bologna was organised as a corporation of different mono-disciplinary "universities". In each "university", depending on the locality of their origin, the students were grouped into "nations". The students were the only members of the institution to enjoy university rights, ${ }^{12}$ while the teachers were simply hired through annual contracts.

The somcalled students" universities that sprang up mostly in the South of Europe during the fourteenth century, adopted the model (the statutes) of Bologna to local circumstances. As in the case of Bologna, these universities generally had an

\footnotetext{
"The term master referred to a scholar that held a master degree in art, that is to say, that succeded in the first wo tiers of the curriculum -- i.e. apprentice and bachelor. Otten he was a student of the advanced courses in theology, law and medicine, and, in the meanwhile, the daught undergraduate courses.

II In particular, only the foreign students were full members of the university. The local students did not need to be member of the university as they were citizens of Bologna, and thus they enjoyed municipal rights.
} 
important faculty of law and a lew other, less developed, faculties. In the fifteenth century, after the Great Schism (1378), the northern and central part of Europe also witnessed a rapid rise in the number of new universities. These new institutions, generally created ex-novo by the Emperor, Kings or Dukes, structured their organisation following the Parisian model -i.e. the masters ${ }^{*}$ university. ${ }^{\text {it }}$ Usually all four faculties of art, theology, law and medicine were present in the new institutions. ${ }^{14}$

Two names were most commonly used to define the university. They were: Universitas Magistrorum et Scholarium ${ }^{15}$ and Studiam Generale. In the early period the "...commonest term in texts... would seem to be universitas and not studium generale" (Verger, 1992a, p.37). More precisely, as the term universitas -i.e. the totality or the whole-- was applied to corporate bodies (guilds) of the most different sorts, "one had to specify the object to which one was referring" (ibidem). Thus the name universitas magistrorum et scholarium or universitas studil were used to signify the guild of the masters and student or the guild devoted to the study. The term studium generale become the legal definition of the university only after the second half of the thirteenth century. During the first half of the century, studium generale was used with descriptive intent, "...the studium part indicating a school ... and generale referring ... to the ability of the school to atract students from beyond the local region" (Cobban, 1975, p.23). Only towards the end of the century did the concept of studium generale acquire a legal connotation. ${ }^{16}$

\footnotetext{
"In the thirteenth century, Oxford and Cambridge developed following the masters' model too.

14 An idea of the historicall university development can be tound in Verger (1992a). He maintain that: "The twenty-eight (or thinty-one) unversities operative in 1378 became thity-one for thirty-four) in 1400 and sixty-three (or sixty-six) in 1500 (Verger, 1992a, p.57).

is It is possible to find both the term Universitas Magistrorum and the term Universitas Scholarium, in relation to the type of organisational structure utilised. Sometimes the term Universilas Studii is also used as a more general way to define the new institution.
}

16 Considerable scholarly work has been dedicated to the discussion of the meaning of the terms universitas and studium generale. See, for example, Chapter I of Rashdall (1936) and Chapter II of Cobban (1975). 
Three particular rights were connected to the status of studium generale. First, the higher education institution recognised as a studium generale was entitled to award masters or doctoral degrees, which were acknowledged throughout the Christendom. The holder of such a degree had the right "to teach in any other uniwersity without undergoing further examination" (ibidem, p.27), the jus wbigue docendi. ${ }^{17}$ Second, the institution was secured from the action of the local, religious and lay authority; it was under papal or imperial protection. Third, clergy (both residents and non-residents) studying at a studium generale were entitled "to receive the fruit of their benefices." As described in the case of Paris, the achievement of a certain degree of independence was the result of conflicts with both the local authority and the universal authorities - -i.e. the Pope and the Emperor. The confrontation with the former was related to the claim of self-governance. The university opposed the direct control and exaction of the local authority. Although located in a specific town, it refused to submit itself to the local jurisdiction, calling for special rights of universial character. To obtain them, two connected strategies were employed. On the one hand, due to the fact that the presence of the university increased the wealth and importance of the town, the threat and use of the cessatio ${ }^{18}$ put pressure on the town's authorities. On the other hand, the university looked for the support of the Pope or of the Emperor, applying to universal entities to have universal rights. The protection from the Pope or the Emperor depended upon the adherence to their rules. Yet, the fact that Imperium and Sacerdotimm were two conflicting powers enabled the university to retain sufficient bargaining power with both of them.

\footnotetext{
17 Although always associated with the stathe of sthdium generate, in the reality the jus ubigue docendi has not been always acknowledged. With the uncrease in the number of shida generalia, the tong-established universities, in the attempt to defend their nonopoly position, tended to refluse the jus ubique docendi, requiring a re-exmination for the candidates coming from other universities (Cobban, 1975: Brizzil and Verger, 1990).

The cessatio was a serious thredt because the early universities were constituted only by masters sudents and a few books. Capital investments - - b. buildings and library-- started only at the end of the hirteenth century. The frequent use of the cessatio is confimed by the origins of different universities. For example, the foundations of Vicenza (1204), Arezza (1215), Padua (1222), Siena (c. 1246) and Pisa (1343) were linked with the migration of students and masters from 3 ologna.
} 
In most of the cases, the title of studium generale was granted by papal bull ${ }^{19}$ to new institutions or to pre-existing ones that requested the official recognition. ${ }^{20} \mathrm{Up}$ to the end of the fifteenth and early sixteenth century the use of the term studium generale, and the connected papal bull, was the norm throughout Europe. ${ }^{21}$ Then, due to religious and political changes, both the terminology and the requested papal charter disappeared, although there were a few exceptions in the Catholic countries. Since the eighteenth century, and more evidently, since the nineteenth century, the term universitas litterarum, translated into nationall languages, has become the official definition of the university. Furthermore, the papal bull has been substituted with an imperial, royal or governmental charter.

As the name universitas testifies the medieval university was a peculiar kind of guild. Peculiar, in so far as a community of magistres and scholares-i.e. masters. and students - that were involved in the elaboration and transmission of a peculiar good: knowledge. As with other types of guild, it was composed of members that decided to join it freely. It was a community with internal cohesion, articulated arganisation and a corporate personality. It was a moral and legal entity enjoying a degree of independence from external powers -i.e. Pope, Emperor, Princes, towns" rulers, etc.-- and capable of continuity through time. The primary objective of this community of practitioners was the transmission of knowledge from masters to students. The medieval university was a teaching institution responsible for the preparation for educational, ecclesiastical, governmental and professional careers. The common curriculum of the seven liberal arts, subdivided in apprentice -i.e. grammar, logic and rhetoric- and bachelor -i.e. arithmetic, geometry, astronomy and

\footnotetext{
In most of the cases the university status was granted by the Popen only in few cases the privilege was granted by the Emperor. Is interesting to notice that Naples, in 1224, was the first university established by Imperid decree. It was founded to rival the pro-Papacy uniwersity of Bologna, that, whlthough consider with Paris the most pre-eminent university of the period, was invested with the same privilege by papal bull only in 129 I (Rudy, 1984, Rashodal, 1936).

wh Oxlord, one of the intial uniwersities, never received such a racogntion.

21 Where the political power was sufficiently strong, like in the cases of the Kings of Poland, Portugal and Spain, the studiwn geverale status was gramted by the King and then confrmed by papal bull.
} 
music- was followed by the three advanced professional courses, then postgraduate faculties, of theology, law and medicine. All of them were often "taught side by side in the same institution" the university (Perkin, 1984). The differences between the university, the studium generale, and other professional training schools were: a) its organisational guild-like status; b) its special right to award master or doctoral degrees $^{22}$ recognised throughout the Christendom, the jus ubique docendi; c) its ability to attract students and masters from regions (countries) other than the one of its geographical location; and d) its multidisciplinary features. The other professional schools (sometimes subsumed under the name of studium particolore), ranging from elementary to higher education schools, were under the control of the locil authority (religious or lay), and served the need of a town or a limited region. They only offered courses in few of the liberal arts and did not offer advanced professional courses.

To better understand the late medieval development of the university, some remarks concerning financial issues are appropriate here. ${ }^{23}$ Although the independent medieval universities were characterised by heterogeneous organisational structure, a similar pattern of finance can be found. Uniwersity incomes can be subdivided into internal and external sources. The former were: a) fees for matriculation and graduation; b) dispensations from the statutory conditions for degree and other dispensations; c) collectae -i.e. money collected from the students once or twice at year; and d) fines for violation of university statutes and discipline. The latter were: a) ecclesiastical benefices; b) salaries paid by Church, King, Duke, or town; c) gift and legacies; and d) grant and endowments given for the permanent support of the university. In the early periods, university expenses were modest, but then, due to the development and the consequent increase in capital investment (houses, buildings and library), they grew rapidly. The expenses were: a) salaries to teachers, b)

\footnotetext{
22. Every faculy had its own master degree, in the case of the advanced professional courses the degree was called doctores or professores.

22. The following analysis of the university financing draws particularly heavily upon Gieysztor (1992) and Verger (1992b).
} 
administration costs; c) salaries to officials; d) law suits; e) cost of academic solemnities and religious feasts; and $\mathrm{f}$ acquisition and maintenance of houses, buildings and library.

Of particular interest is the way in which teachers' costs were covered. During the thirteenth century the masters that were clergy endowed with benefices did not charge fees, while fees for private teachers and clergy without (or extremelly low) benefices were paid directly by the pupils. However this system was against the belief of the Church -i, e. knowledge is a gift of God, thus students do not have to pay for it. Therefore, clergy without benefits started to receive a salary covered with part of the collectae and examination fees. With a growing number of teachers and the inclusion of all the masters in the scheme, the need for external support rose rapidly. Thereafter, salaries of the teachers ${ }^{24}$ were increasingly paid by the Church (Spain), the Commune and the Duke (Italy), and the town (Germany). In France the salary system did not develop until the end of the medieval period. Due to their expansion, the independent universities ${ }^{25}$ of the late Middle Ages could no longer be self-supporting. Teachers' salaries and costs of acquisition and maintenance of academic buildings were too high to be covered by the universities' resources. Kings, Dukes, and towns, in return for their support, became more and more involved in the control and management of university finances.

Counter to the politically fragmented nature of medieval society, the umiversity developed as a cosmopolitan, "super-national" institution. A common language (Latin) a common course of edwcation and a common organisation enabled the creation of an international community of masters and scholars that travelled from one instifution to another enjoying the same privileges and duties regardless of location. The various medieval universities were not only a peculiar kind of teaching

\footnotetext{
${ }^{24}$ There were strong discrepancies between the income of the masters of the higher faculties and the teachers of arts. The income diwersity was due to differences in salary. benefices, fees, and examination fees Furthermore, the masters of the professional training schools had also non-university sources of income due to their professional activity.

25 The universities controlled by the crown were not financially independent since their foundation.
} 
institution, but they all were members of a "super-national" intellectual unity devoted to the cultivation of knowledge, enjoying a certain degree of independence from the papacy, the empire and the municipal authority.

In the late medieval period, due to political and religious changes, and to increased financial needs, the university started to lose both the 'super-national' feature and its independence from external powers. It became more local in character and dependent from the support of local powers. Connected to these changes, the first symptoms of an intellectual sclerosis emerged in the conservatism of the curriculum. Humanistic thought, with the revival of classical literature and philosophy --e.g. Cicero and Plato-- was consider dangerous for religion, and was thus opposed by the religious establishment. The university aligned itself to the church and tended to resist the new learning; it was only in the sixteenth century that universities accepted Humanism. The conservatism of the university in the late fifteenth and sixteenth centuries favoured the development of new institutions, the learned society and academies. ${ }^{26}$ These, and other institutions alternative to the university, were the centre of the development of new knowledge. In the late fifteenth and sixteenth century they were mainly concerned with literary issues, then, with the development of the Scientific Revolution and the acceptance of the Humanism by the university, they became the locus where scientific research was presented and they formed the channels through which the new knowledge was disseminated.

To avoid giving a misleading description a few observations, relevant for university development in general, are required bere. Medieval universilies were heterogeneous institutions sharing some common characteristics. Thus, university conservatism, as in the above paragraph for the late medieval universities, meant that

\footnotetext{
26 The phenomena of the academies had its birth place in Italy. In the period between 1442 and 1462 , the first three important accademie lettararie were founded. In 1442, in Naplles was established the Accademia Pontaniana, followed in 1460 by the Accademia Romana in Rome, and finally in 1462 the famons Ficino's Accademia Platonica was founded in Florence. Over the sixteenth century, the Italiarn model of accademia letteraria spread all over Europe (Mantovani, 1991).
} 
a majority of universities resisted change. Nonetheless, in some universities the new ideas developed extremely fast. Furthermore, some of the scholars meeting in institutions outside the university were often also teachers at the university. ${ }^{27}$ They were thus aware of the new ideas, and they were bringing them inside the university challenging the traditional knowledge organisation of the institution. Therefore, on the one hand, the university system tended towards conservatism, but, on the other hand, the seeds of change were germinating inside it.

\subsection{The Recovery and German Transformation}

Over the seventeenth and eighteenth century universities did not play a crucial role in the advance of knowledge. On the contrary, universities were not responsive to new ideas (in particular science) brought by the Scientific Revolution and the Enlightenment, and they resisted the change. According to Willies Rudy (1984, p.87): "They [universities] still retained narrow and antiquated curriculum and methodologies, made rew contributions to thought, and opposed the ideologies spawned by the Enlightenment." The institutions where scientific research was carried out and diffused were scientific societies and academies. At the end of the sixteenth, early seventeenth century, on the model of the literary academy, private amatorial institutions concerned with the study of science sprang up. The Accadomia Secretorum Naturae founded in Naples in 1589 is considered the first scientific academy (Ferrone, 1992). However, it was only in the seventeenth century that the Accademia dei Lincei in Rome (1603-1630) and the Accademia del Cimento in Florence (1657-1667) developed to a level of institutional organisation (with well delined membershp, hierarchical control and an international scientific community of reference) that made them the prototypes of the late seventeenth and eighteenth century societies. Among other reasons, the strong limitations imposed by the

\footnotetext{
27 Copernous, Descartes. Huygens. Kepler, and Tycho Brahe, among others, accomplished their major wotks independintly of the university, nonetheless they collaborated with scholars that were teaching wh the uniwersity.
} 
counter-reformation ${ }^{28}$ have been particularly important in hindering the development of the Italian academies.

Scientific societies and academies flourished outside the Italian peninsula. The private and official ${ }^{29}$ institutions that developed in Europe essentially had two organisational models, the one of the Royal Society, founded in London in 1662, and the other of the Académie Royale des Sciences, founded in Paris in 1666. The former was the model for fellows" societies. The society was controlled and directed by its: members, neither state finance, nor state interference was present. The institution was mainly a site for confrontation and verification of scientific findings, it never became a real site of scientific research. With more than 300 scientific and non-scientific fellows from around the world and the publication of the journal of Phillosophical Transactions the institution provided the foundations for to the development of an international scientific community.

The French academy was the model for the state academies that followed. It was a state institution for the co-ordination, control and development of scientific research in the kingdom. The institution was not only a site for scientific confrontation and verification, but also a place where scientific research was developed. State finance enabled the creation of laboratories and libraries, and, for the first time, scientists were paid to carry out scientific research. At the beginning of the eighteenth century, with about 200 national and foreign scientists, belonging to the academy in various ways, the Academie Royale des Sciences was the dominant model of scientific organisation (Ferrone, 1992; McClellan 1985).

In the interim between 1660 and the French Revolution in Europe and in America, private and official scientific societies and academies showed an impressive increase, with over one hundred institutions active during this period

\footnotetext{
28 See for example Galiteo"s trial in 1633

2 The officia institutions thad a corporate status, they were legally chartered by some civil authority: Emperor, King, Prince, lown, etc. (McClellan, 1985).
} 
(McClellan, 1985). An international scientific community, as we understand it nowadays, began to develop. A common set of norms and incentives for the pursuit of scientific knowledge - i.e. the institution of "open science" 30 - was emerging. The professionalisation and the development of new fields of scientific inquiry induced the development of specialised societies and academies. The resulting institutions, however, proved unable to cope with the specialisation of science (McClellan, 1985). Their fallure paved the way to the rise of scientific research within the university.

After circa two centuries of atrophy, the nineteenth century saw the university"s recovery. In the new political, religious and scientific environment the university evolved into a new kind of institution, preserving some of the features of its medieval ancestor, and incorporating and developing methodologies and social organisation of the scientific research carried out in the eighteenth century societies and academies. In the late eighteenth century the pursuit of modern scientific and technological knowledge was not carried out within the uniwersily. The late medieval, early modern universities had not been able to cope with the changes and were relegated to a marginal role. ${ }^{31}$

In the early nineteenth century, due to the pressing needs of sociely, new universities were founded and the old ones underwent a process of complete renewal. In particular, in Germany, England and France new models of teaching and research institutions were developed. Although different, the German, English and French models had a few main common characteristics: (a) some of the features of the old medicvall university; (b) the methodologies and social organisation of the scientific research carried out in the eighteenth century societies and academies; and (c) the new and the crucial subdivision of knowledge into disciplines. The teachers were no

\footnotetext{
For an analytical history of the emergence of the institutions of "open science" see David (1997a); for the role played by noms, incentives and organisational stucture in the creation of knowhedge see Dasgupta and David $(1987,1994)$.

"Nonetheless, especially in Scotland, "The Netherlands and Germary, there were few exceptions. For example, the universtics of Edibburgh, Gotungen. Halle, and Leiden were important centres of research and training ouring the Enlightenment (Rudy, 1984).
} 


\section{An Evolutionary Account of European Universities}

longer masters able to teach all required subjects, but specialised, singlediscipline professors focused on the advancement and transmission of a specific, well-defined portion of knowledge.

Although the German model is traditionally considered the source of this 'diwision of labour' approach, subject specialisation originally was developed in eighteenth-century Scotland. During the Scottish Enlightenment the development of the subdivision in disciplines enabled various prominent scholars to advance the knowledge frontier of their specific subject within the structure of the university (Wood, 1994) and not outside it, as was the case in the other European countries. One century later, due to the Sicottish influence, the same process took place in the English universities and autonomously in the new German universities.

Following these two models -i.e. the English and German ones- the structuring of knowledge into disciplines spread to all other European countries. Thus, the second half of the nineteenth century witnessed the emergence of a modern research-oriented university in the whole of Europe. Although national differences existed, which will be discussed below, it is possible to describe the new university as an institution committed to (a) the production of knowledge for its own sake, and $(b)$ the preparation for professional careers, (c) structured in well defined disciplines and (d) characterised by an articulate organisation and a legal status. Moreover, the university became a national institution ${ }^{32}$ allowed to pursue the unconstrained development of knowledge but to the advantage of the nation-state ${ }^{33}$.

The university model developed in Germany during the ninetcenth century has had the greatest influence on the rise of the modern research oriented university. Following the defeat and French occupation of Prussia, a diffused perception of the

\footnotetext{
12. This is more true for the continental countries were the wiversity wats seen as lool for the culurall, ecomomic and social development of the nation.

3 The university should, in wonds of Humboldt, be "the summit where everything that happen direculy in the interest of the monal culture of the mation comes together" (Wittrock, 1993, p.317).
} 
need of innovations and reforms to regain the lost power was present. In this environment, a group of reformers succeeded in overcoming the opposition of conservative circles, and received the royal approval for the foundation of a new university in Berlin. In 1809 , Wilhelm von Humboldt $(1767-1835)^{34}$ and a small group of civil servants of the Ministry of the Interior ${ }^{35}$ defined the aims, structure and organisation of what would have become a new model of the university. As accurately summarised by Spinner (1993, p.142), this "ideal university would be an institution for the cultivation of excellence, which is free in the internal realm of research, privileged by the State and the Law, discharged (entlastet) in relation to the normal state affaurs in the broader society." At the basis of this model there is the combination of teaching and research and the idea that teachers and students are "devoted to science as such for its own sake, within the proper domain of an autonomous realm of knowledge organised according to the principles of free-selfformation" (ibidem). A new "social organisation" of science and a new classification of science developed. The concept of "pure science', carried out within the university, and conversely 'non-pure science', performed outside the university, are the results of the cognitive changes originated by the development of and resistance to the new university (Spinner, 1993, Wittrock 1993).

Founded in 1810, the university of Berlin was the most genuine, and probably the only, example of the Humboldtian model of university. On the basis of this model - he. the union of teaching and research, and the research for its own sake-the evolution of the German university followed other paths. "... [D] espite rather" than because of the Humboldtian ideal, the German university became the embodiment of the specialised research-oriented ideal and the model for the

\footnotetext{
3f It interesting to notice that Wilhelm von Humboldt started his university studies in the Prussian University of Frankfurt an der Oder, then unsatisfied by the conservative and pedantic kind of studies oftered by the university he moved to the Hannoverian University of Gottingen. As previously pointed out, in the eighteenth century Cobttingen was one of the few European universities in which scientific research and the new organisation of scientific inquiry have flourished.

35. More exactly in the part of the ministry devoted to culture and education, that would have become the ministry for education and culture in 1817 (Spinner, 1993).
} 
progressive system of higher education in the other advanced societies" (Perkin, 1984, pp.34-35). The crucial feature of what is considered as the paradigmatic German model is, indeed, the subdivision into specialised disciplines, ${ }^{36}$ that is incompatible with the "holistic thinking and broad historical cultural categories" that were inspiring the Humboldtian university. Nevertheless, the Humboldtian reform enabled "the creation of an autonomous institutional setting for intellectual activities" (Wittrock, 1993, p.320) that during the nineteenth century evolved into what is considered the institutional paradigm of collective disciplinary specialisation and research-orientation in the approach to acquiring and transmitting knowledge. Thus, the development of the German university during the nineteenth century can be seen as the result of the interaction between a new social organisation of science, the Humboldtian model, and a new structure of science -i.e. the spontaneous trend towards the subdivision of knowledge into scientific fields.

The state played a crucial role in the development of the German university. The Prussian state, and from 1871 the imperial state, through the ministry of educiation and culture, carried on an organised series of actions, in modern terms science policy actions, to develop, support and improve the university system. ${ }^{37}$ In particular, the state became the principal founder and financier of the university. The German state saw the university not only as the source of knowledge and of future welfare, but also as the way to strengthen national and cultural identity. As stressed by Wittrock (1993, p.321): "the rise of the [German] research-oriented university was largely coterminous with the formation of a modern nation-state. Universities came

36 The structure of the university was built around the autonomous, state supported, chair holder (Ordinarius). He was the director of a centre of research in which were working a number of assistants (Dozent) without fixed state salary. He enjoyed a large degree of independence both in the setting up of the research priorities and in the management of the centre.

3 A criticall role in the development of German science policy at the end of the nineteenth cenury has been played by Friedrich Althoff (1837-1908). In a period of 25 years (1882-1907) he developed a complex set of policy actions that has been named the "Althoff' system". Anong the other, the folndation of technical universities and the structuring of research institutions, the Kaiser-WilhelmGesellschaft, that would have become the Max-Planck Institult after the Second World War, have been extremely important for the development of the German research and education system. For a detailed analysis of the Althoff system see Backhaus (1993) and Brocke (1991). 
to be the key institutions both for knowledge production and for strengthening a sense of national and cultural identity."

As pointed out above, the nineteenth century witnessed the renewal and restructuring of the uniwersity system in the whole of Europe. Some countries imitated the German model to a large degree, while others borrowed only some of its aspects, developing their higher education and research system on the basis of national specificity. Of particular relewance are the English and French case.

At the end of the eighteenth, early nineteenth century English universities were still characterised as training places for Anglican clergy, and gathering places for rich students. Oxford and Cambridge were still the only two recognised institutions. ${ }^{38}$ Oxford is considered the first English uniwersity. Although it was never formally recognised as a studium generale, at the end of the twelfth century it was regarded as a studium generale ex conswetudine. The origin of Cambridge university is usually connected with the cessatio of the Oxford university in 1209 1214/15. After the closure of the Oxford studium a considerable number of students and masters migrated to Cambridge giving birth to the new university. The organisation of both universities adapted the masters' model of Paris to the local context. Due to the low power of local bishops the universities developed higher independence, and the chancellors were nominated from the assembly of the masters (comgregaziofonvocazio). At the end of the thirteenth century, despite the fact that Oxford was internationally known for the study of mathematics and natural sciences, and Cambridge attained an international reputation in the humanities in the early sixteenth century, the members, both masters and students, of the two universities were mostly from the English islands. During the early thirteenth century, together with other institutions of higher education, Oxford and Cambridge were supported by the crown. However, at the end of the thirteenth century early fourteenth the crown favoured the two institutions giving them the monopoly of English higher education.

\footnotetext{
96. The following brief description of the universities of Oxford and Cambridge draws heavily upon Evans (1990) and Cobban (1975)
} 
Under the influence of secularism and the success of German scientific and technological research, in 1828 the first purely secular institution of higher education in the British history, University College, London, was founded. Following this model new institutions sprang up throughout the country. In particular, the second half of the nimeteenth century witnessed the development of what would then be called 'civic universities', or 'redbrick' universities: Birmingham, Leeds, Liverpool, Manchester, and so on. Contrary to Oxford and Cambridge these new institutions were more responsive to the technological and scientific needs of the country (Rudy, 1984; Wittrock, 1993), and their mission encompassed not only liberal education, but also professional education, and research. New comprehensive curricula with utilitarian subjects such as engineering, architecture, agriculture were offered in the new institutions. Although less promptly, and keeping an elitist approach, Oxford and Cambridge also developed their scientific and technological capabilities along the line of the German research model (Perkin, 1984). Nonetheless, it was under the influence of the Scottish system, more than the German model, that English universities and colleges developed the professorial system (ibidem). Contrary to the German model, the professor was not a civil servant appointed by the state, but an employee of the independent university. Moreover, he was a member of a department, primus inter pares and not an autonomous chair holder with his 'research institute' (Perkin, 1984). As in Germany, research found its place in the university, but the core of the system was the idea of a "liberal education free from narrow consideration of utility and vocational interest" (Rothblatt, 1976; Wittrock, 1993). Together with the research function and the emphasis on liberal education the university was also serving the goal of preparing students for a professional career. In some universities there was the confluence of the different aims, while others tended to be specialised in only one. Converse to the homogeneous and state driven German system, the English system was characterised by a high degree of institutional heterogeneity and institutional independence.

To trace the peculiarity of the French system one has to go back to the end of the eighteenth century. As previously highlighted during the eighteenth-century 
Enlightenment, under the Old Regime, the French universities were playing a minor role in the process of knowledge creation and they tended to be conservative if not reactionary in their teaching. In 1793, the revolutionary authorities abollished the 22 French uniwersities (Rudy, 1984; Verger, 1986). Two new types of institutions with a clear mono-disciplinary orientation were established. On the one hand, independent faculties pursued the study of the liberal arts; ${ }^{39}$ on the other, new schools, les grandes écoles -e.g. Ecole Polytechnique (1794), Ecole Normale Supérieure (1795), focused their research and teaching on utilitarian subjects. During the Napoleonic period a highly centralised state organisation emerged. The main aim of this higher education system was "to train for state service [military or bureaticratic] citizens loyal to their prince, fatherland, and family" (Rudy, 1984; p.102). The complete control of the university was in the hands of the Ministry of Education, and in 1808 the whole public instruction was set under the Imperial University of France. This structure lasted up to 1896 when faculties were reunited in 17 provincial universities. Still, the centralised state organisation did not disappear, but it persisted well into the twentieth century (Karady, 1986). During the nineteenth century, the dominant role in research has been played by les grande écoles. These institutions, utilitarian in character, were devoted to the production of scientific and technological knowledge and they provided highly trained students for the bureaucratic and managerial carriers. Only after the re-founding of the provincial universities, with the development of better research facilities, were some research activities carried out in the university. At the end of the nineteenth, early wentieth century the French system came to be characterised, on the one sicle, by a clear cut subdivision between grandes ecoles and universities, and, on the other, by a bureaucratic state control. The institutional independence, typical of the English system, or the autonomy of the chair holder, of the German system, were impossible in the French system. Higher

\footnotetext{
34 "... with the exception of medicine, the faculties remained examining bodies, providing some public lectures, but they were not meant to organise formal curricula" (Frijhoff, 1992).

"t/ Some special institution, boused on research and on training for high managerial positions, was atready existing betore the rewollution. For example: Ecole des Ponts et Chaussées (1747), and École des Mines (1783).
} 
education in general was considered essentially utilitarian and at the service of national interests.

\subsection{The Expansion and Diversification}

Over the period stretching from the end of the Second World War to the end of the 1970 s the university went through a process of rapid growth. The four main driving forces behind this large expansion were the following. First, due to internall logic i.e. the mechanism of subdivision and re-configuration of fields of research into new sub-disciplines and the increased reliance on instrumentation - the process of scientific inquiry has required an enlarged number of practitioners and widler financial involvement. Second, the successful use of scientific discoveries made during the Second World War ${ }^{41}$ set in a definitive way the 'belief' in the direct applicability of scientific findings. Governments, first in the US and then in the European countries, regarded scientific research as a source of future welfare, thus directing a large amount of financial resources towards university research. Third, in particular during the 1960s, the shift in demand for level and range of skills by industry and government together with social pressures for democratisation of the university system $^{42}$ transformed the perception of the educational role of the university. The university was no longer considered an elite institution open only to a minority of students from the higher classes. It became an institution open to all persons qualified by ability to attend it. The opening of new institutions, and the creation of student support schemes tried to implement this new educational role of the university. Fourth, due to the strong economic growth of the post war period, and to the demographic boom, during the 1950 s early 1960 s, the number of students attending

\footnotetext{
41 See especially the Marhattan Project and the Radiation Laboratory at MIT. For a clear analysis of governmental expectations from scientific research, generated by the war experience, see Geiger (1993. Chapter 1 and Chapter 2). For the rationale used to justify the public support of science see Bush (1945).
}

42 For the UK case see the report on Higher Education of the Robbins Committee (1963). For an analysis of the Robbins achievement see Scott (1984; Chapter 5). 
secondary school increased at an extraordinary pace. Consequenty, the potential demand for higher education - -i.e. the number of students finishing secondary school $\cdots$ expanded dramatically.

The expansion of higher education, from circa one million students in 1960 to circa nine million students in 1990 in the eleven EU countries considered, brought together a process of institutional diversification (see in Table 1 for levels, and Table 2 for the gross enrolment ratio for tertiary education - i.e. total enrolment, regardless of age, divided by the population of the age group 20-24). Mainly under the influence of the respective governments, ${ }^{43}$ the enormous increase was absorbed by the enlargement of existing universities, the creation of new universities, and the foundation of new types of higher education institutions.

Table 2: Gross Enrolment Ratio. (\%)

\begin{tabular}{|c|c|c|c|c|c|c|c|c|c|c|c|}
\hline & $\mathbf{B}$ & $\mathbf{D}$ & $\mathbf{F}$ & $\mathbf{G}$ & $\mathbf{G r}$ & $\mathbf{I}$ & $\mathbf{I}$ & $\mathbf{N I}$ & $\mathbf{P}$ & $\mathbf{S}$ & $\mathbf{U K}$ \\
\hline 60 & 9.1 & 11.4 & 7.4 & 6.1 & 3.8 & 6.6 & 8.1 & 16.7 & 3.5 & 3.9 & 9.0 \\
\hline $\mathbf{7 0}$ & 17.5 & 18.4 & 19.5 & 13.4 & 13.5 & 16.7 & 13.6 & 19.5 & 8.0 & 8.9 & 14.1 \\
\hline $\mathbf{8 0}$ & 26.3 & 28.6 & 25.5 & 26.2 & 17.4 & 27.6 & 20.3 & 30.0 & 11.2 & 24.2 & 20.1 \\
\hline $\mathbf{9 0}$ & 38.2 & 35.6 & 39.7 & 36.1 & 25.0 & 29.8 & 33.8 & 37.6 & 22.7 & 35.5 & 27.8 \\
\hline
\end{tabular}

Source: Unesco Statistical Yearbook $(1975,1983,1993) ; 1965$ value.

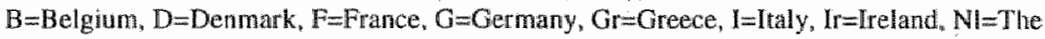
Netherlards, $\mathrm{P}=$ Portugal $S=S$ pain, $U K=$ United Kingdom.

Throughout the 1960 s and 1970 s the EU higher education system has witnessed an impressive growth in the number of students and researchers, and in the financial commitment. Although in some of the less wealthy countries such as Greece. Ireland and Portugal the increase started only in the 1970s, the whole EU higher education system had grown five fold by the end of the period (see Table 3 in Appendix 1). This transformation from elite 10 mass higher education has put the university under strain. Part of the expansion has been absorbed by new universities and new institutions, but also the pre-war universities have seen a large increase in

4. It is only recently that Europe hats developed a number of private higher education institutions. Historically, ondy a tew prixate religions institutions were active. 


\section{An Evolutionary Account of European Universities}

their size. The university structure, defined in the nineteenth century on the basis of the medieval guild-like model. was shaped for an elitist system and not for a mass system. In the attempt to satisfy the new demand, the old uniwersities tried to accommodate the growing numbers. Due to the extreme need for teachers, less qualified lecturers found, first temporary, and then tenure positions in the university (Trow, 1984; Simone, 1993). The number of students attending a class increased dramatically, with a consequent decrease in the quality of instruction. Training oriented courses for new and emerging professions were added to the traditional curricula, creating tensions in the old faculty subdivision. The loss of intellectual preeminence of faculties and departments together with the increase organisational complexity (due to growth and to the diversification of goals) opened the way to the bureaucratisation of the university. The university was no longer a community of peers engaged in the production and transmission of knowledge, but a bureaucratic organisation run by officials where scholars were involwed in teaching and research together or only in one of the two. The budget constraints and the increased demand for accountability of the 1980 s have further weakened the independence and status of universities.

Following the three-fold classification made by Martin A. Trow in 1984, ${ }^{44}$ the different kind of higher education institutions can be categorised as: (1) the pre-war universities, (2) the new post-war universities, and (3) the non-university institutions of higher education or, in our words, the post secondary institutions of higher education. Although sometimes the second and third kind of institutions are under the same institutional hat, as in the case of the German Gesamthochschuten and the comprehensive universities in Sweden, ${ }^{45}$ the diversity among the three classes becomes evident when one considers the differences in: (a) research orientation, (b) funding patterns, (c) degree-granting power, (d) organisational forms, (e) teaching

\footnotetext{
4.4 See Trow, M.A. 1984. The analysis of Status, in Burton R. Clark. Perspectives on Highther Education, University of Califorma Press, Berkelley.

49 In France in some cases the Instituts Universitaires de Techologie (IUT) are part of pre-existent unversities, while nother cases they are independent institurions.
} 


\section{An Evolutionary Account of European Universities}

and training orientation, and (1) autonomy. In particular, focusing on the degreegranting power and on the research orientation, it is possible to distinguish the universities (pre-war and post-war together) from the PSIs. Except for the French grande ecoles and a few other PSIs, the university has retained the right of awarding the Ph.D. degree. The university still has a monopoly position in the highest level of education. Although Ph.D. students represent only a small fraction of the total number of students (see Table 1) they are a crucial input both for the education system, as lecturers and researchers in the higher education institutions, and for the knowledge oriented production system, as researchers in public and priwate research centres. Due to political choice, the university, and not the PSI, became the site where the government directed a large amount of financial resources for the development of scientific research. ${ }^{46}$ Politics directed the new institutions founded by the national governments primarily to satisfy the educational demand and so, originally, they did not have any research orientation. History mattered, too, in that the pre-war universities were already the places were research was carried out, and thus, due to the accumulated capabilities, they were the most suitable place to develop scientific research.

Having said this, it is nonetheless important to acknowledge that, during the 1980s and early 1990s, the distinction between universities and PSIs has become less clear. Relevant for the understanding of this new trend is what the higher education literature has called the academic drift phenomena. Since their foundation PSIs have tended to emulate universities. The most important reason for this behaviour was that their teaching staff, mainly trained in the university, aimed to gain the rights and privileges of the peers working in the university. This tendency has gained strength after the budget constraints of the late 1970s. A process of increased competition for the best professors and teachers, for the most promising students, and for scarce research funds took place. This process found a fertile ground in the diffuse

\footnotetext{
46 This observation is clearly referring only to the higher education system. After the Second World War the development of scientific and technological research took place not only within the university but also in other public and private sites.
} 
perception of the existence of relevant status differences. The lower status institutions (PSIs) developed policies aimed at catching up with institutions of higher status (universities) that had higher funding. The consequence has been a polarisation of the system into three main groups. At the top are almost exclusively the pre-war universities. They have a higher status, more rights and privileges, and wider sources of funds. These high status universities are the sites where much of the top scientific research is carried out. A second group is composed of the majority of the new universities and some of the PSTs. They are characterised by a lower status and lower funds, but they have rights and privileges similar to the pre-war university. They are involved in mainly technical research usually applied and oriented to regional needs. Finally, at the lowest level are the group of vocational PSIs that exclusively undertake teaching responsibilities. ${ }^{47}$

National governments opposed resistance to the academic drift because it was undercutting the policy objective of a diversified higher education system containing a large component of vocational and technical education. Nonetheless, as highlighted above, the combination of budget constraints and the push towards a more market oriented approach reinforced the process of academic drift. The response of the government has then been of trying to level the system downward instead of opposing the trend of levelling upward, allowing only for few centres of excellence. ${ }^{48}$ Policies of higher control and less autonomy have been developed. The higher education in toto has been made more accountable to specific aims of national policy.

An illuminating example of the trends described above is the higher education policy developed in the UK during the 1980s early 1990s. Throughout the $1980 \mathrm{~s}$

\footnotetext{
4h As one of the main forces of this process is the competition for funds, the conseguent polarisation is more clear in those countries, such as the United Kingdom, where the higher education system is more exposed to market forces.

4. Again, this observation is more true for countries such as the UK where mission-oriented policies (selective policies) are applied, while is less relevant for countries like Italy where proportional allocation policies (finanziamento a pioggia) are the norm. Still, as the UK system is becoming a potencial attraction pole for the other European systems, its current implications are of general relevance.
} 
uniwersity, polytechnic and college budgets were restructured in ways that put new pressures (and incentives) on the institutions. The actions were undertaken, on the one hand, to stimulate a process of financial restructuring aimed to reduce costs and, on the other hand, to provide incentives, through mechanisms such as the Research Assegsment Exercise and the Technology Foresight, ${ }^{49}$ by which it was hoped that better direction of research effort would result. In 1988, with the Education Reform Act, the role of uniwersities, polytechnics and calleges was suddenly transformed from the one of public institutions subsidised by the state into that of private suppliers of specific services. Finally, in 1993, 39 polytechnics and colleges were granted university status. The old and new universities now share a common identity. Thus they are all competing for the same research funds and are exposed to a process of selectivity on the basis of assessment of research quality (David, Geuna and Steinmueller; 1995$)^{50}$

The trends and forces described in the previous paragraphs have originated a process of change in the structure of knowledge production within the university. First, although most of the prestigious universities of the pre-war period have retained a position of pre-eminence, their position tends to be limited to particular research fields rather than spanning the knowledge spectrum. Second, the loss of intellectual pre-eminence of faculties and departments has been followed by the rise of the research centre as the intellectual unit of research. ${ }^{5 !}$ This fragmentation has been supported not only by the internal logic of subdivision and re-configuration of

\footnotetext{
49 While the Research Assessment Exercise is run by the Funding Council with the aim of a better allocation of research funds to universilies, the Technology Foresight, run by the Office of Science and Technology. tries to pull scientific research more towards the "need of the mation". Research Assessments Exercises, formerly fermed research selectivity exercises, were conducted in 1986, 1989, 1992. and 1996; for an oflicial cvaluation of the impaci of the 1992 exercise see HEFCE (1997).

5.t See Chapter 5 for the analysis of the changes occurred in the UK higher education system during the 1980s, early 1990 s

31 For an analysis of the importance of research centres in the US research intensive universities see Stahler and Tash (1994).
} 
research fields, but also by a higher degree of autonomy ${ }^{52}$ and lower constraints ${ }^{53}$ granted to the centre. Increasingly the university owes its prestige to the research centre, usually associated with a graduate school, and not to particular departments or to undergraduate teaching. Finally, on the one hand, the process of fragmentation seems to point to a more specialised type of knowledge, while, on the other hand, the knowledge production process at the frontiers of science and technology tends to be more trans-disciplinary in character (Gibbons et al., 1994).

The reconciliation of the process of fragmentation with the trend towards more trans-disciplinary knowledge production is possible when one looks at the development of the research network. ${ }^{54}$ Due to the increased complexity of the scientific research and to the development of cross-field research, such as in the case of information technologies and molecular biology, scholars sitting in different centres and concerned with fields of research that were traditionally considered separate, interact in the production of new trans-disciplinary knowledge. ${ }^{55}$ The rise in cross-country and cross-discipline scientific collaboration is connected to the development of large international scientific institutions, such as CERN, to the rising importance of international co-operative R\&D programmes of the Commission of the European Communities, and to the increased mobility of researchers. In particular, the mobility of researchers can be realised both in physical terms - e.g. through visiting professor schemes, and by the use of electronic media - - e.g. through the

\footnotetext{
5. The research centre enjoys a higher degree of independence in the setting up of research priorities. Furthermore, due to its flexibility, it can better exploit the external sources of financing, an extremely important advantage in a period of budget cuts.

53 Usually the researchers of the centre are less involved in under-graduate teaching.

5* For a broad approach to the development of the scientific network see Callon (1991).

5 For the development of international scientific collaboration see Luukkonen et al. (1992) and Leydesdorti: (1992). For the development of trans-disciplinary and public-private collaboration see Hicks (1995).
} 
development of telecommunication services ${ }^{\text {sto }}$ such as Internet that enable intmate interaction among distant researchers.

\title{
3.4 Conclusions
}

Until recently, the university has played an unique and essential role in the process of knowledge creation and transmission. As clearly stressed by Perkin (1984, pp.45-46) "A knowledge-based society depends on both the constant advancement of knowledge and the reproduction of knowledgeable people as much as industrial society depends on the constant investment of capital and the reproduction of skilled managers and workers."

According to Roger L. Geiger (1985, p.53):

\begin{abstract}
"The development of science in the modern era tas taken place in a variety of institutional settings. However, since the widespread recognition of German scientific leadership in the last third of the nimeteestli century, and continuing through the ascendancy of American science in the mid-twentieth, the university has serwed as the predominant home of sciencie. Although this mexus between universities and research has been considered wirtually axiomatic for a century, it can no longer be regarded as so today. The vast prolifieration of modern science has long-since overflowed the confines of the university, while the parallel expansion af highter education has necessitated departures from the universily model." 57
\end{abstract}

Due to its success both in research and in teaching, the aniversity has grown in number of sudents, number of researchers, and financing. In particular, after the Second World War its rapid growth was also connected with a rise in society"s expectations for economic returns. These two phenomena, the growth and the rise of

\footnotetext{
56 The development of the information and communication technologies and the forecasted fall of the telecommunication costs, down to the level of the simple access cost, can have a crucial impact on the changes that are going on in the higher education system. For example, it is possible to think in terms of interactive video-conferencing at wero variable costs.
}

57. A similar view is presented in Gibbons er at. (1994). 
expectations, put the university under strain. A range of topics such as compatibility between the demands of elite and mass higher education, free research enterprise versus targeted reseatch, private versus public financing, free advancement of the knowledge frontier versus dependence from the needs of the society, competition from teaching-oriented and research-oriented institutions, have led to coumletacting pressures on the institutional organisation and roles played by the umversity.

The historical development of the university testifies to "... its protean capacity to change its shape and function to suit its temporal and sociompolitical environment while retaining enough continuity to deserve its unchanging name" (Perkin, 1984, p. 18). Although a large part of the literature concerned with university development has highlighted the present crisis of the university, ${ }^{58}$ when we look at its historical capacity of adaptation and at its ${ }^{\text {ix }}$....special sort of cultural inheritance with idealistic, spiritual, and high-minded aspiration derived from an important philosophical and theological traditions..." (Rothblatt and Wittrock, 1993, p. 1), hope again rises. The recognition of the adaptive ability of the university enables a better evaluation of its current situation. Instead of being in a phase of loss of importance, the uniwersity is going through a period of institutional change. A complex institution like the university tends to resist re-configuration of its structure and institutional organisation, thus the result of change is only observable after a long period of time.

One of the possible outcomes of the ongoing changes is a clear cut division between a small group of dymamic research-oriented universities and a large group of mainly teaching-oriented institutions. The national university developed in the mineteenth century, composed by a community of mainly national peers, covering a broad spectrum of disciplines, and focused on both teaching and research, will tend to disappear. A new kind of institution, in its international character and in its disciplinary specialisation more similar to the old medieval university, will start to develop. The research universities, usually elite pre-war institutions and a handful of

\$s Sce, for example, Gibbons ef al (1994). Hague (1991) and Scott (1984). 
new post-war universities, will be the privileged actors of this dewelopment. These institutions, internationaly well-known for their competencies in specific fields of knowledge, interconnecked by international (European) research newworks, will tend to increase their international focus. The action of these universities will be influenced not only by local government policy, but also by the initiative of the Commission of the European Communities and other international organisations, and by the opportunities offered by industry at the international and multinational level.

The next wo chapters, focusing on university research, describe the contemporary uniwersity situation both at the European and at the British level. One of the aims of the two chapters is to provide statistical support to the view presented above of the stratification (polarisation) of the university system. Particularly in the analysis of the British case, some tentative evaluation of the ongoing changes and of the policies steering them is put forward. 


\section{Appendix 1: Tables}

Table 3:Students, teachers and growth indices of real public expenditure by countries

\begin{tabular}{|c|c|c|c|c|}
\hline & YEARS & SIUTENTS & TEACHERS & EXPENDTIURE \\
\hline \multirow[t]{4}{*}{ BELGIUM } & 60 & 52,002 & at. a. & $n a_{1}$ \\
\hline & 190 & 124,857 & 细被. & $100(75)$ \\
\hline & 80 & 196.153 & $27.796(88)$ & 117 \\
\hline & 90 & 276,248 & 28.058 & $118(88)$ \\
\hline \multirow[t]{4}{*}{ DENMAMK } & 60 & 28289 & $4.408(65) 4$ & pa.a. \\
\hline & 70 & 76,024 & $4.498(73) \div$ & n. \\
\hline & 80 & $406,24 \pi$ & $6.702(78)+$ & E.a. \\
\hline & 90 & 142,968 & 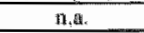 & 50. \\
\hline \multirow[t]{4}{*}{ FRANCE } & .60 & 272037 & $10.824+$ & 觔.3. \\
\hline & 70 & $\$ 01,156$ & $35,679+$ & $100(174)$ \\
\hline & ${ }^{480}$ & $1,076,717$ & $44,678(84)+$ & 97 \\
\hline & 91 & $1,840,307$ & $50,331+$ & $123(48)$ \\
\hline \multirow[t]{4}{*}{ GERMANY } & .60 & 265,366 & $21,635=$ & m.th. \\
\hline & 70 & 503,819 & $81,903(72)$ & 100 \\
\hline & 80 & $1,223,221$ & 171.708 & 142 \\
\hline & 50 & $1,799,394$ & 208,881 & $135(87)$ \\
\hline \multirow[t]{4}{*}{ GREECE } & 60 & 29,339 & 926 & n. 8. \\
\hline & 70 & 85,766 & $3,162+$ & 100 \\
\hline & 80 & 121,116 & 10.542 & 204 \\
\hline & 489 & 194.419 & $|3,45|$ & $358(888)$ \\
\hline \multirow[t]{4}{*}{ IRELAND } & 60 & 12.438 & $984+$ & n.a. \\
\hline & 70 & 28,510 & $4,088(175)$ & 100 \\
\hline & 85 & 70,301 & 6,002 & 218 \\
\hline & 90 & 90,296 & 5,598 & 268 ("4) \\
\hline \multirow[t]{4}{*}{ ITALY } & 60 & 191,790 & 17.47 & ก.a. \\
\hline & 70 & 687,242 & $44_{n} 171$ & $100\left({ }^{\circ} 71\right)$ \\
\hline & .85 & $1,185,304$ & $\$ 1,539$ & 110 \\
\hline & 90 & $1.452,286$ & 55,766 & $224(86)$ \\
\hline \multirow[t]{4}{*}{ NETHER. } & $" 60$ & 105,995 & nuth. & nian. \\
\hline & 50 & $23 \|_{8} 167$ & $11,500+$ & 100 \\
\hline & 80 & 360,033 & n.a. & 119 \\
\hline & 91 & 499,563 & 41348 & $142(87)$ \\
\hline \multirow[t]{4}{*}{ PORTUGAL } & 60 & 24,236 & $\$, 617$ & Bafa. \\
\hline & 70 & 50,095 & 2,869 & $100(13)$ \\
\hline & 80 & 92,152 & 10,694 & 240 \\
\hline & 990 & 198,762 & 14,432 & $503(188)$ \\
\hline \multirow[t]{4}{*}{ SPAIN } & 60 & 87,388 & 3,928 & A. \\
\hline & 70 & 224,904 & $29,701(75)$ & na. \\
\hline & 80 & 607.789 & 42,831 & in, a \\
\hline & .89 & $1,169,[4]$ & 59.310 & n,a. \\
\hline \multirow[t]{4}{*}{ UNIIED KINGDOM } & .60 & 168.759 & 17,863 & niti: \\
\hline & 70 & 604,300 & $50,489-$ & 100 \\
\hline & 85 & $\pm, 032,491$ & 99,621 & 102 \\
\hline & $" 90$ & $1,58,188$ & 86,200 & $90(67)$ \\
\hline
\end{tabular}

Source: Unesco Statistiol Yearbook (1975,1983,1993); OECD (1992).

* National currencies deflated with eduction PPPs.

t: Only umversities and equivalent institutions, other third level institutions are not included.

$\therefore$ Incomplete figures. 
An Evolutionary Account of European Universities 


\section{PART II}

Allocation of Funds and University Research 



\section{Contemporary European Universities: Relationships among Age, Size and Research Output}

The final part of the previous chapter presents a brief description of the ongoing changes in the higher education system in Europe. After the rapid growth of the 1960 s and 1970s, the 1980s have been a period of stall or decline in budgets accompanied by policy changes. Contemporary universities are undergoing a phase of transition and redefinition. Among other forces, national and EU policy actions have an important impact on the ongoing changes. To better understand the implications for the university of policy actions stemming form the competitive approach to university research behaviour and funding, a clearer description of the contemporary population of European universities is needed.

This chapter will mainly focus on the university as a producer of knowledge. The research aspect of the university is put at the centre of the analysis. $A$ methodology for describing the university system in terms of its main characteristics is employed to group universities inlo clusters with small within cluster variation for discriminating variables - i.e. the institutions in a specific cluster have similar characteristics-- and high between-cluster variation --i.e. the universities in the warious clusters have different features. This type of analysis is not definitive. There are no clear a priori grounds for the selection of discriminating variables, nor are there clear a priori reasons for selecting the number of clusters (other than purely numerical relationships). Nonetheless, this methodology allows to identify groups of universities with similar characteristics. The study of the characteristics of the 


\section{Contemporary European Universities}

universities included in the different groups enables one to underscore a few main features of the European university system.

The analysis addresses two main problematiques. On the one hand, the study of the different characteristics of the institutions included in the various clusters gives some indication of the policy impact. As will be discussed in the following sections, the clusters are formed on the basis of size and output indicators, thus the existence of different clusters indicates that groups of universities tend to have similar research output "strategies". Among other factors, university policies strongly influence the different behaviours. On the other hand, the existence of different groups of institutions with high between variation points to the fact that, due to the heterogeneity of the university system, the consequences of policies are different in the various clusters. Therefore, it highlights the need for national and European policies shaped in relation to the various sub-groups of institutions.

The chapter is organised as follows. Section 4.1 introduces a set of statistical indicators of the European higher education system for the period 1981-1993, followed by a statistical analysis of the total population of European universities (Section 4.1.1). Section 4.2 presents the methodology used and its implementation in the case of the total European population. Finally, in the conclusions some policy implications will be put forward.

\subsection{The European Higher Education System}

The aim of this section is to draw an accurate picture of the European university system. The section is divided into wo main parts. First, the higher Education R\&D statistics for the period 1981-1993, and the main publication indicators for the period 1981-1991 will be analysed. Second, a statistical analysis of the total population of European universities in 1992 will be put forward. 


\title{
Contemporary Europeaw Universities
}

In the Frascati manual, the basis for measuring R\&D in OECD countries, the Higher Education sector is defined as:

\begin{abstract}
"All umiversities, colleges of technology and other institutions of post-secondary education, whatever their source of finance or legal status. It also includes all research institutes, experimental stations and clinics operating under the direct control of, or administered by, or associated with higher education establishments."
\end{abstract}

This definition has been interpreted in different ways by the OECD Member countries. Important differences are present in the way government-funded research institutions are classified. For example, while the Centre National de la Recherche Scientifique (CNRS) in France is classified in the Higher Education sector, the Consiglio Nazionale delle Ricerche (CNR) in Italy, which has broadly the same functions of the CNRS $\mathrm{p}$ is accounted for in the Government sector (OECD, 1981). Keeping in mind these limitations, the R\&D performed in the Higher Education sector can be used to analyse the development of the research effort in the European higher education system.

Table 1 illustrates the Higher Education Expenditure on R\&D (HERD) values and intensities-- for the four main EU countries and for nine EU countries together ${ }^{1}$ in the period 1981-1993. The four main EU countries account for about four-fifths of the R\&D expenditure in bigher education in the EU countries. In the period considered, France and UK showed a compounded annual growth rate of about $3.5 \%$, the expenditures in Germany grew at a rate of $4.4 \%$, while, also due to the lower starting level, the growth rate for Italy was 7.0\%. The share of HERD in the Gross Domestic Expenditure on R\&D (GERD) allows an evaluation of the changes in the higher education expenditure on R\&D compared to the total R\&D expenditure. On the one hand, the 1980s are characterised by a group of countries (Denmark, France, Germany, The Netherlands and Spain) with a reducing HERD intensity, and a

\footnotetext{
"Data for Belgium, Luxembourg and Portugal are not awailable for all the points in time considered, hence they have not bee included.
} 


\section{Contemporary European Universities}

group (Greece, Ireland, Italy and UK) ${ }^{2}$ with increasing HERD intensity. On the other hand, the early $1990 \mathrm{~s}$ witnessed an increased importance of higher education expenditure in all the countries except for Denmark. The rise of HERD share in the early 1990s is due more to a reduction in the GERD growth rate, as pointed out by the reduction from $2.01 \%$ in 1989 to $1.97 \%$ in 1993 of the ratio GERD/GDP for the nine EU countries together, than to a relevant increase in the HERD share. These wiew is confirmed by the small increase of the ratio HERD/GDP, of the four main EU countries only Italy showed important improvements.

Table 1. Higher Education Expenditure on R\&D

\begin{tabular}{|c|c|c|c|c|c|c|}
\hline & & 1981 & 1985 & 1989 & 1993 & CAGR 81.93 \\
\hline \multirow{5}{*}{ HERD } & Gevmany & $3,519.1$ & $3,612.0$ & 4.556 .1 & $5,916.9$ & $4.4 \%$ \\
\hline & France & $2,586.0$ & $2,879.5$ & $3,333.0$ & $3,851.8$ & $3.4 \%$ \\
\hline & $U K$ & $2,229.5$ & $2,552.4$ & $2,994.7$ & $3,356.6$ & $3.5 \%$ \\
\hline & Naty & $1,1,66,8$ & $1,718.6$ & $2,214.6$ & $2,636.1$ & $7.0 \%$ \\
\hline & EU9 & $10,920.0$ & In.sil. & $15,335.9$ & 18,927 & $4.7 \%$ \\
\hline \multirow{5}{*}{ HERD/GERD } & Gemprany & $15.6 \%$ & $13.5 \%$ & $14.4 \%$ & $18.0 \%$ & $1.2 \%$ \\
\hline & France & $16.4 \%$ & $15.0 \%$ & $14.9 \%$ & $15.8 \%$ & $-0.3 \%$ \\
\hline & $U K$ & $13.5 \%$ & $14.5 \%$ & $15.0 \%$ & $16.7 \%$ & $1.8 \%$ \\
\hline & Italy & $17.9 \%$ & $19.2 \%$ & $19.8 \%$ & $22.5 \%$ & $1.9 \%$ \\
\hline & EU9 & $16.2 \%$ & n.a. & $16.1 \%$ & $18.8 \%$ & $1.3 \%$ \\
\hline \multirow{5}{*}{ HERD/GDP } & Gexmany & $0.38 \%$ & $0.37 \%$ & $0.41 \%$ & $0.44 \%$ & $1.2 \%$ \\
\hline & France & $0.32 \%$ & $0.34 \%$ & $0.35 \%$ & $0.39 \%$ & $1.5 \%$ \\
\hline & UK & $0.32 \%$ & $0.33 \%$ & $0.33 \%$ & $0.37 \%$ & $1.1 \%$ \\
\hline & lialy & $0.16 \%$ & $0.22 \%$ & $0.24 \%$ & $0.28 \%$ & $5.0 \%$ \\
\hline & EUQ & $0.28 \%$ & n.a. & $0.32 \%$ & $0.37 \%$ & $2.3 \%$ \\
\hline
\end{tabular}

Soure: Elaboration OECD data.

Millon of Us: PPF; Price index 1990.

Overall, the EU higher education expenditure on R\&D has experienced a moderate growth all along the considered period. There are, howewer, important differences among countries. While the R\&D intensive countries have shown constant or slightly increasing R\&D expenditure, both at the gross domestic level and

\footnotetext{
"The positive trend of the UK is manly due to a wery low growth rate of total $R$ ed $D$ expenditure
} 


\section{Contemporary European Universities}

in the higher education system, the countries that started with lower expenditure levels realised higher increases.

The R\&D performed in the higher education system can be analysed in relation to the different financial source. The higher education sector usually draws from four national sources of funds and from a generic "abroad". They are:

- Government, subdivided in Direct Govermment Funds-e.g. contracts and earmarked-and General University Funds (GUF);

- Higher Education, that represents the own funds -e.g. income from endowments;

- Business Enterprises -e.g. R\&D contracts;

- Private Non-profit Organisation;

- Abroad.

Table 2 presents the evolution of the relative share of the HERD funding sources for ten EU countries in the considered period. Due to the different ways of classifying the various funds, a value equal to zero may be interpreted as such or as the indication that the source in that year is accounted for in a different class.

All the countries, without exception, witnessed a significant decrease in Government funds. On the one hand, Greece, UK and Ireland are the countries with the largest reduction, and with the lower share of Covernment funds at the end of the period. On the other hand, The Netherlands and Italy suffered only a small reduction in the Government funds, and have the highest shatres at the end of the period. In the majority of the countries the share of General University Funds has significantly declined, while the share of Direct Government Funds has shown an increasing trend, however not sufficient to offet the decrease of the other component of government funding. 
Table 2: HERD funding sources

\begin{tabular}{|c|c|c|c|c|c|c|c|c|c|c|c|}
\hline & & $\mathrm{B}^{4}$ & $\mathrm{D}$ & $F^{*}$ & $\mathrm{G}^{*}$ & Gr & 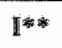 & $\mathbf{I r}^{*}$ & $\mathbb{N I}^{+}$ & $5^{*}$ & $\mathbf{U K}$ \\
\hline \multirow{4}{*}{$\begin{array}{c}\text { Direct } \\
\text { Covern. } \\
\%\end{array}$} & 1981 & 39.4 & 10.9 & 45.1 & 18.7 & 10.5 & 1 & 14.9 & 5.7 & 13.0 & 15.1 \\
\hline & 1985 & 43.4 & 12.2 & 47.0 & 19.8 & An al & 1 & 11.5 & 7.1 & 24.1 & 25.0 \\
\hline & 1989 & 25.5 & 20.6 & 48.1 & 22.4 & 120 & 1 & 19.0 & 7.8 & 27.7 & 27.6 \\
\hline & 1993 & 26.7 & 20.9 & 46.4 & 21.6 & 15.7 & 1 & 27.1 & 5.7 & 203 & 27.1 \\
\hline \multirow{4}{*}{$\begin{array}{l}\text { GUF } \\
\%\end{array}$} & 1981 & 46.8 & 85.6 & 52.6 & 75.6 & 89.5 & 96.2 & 67.6 & 91.1 & 870 & 66.1 \\
\hline & 1985 & 43.4 & 807 & 512 & 74.3 & nuxit. & 98.0 & 66.0 & $\$ 8.1$ & 74.7 & 57.2 \\
\hline & 1989 & 52.2 & 70.5 & 49.4 & 706 & 71.6 & 96.4 & 46.7 & 87.6 & 62.0 & 47.3 \\
\hline & 1993 & 49.5 & 66.5 & 46.3 & 71.4 & 43.4 & 93.4 & 397 & 89.5 & 68.6 & 41.6 \\
\hline \multirow{4}{*}{$\begin{array}{l}\text { HE } \\
\%\end{array}$} & 1981 & 2.9 & 0 & 0.9 & 0 & 0 & 0 & 0.4 & 0.3 & 0 & 0 \\
\hline & 1985 & 2.7 & 0 & 1.9 & 0 & na. & 0 & 2.3 & 0.2 & 0 & 4.2 \\
\hline & 1989 & 5.6 & 0 & 1.0 & 0 & 0.3 & 0 & 4.2 & 0.1 & 0 & 4.8 \\
\hline & 1993 & 3.6 & 0 & 2.1 & 0 & 5.9 & 0 & 4.4 & 0.1 & 0 & 4.4 \\
\hline \multirow{4}{*}{$\begin{array}{c}\text { Business } \\
\text { \% }\end{array}$} & 1981 & 9.3 & 0.7 & 1.3 & 5.7 & 0 & 2.7 & 7.1 & 0.3 & 0 & 28 \\
\hline & 1985 & 8.7 & 1.0 & 1.3 & 5,9 & n,a & 1.5 & 6.9 & 1.0 & 1.1 & 5.2 \\
\hline & 1989 & 12.6 & 1.5 & 4.6 & 7.0 & 6.2 & 2.6 & 9.2 & 1.1 & 9.2 & 7.7 \\
\hline & 1993 & 15.4 & 1.8 & 3.6 & 7.0 & 3.8 & 4.7 & 7.3 & 1.5 & 7.3 & 7.8 \\
\hline \multirow{4}{*}{$\underset{\%}{\text { NPO }}$} & 1981 & 0 & 1.6 & 0.1 & 0 & 0 & 0 & 2.6 & 2.3 & 0 & 4.9 \\
\hline & 1985 & 0 & 4.3 & 0.1 & 0 & 0 & 0 & 1.9 & 3.1 & 0 & 6.4 \\
\hline & 1989 & 0 & 4.4 & 0.1 & 0 & 0 & 0 & 1.8 & 29 & 0.5 & 8.4 \\
\hline & 1993 & 0 & 5.0 & 0.1 & 0 & 0 & 0 & 1.5 & 2.7 & 0.5 & 12.5 \\
\hline \multirow{4}{*}{$\begin{array}{c}\text { Abroad } \\
\%\end{array}$} & 1981 & 1.6 & 1.3 & 0 & 0 & 0 & 1.1 & 7.3 & 0.3 & 0 & 1.8 \\
\hline & 1985 & 1.8 & 1.8 & 0.1 & 0 & na a. & 0.6 & 11.4 & 0.4 & $0 . \mathbb{1}$ & 2.1 \\
\hline & 1989 & 4.1 & 3.0 & 0.7 & 0 & 10 & 1.0 & 19.1 & 0.5 & 0.7 & 4.1 \\
\hline & 1993 & 4.8 & 5.8 & 1.5 & 1.1 & 31.1 & 1.9 & 20.0 & 0.4 & 3.3 & 6.1 \\
\hline
\end{tabular}

Source: elaboration OECD data.

*: 1983-1991; " : 1981-1992; **: Itally does not supply at subdivision between Direct Government and GUF, the value refers to total Government.

IB $=$ Belgium, $D=$ Denmark, F=France, G=Germany, Gr=Greece, I=Italy, Ir=Ireland, $N l=T h e$ Netherlands, $S=$ Spain, UK=United Kingdom.

Among the other possible reasons for these changes, the following two are particularly important. First, the budget constraints suffered by the various national governments, during the 1980 s and early 1990 s, have caused a overall reduction of the funds to the higher education sector. Second, governments have developed policies aimed at a more purpose-directed allocation of the research effort, and at the creation of quasi-market incentive structures to increase the contribution of the higher education system to specific objectives. ${ }^{3}$ Thus, the decrease of GUF and rise of Direct

- See Section 2.2 for the analysis of the competitiwe approach to university research behavion and funding. See Chapter 5 for the analys of the changes occurred in the UK higher education system during the 1980s, early $1990 \mathrm{~s}$. 


\section{Contemporary European Universities}

Government Funds can be interpreted as the result of the implementation of selective policies.

The share of HERD financed by business enterprises showed positive growth rates in all the countries. The increase has been particularly important for the nations that were starting from a low share, while Germany and Ireland, that had already relatively high values, witnessed only a moderate rise. Peculiar is the case of Belgium. Although with the highest share of HERD financed by business enterprises in 1983, Belgium showed a relevant growth rate maintaining the highest share all along the considered period. Finally, the early 1990 s seem to be characterised by a slowing down, and in some cases by a decrease, in the growth of the share of HERD financed by business enterprises.

To compensate for the declining trend of government funding, the higher education sector has drawn more heavily from other sources of funds. Where the figures are available, Higher Education, Private Non-profit Organisation and Abroad sources of funds show positive trends. The growth of financing from abroad is particularly relevant. Especially in the case of the small less-advantaged countries such as Greece, Ireland and Portugal ${ }^{4}$ this source of funds became extremely important for their higher education systems. Particularly for these counties, but also for the other EU countries, an important part of the funds received from abroad can be ascribed to the European Commission. More in general, the growth of the component from abroad in the funding structure of $R \& D$ performed in the higher education sector is an indication of an increased internationalisation of science.

The analysis above developed is concerned with a limited number input indicators of the R\&D process carried out in the higher education sector in the EU countries. In the following a few aggregate research output indicators will be briefly

\footnotetext{
"The share of HERD financed by "abroad" in Portugal was $16.8 \%$ of the tolal in 1992.

${ }^{5}$ See Chapter 6 for the analysis of the participation of European universities into the EU Frameworks Progranmes.
} 
examined. The three methods most commonly used to evaluate research performance are publications counts, citations analysis and peer review. They are usually calculated from the database Science Citation Index of the ISI. As discussed in Appendix 1, these indicators have some relevant limitations such as the fact that depending on the selected type of publications Gournal articles, book articles, reviews, notes, letters, books, etc.) the output indicator may vary considerably. Moreover, the publicly avalable data used in the following analysis refer to the aggregate country production without allowing a separate identification of the higher education sector output. For example, in the period 1981-1991, in the UK the higher education sector accounted for about $60 \%$ of the total number of publications, hospitals, academic and not, between $19 \%$ and $23 \%$, research council laboratories $11 \%$ and industry $8 \%$ (Katz et al, 1995).

Table 3 illustrates the World and EU publication share, and the impact factor ${ }^{7}$ for the $\mathbb{E U}$ countries in 1991, and their evolution in the period 1981-1991. The EU countries together account for $27.7 \%$ of world publications, showing a small increase over the period. This rise is manly due to the growth in the publication output of the southern European countries, probably also due to the increasing propensity to publish in English of these countries. The European situation is characterised by a similar pattern. The UK with $30.2 \%$ of European publications is the country with the largest share, together with Germany and France they account for about $70 \%$ of EU publications. The citations counts put the EU exactly at the world mean. Only The Netherlands, UK and Denmark succed in having an impact factor higher than 1 . The indicator of growth points to an slight reduction in the impact of EU publications. Only a few countries, and especially Spain, have witnessed an increase in the relevance of their publications as measured by the impact factor.

\footnotetext{
"The source of the data is OST (1994).

${ }^{7}$ The inpact factor ss the mean number of citations recei wed in the two years following the publication compared to a workit inergag or 1 .
} 
Table 3: Scientific publications, World and EU shares, and inport factor.

\begin{tabular}{|l|c|c|c|c|c|c|}
\hline & \multicolumn{2}{|c|}{ World Weight } & \multicolumn{2}{c|}{ EU Weight } & \multicolumn{2}{c|}{ Impact Factor } \\
\hline & 1991 & $\begin{array}{c}\text { Growh } \\
81-91\end{array}$ & 1991 & $\begin{array}{c}\text { Growth } \\
81-9\end{array}$ & 1991 & $\begin{array}{c}\text { Growh } \\
81.91\end{array}$ \\
\hline EU & 27.7 & 103 & 100,0 & 100 & 1.0 & 99 \\
\hline Belgium & 0.8 & 100 & 2.9 & 96 & 1.0 & 97 \\
\hline Denmark & 0.8 & 89 & 2.7 & 86 & 1.1 & 87 \\
\hline France & 4.7 & 110 & 17.0 & 107 & 0.9 & 99 \\
\hline Germany & 6.2 & 95 & 22.5 & 92 & 0.9 & 104 \\
\hline Greece & 0.3 & 140 & 1.1 & 135 & 0.5 & 94 \\
\hline Ireland & 0.3 & 102 & 1.0 & 98 & 0.7 & 104 \\
\hline Italy & 2.7 & 123 & 9.8 & 119 & 0.8 & 105 \\
\hline The Netherlands & 1.9 & 118 & 7.0 & 114 & 1.2 & 101 \\
\hline Portugal & 0.1 & 209 & 0.4 & 202 & 0.5 & 84 \\
\hline Spain & 1.5 & 206 & 5.3 & 199 & 0.6 & 128 \\
\hline UK & 8.4 & 91 & 30.2 & 88 & 1.1 & 97 \\
\hline
\end{tabular}

Source: OST (1994).

Values in 1991= mean value 1989-1991; value in 1981= mean value $1981-1983$.

For the growth index $1981=100$.

To better understand the implication of the ongoing changes in the higher education system, an analysis at a more detailed level is needed. The following study aims to develop a better understanding of the characteristics of the European universities in the early 1990 s.

\subsubsection{Contemporary European Universities}

In 1992, the total HEIs population in the EU countries considered was of circa 1429 institutions. Of these, 379 were universities, and 1050 PSIs. ${ }^{9}$ An institution is classified in the category university following the official national classification. However, in Europe there is no standardisation on the definition of PSI and university. In the different countries this terms carry varying connotations. Nonetheless, in all the EU countries, the institutions (the new post-war universities)

\footnotetext{
Austria, Finfand, Luxembourg, and Sweden are not included

In the 1050 are included also 39 new British universities. These were Polytechnics and Colleges that have been granted uniwersity status in 1992-93, as they were mainly teaching institutions, it is important to differentiate them from the "old" British universitic: Moreower, many of the PSLs. especially in France, allso fall within the framework of one of the universities.
} 


\section{Contemporary European Universities}

that have been granted the university status went through a national selection process that can be consider more stringent than the one for the granting of the PSI status. Therefore the category including universities can be considered more homogeneous at the European level. In addition to the national classification systems two other main sources of information have been used: 1 ) the International Handbook of Universities (1991. 1993), and 2) the World of Learning (1995). When discrepancies between the sources were found, an institution has been classified in the category university if that institution was entitled to grant a doctoral (Ph.D.) degree. In a few cases, mainly in Spain and Portugal, the most recent and not yet developed universities were not taken into account. When clcarly distinguishable Art, Physical Education, and Education schools were excluded. ${ }^{10}$ The three institutions Universitair Centrum Antwerpen, Universitaire Faculteiten Sint-Ignatius te Antwerpen and Universitaire Instelling Antwerpen have been subsumed under the hat of the University of Antwerp. Finally, to calculate the number of UK universities the information of the Universities' Statistical Record (1994) was used. The resulted value of 71 is due to the fact that the University of London is subdivided in 22 colleges; both the University of Cambridge and the University of Oxford are included as single institutions (the different colleges forming them have not been considered); the three institutions Manchester Business School, Manchester University and UMIST have been subsumed in the University of Manchester. ${ }^{\text {"I }}$

Table 4 shows the count and share of universities and HEIs broken down by EU country. France (73), Germany (75) and United Kingdom (71) together have about three-fifths of all European universities. About one fifth is shared between Italy (47) and Spain (39). Finally, the universities of the six small countries, Belgium, Dennark, Greece, Ireland, The Netherlands and Portugal, account for the last fifth of the population.

\footnotetext{
10 In most of the countries this schools are not included in the university categrory. In the fow cases in which they have university status, they were not accounted.

"Both in the case of the University of Antwerp and the University of Manchester the different institutions have been subsumed due to the impossibility of identify a more detailed institutional association of the scholars in the publications counts.
} 
Table 4: Count and share of HEIs and whiversities in 1992, by coumtry

\begin{tabular}{|l|c|c|c|c|c|c|c|c|c|c|c|c|}
\hline & $\mathbf{B}$ & $\mathbf{D}$ & $\mathbf{F}$ & $\mathbf{G}$ & Gr & I & Ir & NI & P & S & UK & Tot \\
\hline HEIs & 76 & 41 & 535 & 270 & 17 & 69 & 34 & 32 & 57 & 48 & 250 & 1429 \\
\hline Percent & 5.3 & 2.9 & 37.4 & 18.9 & 1.2 & 2.4 & 4.8 & 2.2 & 4.0 & 3.4 & 17.5 & 100 \\
\hline No. Uniw. & 15 & 7 & 73 & 75 & 15 & 47 & 7 & 13 & 17 & 39 & 71 & 379 \\
\hline Percunt & 4.0 & 1.8 & 19.3 & 19.8 & 4.0 & 12.4 & 1.8 & 3.4 & 4.5 & 10.3 & 18.7 & 100 \\
\hline
\end{tabular}

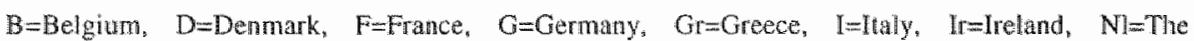
Netherands, $P=P$ ordugal, $S=S p a i n, U K=U$ rited Kingdom.

For each university, on the top of the geographical information, the following data have been gathered: ${ }^{12}$

NEWOLD:

No. Resewrchers:

No. Students:

EU Participation:

Publications: the institution founding year. This has been turned into a categorical variable (with four values) to classify the institutions in relation to their historical age.

the number of researchers in $1992 .^{13}$

the number of full-time students in 1992.

the number of times the institution has been involved in an EU R\&D project. They refer only to shared-cost actions funded by the DG XII under the First, Second and Third Framework Programmes. ${ }^{14}$

the number of papers published within a specific institution in 1993.

From these row data, wo other variables have been constructed. They are:

\footnotetext{
12 Drta sources are giwen in Amex $A$.

1. The number of researchers includes the totaliy of full-me academic staff plus, when present, $50 \%$ of part-time academic staft.

1. See Chapter 6 Section 6.3 for a deatad description of the data source.
} 


\section{Contemporary European Universinies}

Researchers per Student. the ratio between the number of researchers and the number of students. It is used as a proxy for the research orientation of the university.

Publications per Researcher: the ratio between the number of publications and the number of researchers. It is used as a proxy for the scientific research productivity of the university.

To avoid giving a misleading description, a few remarks concerning the kind of data gathered are required here. First, the figure for the number of researchers refers to both teachers and researchers. Due to different ways of classifying university personal in the various EU countries - - h.e. in Germany and The Nethedands the teachers' group accounts also for short-term lecturers and student assistants - the Germanic countries tend to have a positive bias in the number of researchers.

Second, the variable Publications has been built only on the basis of the Science Citation Index. The variable Publications is, thus, relevant for medical, nataral and engineering sciences and not for the other fields of knowledge present in universities. Three main approaches are usually applied to the count of publications. They are: 1) a fractional count, where the paper is divided up between the contributing authors; 2) an all-author count, in which the paper is credited to each of the participating authors; and 3) a first author count, in which the paper is atributed to the first author only. All three methods have advantages and drawbacks. For the purposes of this thesis, the all-author count approach has been applied. ${ }^{15}$ This method has been chosen for the lollowing reasons. First, it is a rather simple and straightforward method especially in the case of a large number of institutions. Second, the fact that the indicator is calculated for similar institutions, with similar publication profiles, neduces some of the impact of differing publication practices. On the other hand, due to the variance in the disciplinary composition of universities

\footnotetext{
15 A simim approach is also applied by Katz ef al (1995) in the bibliometric analysis of British seitince.
} 


\section{Contemporary European Universities}

systematic differences may still exist in the propensities to co-author in various scientific fields. This can introduce a positive bias in favour of those disciplines, such as medicine ${ }^{\mathrm{i} 6}$ or physics, where it is more common to have publications with a large number of co-authors. ${ }^{17}$ Finally, co-authorship requires common competencies and common work, making it difficult to assign a fraction of the credit to the contribution of each author. Therefore, the variable Publications, due to the way in which it has been built, can be considered only as a partial proxy of the scientific research output of each university.

Third, the variables NEWOLD, Publications and EU Participation are arguably poor measures for the French university system. In 1970 a large number of French universities were subdivided into two or more different institutions. It was difficult to assign an exact founding year to these institutions. In listings all of them report the founding date of the predecessor, although, at the same time, new institutions were established. Still, the old founding year has been used, pushing up in an artificial way the share of old universities. ${ }^{18}$ In the process of gathering the publication data, due to the fact that for a number of French authors the faculty affiliation was before the university name, an amount of publications larger than in other countries has not been classified under a specific institution. The variable Publications is, thus, biased downward for some of the French institutions. Besides, due to the fact that a large share of scientific research is realised outside the university system, ${ }^{19}$ the participation of French universities in EU-funded R\&D co-operative

\footnotetext{
${ }^{15}$ Special mention must be made of the peculiar role played by hospitals. Their weight in the presence count is not just over-estimated because of the effect of co-authorship, it is also often unclear whether they are linked to the university or not. Hence in some cases the publication is coumed ass university and other as hospital. This varies anong the European countries due to institutional variety (Commission of the European Communities, 1994a).

17 To limir the importance of this problem in the regression analysis carried out in Chapter 6, control variables for the disciplinary composition of the university have been inciuded.

With this attribution of the founding year, $66 \%$ of French uniwersilies result established before the French revolution. This is the highest figure for the European countries.

19 The CNRS is the principal site where publicly funded scientific research is carried out. Although in part of it is overlapping with the university systern, the participation in EU-funded R\&D Cowoperative
} 
projects was underestimated (Geuna, 1996). ${ }^{20}$ Finally, the variable EU Participation refers only to scientific $R \& D$ projects, thus, institutions with a clear focus on humanities and social sciences are badly represented in it in all the countries.

In short, due to the bias present in the variables Publications and EU Participation, the observations concerning research output and scientific research productivity of the universities presented in the following analysis will not be relevant for institutions with an important involvement in humanities and social sciences. The conclusions developed in this chapter, based on research output and scientific research productivity measurements, are only pertinent for natural, medicine and engineering sciences.

Table 5: Distribution of universities by historical classes

\begin{tabular}{|c|c|c|}
\hline Historical Class & $\begin{array}{c}\text { No. of } \\
\text { Universities }\end{array}$ & Percent \\
\hline Post-1945 & 144 & 38.0 \\
\hline $1900-1945$ & 32 & 8.4 \\
\hline 1800-1899 & 77 & 20.3 \\
\hline Before-1800 & 126 & 33,2 \\
\hline ToTAL & 379 & 100 \\
\hline
\end{tabular}

Looking at the historical development of European universities four broad phases can be found. ${ }^{21}$ In relation to the founding year of the university, the total university population has been subdivided into four historical classes. They are: (1) the new post-war universities [Post-1945]; (2) the early twentieth century universities, that have been founded over the period stretching from the starting of the twentieth century to the end of the Second World War [1900-1945]; (3) the nineteenth century universities, that have been founded in the period of the so called German transformation after the founding of the university of Berlin in 1809 by Wilhelm von

projects is attributed to the CNRS. Moreover, engineering sciences are primarily studied at the grande tooles, that are institutions not included in the class "uni wersity."

20 See Chapter 6 for the analysis of university participation in EU R\&D projects.

21 More detailed sub-divisions, considering also the history of non-European universities, can be found in the historical literature. See, for example, Perkin (1984) and Wittrock (1993). 
Humboldt [1800-1899]; and (4) the old universities, that have been founded before the French revolution [Before-1800]. Table 5 illustrates the count and share of universities broken down by historical classes. The largest class, with 38 per cent of the universities, is the one of the new post-war institutions. Circa two-fifth of the active universities have been founded in the last 50 years.

Table 6: Descriptive statistics for the main variables

\begin{tabular}{||l|c|c|c|c|c|}
\hline Variable & Cases* & Mean & Std dev & Min & Max \\
\hline No. Researchers & 371 & 887 & 946 & 15 & 7,330 \\
\hline No. Students & 371 & 15,376 & $17,628$. & 100 & 166,301 \\
\hline EU Participation & 371 & 49 & 65 & 0 & 420 \\
\hline Publications & 371 & 415 & 520 & $5 \%$ & 3,185 \\
\hline Researchers per Student & 371 & 0.078 & 0,074 & 0.010 & 0.652 \\
\hline Publications per Researcher & 371 & 0.568 & 0.971 & 0.005 & 12.340 \\
\hline
\end{tabular}

* Eight cases have been excluded due to missing data. Estimate value.

Table 6 presents the descriptive statistics for the six other variables. All the variables show a high kurtosis and a positive skewness (in particular in the case of Researchers per Student and Publications per Researcher) that indicates concentration in the values. ${ }^{22}$ Taking also into account the high standard deviations and the large differences between Min and Max, the population of universities can be described as composed by a large number of small-medium sized institutions and some very large institution. Moreover, as the variable Researchers per Student can be interpreted as the propensity of the institution to carry out research -i.e. scientific research orientation, its high skewness points to the fact that a large number of universities have a low scientific research orientation. Finally, as the variable Publications per Researcher can be used as a proxy for the research productivity of the institution, ${ }^{23}$ the population of universities is characterised by a large group of institutions with a

22 Moreover, the variables are correlated as noted below.

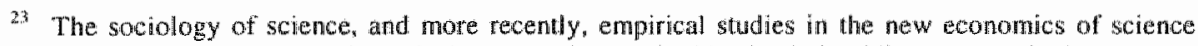
have made use of bibliometric analystis. In parficular, the idea behind publications or citations counts is that they can be used as an indicator of the underlying productivity of the rasearcher. Consequently is possible to depict the scientific research productivity of the unikersity as the ratio between the publications realised in one year and the number of researchers atached to that instivtion. 
low scientific research productivity, and a small group of institutions of high research productivity.

\subsection{Clusters of European University}

On the basis of these observations cluster analysis is used to group the total university population in clusters of institutions with small within-cluster variation for discriminating wariables and high between-cluster variation-i.e. the institutions in a specific cluster tend to have similar characteristics, while the universities in the various groups have different features. Due to the peculiarities of the French data the analysis has also been carried out with a database that did not include the French universities. As comparable results were found the following discussion will focus on the results for the case of the total university population while the results of the case where the French universities are excluded will be presented only when particularly interesting.

Table 7: Latent Roots and per cent of total variance

\begin{tabular}{|l|c|c|c|c|}
\hline Variable & Prin. Comp. & Latent Root & Pct of Var & Cum Pct \\
\hline No. Researchers & 1 & 2.54883 & 42.5 & 42.5 \\
\hline No. Students & 2 & 1.32907 & 22.2 & 64.6 \\
\hline Publications & 3 & 1.04758 & 17.5 & 82.1 \\
\hline Publications per Researcher & 4 & 0.63088 & 10.5 & 92.6 \\
\hline Reseurchers per Students & 5 & 0.25512 & 4.3 & 96.9 \\
\hline EU Participation & 6 & 0.18853 & 3.1 & 100.0 \\
\hline
\end{tabular}

The six variables used for the analysis (NEWOLD is exc "uded at this stage of the analysis), due to the high correlation, are firstly combined in principal component $-i$.e in this way uncorrelated linear combinations of the observed variables are formed. ${ }^{24}$ Table 7 illustrates the Latent Roots (variances) and the percentage of total variance explained by each principal component. The first three principal components are selected, all of them have a Latent Root higher than 1, and $82.1 \%$ of

\footnotetext{
${ }^{24}$ For a clear description of principal component analysis see Dunteman (1989).
} 
the total variance is attributable to them. To construct the three new variables on which the cluster analysis is run, the Latent Vectors associated with the Latent Roots after a Varimax rotation ${ }^{25}$ are used as weights of the linear combinations

Table 8 illustrates the rotated loading matrix for the three principal components. When one looks at the loading (the correlation of the original variables with the principal components) of the first principal component, No. Researchers and No. Students bave the higher loading (correlation), also Publications and EU Participation have important loading, thus, the new variable represents the combined dimensions of the institution. It is a proxy for the size of the institution. The second principal component has high correlation with Publications, EU Participation and Publications per Researchers, thus it can be interpreted as an index of the science research output. Finally, the only important correlation of the third principal component is with Researchers per Student. Therefore, the new variable depicts the research orientation of the institution.

\section{Table 8: Rotated loading matrix}

\begin{tabular}{|l|c|c|c|}
\hline Variable & $\begin{array}{c}\text { First Principal } \\
\text { Component }\end{array}$ & $\begin{array}{c}\text { Second Principal } \\
\text { Component }\end{array}$ & $\begin{array}{c}\text { Third Principal } \\
\text { Component }\end{array}$ \\
\hline No. Researchers & 0.90903 & -0.00894 & 0.24568 \\
\hline No. Students & 0.85033 & -0.00832 & -0.27436 \\
\hline Publications & 0.66416 & 0.64028 & 0.01062 \\
\hline Pubblications per Researcher & -0.21552 & 0.85673 & 0.11344 \\
\hline Researchers per Studlent & -0.00766 & 0.05094 & 0.98412 \\
\hline EU Participation & 0.48950 & 0.61628 & -0.07248 \\
\hline
\end{tabular}

In order to analyse any possible grouping of the institutions according to their salient characteristics a hierarchical cluster analysis ${ }^{26}$ on the three new variables $-i \cdot e$. the uncorrelated linear combinations of the 6 original variables: PRINCOM1, PRINCOM2, PRINCOM3-- was performed. Ward's minimum variance method, that

\footnotetext{
25 The Varimax method attempts to minimise the number of variables that have high loading on a factor. This orthogonal rotation does not effect the goodness of in of a factor solution, the total variance explained does not change.

${ }^{2 t}$ For a clear description of cluster analysis see Aldenderfer and Blashfield (1984).
} 
combines clusters with the smallest increase in the overall sum of the squared withincluster distances, has been chosen due to its propensity of joining clusters with a small number of observations. One characteristic of the hierarchical cluster analysis is that the number of clusters is not fixed. To determine the number of clusters to be analysed, a Schefte test has been performed with a significance level of 0.05 . For each variable used, the test makes a comparison of the means of the various clusters. The best solution by this criteria is given by the grouping into four clusters. The clusters are well separated in the variables PRINCOM1 and PRINCOM2, and less clearly in the variable PRINCOM3. The four cluster solution has also been tested with a non-parametric Kruskal-Wallis Test, the hypothesis that the four clusters come from populations having the same distribution is rejected.

Grouping the universities according to their salient characteristics - -i.e. number of researchers, number of students, participation in EU R\&D projects, publications, researchers per student and publications per researcher- four main clusters of institutions are identified. Cluster I is composed by 192 universities, Cluster II and Cluster IV include a smaller number of institutions, respectively 107 and 64 , and only 8 institutions form Cluster $\mathrm{III}$.

Table 9: Cluster composition, count and share of universities

\begin{tabular}{|c|c|c|c|c|}
\hline \multirow[t]{2}{*}{ Clusteris: } & \multicolumn{2}{|c|}{ Totul Unversity Population } & \multicolumn{2}{|c|}{ Exclusion of T rance } \\
\hline & Fragueney & Percent & Frequency & Per cent \\
\hline Cluster II & 192 & 51.8 & 168 & 562 \\
\hline Chingter 11 & 1107 & 28.8 & 56 & 18.7 \\
\hline Cluster III & 8 & 2.2 & 7 & 2.3 \\
\hline Cluster $1 \mathrm{~V}$ & 64 & 17.3 & 68 & 227 \\
\hline Total & 371 & 100.0 & 299 & 100.0 \\
\hline
\end{tabular}

Table 9 shows the number and share of universities in each cluster. The exclusion of France causes the movement of 8 universities from the second to the fourth cluster and 1 in the other way. While, 33 universities transfer from the second to the first cluster and 1 from the third to the first. 
What are the characteristics of the cluster? First, the historical composition of the clusters is studied. Table $10 \mathrm{a}$ and Table $10 \mathrm{~b}$ in Appendix 2 illustrate the frequency chart for the four historical classes defined above for the case of the total university population and for the case of the exclusion of France. The majority of institutions included in Cluster I was founded after the Second World War; more than $73 \%$ of the new post-war universities are included in this cluster. Cluster IV is composed by a majority of medieval universities and only $7.8 \%$ of the institutions of this cluster are new post-war institutions. Cluster II and Cluster III do not show a relevant concentration of institutions in any of the four historical classes. If one thinks in terms of pre-war versus post-war universities Cluster IV can be defined as the cluster of the pre-war universities, while for Cluster I it is possible to speak only of stronger polarisation towards the new post-war universities. When the French universities are excluded from the analysis the share of the new post-war universities included in Cluster I increases. This is consistent with the bias in the historical classification of French universities, and thus Cluster I can be defined as the cluster of the new post-war universities.

Table 11: Cluster composition, mean values for the six wariables

\begin{tabular}{||l|c|c|c|}
\hline \hline & $\begin{array}{c}\text { Cluster I } \\
\text { (Mean Values) }\end{array}$ & $\begin{array}{c}\text { Cluster II } \\
(\text { Mean Values) }\end{array}$ & $\begin{array}{c}\text { Cluster IV } \\
\text { (Mean Values) }\end{array}$ \\
\hline No. Researchers & 454 & 782 & 2,115 \\
\hline No. Students & 9,364 & 13,532 & 38,304 \\
\hline EU Participation & 13 & 72 & 125 \\
\hline Publications & 81 & 560 & 1,174 \\
\hline Researchers per student & 0.066 & 0.069 & 0,091 \\
\hline Publications per researcher & 0.198 & 0.912 & 0.617 \\
\hline No. of Universities & 192 & 107 & 64 \\
\hline
\end{tabular}

*: For each variable the non-parametric Kruskal-Wallis "Test has been run. The hypothesis that the four clusters come from populations having the same distribution is rejected.

Second, size, scientific research quality and research orientation of the universities in the three clusters with a relevant population are analysed (see Table 11). Cluster $I$ is composed by institutions with a mean of 454 researchers and a mean of 9,364 students. They have participated in a mean of $13 \mathrm{EU}$ R\&D project, and they 
have published a mean of 81 publications. The research orientation, expressed in number of researchers per students, has a mean value of 0.066 . The mean scientific ressearch productivity of the institution in terms of publications per researcher is 0.198. Comparing these values with the ones of the total population one can highlight that the 192 universities of the Cluster I tend to be of small size, they have a low output in terms of publications and participation in EU R\&D projects, and they have a scientific research productivity and research orientation lower than the means of the population. The 64 members of Cluster IV are large universities (mean number of researchers of 2,115 and mean number of students of 38,304 ), they participated in a large number of EUJ-funded R\&D co-operative projects (mean number of EU Participation of 125) and they tend to publish prolifically (mean number of publications of 1,174 ). Their mean scientific research propensity and research orientation tend to be higher than the ones of the total population, but not in an extremely important way. Cluster II is characterised by institutions with a mean number of researchers and students slightly smaller than the total population (782 and 13,532) and a mean number of Participation and publications higher than the total $(72$ and 560$)$. The research orientation is a bit lower then the average $(0.069)$, while the mean scientific research productivity of the institutions tends to be higher than the one of the total population, and the highest of the four clusters (0.912). Of particular interest not for the statistics, but for the institutions included is Cluster III. Five of the eight institutions are London University Medical Schools. Due to way the publications are gathered these schools are characterised by an extremely high number of publications, and they have extremely high walues in both Researchers per Student and Publications per Researcher. The existence of a cluster of this type testifies to the discriminatory power of the statistical methods used.

The same kind of analysis has been carried out with the database in which the French universities are excluded. The movement of institutions among clusters above-mentioned tends to slightly increase the mean values of output, scientific

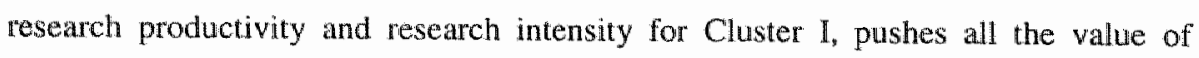
Cluster II only a bit above the average of the total population $(954,17730,79,583$, 


\section{Contemporary European Universities}

$0.061,0.755)$ and increases in a significant way the scientific research quality of the institutions of Cluster IV (0.734). A possible interpretation of these results is that the exclusion of the French universities ${ }^{27}$ induces the attraction in Cluster 1 of the institutions on the left side of the distribution of Cluster II. Consequently some of the institution on the right side of the distribution of Cluster II are attracted in Cluster IV. In this case the divide between Cluster I and Cluster IV become even more clear. While the institutions in Cluster II tend to have characteristics, included the scientific research productivity, that position them somewhere between the two extreme configurations of Cluster I and Cluster IV.

A frequency analysis has also been carried out. The variables No. Researchers, EU Participation, Publications, Researchers per Student and Publications per Researcher have been transformed into categorical variables at the quartile. In this way five indexes, one of size, two of research output, one of research intensity, and one of scientific research productivity have been built. The association of these indexes with the clusters formed enables us to confirm the previous observations.

The analysis of the European university population in the early 1990 s points to the existence of two clearly distinct clusters of institutions. The first (Cluster I) is mainly composed by new post-war universities characterised by: (1) small size, (2) low research output in terms of scientific publications and Participation in EU R\&D project, and (c) low research orientation and low scientific research productivity. The second (Cluster IV) comprises almost exclusively pre-war universities (in particular medieval institutions) characterised by: (1) large size, (2) high research output, and (3) high scientific research productivity. These two models of university, on the one hand new post-war, small, teaching oriented universities, and on the other hand old, very large, research active institutions are the extremes of a continuum of possible

\footnotetext{
27 Due to data gathering problems the French uniwersity tend to be large, but with low output "low scientific research productivity and low research intensity. Thus, the ligh number of French universities in Cluster I biases the mean values of the cluster.
} 


\section{Contemporary European Universities}

configurations. A third group of universities (Cluster II) characterised by a less clear cut configuration has been identified too.

\subsection{Conclusions}

The picture of the European university population drawn in the previous sections tends to confirm the view that after a period of rapid growth and a period of budget cuts and policy changes, a portion of the prestigious pre-war universities have managed to retain a position of pre-eminence. Whereas, the large majority of the new post-war universities did not succeed in increasing their status. Although some of them tried to upgrade their status, perhaps due to the impact of cumulative and selfreinforcement phenomena, they usually did not succeed.

One of the main reasons for the polarisation of the university system can be found in the increased competitive character of university research funding, aimed at the concentration of research resources, that exacerbates the consequences of the socalled Matthew effect. ${ }^{28}$ A good researcher is usually attracted by centres or universities of excellence where she can find the human and physical capital that enables her to develop high level research. Doing that she will improve her quality and the overall quality of the institution, with the consequence of attracting new research funds and new high value researchers. This situation is characterised by two interrelated virtuous circles. First, a centre of excellence attracts high quality researchers that have high probability of doing valuable research increasing then the quality of the centre and therefore attracting new talented researchers. Second, a high level of human and physical capital implies a higher chance of achieving important research results, hence as a consequence of the high quality research there is an

\footnotetext{
23 For an economic analysis of the Matthew effect and its implications for resource allocation see Arora, David and Gambardella (1995), Dasgupta and David (1987, 1994), and David (1994). For its implications on the university status see Trow (1984). For the original definition in the sociology of science see Merton (1968). For an early analysis on the relationships between scientific productivity and cumulative effect see De Solla Price $(1963,1976)$.
} 


\section{Contemporary European Universities}

increased probability of having new research funds and therefore a possibility of expansion in the investment in human and physical capital.

The changes in the knowledge production emphasised at the end of Chapter 3 , Section 3.3 -i.e. 1) the old universities are no longer spanning the knowledge spectrum, 2) the rise of the research centre as the intellectual unit of research, and 3) the development of the research network-- are more likely in the pre-war institutions highly involved in scientific research. These research intensive universities, usually elite pre-war institutions and a handful of new institutions, probably will go through a process of institutional change adapting to the changing environment, while retaining a few main features, such as their autonomy, that characterised universities in their historical evolution. The institutions in the lower scientific research productivity cluster, either involved in technological research or only teaching institutions, will tend to be marginalised by the ongoing changes. These institutions, pushed by government policy to satisfy the current need of the society, in terms of mass higher education and industrially oriented research, will tend to increase their national or local focus and will be only partially influenced by the changes in the international production of knowledge. Less clear is the position of the universities in the intermediate cluster. For them, probably, the changes in the knowledge production process will be a strong challenge to move towards the cluster with higher scientific research productivity.

The results of the econometric analysis suggest that the changes occurred in the university research funding structure (decrease of General University Funds, less than proportional increase of Direct Government Funds, increase of the other sources of funds based on competitive allocation mechanisms) during the 1980 s have already produced an extremely high level of concentration of university research. Further increase in the use of competitive mechanisms for the allocation of public funds may result in a drift of those institutions that where classified in a intermediary position towards the low research intensive configuration. 
Although, this situation is more evident in a country such as the UK where budget cuts and market pust have been more relevant, it can be considered a general trend. The other EU countries are following, with different delays, the British path. For example, currently in The Netherlands and in some German Lender research assessment exercises on the model of the first UK Research Assessment Exercise have been developed. Systems of linking government research contract funds with industry recejpts - i.e. if this year the research centre raises 50,000 pounds from research contracts funded by industry, next year the government will offer contracts for the same amount-- are becoming common in all the university systems. Selective reductions of state financing of university research, in expectation of a substitution of industrial research funding, are part of the changes going on in the university systems of all EU countries.

During the last ten years the Commission of the European Communities financed a series of programmes targeted at developing university-university and university-industry research co-operations at the European level. Programmes such as Human Capital and Mobility, for the mobility of graduate and postgraduate students, and the other research actions of the Framework Programmes supported the development of international relationships. As it will be shown in Chapter 6, due to the selection criteria used by the Commission of the European Communities, the elite reseach intensive universities tend to be he higher education institutions with the highest lewel of participation in these international research networks. An example is the situation in the UK. In the pertod 1990-1993 the universties that had large rectpts from the Research Councll, obtained also a large amount of funds from the EU (David Geuna and Steinmueller, 1995). Thus, national policies aiming at the concentration of university research may be further reinforced by the action of the Commission of the European Communities. ${ }^{29}$

\footnotetext{
29. The implications of the overlapping of mationall and EU university research funding will be analyse in Chapter 7.
} 


\section{Contemporary European Unversities}

To better understand the possible consequences of current changes an analysis at a more detailed level is needed. In the following chapter a specific group of British universities is studied to assess how they are adapting to recent modifications of funding allocation procedures. Next, in Part Three, the implications for European universities of the participation on EU-funded R\&D co-operative projects will be directly examined. 


\section{Appendix 1: Research Performance Indicators}

The main difficulties and drawbacks in using publications counts, citations analysis and peer review are briefly considered here.

Publications counts allow to evaluate the research output of individuals, research groups, deparments, or institutions. The per capita publications counts are used as a proxy for the research productivity. Among the most commonly cited shortcomings in the use of publications counts are:

1. Depending on the selected type of publication output (journal articles, books, review articles, etc.), and on the weighting scheme applied, the output indicator maty wary considerably (see, for example, Johnes, 1990).

2. The mobility of staff may alter in a significant way the output of a department, consequently different ways of ascribing the output of a researcher to a department -e.g. to the one where he was based or to the current one-- may have an important impact on the output indicator (see, for example, Nederhof and van Raan, 1993).

3. The determination of the number of staff in a department depends on who is classed as a research member of the department, different accounts for research students, Ph.D. students, visiting staff, etc. results in important variation in the per capita figures (see, for example, Hare and Wyatt, 1988).

4. Particularly in medicine and natural sciences it is common practice to have a large number of co-authors. The publication can be credited to each of the participating authors (all-author count), divided up between the contributing authors (fractional count), or attributed to the first author only (first author count). These different counting methods may give rise to different output indicators.

5. Biases favouring publications of established authors may exist in the publishing process, distorting the significance of the indicator. 


\section{Contemporary European Universities}

The use of publications analysis to measure research performance is constrained by the fact that it represents only a measure of quantity and it does not capture the impact, quality and utility of the research. ${ }^{30}$ Citations analysis (the count of the citations obtained by a scientist or a department) is used to assess the impact (quality) of the research output. The database most commonly used is the Science Citation Index ( $\mathrm{SCI}$ ) of the ISI. Some of the shortcomings referred above are also relewant for citations counts; particularly important for the latter are the following: ${ }^{31}$

1. The SCI tend to have a bias in favour of publications in English language and especially towards North American sources.

2. The SCI reports only the first author; moreover is not uncommon to find programming errors both in the authors' name and in the journal citation (see, for example, Moed et al, 1985; Cave et ah., 1997).

3. Citations are not only to works considered of high quality, but also negative or derogatory, however citations counts cannot distinguish between the two.

4. Different citation windows (how many years are considered after the publication) may give rise to variations in the indicator measurement.

5. Self-citations, citations to co-authored papers, citations to different journals, all require the development of weighting schemes that at present can not be done in an objective way.

6. Seminal or radical works may be difficult to understand or, after the acceptance, they become common knowledge, hence they may not receive the number of citations that they deserved (see, for example, Cole and Cole, 1972).

7. Citations counts can be distorted by the inappropriate use of the citation such as in the case of citations circle (researchers unduly citing each others) or citations for reconnaissance (junior staff citing senior researchers).

\footnotetext{
30 A certain level of quality correction can be introduced in the publications counts if the publications are weighted by the impact factor of the journal. For an application of this methodology sec, for example, Arora, Gambardella and David (1995).

"For the analysis of the drawbacks of citations analysis see, among others, Cozzen (1989).
} 


\section{Contemparary European Universities}

The difficulties and drawback of citations analysis and its costly and time-consuming character indicate that, at the current level of methodological development, and with the available technology, this technique is not optimal for a comparative evaluation of the research performance of universities.

The last research performance indicator briefly considered here is peer review. A large body of literature has been devoted to the analysis of the peer review system in science. ${ }^{32}$ As a performance indicator peer review is most commonly understood as the evaluation (ranking) of the research output of a department by peers. It allows a quantitative judgement of the research including the analysis of cognitive aspects such as contribution to basic knowledge and contribution to methodology. The three most important shortcomings of peer review as a performance indicators are:

1. Peers judgement tends to be subjective and not sufficiently systematic.

2. Large departments are usually better known and they contain active researchers in a large set of sub-disciplines, hence they tend to be favoured in peer review not supported by quantitative data.

3. The reputation of the whole institution may exercise a positive bias (the halo effect) on the peer review of the department (Fairweather, 1988).

\footnotetext{
${ }^{32}$ For a recent study see Wood (1997).
} 
Contemporary European Universities
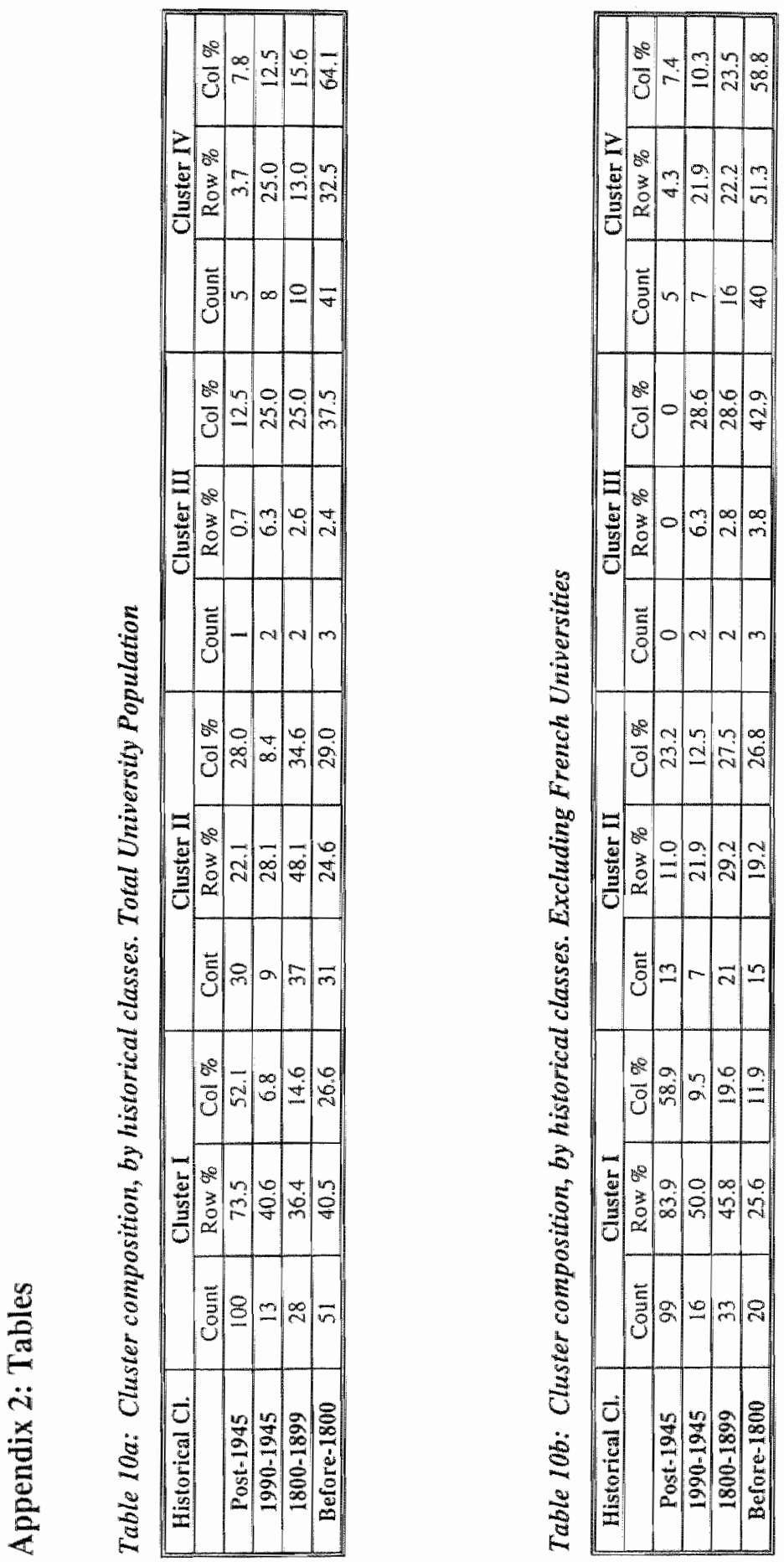
Contemporary European Universities 


\section{Allocation of Funds and Research Output: The Case of British Universities}

As the previous two chapters have shown universities, especially in the UK but also in other European countries, are undergoing profound modifications due to budget constraints and changes in policy regarding their purpose in society. These changes are straining the university structure developed after the Second World War. The role of universities is changing from the one of public institutions subsidised by the state into that of suppliers of specific services. Research services offered by the universities are bought by research councils, government departments, charitable foundations, commercial firms and (increasingly) international organisations such as the Commission of the European Communities. On the one hand, the developing market system for university research services has beneficial influences such as reducing financial inefficiency. Nonetheless, on the other hand, given the peculiar features of knowledge production and distribution processes, the market for university research is far from a perfect market, so that the development of a more 'competitive' market does not necessarily imply the production of desirable results from an economic and social point of view (Ziman, 1994).

In this context, and in order to understand the possible results of current changes, it is useful to assess how a specific group of institutions mathe multidisciplinary old British universities-- are adapting to recent modifications of funding allocation procedures. The British case has been chosen due to its unique characteristics. The UK is the country of the EU with the most market oriented university system, and consequently with a clearer propensity, or push, towards a more utilitarian, applied, type of research (a summary of the philosophy behind it is 


\section{Allocation of Funds and Research Output}

the famous statement "value for money"). The UK system, with its mission-oriented policies (selective policies), can be considered an 'attraction pole' or model for emulation that other European countries may follow in the restructuring of their university funding systems. Therefore, the understanding of the possible consequences of the ongoing changes in the UK universities can provide insights which can be used to better direct the evolution of the other European university systems.

Current developments in the university research system suggest changing relationships between resource allocation and research output. Using the methodology developed in the previous chapter the "old" UK universities are clustered in group of institutions with similar characteristics. The study of the different groups at two points of time, and, in particular, of the movement of institutions among groups indicates the existence of relationships between funding and research output.

The chapter is organised as follows. The next section gives a description of the evolution of the funding structure of UK universities. The changes in the different sources of funds in the period $1989-93$ are analysed paying particular attention to the evolution of the receipts from specific services (Section 5.1.1). In Section 5.2 the methodology to explore the relationships between allocation of funds and research output is developed. A cluster analysis for the two period 1989-90 and 1992-93 and the preliminary analysis of the results are presented in Section 5.2.1. The studly of the changes in clluster's' membership and some interpretations are offered in Section 5.2.2. Finally Section 5.3 presents the conclusions and policy implications.

\subsection{The Evolution of the Funding Structure of British Universities}

In recent years the $\mathrm{UK}$ higher education funding structure has gone through some marked changes. These transformations were the result of government policies that 
began, in 1980, with the decision to charge fees to foreign students to cover the full costs of their courses. Then, throughout the 1980s, university, polytechnic, and college budgets were restructured in ways that put new pressures (and incentives) on these institutions. A major instrument of reform was a reduction in block grants to HEIs which then were offset, less-then-proportionately, by increases in funds from other government sources. The actions were undertaken, on the one hand, to stimulate a process of financial restructuring aimed at reducing costs and, on the other hand, to provide incentives (through mechanisms such as the Research Assessment Exercise and the Technology Foresight) ${ }^{\natural}$ by which it was hoped that better direction of HEIs research effort would result.

The turning point in the process of change of the funding system was, however, the Education Reform Act of 1988. This Act created two new funding agencies, the Universities Funding Council (UFC) and the Polytechnics and Colleges Funding Council (PCFC), but most importantly it modified the 'logic' of higher education funding. The two agencies were created to act as buyers of academic services. The role of universities, polytechnics and colleges was suddenly transformed, from one of public institutions subsidised by the state into that of private suppliers of specific services -i.e. teaching and research. This change implied the creation of a new market for HEIs services. HEIs had to learn the new rules of the game, such as bidding for students and interacting with other potential buyers of their services such as industry, or the Commission of the European Communities. Furthermore, they had to adapt their management structure and allocation of funds to the new external situation. ${ }^{2}$

\footnotetext{
' While the Research Assessment Exercise is run by the Funding Councils with the aim of a better allocation of research funds to universities, the Technology Foresight "run by the Office of Science and Technology, tries to pull scientific research more towards "the needs of the nation". Research Assessments Exercises, formerly termed research selectivity exercises, were conducted in 1986,1989 , 1992, and 1996; for an official evaluation of the impact of the 1992 exercise see HEFCE (1997).
}

2 For an exhaustive analysis of these changes see G. Williams (1992). 


\section{Allocation of Funds and Research Output}

The latest step of this revolution has been the merging of UFC and PCFC into a single Higher Education Funding Council (HEFC) with separate agencies for England. Scotland and Wales in 1993. In addition, 39 polytechnics have been granted uniwersity status. This new situation is also the result of the White Paper of May 1991 Higher Education. A New Framework. The report drew the outline for the new structure of the higher education sector in the UK. Of particular relevance for the funding system are the following. First, it has favoured competition for research funds among all the 'old' universities and polytechnics, which now share a common identity as universities. Second, it endorsed and reinforced the dual support approach. Universities should receive public funds for research from both the national HEFC, and from the Research Councils ${ }^{3}$ for specific projects. Third, together with competition among institutions and the dual system, selectivity on the basis of assessment of research quality and the subdivision of the block grant in veaching and research are the principles that inform the new structure for public funding.

Finally, in May 1993, as a demonstration of the Government 's concern for the science and technology situation, a new White Paper (the "Waldegrave Report") on science and technology, Realising our Potential - A Strategy for Science, Engineering and Technology, was published. ${ }^{4}$ Rather than just being another proposal for further changes, it offered an evaluation of what had happened in the preceding yeats, and the-thinking of the system of science, engineering and technology in general. Central to the Waldegrave Report is an examination of the research councils" operations. The report proposed to modity two of the existing five research councils. From 1994 there are six active research councils, namely the Natural Environment Research Council (NERC), the Medical Research Council (MRC), the Economic and Social Resem Council (ESRC), the new Engineering and Physical Science

\footnotetext{
"Contract overheads have been increased io $40 \%$ so that the Research Councills have to meet all the cosits of their projects. Acadernic salaries and premises continue to be met from institutions ${ }^{*}$ general lunds.
}

"For a critical analysis of the White Paper 1993 see Webster (1994). 
Research Council (EPSRC) and Particle Physics and Astronomy Research Council (PPARC), and the renamed Biotechnology and Biological Sciences Research Council (BBSRC). The Office of Science and "Technology has responsibility for all the Research Councils and for the LINK programme, "a cross-Government initiative that aims to bridge the gap between the science and engineering base and industry for the benefit of the United Kingdom economy" (White Paper, 1993, p. 35).

\subsection{The Aggregate Situation}

Due to the relevance of the Education Reform Act, and the fact that data after 19921993 are mot consistent with those of the previous years, this analysis will focus on the period between 1989-90 and 1992-93. Furthermore, the "old" universities are the only institutions included due to their distinct research orientation. Indeed, polytechnics and colleges receive much less research funding; in 1989-90 the levels were $£ 1,620$ million for the 'old' universities and $£ 70$ million for polytechnics and colleges (White Paper 1991, pp. 16). ${ }^{5}$

For the four years considered, the Universities' Statistical Record provides an annual report on university funding. All the 'old' universities are covered in this survey. The university funding (income) is broken down in detail by income source. At the most aggregate level the break-down is between General Incomes and Specific Incomes. The former represent the incomes attributed to teaching and to the part of research not covered by specific sources. The main part of it is due to the HEFC grant (Exchequer Grants) and to tuition fees (Fees). Specific Incomes consist of the funds gathered by academic departments or academic services for the supply of specific services to outside parties. Among these services, research grants and contracts are the most important items and the following are the largest buyers of university research: Research Council, Government Bodies, UK - based Charitable Bodies, UK Industry and the Commission of the European Communities.

\footnotetext{
s. However, with the new system of funding, expolytechnics and colleges are starbing to compete more and more for Research Council tunding, and they are therefore becoming nore involved in research.
} 
Table 1 shows the evolution of the relative share of the main sources of funds. The most striking trend is the decrease of more than 15 points of the Exchequer Grants' share in university funding (from $48.4 \%$ to $33.3 \%$ of the total). This is the result of both the policy of funding a higher share of university research directly through specified projects, and the decision to link part of teaching money to the number of students, wiat the increase in fees. ${ }^{6}$ In addition, the share of Fees grew by 11.5 points, raising the share of this funding component to $25.3 \%$. There are two main reasons for this increase. First, the Government sought an incentive for enlarging the number of students admitted to the university. Thus, to spur on universities to accept more students they increased the money given to the institution for each admitted student. Second, this policy was successful in the sense that the number of students admitted to higher education markedly increased during the period, raising the total funds paid through this source.

\section{Table 1: Relative share of university incomes}

\begin{tabular}{|l|c|c|c|c|c|c|c|}
\hline Year & $\begin{array}{c}\text { Exch. } \\
\text { Grants }\end{array}$ & Fees & $\begin{array}{c}\text { Total } \\
\text { Specific }\end{array}$ & $\begin{array}{c}\text { Resear. } \\
\text { Councils }\end{array}$ & $\begin{array}{c}\text { Govern. } \\
\text { Bodies }\end{array}$ & $\begin{array}{c}\text { UK } \\
\text { Industry }\end{array}$ & EU \\
\hline $1989-90$ & $48.4 \%$ & $13.8 \%$ & $23.1 \%$ & $6.5 \%$ & $3.0 \%$ & $2.6 \%$ & $1.1 \%$ \\
\hline $1990-91$ & $39.8 \%$ & $20.7 \%$ & $24.2 \%$ & $6.4 \%$ & $3.3 \%$ & $2.6 \%$ & $1.3 \%$ \\
\hline $1991-92$ & $35.5 \%$ & $25.0 \%$ & $23.9 \%$ & $6.0 \%$ & $3.1 \%$ & $2.5 \%$ & $1.6 \%$ \\
\hline $1992-93$ & $33.3 \%$ & $25.3 \%$ & $25.1 \%$ & $7.1 \%$ & $3.1 \%$ & $2.3 \%$ & $1.9 \%$ \\
\hline
\end{tabular}

Source: ellaboration of Universities" Statistical Record data.

The share of Total Specific Incomes grew by only 2 points. Consequently, part of the university research that previously was covered by the Exchequer Grants did not find direct support through specific projects. In particular, the Research Councils' share of funds, after a slight decrease over two years, increased in the last year. This is mainly due to the new regulation that states that from 1992-93 the Research Council "will become responsible for meeting all the costs of the projecis, except for academic salaries and premises, which will continue to be met from

\footnotetext{
"The share of self-supporting hone fees, paid by UK residents or by residents abroad who are entitled by special circumstances to pay home fees (EC students), ranged from $2 \% 104 \%$ in these four years. In short, fees are principally paid by the UK Government.
} 


\section{Allocation of Funds and Research Output}

institutions" general funds" (White Paper, 1991, p.17). "The result is that part of the costs associated with the conduct of research facilities, like libraries, were then paid for by the research councils. The share of funds from UK industry, contrary to the expectations of the government, decreased over the period. This may also be due to the recession period. Nonetheless it points to the fact that, at least in the period analysed, industry funds did not counterbalance decreasing government support at the aggregate level. Finally, the EU funding share, although very low, constantly increased almost doubling its value over the period. Taking into account that the EU source is part of Specific Incomes, not only does its relevance increase, but about $50 \%$ of the growth of the specific component is the result of the increase of EU funding.

Table 2:" Annual growth rate of university incomes, constant price 1986 , by source

\begin{tabular}{|l|c|c|c|c|c|c|c|c|}
\hline Year & Total & $\begin{array}{c}\text { Exch. } \\
\text { Grant }\end{array}$ & Fees & $\begin{array}{c}\text { Total } \\
\text { Specific }\end{array}$ & $\begin{array}{c}\text { Resear. } \\
\text { Councils }\end{array}$ & $\begin{array}{c}\text { Govern. } \\
\text { Bodties }\end{array}$ & $\begin{array}{c}\text { UK } \\
\text { Industry }\end{array}$ & EU \\
\hline $89 / 90-90 / 91$ & $0.0 \%$ & $-17.7 \%$ & $49.7 \%$ & $4.7 \%$ & $-1.6 \%$ & $11.0 \%$ & $0.4 \%$ & $19.1 \%$ \\
\hline $90 / 91-91 / 92$ & $2.9 \%$ & $-8.4 \%$ & $24.2 \%$ & $1.8 \%$ & $-4.8 \%$ & $-4.6 \%$ & $-1.5 \%$ & $21.6 \%$ \\
\hline $91 / 92-92 / 93$ & $5.9 \%$ & $-0.6 \%$ & $7.2 \%$ & $11.2 \%$ & $26.4 \%$ & $6.1 \%$ & $-4.2 \%$ & $26.4 \%$ \\
\hline
\end{tabular}

Source elaboration of Universities" Statistical Record data.

Table 2 presents the annual growth rate of the various sources of funds expressed in constant 1986 prices. ${ }^{8}$ First, the decrease in the real walue of Exchequer Grants, which started during the 1980s is moderating. Indeed, in 1992-93 there was a nominal (without taking into account inflation) increase. Second, the Research Council component after two years of decline realised an increase of $26.5 \%$. However, when the real value of the flow of money from the Funding Council (see note 7$)$ is computed the research Council component decreased of 2.3 points. Therefore, it appears that even over the recent past the two most important sources of

\footnotetext{
In particular, research grants and contracts income from the Research Council increased from 2288 minilion to $£ 382$ million due mainly to the transfer of $£ 87$ million from the Funding Council to the Science Vote.

The unversity cost deflator has been used as the index.
} 
government funding have shown negative trends. Only in the last year, after the policy decision of increasing the overheads for the contracts funded by the Research Councils, does it seem possible to identify the impact of the government strategy oriented towards an increase of specific incomes ${ }^{9}$ rather simply cutting both general and specific incomes. Third, UK Industry funding receipts, after a negligible rise in real terms during 1989-90/1990-91, show increasingly negative growth rates. Fourth, EU funding receipts have risen throughout the period, whereas the positive growth of university income from Fees has been slowing down. Fifth, and finally, after approximately no changes in real terms during 1989-90/1990-91, Total Recurrent income has shown a positive growth rate during the two following periods.

In summary, these changes have led to offseting impacts. On the one hand, taking into account the differences in the relative share of funds for Exchequer Grant and Fees, ${ }^{10}$ and the fact that student enrolment has grown in the three periods by $5.0 \%, 9.1 \%$, and $8.6 \%$ respectively, the increase of receipts in real term from tuition fees has balanced the decrease in the income from the Exchequer Grant for the teaching side." On the other hand, the growth of Specific Incomes has not been sufficient to cover the diminishing of General Funds for research.

To study the impact on university research output of the changes described above a more disaggregated approach has to be used. In the next section the relationships among scientific research output, size and funding structure will be analysed at the institutional level. ${ }^{12}$

\footnotetext{
2) To favour specific incomes is a way to create incentives for the university in the competitive approach to uniwersity research behaviour and funding that the government is pursuing.

"Fon example in 1989-90 the receipts from the exchequer grant were about 3.5 times larger than those
from fees. "In the last period the nominal increase of income from Fees is sufficient to balance the increase in the number of students.

12 For the analysis of the determinants of university departments" research productivity see, amang others, Gilmore and 'To (1992), Hare and Wyatt (1988) and Ramsden (1994)
} 


\subsection{Allocation of Funds and Research Output}

In order to investigate the relationships among scientific research output, size and funding structure only 'scientific' faculties (natural sciences, engineering sciences, medical sciences and agricultural sciences) have been considered. Social sciences and humanities are not included in the analysed sample of universities. In the period considered there were 72 "old" universities in the UK, ${ }^{13}$ of these 5 did not have scientific faculties. Twenty universities granted a Ph.D. degree in only one or two scientific fields. To reduce the variance in the sample and in order to compare similar institutions, only the institutions that granted a Ph.D. degree in at least three scientific fields have been included in the analysis. For each of the 47 universities considered, the following data have been gathered: ${ }^{14}$

NEWOLD: The founding year of the institution.

NSCIRES: The number of academic staff in the "scientific" faculties: 1989-90, $1992-93 .^{15}$

SPRUPUBS: Number of papers published by a scholar associated to a specific institution: $1990,1993 .^{16}$

SCIPRO: The ratio between the number of publications and the number of researchers (SPRUPUBS/NSCIRES).

RETOT: $\quad$ The share of research grant and contract receipts in total recurrent income: $1989-90,1992.93$

INDRE: $\quad$ The share of UK industry receipts in the total amount of funds from research grants and contracts: 1989-90, 1992-93.

1. Due to their peculiar characteristics the Senate Institutes and Central University of London University, and the University Central Registry of the Universilty of Walles are excluded from the analysis. Manchester University and UMIST have been considered as one institution. Finally, London University is not considered as a single institution. Its 22 component colleges are indiwidually counted.

${ }^{14}$ Data sources are given in Anmex A.

${ }_{15}$ The number of researchers includes the total of full-time academic staff plus, when present, $50 \%$ of part-lime academic starf.

${ }^{14}$ For the methodology used in gathering the data see Katz et al (1995). 
The first variable describes the institution in terms of historical development. The variable number of researchers is a measure of input to research; while the number of publications is an indicator of the scientific output dimension. The ratio between the number of publications and the number of researchers is used as a proxy for the scientific research productivity of the university. The share of research grant and contract recepts to the university's total recurrent income is used as a proxy for the research orientation of the institution. Finally, the share of UK industry receipts in the total amount of funds from research grants and contracts can be interpreted as a proxy for the propensity to carry out research of a more applied nature.

The representation of the data according to the analysed characteristics of the universities allows us to highlight the existence of relationships among scientific research output, size and funding structure. Moreover, indications of the impact of the changes occurring in the UK university system during the period 1989-90/199293 may be extracted by comparing the data at the start and at the end of the period considered.

\subsubsection{Cluster Analysis}

In order to analyse any possible grouping of the institutions according to their characteristics a cluster analysis is implemented. More exactly, first principal components ane extracted from the original four variables (NSCIRES, SCIPRO, INDRE, RETOT), then a hierarchical cluster analysis is performed on the principal components. ${ }^{17}$ To define clusters that have small within variation and high between variation the same methodology is used for the 47 universities both in 1989-90 and in 1992-93. For simplicity, only the figures that refer to the period 1989-90 are presented in the following description of the methodology.

\footnotetext{
1" For a nore detailed description of the methodology used see previous chapter.
} 


\section{Allocation of Funds and Research Output}

Table 3: Rotated loading matrix

\begin{tabular}{|l|c|c|c|}
\hline Variables & $\begin{array}{c}\text { First Principal } \\
\text { Component }\end{array}$ & $\begin{array}{c}\text { Second Principal } \\
\text { Component }\end{array}$ & $\begin{array}{c}\text { Third Principal } \\
\text { Component }\end{array}$ \\
\hline INDRE90 & -0.10525 & 0.98633 & -0.06006 \\
\hline SCRPRO90 & 0.21735 & -0.06591 & 0.97099 \\
\hline RETOT90 & 0.87844 & 0.03923 & 0.25805 \\
\hline NSCIRES90 & 0.88620 & -0.22842 & 0.09530 \\
\hline
\end{tabular}

The first step consists in extracting the principal components from the original data. Given that $94 \%$ of the total variance is explained by the first three principal components (the first two accounts for only $74 \%$ ) the four original variables can be reduced to three. The loading (correlation) of the four variables with the three principal components are presented in Table $3 .^{18}$ The first principal component combines the number of academic staff in the scientific faculties and the share of research grant and contracts receipts in the total recurrent income, it can be defined as a proxy for the scientific research size of the university. The second principal component has a high loading only for the share of UK industry receipts, thus it can be interpreted as an index of the propensity to carry out research of a more applied nature. Finally, the only important loading of the third principal component is related to the ratio between the number of publications and the number of scientific researchers, it can be defined as a proxy for the scientific research productivity of the institution.

To investigate the possible clusters within the three new variables a hierarchical cluster analysis (Ward method) is used. As in the previous chapter, the Scheffe test with a significance level of 0.05 has been used to determine the number of cluster that should be analysed. The best representation of the data is given by the grouping into three clusters. This solution has been also verified with a nonparametric Kruskal-Wallis Test. The hypothesis that the three clusters come from populations having the same distribution is rejected.

\footnotetext{
In Table 3 the principal component loading after a Varima rotation are presented.
} 


\section{Allocation of Funds and Research Output}

\section{Grouping in 1989-90}

In the first period three main clusters are identified. ${ }^{19}$ Cluster II is composed by the largest number of institutions (42.6\%), Clusters I and Cluster II include a smaller number of universities ( $31.9 \%$ and $25.5 \%$ respectively). What are the characteristics of these clusters?

The first cluster is composed by institutions with a mean of 346 researchers which have published a mean of 173 publications; the mean scientific research productivity of the institution in terms of publication per researcher is 0.51 . The average research orientation is 0.13 , and the mean propensity to carry out applied research is 0.20 . The institutions that are members of the second cluster are generally of larger size (mean number of researchers of 479) and tend to publish more (mean number of publications of 350). Their mean scientific research productivity is higher than the previous cluster (mean publications per researcher of 0.75 ). While the research orientation is higher, the average share of industrial funds tends to be lower. Finally, Cluster III is composed by large universities (mean number of researcher of 1206) with high publication output (mean number of publications of 1001) and high scientific research productivity (mean publications per researcher of 0,82 ). As for the previous cluster, while the research orientation increases (mean research grant and contract funding share of 0.23 ) the applied research propensity tends to be lower (mean industry funding of 0.11 ).

The variable NEWOLD is used to study the historical composition of the clusters. Half of the post-war universities are in Cluster 1; $60 \%$ of the institutions in the cluster have been founded in this century. The second cluster is polarised towards old institutions, $60 \%$ of the universities in this cluster were created before the twentieth century. In the third cluster the share of institutions founded before the end

\footnotetext{
See Appendix 1 for the list of the universities.
} 
of the nineteenth century rises to $83.3 \%$; none of the post-war tuniversities are in this cluster.

Table 4: Cluster composition in 1989-90, mean values for the five variables

\begin{tabular}{|l|c|c|c|}
\hline Variables* & Cluster I & Cluster II & Cluster III \\
\hline No. of researchers 90 & 346 & 479 & 1,206 \\
\hline Publications 90 & 173 & 350 & 1,001 \\
\hline Publications per researcher 90 & 0.51 & 0.75 & 0.82 \\
\hline Research funding share 90 & 0.13 & 0.16 & 0.23 \\
\hline Industry funding share 90 & 0.20 & 0.15 & 0.11 \\
\hline No. of Universities & 15 & 20 & 12 \\
\hline
\end{tabular}

* For each variable the non-parametric Kruskal-Wallis Test has been run. The hypothesis that the the clusters come from populations having the same distribution is rejected.

The analysis of the data according to the considered characteristics enables us to define three groups of institutions with small within-cluster variation for discriminating variables -i.e. the institutions in a specific cluster have similar characteristics-- and high between-cluster variation --i.e. the universities in the various clusters have different features. Cluster I is composed mainly of twentieth century universities with small scientific faculties that tend to have low scientific reseanch productivity and have the highest propensity to carry out applied research. The institutions in Cluster III are mostly nineteenth century universities, thay tend to have scientific faculties of bigger size with larger scientific research output and higher research orientation. However, while their mean scientific research productivity is high, their propensity to develop research in collaboration with industry is lower than in the previous cluster. Finally. Cluster III is almost entirely composed of medieval and nineteenth century universities of very large size that have high scientific research productivity and a low applied research propensity.

In 1989-90 the 47 multi-disciplinary UK universities were characterised by a positive relationship among size, research orientation and scientific research output, and a negative relationship between these thee variables and applied research propensity (share of contract research and grant financed by UK industry). On the 
one hand the institutions of small scientific size with low scientific research productivity of Cluster 1 , on average, received only $13 \%$ of their total recurrent incomes from grants and rescarch contracts, but $20 \%$ of these funds were receipts from UK industry. On the other hand, the very large high scientific research productivity universities of Cluster III had $23 \%$ of their total recurrent incomes originating in research grants and contracts, but only $11 \%$ of these were funded by UK industry. Moreover, the institutions in Cluster I were those with the largest share of UK industry receipts in total recurrent income.

The above analysis seems to point to the existence of a divide between a group of universities of smaller scientific size, with lower scientific research productivity that tend to have relatively higher relationships with industry, and a group of large institutions with high scientific research productivity that, despite having a significant research orientation, tend to have a less important interactions with UK industry. Between these extremes a large group of institutions tend to have average values for the variables considered.

\section{Grouping in 1992-93}

Also in 1992-93 the three cluster solution gives the best representation of the data. ${ }^{20}$ The first wo clusters encompass similar number of institutions, while the third includes only the Universities of Cambridge and Oxford. What are the characteristics. of these clusters?

The institutions in the first cluster tend to be of small size (both in the case of the scientific faculties only and in the case of the complete university), ${ }^{21}$ with low scientific research productivity. While their research orientation is low the share of UK industry funds tend to be high. The second cluster is composed of universities of larger size with larger scientific research output and higher scientific research

\footnotetext{
20 See Appendix 1 for the list of the universities.

2t When the entire university is considered the number of researchers and students, and the total recurrent income have low mean walues.
} 


\section{Allocation of Funds and Research Output}

productivity. Even if they have higher research ortentation, they tend to have a lower share of research financed by UK industry. Finally, Cambridge and Oxford, due to their peculiar characteristics the highest scientific research productivity, extremely high research orientation, low share of UK industry funds, and large size and scientific research output) form Cluster III. Contrary to the 1989-90 case the analysis of the historical composition of the clusters does not allow us to highight any historical polarisation either in Cluster I or in Cluster $\mathrm{II}^{22}$

\section{Table 5: Cluster composition in 1992-93, mean values for the five variables}

\begin{tabular}{|l|c|c|c|}
\hline Variables* & Cluster I & Chuster II & Cluster III \\
\hline No. of researehers 93 & 478 & 836 & 1698 \\
\hline Publications 93 & 293 & 667 & 2266 \\
\hline Publications per researcher 93 & 0.60 & 0.84 & 1.33 \\
\hline Research funding share 93 & 0.14 & 0.20 & 0.33 \\
\hline Industry funding siluare 93 & 0.16 & 0.09 & 0.08 \\
\hline No. of Universities & 24 & 21 & 2 \\
\hline
\end{tabular}

*: For each wariable the non-parametric Kruskal-Walls Test has been run. The Inypothesis what the Whee clusters come hom populations hawing the same distribution is regected.

In 1992-93 the 47 UK universities considered tended to be characterised by relationships among size, research orientation and scientific research output similar to the ones of four years before. Also, the negative relation between these three variables and the applied research propensity (share of contract research and grant financed by UK industry) is confirmed. On the one hand the universities of Cluster 1 received, on average, $14 \%$ of their total recurrent incomes from grants and research contracts, and $16 \%$ of these funds were receipts from UK industry. On the other hand, the institutions of Cluster II had $20 \%$ of their total recurrent incomes originated by research grants and contracts, but only $9 \%$ were financed by UK industry.

Going from 1989-90 to 1992-93 some institutions moved among the clusters. The intermediate Cluster II of 1989-90 disappears. Nine universities have moved to the lower scientific research productivity cluster, while eleven institutions have been

\footnotetext{
2 Obvious: y Cluster III includes only medieval aniversities!
} 
attracted by the cluster on the other extreme. What are the characteristics of these institutions? Did their funding structure change in the time interval considered?

\subsubsection{An Analysis of the Changing Membership of Clusters}

The representation of the data according to the analysed characteristics has underscored the existence of particular relationships among scientific research output, size and funding structure. Given the fact that two different cluster structures are present at the start and at the end of the period considered it is possible to study if this modification --the movement of institutions among groups- is related to changes in the funding structure. ${ }^{23}$

In the following section the analysis will focus on the twenty universities that were members of Cluster II in 1989-90. ${ }^{24}$ Four years later nine institutions were attracted by the first cluster and eleven by the third cluster. ${ }^{25}$ For convenience the first nine are defined as 'Downgrading' and the other eleven as 'Upgrading", meaning that the former were attracted by Cluster I and the latter by Cluster III. Did the characteristics of these universities change over the studied time interval? In the first period the 'Downgrading' institutions were of larger size, with lower scientific research productivity, but they had a research orientation and a propensity to carry out research of a more applied nature (share of contract research and grant financed by UK industry) similar to those of the 'Upgrading' universities. Compared to four years before, in 1992-93 the eleven 'Upgrading' institutions were characterised by an extremely high scientific research productivity, while their applied research propensity was much lower. The nine universities attracted by Cluster I witnessed

\footnotetext{
2. Hare and Wyat (1992) studied the changes in resource allocation of the old British universities in the period $199 \mathrm{~J} / 2$ and $1992 / 3$. They found some evidence to sivpport the view that the funding policy of the UFC had the effect of strengthening the strong universities while the weak one were increasingly starved of resources.
}

\footnotetext{
2. The following analysis is based on the mean values of the two groups of institutions considered. For each variable used in the discussion the non-parametric Kruskal-Wallis Test has been run. The hypothesis that the two groups come from population having the same distribution is rejected.
}

25 In 1992-93 the universities originally in Cluster III (exciuded Cambridge and Oxford) plus the eleven institutions that moved form Cluster II. 


\section{Allocation of Funds and Research Output}

only minor changes; nonetheless, given the fact that all the other institutions, on average, saw an important decrease of the share of UK industry receipts (in real terms), their roughly unchanged share of UK industry funds indicates a change in their propensity towards research of a more applied nature. ${ }^{26}$

Going from 1989-90 to 1992-93, on the one hand the eleven "Lpgrading" universities increased their scientific research productivity and decreased their applied research propensity, while, on the other hand, the nine 'Downgrading" universities had a nearly unchanged scientific research productivity retaining a high propensity to conduct a research of a more applied nature -i.e. firanced by $U K$ industry.

Table 6: Fractional changes in the real value of university receipts; mean values for institutional receipts from selected funding sources:

\begin{tabular}{|l|c|c|}
\hline & $\begin{array}{c}\text { 9 "Downgrading" } \\
\text { Universities }\end{array}$ & $\begin{array}{c}\text { 11 "Upgrading" } \\
\text { Universities }\end{array}$ \\
\hline Exchequer Grant & -0.28 & -0.23 \\
\hline Research Council & 0.16 & 0.34 \\
\hline UK Industry & 0.15 & -0.25 \\
\hline Industry funding share & -0.03 & -0.39 \\
\hline
\end{tabular}

For each wariable the nom-parametric Kruskal-Wallis Test has been run. The hypothesis that the two groups come from populations having the same distribution is rejected.

Table 6 shows the mean real changes in the receipts from Excheguer Grant, Research Council, UK Industry and in the Industry funding share ${ }^{27}$ for the fwo groups of institutions. Both groups of universities suffered important cuts at the Exchequer Grant receipts, and witnessed an increase of the funds from the Research Council. However, while the reduction in the Exchequer Grant has been more relevant for the

\footnotetext{
${ }^{26}$ In $1992-93$ the nime "Downgrading" institutions had an share of contract research and grant financed by UK industry similar to the one of the uniwersities originally in Cluster I.

27 Also the changes of other sources of funds have been studied, however only for the four variables discussed in the text the non-parametric Kruskal-Wallis Test atlowed us to reject the hypothesis that the two groups come from populations hawing the same distribution. Nonetheless, the changes in the other consinlered sources were coherent with the interpretation presented.
} 


\section{Allocation of Funds and Research Output}

'Downgrading' institutions, the rise of Research Council receipts has been more important for the 'Upgrading' universities. The funds from UK industry followed opposite trends for the two groups. On the one hand the 'Downgrading' institutions succeeded in attracting a larger amount of funds from UK industry, and the share of these receipts in their total amount of funds from research grants and contracts stayed approximately constant. On the other hand, both the total amount and the share of UK industry fell dramatically for the 'Upgrading' universities.

In the period considered the nine 'Downgrading' universities suffered extremely large cuts to their general state support, consequently they tried to increase the income from specific sources, and in particular, they succeeded in attracting an increasing number of contracts from UK industry. The eleven "Upgrading" institutions saw their Exchequer Grant receipts decreasing, although less than in the case of the other group. They too had to relay more on specific sources of funds, but instead of orientating their research effort more towards the need of UK industry, such as the "Downgrading" universities, they managed to obtain a larger amount of funds from research contracts and grants of the Research Council.

Are the characteristics of the universities member of the two groups related to the changes in their funding structure? A clear answer to this questions is not possible with the current level of analysis. Nonetheless, is important to notice how the negative relationship between the applied research propensity (share of contract research and grant financed by UK industry) and the scientific research productivity highlighted in the two period analysis is confirmed also when the changes are studied. The 'Downgrading' universities that suffered extremely large cuts in their Exchequer Grant receipts, and partially substituted these funds with industry money, are also the ones that tend to have a decreasing scientific research productivity. ${ }^{28}$ The "Upgrading" institutions that partially counterbalanced the cuts in the Exchequer Grant with an

\footnotetext{
28 A basic feature of scientific production is the increase in the number of publications, thus a stationary trend meats in practice a decrease in the productivity. See Katz ef al. (1995) for a detailed analysis of publishing patterns in the UK.
} 


\section{Allocation of Funds and Research Output}

increase of receipts from the Research Council, reducing at the same time their interactions with UK industries, are the one that showed an important raise in their scientific research productivity.

The findings both at the static level and dynamic level form a consistent picture. At each point in time the universities with smaller scientific faculties and with lower average scientific research publications per researcher tend to depend more heavily on industrially funded research. ${ }^{29}$ Where the cuts in the general public support, not offset by an increase of public specific funds, were greatest the universities involved were pushed to rely more heavily on industry funding, and this was accompanied by further lowering of average scientific publication rate. ${ }^{30}$ The evidence offered suggests the possibility that two mechanisms were at work in the adaptation to change in state funding: (1) the removal of research support from Cluster I and from the nine 'Downgrading' institutions, pushed these universities to accept industry funding for work that did not lead to high publication output; (2) Changed research orientation led to the departure of researchers with stronger academic research records and aspirations, this was reflected in a reduced publication output in the 'Downgrading' institutions, and a rise in the 'Upgrading' universities to which the researchers went.

The subdivision in two groups of the UK universities, one of lower scientific research productivity more involwed in applied research orjented to the commercialisation of research, and the other of thigher scientific research productivity with relatively lower interactions with industry may seem, at least to some observer, a desirable outcome. Nonetheless, if the budget cuts and the push towards higher

\footnotetext{
29 Baldwin (1996) presents a similar picture for the USA. Using 1991 funding figures for US universities, he points out that "...the universities which have become most dependent on private industry support for their $\mathbb{R} \& D$ activities are not, in the main, the nation's leading research uniwersities."

3in Senker. Senker and Grossman (1997) found a negative correlation between university department involvement in the Teaching Company Scheme (programme in which academics in universities work with companies to contribute to the implementation of strategies for technical or managerial change) and publications output.
} 
university funding from industry will continue ${ }^{31}$ what is now true for the lower scientific research productivity group may become true for the majority of the universities. Moreover, as pointed out in Faulkner and Senker (1995) and confirmed by the aggregate real decrease of UK industry receipts showed in Section 2, there are indications that industrialists are beginning to think that contracting to university may cause a diminution of the available stock of basic knowledge that is most useful to their innovation processes.

In this situation further cuts to government support will put universities in funding crisis causing a decrease in the bargaining power with industry that may lead the way to the destruction of the norms, incentives and organisational structure of the "open science" ${ }^{32}$ kind of research typical of the university. In a context of reducing state support the increase in commercializable research in universities, possibly to foster state economic development, may result in a shift away from basic research (to the extent that this is measured by publications per researcher) that will cause a lower rate of technological innovation in the long term (Feller, 1990). ${ }^{33}$ This shift is more relevant for those universities with tighter budgets more dependent on the general funds that, in a period of reducing state support, are constrained to involve a large amount of their scarce resources for research in contracts with industries.

\footnotetext{
31 There are proposals to increase the weight given to the collaboration with industry in the Research Assessment Exercise.

${ }^{38}$ For an analytical history of the emergence of the institutions of "open science" see David (1997a); for the role played by norms, incentives and organisational structure in the creation of knowledge see Dasgupta and David (1987. 1994).

" On the shift from basic to a more applied type of research see also Cohen, Florida and Goe (1992), and Faulkner and Senker (1995). Arora and Gambardella (1997) show that, on the top of the above discussed problematique, industry funding of scientific research will also lead to an excessive allocation of resources to scientists with great past reputation.
} 


\section{Allocation of Funds and Research Outpu}

\subsection{Conclusions}

Governmental and industrial decisions are influencing the evolution of the university system. The modifications involved in this process will affect, for better or for worse, the production and distribution of scientific and technological knowledge. The science and technology policy frameworks of today, that originated in a period of continuously expanding state financing, are of little use in the current context of budget restrictions. Contemporary policy initiatives, to increase the amount of commercializable research carried out in universities, with the aim of possibly fostering state economic development, are being taken more on the basis of the laissez-faire philosoplyy in fashion rather than on the basis of a sound theoretical analysis. In the most influential policy circles it is thought that what has been beneficial for the industrial sector (deregulation and privatisation) will also be good for the publicly funded scientific research. "This neglects the peculiarities of knowledge production and distribution processes. With a lack of theoretical guidance, the medium to long-term results of governmental and industrial decisions may be far from desirable from an economic and social point of view, creating a variety of unintended consequences.

This exploratory work is an attempt to develop an empirical approach for analysing the relationships between funding and research output. In particular, it focuses on how the changes in the funding structure of multi-disciplinary "old' British universities have affected their propensity to carry out research of a more applied nature. First, the evolution of the funding structure of UK universities in the period 1989-93 is studied. Then, in order to assess the influence of the funding structure on the research output, the characteristics of 47 multi-disciplinary universities are examined at the start and at the end of the period considered.

The competitive approach to university research behaviour and funding pursued by the British government, that originated from a laissez-faire or perfect competition model of how institurtions should be made to operate, favours, directly 


\section{Allocation of Funds and Research Output}

and indirectly, the receipt of incomes from specific services rather than general funds which have been systematically cut. The aggregate analysis of university funding has shown that in the four years considered the real growth of specific incomes has not been sufficient to cover the reductions in general funds. Moreover, of particular importance, and contrary to the alleged increase of uniwersity-industry co-operation, is the decrease of UK industry funding receipts. Despite British government programmes to facilitate research collaborations between university and industry, at the aggregate level the share of funds from UK industry declined over the period. ${ }^{34}$

The methodology used to represent the data according to the analysed characteristics of the 47 universities has allowed us to highlight the existence of specific relationships among scientific research output, size and funding structure. The analysis at the static level (at the start and at the end of the period) offers some evidence that universities with smaller scientific faculties and with lower scientific research productivity tended to depend more heavily on industrially funded research. Although they had a lower share of receipts from grants and research contracts, the share of these receipts received by the universities from UK industry tended to be high. At the dynamic level (changes between the two periods) some indication have been found that where the cuts in the general public support, not offset by an increase of public specific funds, were greatest the universities involved were pushed to rely more heavily on industry funding, and this was accompanied by further lowering of average scientific publication rate.

On the one hand, the leading research intensive UK universities are the most important recipients of industry support; on the other hand, when industry funds are considered velative to the total amount of R\&D funds -i.e. the share of UK industry receipts in the total amount of funds from research grants and contracts, the leading research intensive universittes tend to be among the less dependent on industrially funded researct.

\footnotetext{
If This may also be due to the fact that UK industry went through a recession in the considered period.
} 


\section{Allocation of Funds and Research Output}

The analysis offers some evidence to support the hypothesis that policies oriented towards decreasing state financing of university research in the expectation of a substitution of industrial research funding, possibly to foster state economic development, may be disappointed in two senses: (1) Industrial funding is not likely to be large enough to replace major cuts in public support for R\&D, so that the net effect is a contraction of R\&D; (2) Universities hit hardest by budget cuts are pushed to do routine contract research for industry, which neither leads to high publications (and spillovers), nor does it lay a basis for long term fundamental innovation. Putting university researchers at less prestigious institutions at the 'service' of industry is a form of "subsidy" for the kind of research that industry can and has to pay for itself.

Further analysis taking into account better indicators of the scientific research activity, such as publications weighted by their impact factor, publications by scientific field, movement of researchers, is need to support these conclusions. Nonetheless, the outcomes of this study point to the existence of a series of problematiques that the current policy approach has avoided. A rethinking and reassessment of the science and technology policy frameworks that take into account the benefits and the drawbacks of the market approach on a medium to long term horizon are needed. In particular, regarding the university system, the answers to questions such as the following have to become the building blocks for the development of a new policy framework. What are the consequences for research and teaching of a more contract oriented type of university research? What are the economic and social returns of a larger industry funding of university research? What share of university incomes should be financed by industry? Are the advantages of scientific agglomeration -i.e. geographical concentration of scientific capabilities, and the localisation of the large part of research in a few universities-- offset by the negative externalities imposed on smaller universities which are excluded or marginalised by this process? 


\section{Allocation of Funds and Research Output}

\section{Appendix 1: List of Universities}

\begin{tabular}{|c|c|c|}
\hline Growerentifes & & \\
\hline & $1989-90$ & 1992.93 \\
\hline Aston Universily & $\pi$ & 1 \\
\hline Bath University & I & 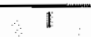 \\
\hline Bradford University & I & 11 \\
\hline Bringl Universicy & I & 1 \\
\hline Heriat-Wati Unithergity & i & I \\
\hline Hull Universily & 1 & 1 \\
\hline Kent at Canterbury Uniwersity & 1 & 1 \\
\hline Lughghborough University of Techinology & $i$ & $\mathrm{I}$ \\
\hline Wotingham Liniversity & $\overline{1}$ & $\bar{\square}$ \\
\hline Sallond University & I & li \\
\hline Stivling Inivershty & 1 & I \\
\hline Higter University & T & I \\
\hline Wales: University, Swansea & i & T \\
\hline Walles Univeratily, Aberystwyth & 臬 & 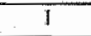 \\
\hline Wourwick Universtity & 1 & 1 \\
\hline Aberdean Uniwersiny & 11 & I! \\
\hline Exeter brisversity & TI & $\mathbb{1}$ \\
\hline Leed s Unversity & II & 1 \\
\hline Newcasile University & III & 1 \\
\hline Resuding Universtry & II & I \\
\hline Strathclyde Uniwersity & II & 1 \\
\hline Surrey Universily & III & 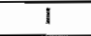 \\
\hline Walles Universily, Cardliff & 11 & 1 \\
\hline Tork Universily & III & 1 \\
\hline Belfast Oueen"s Unaiversity & III & II: \\
\hline Dundee Universiky & II & II \\
\hline Denrluam University & II & IIII \\
\hline Eatst Anglia University & 11 & III \\
\hline Essux Universily & II & II \\
\hline Keele Uniwersity & II & II \\
\hline Lancasiter University & II & 71 \\
\hline Letectester Liniventy & III & II \\
\hline London Ugiversity Q Queen Mary and Westfield College & 11 & II \\
\hline Sherfold University & il & II \\
\hline Susisex Ulmotorsity & II & III \\
\hline Birmatrogham Unu wersity & IIII & T11 \\
\hline Bristol Untwersity & แก & II \\
\hline didnbwrgh Uniwersiiy & IIII. & II \\
\hline Cahisgow Linversity & III & [1] \\
\hline Linerpool Uainersity & III & III \\
\hline London University, lwoperigal Colloge & 111 & III \\
\hline London University, King s Collegge & III & II \\
\hline Londugn University, Univerrsity Collewge & III & Il \\
\hline Mamchester Uninersity & lii & II \\
\hline Southia wopinn University & IIII & II \\
\hline Conuthotidge University & III & III \\
\hline Oxfond University & Will & III \\
\hline
\end{tabular}




\section{PART III}

EU Funding of University Research 



\section{University Participation in Community Framework Programmes}

In a context of ongoing profound modification in the funding and structure of the European higher education system, an important role is played by the development of international co-operative R\&D projects. Since the early 1980s, HEIs, partially independently and partially pushed by national policies, have increasingly participate in international R\&D projects. Although this participation is not completely new from an historical point of wiew, the scale and intensity of current international cooperative R\&D projects makes it a new phenomenon.

Facusing the attention on the European situation, HEIs are taking part in at least two kinds of international co-operation. First, there are the direct links between universities and between university and industry. Second, there are the co-operative relationships formed under the aegis of the Commission of the European Cormmunities through Community Framework Programmes. In the period 1984-1994, during the three Framework Programmes, this type of co-operation has become even more important due to the growing budget of the Framework Programmes and to the increasing participation of HEIs in each successive framework. In this chapter the latter kind of international relationships is analysed.

Since the First Framework Programme in 1984, the number of organisation receiving $\mathrm{EU}$ funding for $\mathrm{R} \& \mathrm{D}$ co-operative projects has increased considerably. In the Third Framework Programme, the type of organisation that participated in EU- 


\section{University Participation in Communty Framework Programmes}

funded $R \& D$ co-operative projects with the highest frequency was the one of HEIs i.e. almost exchsively universities.

The increasing paticipation of HEIs in each successive Framework Programme carries important consequences both for the funding structure of uniwersities and for the process of network formation and internationalisation of research. As an example of the former, consider the situation in the UK. A comparison of funding for each university from the European Community sources versus research grants and contracts from the British Research Council in 1992-1993 shows that, on average, the European Community funds are $21 \%$ of Research Council Funds. However for about $10 \%$ of the institutions EU funding represents more than $50 \%$ of Research Council funds. Besides, as part of the trend towards the internationalisation of network structure, 'Framework Programmes represent a useful vehicle to develop or reinforce linkages for a more extensive European research network. Thus, the participation in EU R\&D co-operative projects may have important impacts on the future research potentialities of the participants. ${ }^{2}$

The purpose of this chapter is to study university participation in EU-funded R\&D co-operative projects, paying particular attention to the factors that can influence the participation. Specifically, it will be highlighted how, among other Factors, the chatacteristics and behaviour of the universities, the behaviour of the funding agency, and the unintended consequences of the selection mechanisms for allocating funds ane televant for the understanding of university participation. The unit of analysis can vary from the most disaggregate level of the research group to the entire institution. For the present study, a cross-country analysis at the university level is developed. To avoid biases, the availability of information on the reference population - -i,e participant and non participant-- is extremely important. In this

\footnotetext{
"For the devalopment of international scientific collaboration see, among others, Luukkonen et al. (1992) and Leydesdorff (1992).

For the contintation of co-operation atter the end of the project see AXION (1995).
} 
study it is possible to consider the totality of recognised universities in the $\mathrm{EU}$ countries as the total population without imposing any selection bias.

This chapter is subdivided into two main parts. In the first, after a short introduction to the EU Framework Programmes, the participation of HEIs in R\&D co-operative projects is discussed (Section 6.1); then, Section 6.2 introduces an interpretative framework explaining university participation. The second part develops, in Section 6.3, a descriptive analysis of the universities participating in $\mathbb{E U}$ R\&D co-operative project; then an empirical model to test for the relevance of different factors on both the probability of joining a $E U R \& D$ project and the number of times a university participated in these projects is formulated and estimated (Section 6.4).

\subsection{The Participation of Higher Education Institutions in Community Framework Programmes}

Recent efforts of the EU to establish a targeted programme for improving industrial competitiveness through the mechanism of funded research officially began with the First Framework Programme (1984-1987). The Framework was set up with the goal of strengthening strategic areas of European competitiveness. "The mechanisms selected for the Framework included: a) funding the R\&D effort of private firms, research institutes, and higher education institutes ${ }^{3}$ in the strategic areas, and b) attempting to allocate funding to stimulate the formation of research networks spanning organisational and national boundaries. With the Second Framework Programme (1987-1991) the Community decided to use the Framework as "..the basis and instrument of European research and technology policy...thus providing a clear

\footnotetext{
${ }^{3}$ The Community reimburses up $10.50 \%$ of project actual costs to companies or research instituies, and to universities and other higher education establishments it reimburses the $100 \%$ of additional costs.
} 


\section{University Participation in Community Framewark Pragrammes}

smucture for long term overall objectives". ${ }^{4}$ A comprehensive political strategy on technology, enjoying equal status with other key Community policy areas, was set. The Third Framework Programme (1990-1994) is characterised by the regrouping of activities around only three strategic areas with 15 separate programmes and by the reinforcement of the aim of convergence among the member states of the EU. Nonetheless, as is clearly stressed in Commission of the European Communities (1992; p.11), "...where projects are evenly matched in qualitative terms, preference will be given to projects involving participants from technologically less well developed regions," the Community shows a lexicographic structure of preferences, with convergence subordinated to quality. The Fourth Framework Programme (19941998) pursues the guide lines of the previous one, putting more emphasis on the consistency between national and Community policy. The Programme is structured in 13 "vertical" programmes and 3 'horizontal' actions. Two new area of research, transport and socio-economic research, have been added. Lastly, in April 1997 the Commission of the European Communities put forward the proposal for the Fifth Framework Programme (1998-2002). The new Framework Programme is characterised by a 'problem-solving' approach with a focus on generic technologies and user needs and inwolvement. The aims of the Programme have been broadened giving higher importance to the socio-economic impact of research.

\section{Table 1: The Framework Programmes.}

\begin{tabular}{|c|c|c|}
\hline Programme & Duration & RU Conatribation \\
\hline Fitrst Framework Programme & $1984-1987$ & $3,750 \mathrm{MLCUs}$ \\
\hline Second Framework Prograntime & $1987-1991$ & $5.396 \mathrm{MECUS}$ \\
\hline Third Framework Programme & $1990-1994$ & $6,600 \mathrm{MECUS}$ \\
\hline Fourlh Framework Programme & 1994.1998 & $13,100 \mathrm{MECU}$ \\
\hline Fifh Framenork Programme & 1998.2002 & $14,000 \mathrm{MECU}_{\mathrm{S}}{ }^{+}$ \\
\hline
\end{tabular}

Sources: Commission of the European Communities (1994a, 1997a).

". It includes activities that were not encompassed in the other three Frameworks. The original anoumt of 12,300 MECs has been increased after the enlargement of the TUU.

": The Commission of the European Communities proposed a budget of 16,300 MECUs im Aprit 1997. February $12^{\text {th }} 1998$ the Council of Ministries approved a reduction of 2,3 MECUs.

\footnotetext{
4ee Commission of the European Communities (1992a)
} 


\section{University Participation in Community Framework Programmes}

In the course of implementing the succession of Frameworks, EU's research and technological development policy has expanded in budgetary scope, as is illustrated in Table 1, and has developed a few key goals. In particular, the total budget of the Fifth Framework is about four times that of the First Framework Programme in nominai value. However, the budget of the Fifth Framework is slightly inferior than the previous one in real terms.

Table 2: Distribution of participation and funding, by organisational type: $2^{\text {nd }}, 3^{\text {rd }}$ and $4^{\text {th }}$ Framework Programmes.

\begin{tabular}{|c|c|c|c|c|c|c|}
\hline & $\begin{array}{c}2^{\text {ned }} \mathrm{FP} \\
\text { Part. }\end{array}$ & $\begin{array}{c}3^{\text {rd }} \mathrm{FP} \\
\text { Part. }\end{array}$ & $\begin{array}{l}4^{\text {th }} \text { FP } \\
\text { Part.* }\end{array}$ & $\begin{array}{l}2^{\text {nd }} \mathrm{FP} \\
\text { Funds }\end{array}$ & $\begin{array}{l}3^{\mathrm{fd}} \mathrm{FP} \\
\text { Wunds }\end{array}$ & $\begin{array}{l}4^{\text {lh }} \mathrm{TP} \\
\text { runds }\end{array}$ \\
\hline $\mathrm{BrG}$ & 21,9 & 213 & 19,3 & 41,1 & 34,2 & 26,8 \\
\hline SMLEs & $|\overline{8}|$, & 14,5 & 17,3 & 18.7 & 16,4 & 16,1 \\
\hline $\mathrm{REC}$ & 29,5 & 29,8 & 25,1 & 20,8 & 23,5 & 23,9 \\
\hline HIIIs & 29.2 & 31.5 & 29,3 & 18.9 & 22,5 & 27.4 \\
\hline Altri & 1.2 & 29 & 9,1 & 0,6 & 3,4 & 5,9 \\
\hline
\end{tabular}

Soruce: Ellaboration data Commission of the European Communities (1994a 1997a).

*." The figures refer to the period January 1994, December 1996.

The institutions that participate in the Framework Programmes are classified by the European Commission ${ }^{5}$ in one of the following five categories: Big Companies (BIG), Small and Medium Enterprises (SMEs), Public or Private Research Centres (REC), Higher Education Institutions (HEIs) and Others. Table 2 shows the distribution of the five types of institutions in terms of (a) number of limes they participated in an R\&D co-operative project and (b) funding for shiared cost action for the Second and Third Framework Programme.

Three main observations emerge from the analysis of Table 2. First, Big Companies have suffered an important decrease between the Second and Forth Framework both in their participation level and in their funding. Part of the 14.3 percentage point cut in Big Companies" funding was redistributed to public or private research centres and, especially, to higher education institutions and other

\footnotetext{
5The participant into a project is required to classify her instifution in one of the categories.
} 
organisations, with the result that the funding HEIs approached $28 \%$ in the Forth Framework Programme, up from 19\% during the Second Framework. Second, the share of HEIs has increased, accounting for a bit less than one third of the total participation in projects. Universities, almost the totality of HEIs, as it will be shown in the following sections, became in the Forth Framework Programme the largest single type of institution both in terms of the number of times they participated in an EU-funded $R \& D$ co-operative project and in terms of funds received. Third, in all the three periods "research institutions" have a higher share of participation than their share of funds. This means that funds are more thinly spread, on average, across participating units in the research centres and higher education community than among participating businesses. For HEIs, the difference in share of participation and funding shrank in an important way between the Second and Forth Framework Programmes.

Table 3: Collaborative links involving HEIs and REC, by Framework.

\begin{tabular}{|l|c|c|c|c|}
\hline Organisation type & \multicolumn{2}{|c|}{$2^{\text {nd }}$ Iramework } & \multicolumn{2}{|c|}{$3^{\text {ra }}$ Framework * } \\
\hline & $H E I s$ & $R E C$ & $H E I s$ & $R E C$ \\
\hline HGIs & $25.6 \%$ & $36.0 \%$ & $29.8 \%$ & $42.4 \%$ \\
\hline REC & $36.7 \%$ & $28.6 \%$ & $40.6 \%$ & $28.5 \%$ \\
\hline BIG & $19.6 \%$ & $18.5 \%$ & $14.8 \%$ & $14.1 \%$ \\
\hline SMEs & $16.6 \%$ & $15.4 \%$ & $12.1 \%$ & $11.8 \%$ \\
\hline Other & $1.5 \%$ & $1.5 \%$ & $2.7 \%$ & $3.1 \%$ \\
\hline Total & $100 \%$ & $100 \%$ & $100 \%$ & $100 \%$ \\
\hline
\end{tabular}

Source: Duwid, Geuna and Steinmueller (1995).

* : The figure for the Third Framework Programme refers to circa $85 \%$ of the contracts

HEls play an important role in the EU's research and technological development policy. On the one thand, they are supplying basic knowledge needed by business enterprises, and, on the other hand, they are benefiting from gaining access to complementary expertise and instrumentation in Big Comparies' R\&D laboratories. Moreover, for HEIs, participation in a Framework project means not only access to $\mathbb{E U}$ funding, but also the opportunity to interact with industry and other research organisations in the formation of new, high quality research networks. This is extremely important, especially for those countries with lower scientific and 


\section{University Participation in Community Framework Programmes}

technological resources, because it enables such countries to overcome the constraints imposed by the small size of their research community.

Table 3 describes the evolution of collaborative links ${ }^{6}$ by organisation type for HEIs and RECs. In moving from the Second to the Third Framework programmes, both the number of HEIs' links with other HEIs and with research centres increased, nonetheless $29 \%$ of their links are still with industrial partners. The number of links is affected by the increasing numbers of HEIs and REC participating in the framework. Despite this increase, university-industry collaborations remain important in the Third Framework.

\section{Table 4: Total collaborative links, by Framework}

\begin{tabular}{|c|c|c|c|c|c|c|c|c|c|c|c|c|}
\hline & \multicolumn{2}{|c|}{ BIG } & \multicolumn{2}{|c|}{ SMES } & \multicolumn{2}{|c|}{$\mathrm{REC}$} & \multicolumn{2}{|c|}{ HEIs } & \multicolumn{2}{|c|}{ Others } & \multicolumn{2}{|c|}{ Total } \\
\hline & $2^{\text {ndid }}[E P$ & $\mathbb{f}^{\text {nd }} F P$ & $2^{\sin t} F P$ & $y^{\prime \prime d} F P$ & $2^{m a^{\prime}} F F$ & $a^{n d y}$ & $2^{\text {sid }} F P$ & $3^{\text {pid }} \mathrm{FP}$ & $2^{\text {Ad }} \mathrm{FPA}$ & $3^{\text {rd }} \mathrm{FP}$ & $2^{\text {ka' }} \bar{P}$ & $3^{\text {nd }} p \mathrm{p}$ \\
\hline $\mathrm{BIC}$ & 6,609 & 3,703 & 4,753 & 3,954 & 3,770 & 3,569 & 3,898 & 3,914 & 81 & 558 & 19,111 & 15.698 \\
\hline SMEs & 4,753 & 3,954 & 2,643 & 2,227 & 3,135 & 2,986 & 3,305 & 3,194 & 73 & 830 & 13,909 & 12,991 \\
\hline REC & 3,770 & 3.569 & 3.135 & 2,986 & 5,813 & 7,204 & 7.320 & 10,706 & 305 & 789 & 20,343 & 25,254 \\
\hline HEIs & 3,898 & 3,914 & 3,305 & 3,194 & 7,320 & 10,760 & $\$, 091$ & 7,876 & 307 & 700 & 19.921 & $26,3,90$ \\
\hline Others & 81 & 5.58 & 73 & 630 & 305 & 789 & 307 & 700 & 25 & 311 & 791 & 2,988 \\
\hline
\end{tabular}

Sontce: Elaboration of CEC data.

*: The tigure for the Third Framework Programme refers to circa $85 \%$ of the contracts

When one considers the total number of collaborative links between the same and different type of participants (see Table 4), it is possible to identify three relevant groups. First, the industrial group -i.e. collaborative links BIG-BIG, SME-SME and BIG-SME-- with about $30 \%$ and $19 \%$ of the links in the Second and Third Frameworks respectively. Second, the research group -i.e. collaborative links HEIHEI, REC-REC and HEI-REC-- which have not only the largest but also an increasing share of links, circa $39 \%$ and $50 \%$. Third, the hybrid group -i.e. collaborative links across the institutions of the two previous groups-- with about

\footnotetext{
- A collaborative link is a connection established between each of the participants in a research and technological development contract. For the calculation of the number of collaborative links a participant may be the comordinator, a contractor or an associate contractor (Commission of the European Communities, $1994 \mathrm{a}$ ).
} 
$30 \%$ and $27 \%$ of the links respectively. The co-operation between research institutions" and industry, characteristic of the hybrid group, although decreasing is nonetheless significant part of the picture.

Finally, the EU contractual funding across different programmes managed by DGXII, (Directorate-General Science, Research and Development) of the Commission of the European Communities is analysed On the one hand, when one considers the share distribution for each programme by type of participant, it is possible to identify a group of programmes in which HEls have about $50 \%$ of the funds. They are Step/Epoch, Bridge and Science And Technology For Development, ${ }^{7}$ in the Second Franework, and Environment, Marine Science And. Technology, Biotechnology and Life Sciences And Technologies For Developing Countries, in the Third Framework. ${ }^{8}$ On the other hand, when the share distribution for each type of participant by programme is considered the previous group of university-oriented programmes loses importance. The two industrially-oriented programmes, Esprit and BRTE-EURAM, and their continuations under the Third Framework Programme, are always the most important sources of HEIs funding. ${ }^{9}$

HEIs became in the Forth Framework Programme the largest single type of institution both in terms of the number of times they participated in an EU-funded RRD co-operative project and in terms of funds received. They have developed collaborative links especially with other research institutions, nonetheless taking part in a significant number of projects with industrial partners. Finaly, although they are the dominant player in a few Framework Programmes particularly oriented towards

\footnotetext{
${ }^{\gamma}$ Due to their specific onatacter the programmes under the headings Improvemants To European Scienticic And Technological Co-operation, Medical and Health, BCR and Fusion are not included in the analysis.

${ }^{8}$ Due to their specific character the programmes under the headings Human Capital and Mobility and Fusion ate not included in the analysis.

- Only Environment, among the programmes of the previous group, receives in absolute terms a relevart share of funds $(16 \%)$.
} 


\section{University Participation in Community Framework Programmes}

HEIs, they also participate in a respectable number of projects in the industriallyoriented programmes.

Four main observations can be drawn from the previous analysis. First, if the financiall trend of the first part of the Fourth Framework Programme is sustained throughout it end, ${ }^{10}$ the distribution of funds by type of participant will tend to become more homogeneous across the groups. Second, the increasing share of HEIs, within a Framework Programme characterised by a growing budget, implies growing impact over time of EU funds on the higher education finance system. In particular, in a period of budget cuts, restructuring and internationalisation of the European higher education system, the availability of a new competitive source of funds can have extremely important consequences." Third, the growing budget of the Framework Programme represents a vital opportunity for institutions in countries with few resources to overcome the constrains imposed by the small size of their national research community. Fourth, in the course of the four Framework Programmes HEIs have developed varied ways to draw upon the EU funds. They have joined co-operative project that range from grant to university consortia for basic nesearch to university/industry co-operation in market-oriented research.

With these issues in mind, it becomes crucial to understand why some uniwersities and other post secondary education institutions are taking part with different frequency in co-operative projects within the EU Framework Programme.

\footnotetext{
"As the Fourth framework Progranme pursues the guide lines of the previous one and as consistency in the policy behawiour of the Commission can be presurned one may expect that the tread will be confirmed.

II Inpact and unintended effects of EU funding upon the allocition of national public and priwate research funding going to ligher education instiputions --i.e. uniwetsily deparments-m in UK are discussed in Chapter 7. A detailed analysus of substitution effects and additionalicy of EU $R \& D$ funding is presented in David, Geuna and Steinmueller (1995).
} 


\subsection{An Interpretative Framework}

Two main phenomena that, in different but interrelated ways, have a strong influence on HEIs" participation in Framework Programmes will be considered here. First, both at the level of building up of research networks and of the funding selection process, the lack of information, and the consequent presence of informational asymmetry, among different research institutions on the one hand, and between funding agency and research institution on the other hand, points to the extremely important role played by information signalling. ${ }^{12}$ Second, the distinctively competitive character of the EU funding ${ }^{13}$ system, together with an increased mobility of researchers, have raised the impact of cumulative and self-reinforcement phenomena. In particular, the so-called Mathew effect ${ }^{1 / 4}$-i.e. research groups that are successful in finding external funding for their research have a higher probability of producing publishable research, which improves their probability of getting funds in the future-- that has less relevance in some of the less competitive national systems ${ }^{15}$ becomes crucial to understand the EU funding system.

\footnotetext{
12 For the importance of pre-contractual informational asymmetries and market signalling see the original contribution of Spence (1974).

"The funding and in general the mangement of the European higher education system, in both teaching and research, has been manly driwen by non competitive criteria. Only recently in few countries wi e. especially in the Unired Kungdon-- the system is undergoing at profound modilication directed towards a more manked oriented approach. For the discussion of the ongoing changes see the Chapter 2 and final part of Chaptes 3, see also Geuna $(1998,1997)$.

${ }^{14}$ For an economic analysis of the Mathew effect and its implication for rescurce allocation see Arora, David and Gambardella (1995). Dasgupia and Dawid (1987, 1994) and David (1994). For the original definition in the sociology of science see Merton (1968). For an early analysis on the relationships between scientific productivity and cumulative effect see De Solla Price (1963; 1976).

${ }^{15}$ A number of national university systems are still characterised, on the one hand, by extremely high entrance cost but, on the other hand, by low competition for research funding when in the system. To obtain a tenure the candidate has to ga through a wigorous selection process. However, when she has succeeded in being selected, the competition for fund raising tend to be low. In practice, every year ench professor is entitled to use a certain amount of research funds independently from her research productivity. However, ans described in Chapter 2 and Chapter 3 , this situation is clanging at an increasing pace. Due to budget constrains the national systems are developing a competitive approach to university research behavion and funding.
} 
HEIs" participation in Framework Programmes is conceptualised as the result of the interaction among $n$ suppliers --i.e. the different institutions-- and one consumer -i.e. the funding agency. This is a quasi-monopsony situation. ${ }^{\text {ts }}$ The exchanged product is, as first approximation, the result of the research project, and thus a non-thomogeneous good. Howewer, in most of the case, the real object of the agency is not to buy the research service but to succeed in reaching the policy goals through the tool of the research contract. Then, a variety of institutions, although each offering distinctive heterogeneous products, can satisfy the agency's potential demand. The emerging competition is based on the ability to perform research -i.e. the quality, the research productivity-m of the institution. In this sifuation the producers know their quality, whereas the consumer learns it only if it selects the "producer".

In implementing its policy the agency is using various research contracts. They range from the tender for a specific research serwice to the generic grant via the open call for proposal. The former is characterised by a needed service, well or less specified, and a call for suppliers. The price, if not yet fixed, represents a carrier of information and can be used to signall the quality. ${ }^{17}$ In all the other cases, the diffrculty of defining a product, previously described, limits the role played by price. Other ways should be used to infer the private information

Although the agency does not know the quality of the applicant, it does have a number of sources of potentially useful information in the form of verifiable statements, observable characteristics, and actions of individual applicants. Action and statements, together with partially or completely controllable individual features

\footnotetext{
"6 Taken into account the fact that a university can apply not only to the Commission of the European Communities, but, for example, also to its national funding agency, it is no longer correct to speals of momopsony. Indeed, as Community and rational policy objectives are sometimes overlapping one can assume that for an institution to apply to the nutional agency is a mon perfect, but still possible, substitute of the Community application.

17 The relevance of price as signalling device, does not mean that the other ways of quality signalling, described in the next section. are less important for this kind of contract.
} 


\section{University Participation in Community Framework Programmes}

are called signalling, while the term index refers the unaiterable characteristics (Spence, 1974). In the specific case studied here, the applicants can signal their quality at two levels. First, the research group level. Signalling will be related to the recorded history of the researchers member of the group. Information like education, research experience, publications, patents, etc. will be transferred from the applicant to the agency. Second, the university level. Being member of a particular institution exerts positive or negative externalities on a research group. It is possible to assume that the presence of a good research group in a department creates positive externalities, then there is a high probability that the average quality of the department is high. In general, it is difficult, although possible, to have a good research group in a low quality university. With this, the possibility of a dynamic improvement of the university's quality is not excluded. Indeed, it is possible to suppose that a single good research group is at the starting of the process of quality improvement. Nonetheless, the extremely high inertia and sclerosis of the university system tend to curb this kind of dynamic. ${ }^{18}$ The history of the university and its reputation are then signals of the potential quality of the applicant.

To "digest" additional information is costly for the agency. To evaluate in detail the signals received from the various research groups is not only time consuming, but it also requires specific competencies in the field of science related to the proposals. Usually these competencies are not present intemally to the agency, which must then make use of external reviewers. ${ }^{19}$ The agency can reduce the costs of the selection process using the information that is possible to extract from university signalling. Indeed, its general character implies low cost of evaluation. Clearly, a trade-off exists between the lower quality of the university signalling information and the higher cost of analysing the research groups" signals. The agency has then to go through a decision process focused on which type and how much of additional

\footnotetext{
18 The results of Chapter 4 support this wiew. Only a very small number of new post-war universities are nember of the thigh scientific research productivity, research intensive cluster.

"For example, in the second call for proposals of the Brute-Euram Prograrmme, 207 experts were involved in technical assessment of the proposals.
} 


\section{University Participation in Community Framework Programmes}

information to digest. In term of signals, the funding bureau has to decide how many signalled characteristics it wants to analyse. As a first approximation, it can be assumed that the funding agency analyses both types of signalling, complementing the lower cost university information with the high value research group information.

From the point of view of a study of the EU funding system, the Mathew effect is characterised not only by an increased probability of producing publishable results, but also by the creation of asymmetry between selected and un-selected institutions. The furst cumulative effect, or virtuous circle, based on increasing productivity and consequently future funding has been discussed in detail in David (1994). Here the focus is on the creation of asymmetries. The participants that have been selected to get funding and have performed well, have a higher probability of being funded again because their display of good performance is an indication of their high quality. As the funding agency is not able to observe the "real quality" of the applicants it has to base its decision on the signals received from the institutions and other sources of incomplete information. An institution that has been already chosen and has had a good performance is less risky than an organisation that has never been funded. The latter, although the funding agency, with the information collected, can classify it as a high quality institution, has not yet been proven to be a good performer. It is, then, associated with higher uncertainty and higher risk. A new applicant must overcome this 'barrier to entry.' To be selected its signalled quality must be higher than that of the previously selected candidates.

This condition becomes harder to satisfy after each new call for funding. Indeed, in each subsequent turn there will be a lower probability of having chosen low performers. The agency may classify an applicant using two sources. The signalled characteristics, in the case of an institution that has not yet been chosen. The signalled characteristics and a performance indicator $\eta$, when the applicant has already taken part into a project. The value of $\eta$ is zero at the starting. For each good performance of the institution $\eta$ raises, while it decreases in the opposite case. The probability of being selected for an institution that has already laken part into a 


\section{University Participation in Community Framework Programmes}

project is thus proportional to the value of $\eta$. In this way the agency tends to keep high performers and to reject low performers. Making the assumption that for each low performer rejected there will be a new applicant selected ${ }^{20}$ at time $t+I-$ i.e. new call for tenders--, and that the total population of potential applicants -i.e. in this case the totality of HEIs in Europe- is fixed, it follows that the probability of choosing good performers is increasing with time. The average 'quality' of the participants is thus increasing. Moreover, also some of the good performers can be replaced by applicants with higher signalled quality, increasing then further the average "quality" of the selected institutions. Allowing for the entrance of higher quality applicants. means to make the following two assumptions:

- The candidates enter in the competition whenever they prefer, they are not obliged to start at time $t$.

- There is space for "quality" or signalling improvements. During time an institution can enhance its signalled quality.

With subsequent calls for tenders the process may arrive at a situation of lockin in which a ' $c l u b$ ' of good performers is repeatedly selected by the funding agency. This situation may not be optimal. ${ }^{21}$ The best performers can be in the club, in which case we have an optimum solution, but they can be also not included in the club. Indeed, it is possible that the process dynamic leads to a lock-in situation in which there are $n$ institutions not selected with a signalled quality $q_{i}=F\left(q_{i}, q_{2}, \ldots q_{p}\right)$, where $q_{p}$ are the "digested" signalled characteristics of the institution $\vec{k}=1,2, \ldots, n$, higher than the signalled quality $\left.Q_{j}=, Q_{1}, Q_{2}, \ldots Q_{p}\right)$, where $j=1,2, \ldots, m$, of $m$ organisations within the club. This is due to the fact that the accumulated experience of the institutions within the club has created a barrier to entry $B_{j}$ that summed to the signalled quality of these institutions, $Q_{j}+B_{j}$, does not allow the entrance to the $n$ organisations. A new applicant will succeed in entering the club only if it has a

\footnotetext{
2010 He the in ir hypothesis that there is a fixed number of places is made.

21 This suboptimality may be mitigated in the long lem by a high human capital mobility.
} 
signalled quality $q_{l}>Q_{j}+B_{j}$. Therefore, the lock-in situation can be characterised by one or more institutions with a signalled quality $Q$ lower than the signalled quality $q$ of some organisations that have not been granted the support.

These mechanisms, in general, and the path to the lock-in situation, in particular, can be reinforced or weakened by the following three phenomena. First, the broad policy vision of the funding agency, in this case of the Commission of the European Communities and indirectly of the European Parliament, is shaping the approaches that are driving the distribution of funds. At the one extreme there is the pure quality oriented approach that, if followed, as described previously, creates a lock-in situation that can be non optimal. At the other extreme, the selection process can be based only on principles like inter-country cohesion, technological convergence, etc. that supplement quality and may outweigh a quality-only measure. Each of the possible combinations of these two extremes has a different impact on the degree of diversity present in the output of the selection process. Second, every time that there is a process of selection for funding there is space for different kind of pressures on the selection committee. Usually, with this, one refers to the "accepted" form of lobbying. A strong impact of Jobbying can cause an earlier sclerosis of the system with a lock-in situation at a lower level of quality. Notwithstanding that, if a broad definition of signalling is accepted, lobbying can be considered as a peculiar kind of quality signalling which can be reintegrated with in the previous analysis. Third, as clearly stressed by Peacock (1991) in the case of art subsidies, if the officials in charge of the selection process are members of particular community, and thus they have a specific reference group within the same community, or if they are bureaucrats who "for understandable reasons wish to develop congenial relations with a few established clients" the selection may be biased toward well established groups. The risk that funding support only reaches a selected group of "incumbent" institutions, in our terms, the institutions of the club, is then reinforced by bureaucratic inertia. In particular, a decisionmaking process can be strongly influenced by preference for the 'status quo' (Lambert and Willinger; 1994; Samuelson and Zeckhauser; 1988). In our case, an official tends to replicate the same 
choice as before -i.e. selecting the same institutions-- due to the presence of psychological transition costs and to its natural loss aversion (Tversky and Kahneman; 1991). To switch from the 'status quo' to a new configuration, the official should perceive the new choice -i.e. selection of new participants-- as a carrier of additional benefits and advantages that can compensate for the costs and disad wantages connected with choosing an alternative to the "status quo."

If information signalling and cumulative and self-reinforcement mechanisms are relevant phenomena to explain the participation in EU R\&D projects one should expect to have a small group of high quality well known institutions that obtain the largest share of EU R\&D contracts. In the next section, after the presentation of the unit of study and the description of the data-set, the analysis focuses on the understanding of the determinants of thiversity participation in EU R\&D com operative projects. Then, in Section 6.4, an econometric model for university participation will be estimated.

\subsection{Determinants of University Participation in EU-funded R\&D Co-operative Projects}

In Europe there is no standardisation on the definition of PSIs and University. In the different countries these terms carry varying connotations. However, in all the EU countries, the institutions that have been granted the university status, went through a national selection process that can be considered more stringent then the one for the granting the PSI status. Therefore, this category can be considered more homogeneous. Moreover, most PSIs are teaching oriented institutions only marginally involved in research. Those that are involwed in research are generally more oriented towards regional or national type of networking, and only when their scientific 
research quality is high they will try to access the EU funding system. ${ }^{21}$ For this reason, whereas all universities can be considered candidates for EU research funds, a minority of PSIs would qualify as such. Therefore, the totality of recognised universities in the EU countries is considered the reference population.

The ideal unit of analysis to understand university participation in EU R\&D project would be the research group or research centre that applied for EU funds. This information is currently not available at the cross country level. Although less informative, the analysis of university participation in EU R\&D co-operative projects at the aggregate level of the university can offer useful insights. Clearly, this unit of aralysis has a size bias. Large universities tend to have more research groups and consequently tend to participate more in EU projects. Nonetheless, controlling for size, other factors such as scientific research productivity, geographical localisation, scientific orientation are useful to explain the participation in EU projects. Besides, the analysis at the institutional level has independent justifications. First, although the literature on R\&D co-operation emphasises the centrality of the research group, particularly in this special case of international co-operation, the identity of the institution -i.e. Cambridge University versus De Montfort University-- plays an important role. In particular, because the funding agency --i.e. the Commission of the European Communities- is not perfectly informed, the institutional reputation or "the name" of the institution becomes a substitute for" missing information on specific researchers or research groups. Second, to develop an international co-operation with a well known university means also to originate positive image externalities for the institution involved. The literature recognises in the augmented image and prestige due to the link one of the main incentives for co-operation. ${ }^{22}$ Then, again, the institution itself comes to the fore. Thind, taking the university as unit of analysis enables to have information on the total population -i.e. both the universities that

\footnotetext{
${ }_{21}$ Armong the 427 HEls participating in Community Framework Programmes 97 are PSIs. However, each of these PSIs has participated in few projects, accouming for only $4.3 \%$ of the total number of times HEIs participated in EU R\&D projects (Geuna, 1996).

${ }^{22}$ See for example Malerba et al. (1991).
} 
have joined EU R\&D projects and the ones that did not have taken part in them-- and consequently the analysis at the level of the university will not have any selection bias. Fourth, from a methodological point of wiew, the macro analysis at the institution level enables to draw the background picture of this particular area of R\&D co-operation. In future research, the micro analysis at the research group level will be carried out on the basis of the results of the current work.

Universities participating in EU R\&D projects are a sub-group of all universities that applied for EU funds, while the ones that applied are a sub-set of all universities that tried to initiate a co-operative project. In addition, some universities did not try to initiate a co-operative agreement and others have not made a decision because they did not have information or they were uncertain on what to do. These different groups constitute the total population of universities in Europe (Figure 1).

\section{Tigure 1: Decision Tree for Initiation of a Co-operative Project}

\section{Total University Population}

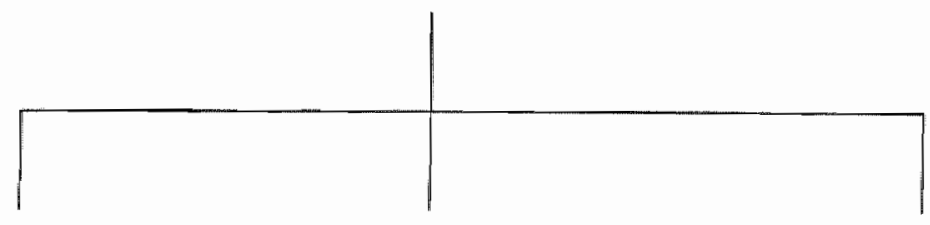

Do not Initiate

Try to Initiate

Wait to Initiate

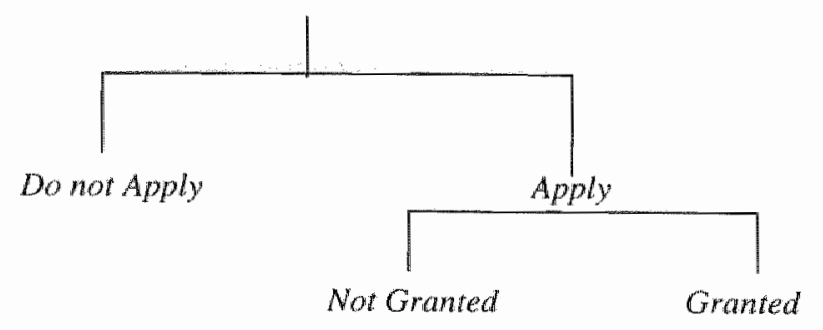




\section{University Participation in Community Framework Programmes}

At present, the data concerning the universities that have been involved in a EU-funded R\&D co-operative project (granted), and the total university population have been gathered. The analysis of this information will enable to highlight some of the factors affecting university participation in co-operative projects within the EU Framework Programme.

The data regarding the participation of universities in EU-funded R\&D Cooperative projects have been provided by DG XII -i.e. Directorate-General Science, Research and Development-- of the European Commission. They refer to shared-cost actions funded by DG XII under the First, Second and Third Framework Programmes. ${ }^{23}$ However, the data for the First Framework Programme are not complete because the database of DG XII has been created only after the end of the programme, then only part of the data concerning the First Framework Programme has been stored in it. Moreover, the information for the Third Framework Programme is only up to $15 / 3 / 1994$.

For each university the geographical information and the Number of Contract Partner Links were made awailable. The latter represents the number of times a HEI has been involved in a EU-funded R\&D co-operative project. No time or programme information were released. Constructed in this way, the database comprises 330 universities, representing $86 \%$ of the total population of universities in the $\mathrm{EU}$ countries considered. ${ }^{24}$

\footnotetext{
23 In both the Second and the Third Framework the research concerned with information and communications technologies was under the supervision of DG XII, therefore it is not included in the data set. Some other small programmes directed by DO VI, DG XIII and DO XIV are not included either. Still, about $55 \%$ - $60 \%$ of the funds were adninistered by DG XII.

24 When the totality of HEIs is considered, the number of institutions taking part into EU RaD projects rises to 427, respectively 69 PSIs, 28 New British Universities and 330 Unwersities.
} 
The 379 institutions forming the total population of European universities ${ }^{2 s}$ can be subdivided in the participants and the non-participants. The following variables ${ }^{26}$ have been used to study both groups:

EU Participation:

The number of times a university has been involved in an EU R\&D project (EUPART).

No Researchers:

The number of researchers in 1992 (NRES).

Publications:

The number of papers published within a certain institution in 1993 (PUBS), ${ }^{2 \pi}$

Publeations per Researcher: The ratio between the number of publications and the number of researchers (RATIO = PUBS/NRES).

Scientific Fields:

The scientific fields in which the institution grants a doctoral degree.

NEWOLD:

The institutions" founding year.

Table 5: Descriptive statistics for the main variables (TP=Total Population; $P=$ Participants $;$ NP $=$ Non-Participants $\rangle$.

\begin{tabular}{|c|c|c|c|c|c|c|c|c|c|c|c|c|}
\hline & \multicolumn{3}{|c|}{ Mean } & \multicolumn{3}{|c|}{ Std Dey } & \multicolumn{3}{|c|}{ Min } & \multicolumn{3}{|c|}{ Mass } \\
\hline & $r p^{3}$ & $P^{2}$ & $N P^{T}$ & $T^{2}$ & $p^{3}$ & $N p^{\prime}$ & $T T^{2}$ & $p^{x}$ & $N P^{3}$ & $T P^{I}$ & $P^{3}$ & $N P^{i}$ \\
\hline DUPAIRT & 49 & 56 & 0 & 65 & 56 & 0 & 0 & I & 0 & 420 & 420 & 0 \\
\hline NRES & 887 & 922 & 631 & 946 & 896 & 1232 & 15 & 36 & 15 & 7330 & 70000 & 7330 \\
\hline PUBS & 415 & 461 & 84 & 519 & 530 & 258 & 5* & $5 *$ & $5 \%$ & 3085 & 3185 & 1392 \\
\hline RATLO & 0.568 & 0636 & 0,078 & 0.971 & 1.016 & 0,142 & 0.005 & 0.005 & 0.005 & 12.34 & 12.34 & $0.59 \%$ \\
\hline
\end{tabular}

* Estimate value; "371 vatid cases, 2326 walid cases" ${ }^{3} 45$ valid cases. Eight cases have been excluded due to missing data.

\footnotetext{
${ }^{25}$ See Chapter 4 for their description.

26 For a detailed description of the variables see Chapter 4, Section 4. 1.1.

${ }^{27}$ For humanities and sociat sciences there exists the specific Social Science SCI which, however, has not been utilised due to the much lower propensity to publish of researchers in humanities and social sciences. Thus, these data are biased to the detriment of institutions with humanity of social science depatment. However, under the first three Framework Programmes only a minor part of the budget was indirectly committed to socio-economic studies, so that this is not considered a serious weakness for purposes of the present analysis.
} 


\section{University Participation in Community Framework Programmes}

Table 5 presents the descriptive statistics for the four contimuous variables. 326 universities (four cases have been excluded due to missing data) have participated from a minimum of 1 time to a maximum of 420 times in a co-operative project. They have participated on average in 56 projects. The ligh Kurtosis (5.536) and the positive Skewness (2.130), together with the high standard deviations (66) and large difference between Min and Max, indicate concentration in the values. Moreover, as the first three quartiles have respectively values 10,32 and 78 one can describe the population of universities participating in EU R\&D projects as composed of a large number of institutions with little participation and a small group of institutions involved in a large number of co-operative agreements. Similar observations can be done when the other three variables are analysed. Finally, when the descriptive statistics for the total population are compared to those of participants and non-participants, small positive differences for each of the four variables are present in the participants' distribution, while important negative differences characterise the non-participants' distribution. Thus, the participation or notparticipation in co-operative R\&D projects financed by the EU appears to be non independent from the size and the scientific research productivity of the institution.

Table 6: Distribution of participating institutions and participation counts, by countries (\%).

\begin{tabular}{|l|c|c|c|c|c|c|c|c|c|c|c|}
\hline & $\mathbf{B}$ & $\mathbf{D}$ & $\mathbb{F}$ & $\mathbf{G}$ & $\mathbf{G r}$ & $\mathbf{I}$ & $\mathbf{I r}$ & $\mathbf{N L}$ & $\mathbf{P}$ & $\mathbf{S}$ & UK \\
\hline IC & 5.0 & 2.1 & 17.6 & 19.7 & 4.1 & 12.6 & 1.8 & 3.8 & 4.1 & 9.4 & 19.7 \\
\hline $\mathbf{P C}$ & 9.8 & 3.4 & 7.7 & 17.5 & 4.8 & 10.4 & 3.5 & 8.7 & 3.5 & 6.2 & 24.4 \\
\hline $\mathbf{T P}$ & 4.0 & 1.8 & 19.3 & 19.8 & 4.0 & 12.4 & 1.8 & 3.4 & 4.5 & 10.3 & 18.7 \\
\hline
\end{tabular}

$B=$ Belgium, $D=$ Denmark, F=France, $G=$ Germany, Gr=Greece, INItaly, Ir-lreland, Nl=The Netherlands, $P=$ Portugal, $S=$ Spain, UK=United Kingdom.

Table 6 illustrates the universities' share in terms of institutions counts (IC), parricipation counts (PC) and total population (TP) broken down by EU country. The comparison of the institutions counts with the total number of universities present in each country highlights only small differences. When the participation counts -i.e. how many times the institution got funding-- are considered, important differences 
appear. On the one hand, France with $7.7 \%$ shows the worst performance, with Germany, Italy, Spain and Portugal also having lower shares. On the other hand, Belgium and The Netherlands more than double their share of participation relative to number of universities. Finally. Denmark and the UK (the country with the largest share of participation, about one fourth of the total) have a PC share significantly higher than their share of institutions.

Table 7: Institutions and participation counts, by size classes (\%).

\begin{tabular}{|l|c|c|c|c|}
\hline & \multicolumn{2}{|c|}{ Researchers } & \multicolumn{2}{c|}{ Weighted Researchers } \\
\hline & $I C^{*}$ & $P C$ & $I C^{*}$ & $P C$ \\
\hline Sunall Universities & 4.8 & 0.9 & 9.7 & 9.3 \\
\hline Small-Medium Universities & 37.3 & 20.1 & 38.2 & 30.3 \\
\hline Medium-Large Universities & 45.4 & 53.8 & 40.3 & 51 \\
\hline Large Universities & 12.5 & 25.1 & 9.7 & 9.4 \\
\hline
\end{tabular}

"The share does not sum to 100 dte to missing cases.

University participation can be analysed from the point of view of institutional size. To do so, the variable number of researchers has been subdivided into four categories: Small University from 0 to 100 researchers, Small-Medium Uniwersity from 100 to 500 , Medium-Large University from 500 to 1800, Large University more than 1800. Furthermore, to take into account the fact that some universities are more research oriented than others, the number of researchers has been divided by the number of students. As for the previous variable, the weighted number of researchers has been transformed into a categorical variable with four size classes. Table 7 illustrates institutions and participation counts broken down by size class. In the case of un-weighted researchers' number, the Medium-Large and Large institutions are performing better than the others. It seems thus that the success in raising EU funds is connected with the research size of the university. However, when one looks at the weighted researchers' number variable, a betten measure of the research size of the institution, the previous observation is no longer true. Both Small and Large universities do not show rellevant changes, the share of participation and the share of institutions are approximately equal. Only Medium-Large universities have a higher participation"share. 
Table 8: Institutions and participation counts, by historical class (\%).

\begin{tabular}{|c|c|c|}
\hline & Institutions Counts & Participation Counts \\
\hline Post-1945 & 38.8 & 20.8 \\
\hline $1900-1945$ & 8 & 10.5 \\
\hline $1800-1899$ & 20.1 & 31.3 \\
\hline Before-1800 & 33.1 & 37.4 \\
\hline
\end{tabular}

University participation in Framework Programmes can be analysed in relation to the age, or period of establishment of the institutions. To do so, the four classes subdivision introduced in Chapter 4 is used. Table 8 illustrates institutions and participation counts broken down by historical class. While in institutions counts the new post-war universities have the largest share, in participation counts their share is much smaller. On the contrary, the other three classes have higher shares in the second distribution. The distribution of institutions counts is almost equal to the distribution of the total population of universities, while when the participation level is considered the older universities have a larger share.

Table 9: Institutions and participation counts, by university type (\%).

\begin{tabular}{|l|c|c|}
\hline & Institutions Counts & Participation Counts \\
\hline ModWum & 0.6 & 0 \\
\hline ModAgr & 0.9 & 1.9 \\
\hline ModMed & 4.1 & 0.8 \\
\hline ModNat & 0.6 & 0.1 \\
\hline ModEng & 4.7 & 6.5 \\
\hline ModSoc & 3.2 & 0.3 \\
\hline BidNatEng & 3.5 & 2.4 \\
\hline BidNatSoc & 3.2 & 1.2 \\
\hline BidNatHum & 2.9 & 1.1 \\
\hline BidNatMed & 2.1 & 2.8 \\
\hline BidEngSoc & 1.2 & 2.1 \\
\hline BidMedSoc & 1.8 & 0.3 \\
\hline BidSocHum & 4.7 & 0.5 \\
\hline MUDM & 0.9 & 0.3 \\
\hline MUDE & 1.8 & 0.5 \\
\hline MUDN & 5.3 & 3.2 \\
\hline MUDME & 2.1 & 3.3 \\
\hline UDMN & 9.5 & 23.9 \\
\hline MUDNE & 14.2 & 12.7 \\
\hline MUDMEN & 22.7 & 35.1 \\
\hline
\end{tabular}


The widespread institutional variefy of the European university system has always constrained the value of international comparisons. For example, the Rheinish-Westphalian Technical University in Aachen, Germany has few things in common with the Eindhoven Technical University in Eindhoven, ${ }^{28}$ The Netherlands. The former one has faculties like philosophy and education, while the latter is an engineering school. Nonetheless, starting from the fact that the requirements for the doctoral degree are approximately standardised among the EU countries, the various diversified institutions can be classified according to the scientific flelds in which they grant the Ph.D. degree. In particular, taking into account the $O E C D$ classification for scientilic fields -i.e. Agriculture, Medicine, Natural Sciences, Engineering. Social Sciences and Humanities- 28 categories have been created. ${ }^{29}$ Six for the universities defined Mono-discipline, which grant the doctoral degree in only one scientific field. Each of the six classes contains observations. Fifteen for the universities Bi-discipline, which grant the doctoral degree in two scientific fields. Only nine of them include some institutions. Seven for the universities Multidiscipline. In this latter group all the institutions that award doctoral degree in three or more scientific fields are included. To better classify these universities, the presence of a Ph.D. degree in Engineering, Medicine and Natural Sciences has been used as a discriminatory variable. The multi-discipline group has been thus subdivided in seven categories. All of them contain observations. Table 9 shows the shares of institutions and participation counts broken down by the types of institution. First, rwo lypes of universities are not present in the Framework Programme. Among the twenty types that have succeeded in entering the system only thirteen achieve more than $2 \%$ of institutional participation share. Only three (multi-discipline with medicine and natural sciences (MUDMN), multi-discipline with natural sciences and engineering (MUDNE) and multi-discipline with medicine- engineering natural sciences (MUDMEN)) score more than 10\%. These last three categories account for about $56 \%$ of the institutions. Second, the system is more concentrated in the

\footnotetext{
${ }^{2}$ The two towns are only 120 kilometres one from the other.

${ }^{29}$ In six catregories there are no entries.
} 
participation counts. Nine types of institutions have a share higher than $2 \%$. The three multi-discipline categories previously in a dominant postion are, in this case, responsible for approximately $73 \%$ of the participation. They are performing much better than the others. The prior description points to the fact that although the system includes a large variety of institutions, the largest share of participation is realised by a specific kind of institution. This institution can be characterised as a general university that always includes faculties of medicine and natural sciences and often also of engineering.

The number of times an institution participated in EU R\&D co-operative projects is a fraction of the number of its applications. Among other factors, the characteristics of the university such as scientific research productivity, reputation, scientific orientation, influence the fraction of accepted applications. In um, the tatal number of applications of a university is the sum of the applications of the single centres, thus it depends on the number of the centres -i.e. the size of the institution-and on the characteristics of the centres and of the university. In the following section, an econometric model that analyses the importance of a few institutional characteristics on university participation is developed. In particular, the analysis focuses on the relevance of size and scientific research productivity.

\subsection{An Econometric Test of the Determinants of University Participation}

The aim of the regression analysis is to test the relevance of size, scientific research productivity, and other fixed factors on university participation in EU R\&D projects. In particular, the analysis of the estimates shall enable to highlight how the behaviour and characteristics of the universities, the behaviour of the Commission of the European Communities and the presence of un-intended effect of the selection criteria influence the participation of universities in EU-funded R\&D co-operative projects. 
As the number of times a university participated in EU-funded R\&D cooperative projects (EUPART) takes discrete values between 0 and 420 , the OLS regression is not a suitable estimation procedure. Two different approaches can be used. One is a Tobit model with number of times a university participated in a project as censored dependent variable. The other is a two equation model, where the first specification is a Probit model with a binary dependent variable which takes the value 1 when the university has a participation, and 0 when it does not, and the second equation is a Truncated regression model for the non-limit observations --i.e. for the number of participation greater than zero. The two alternative approaches can be tested against each other. ${ }^{30}$ The double specification can also be tested as the unrestricted model against the restricted Tobit model.

The advantage of the two equations model is that it separates the anallysis of the participation or not in a project from the analysis of the multi-participation. In this way is possible to separate the analysis of the probability of joining a EU R\&D project from the study on the level of participation in projects. The former revels the relevance of the considered factors on the selection, while the latter provides information about the level of participation.

In the Tobit model (Eq. 1) the dependent variable EUPART is regressed on the independent variables number of researchers (NRES), and ratio between number of publications and number of researchers (RATIO). The first independent variable measures the size of the university, while the second is used as a proxy for the scientific research productivity of the institution. A log-linear relation is assumed. Dummy variables (DCOUNTRY) for national fixed effects and control dummy variables (DSCIFIELD) for scientific fields ${ }^{31}$ are included. In the Probit model (Eq. 2) the dependent variable $Y$ is the probability of being involved in a project, which

\footnotetext{
Wee Cragg (1971) for the ariginal specification of the wo equation model.

The 9 dummies for scientitic fields orientation are the result of a recategorisation af the original classification in 22 cllasses given by the variable Scientific Fields.
} 
takes the value 1 when the university has a participation, and 0 when it does not. The same set of independent variables are used. ${ }^{32}$ In the "Truncated regression model (Eq. 3) only the universities that have participated in at least one EU R\&D project are considered. The dependent variable $P$ is the number of times an institution participated in a project and is recorded only when it is greater than zero. The independent variables are the ones used in the previous two equations. As in the Tobit model a log-linear relation is assumed. The equation (1), (2) and (3) are then formulated as:

(1) $\ln \left(1+E_{\text {UPART }}=\alpha+\beta_{1} \ln\right.$ NRES $+\beta_{2} \ln$ RATIO $+\sum_{i=1 \ldots 12} \beta_{i}$ DCOUNTRY $_{i}+$ $+\sum_{\mathrm{j}=1 \ldots \mathrm{m}} \beta_{\mathrm{j}}$ DSCIFIELD $_{\mathrm{j}}+\epsilon_{\mathrm{I}}$

where $\mathrm{a}=$ number of countries $=10$ and $\mathrm{m}=$ scientific fields categories $=8$.

(2) $\mathrm{Y}=\delta+\gamma_{1} \ln$ NRES $+\gamma_{2} \ln$ RATIO $+\sum_{\mathrm{i}=1 \ldots \mathrm{n}} \gamma_{\mathrm{i}}$ DCOUNTRY $_{\mathrm{i}}+$ $+\sum_{j=1 . m} \gamma_{j}$ DSCIFIELD $D_{j}+E_{2}$

where $\mathrm{Y}=1$ if EUPART $>0$ and $\mathrm{Y}=0$ if $\mathrm{EUPART}=0 ; \mathrm{n}=$ number of countries $=$ 9 and $m=$ scientific fields categories $=7$.

(3) $\ln (1+\mathrm{P})=\zeta+\eta_{1} \ln \mathrm{NRES}+\eta_{2} \ln \mathrm{RATTO}+\Sigma_{\mathrm{i}=1 . \mathrm{n}} \eta_{i} \mathrm{DCOUNTRY}_{i}+$

$$
+\Sigma_{\mathrm{j}=1 \ldots \mathrm{m}} \eta_{\mathrm{j}} \text { DSCIFIELD }_{\mathrm{j}}+\epsilon_{3}
$$

where $P$ is observed only when EUPART $>0 ; n=$ number of countries $=10$ and $\mathrm{m}=$ scientific fields categories 8 .

\footnotetext{
32 The dummy variables for The Netheriands, Demmark and Naturald Medicine universities are not included in Eq. 2 because the related universities have al ways probability 1 .
} 
Table 10: Estimation results.

\begin{tabular}{|c|c|c|c|c|c|}
\hline & Toblt & $\begin{array}{c}\text { Aestricted } \\
\text { Probint }\end{array}$ & Probyt & $\begin{array}{l}\text { Restrictiod } \\
\text { Truncited }\end{array}$ & Trumbregad \\
\hline LIL & $-49,46$ & $-137,08$ & -77.18 & -54672 & -34995 \\
\hline Consitanat & $-1+312(01)^{6}$ & $1.168(.00)^{*}$ & $4333(80)$ & $3.316(.00)^{*}:$ & $-1,552$ como \\
\hline DrithIN & Q.948 $(.00)^{3}$ & & (0. $197(19)$ & $x_{1}$ & $0.888(0.00)^{-7}$ \\
\hline Ind $\mathrm{LAO}$ & $0.560100)^{*}$ & & $0.321(.00)^{*}$ & & $0.498(.00)^{*}$ \\
\hline DCOUNRI & - & & $=3$ & $\therefore$ & \\
\hline Beligturini & $0.769(00)^{\circ}$ & & $-3.961(94)$ & & $0.853(00)^{*}$ \\
\hline Derumaris & $0.78 \mathrm{E}-1.84)$ & & $\div$ & & $-0.112(70)$ \\
\hline Firainitife & $10.522(00)$ & & $.3 .958(.94)$ & & $-0.646(.00)^{14}$ \\
\hline Germatay & $-0.8090(100) *$ & $\therefore$ & $4004(294)$ & & $-0.707(0.00)^{\text {sid }}$ \\
\hline Gropere & $0,706(.01))^{14}$ & & $2.777(.96)$ & & $0.293(20)$ \\
\hline Italy & $0.45 \times 1023^{\circ}$ & & $-3.654(95)$ & & $-0.595(00)^{6}$ \\
\hline Irelardid & $0.950(01)^{46}$ & & $-4.280(94)$ & & $1.39(000)^{16}$ \\
\hline 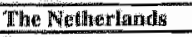 & (0.18E-1(95) & & 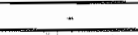 & & $-0.283(.25)$ \\
\hline Partw㳗a & $0,312(29)$ & & $3.997(94)$ & & $0.3466(17)$ \\
\hline Songin & $0.852(.00)^{4}$ & & $4.465(94)$ & & $-0.860(00)^{*}$ \\
\hline Unilged Kingdam & $\div$ & & $4.036(.54)$ & & - \\
\hline \multicolumn{6}{|l|}{ DSCITTELD } \\
\hline 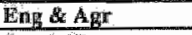 & $0.804(.00)^{*}$ & & $-3.653(95)$ & $\because$ & $0.930100 \%$ \\
\hline Soc He Hum & $-0.844(00)$ & & $5067(93)$ & & $0.100(68)$ \\
\hline Wat \& dad & $-0.318(24)$ & & - & & $0.313(.93)$ \\
\hline Wh-seldet:ine & $0.460-1(85)$ & & $-3.677 .95 \mathrm{j}$ & & $0.90 \mathrm{E}-1.4)$ \\
\hline Alix-technienal : & $0.952(.100)^{4 * 1 \%}$ & & $-3.329(95)$ & $\therefore$ & $0.924(00)^{5}$ \\
\hline 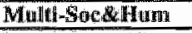 & $-0.124(.58)$ & & $4.240(94)$ & & $0.87 \mathrm{E} \times 1(61)$ \\
\hline Mullu-Sodentatife & $0.192(.26)$ & & $-3.896(94)$ & & $-0,137(29)$ \\
\hline 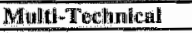 & $0.305(101)$ & & $-3.798(94)$ & & $0.331(001)^{6}$ \\
\hline Huif d liget jolmary & 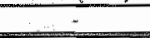 & & $.602(95)$ & & - \\
\hline
\end{tabular}

Non linear Probit. Dependent variable: Binary. Number Obs: 371.

Truncated regression. Dependent variable: Positive participation. Number Obs. 326 .

Coefficient significance between brackets. Marginal effec ts have the same significance of coefficients.

Taking equation (1) as the restricted model, and equations (2) and (3) together as the unrestricted model a likelihood ratio test (LLR) has been used to decide the best specification. As the LLR is equal to 136.66 , using a Chi-squared test with 21 degrees of freedom, the Tobit model was rejected at $99 \%$ probability.

The results of the estimation are shown in Table 10. In the Probit equation ${ }^{33}$ the scientific research productivity of the institution has a positive and significant effect on the probability of taking part in a EU R\&D co-operative project. While, the size of the university is not significant. None of the dummy variables for country and scientific field fixed effect have a significant value. These results highlight that the probability of taking part in a co-operative project financed by the EU depends

33 The Probit model correctly predicts $90 \%$ of the outcomes. 


\section{University Participation in Community Framework Programmes}

primarily on the scientific research productivity of the university. This is consistent with the results of Arora, David and Gambardella (1995), who showed that "in the case of publicly funded $R \& D$ projects, the scientific reputation of the research group, and in particular its weighted number of past publications, is the main factor influencing the probability of being selected. Moreover, these results seem to confirm that the Commission of the European Communities acted consistently with its stated policy objectives of awarding research founds primarily on grounds of scientific and technological excellence. ${ }^{34}$

Important differences in the influence and significance of the explanatory wariables are present in the result for the Truncated regression model. Both size and scientific research productivity have positive and significant coefficients. Consistent with the analysis in the previous section, the size effect -i.e. large universities tend to have more research groups and consequently tend to participate more in EUfunded R\&D co-operative projects-- has an important positive impact on the number of times a university participated in projects. Nonetheless, given the size, institutions with higher scientific research productivity are involved in more projects. Thus, while the probability of receiving a grant depends primarily on the scientific research productivity of the university, the participation in EU-funded $R \& D$ co-operative projects is affected by the size of the institution, and, given its size, by its scientific research productivity.

Major country fixed effects ${ }^{35}$ are present in the Truncated regression model. They can be subdivided in three sub-groups. First, the dummy variables for France, Germany, Italy and Spain have negative significant values. Given the size and scientific research performance, universities of these countries had a lower participation rate. Among the many possible explanations, the negative sign of these dummies could be related to the administrative and bureaucratic structure of their

\footnotetext{
${ }^{34}$ See for example Commission of the European Communities (1992a; p. 10).

15 The reference country is United Kingdom.
} 
national university system. In predominantly public financed systems the novelty of a competitive financing process has constrained the propensity to participate in EU R\&D projects. Although their university systems have a high quality, they are extremely bureaucratic and they are not used to external co-operation and competitive fund raising. Moreover, in particular in the case of France and Italy, a large portion of research is realised in public research organisations -e.g. CNRS (F), Max Planck Society (G), CNR (D), CSIC (S) and other public research centres- thus the research intensity of the university system tends to be lower than in other countries.

Second, the dummy variable for Ireland has positive and significant values. Other factors being equal, this indicates that Irish uniwersities had an advantage in the level of participation. This advantage can be interpreted as the result of the policy objectives of the Commission of the European Communities. As highlighted in Section 6.1, since the First Framework Programme, technological and economical convergence among the member states of the EU is a major policy aim. Especially from the Third Framework Programme a clear technological cohesion policy has been developed. Projects involving partners from less-favoured ${ }^{36}$ regions tend to be preferred to projects of the same quality but without member from less-developed regions. Some results show that probably the cohesion policy also has a positive influence on the participation of Greek universities, while the statistical evidence does not support the same conclusion for Portuguese universities.

Third, the dummy variable for Belgium has a positive and significant value. This indicates that, given the size and scientific research productivity, Belgian institutions succeeded in having a higher participation rate. A possible explanation is connected with the fact that the diffusion of information about how, were and when to apply for EU funds has taken a relatively long period of time. Belgian universities, benefit from their proximity, and have easier access to information and the possibility

\footnotetext{
${ }^{ \pm 0}$ In the last Council Regulation 93/2081/EEC Greece, Ireland and Portugal are still included as entire country in the less-favoured regions.
} 


\section{University Participation in Community Framework Prograwmes}

of face-to-face contacts with the Commission that increase their rate of success. Moreover, the localisation advantage has allowed them to enter early in the system and, consequently, to develop a "first entry advantage" that has enabled the creation of "barriers to entry" to the disadvantage of later comers. 3 ?

The dummy variable for scientific field has been used to control for the bias inherent in the way the number of publications was collected and to control for the different propensity in publishing. In the chosen specification, the technology oriented institutions have positive and significant values. ${ }^{38}$ The high value of their coefficients, on the top of the control meaning, may also indicate the existence of an advantage for technology oriented universities. However, with the available date, no conclusive observations can be made.

Fixed effects to account for the age of the university have also been included. Four dummies for the founding year have been used as proxies for the reputation effect $-i$. the older the university, the higher the reputation. Even if some evidences of a positive coefficient for the universities created in the interim between 1900 and 1945 were found, the test for the restricted against the unrestricted specification rejected the latter.

The results of the estimations of the two equation model presented above point to the existence of important difference in the significance of the factors when they are used to explain the probability of joining an EU-funded R\&D co-operative project or when they are used to explain the actual number of times a university participated in projects. Given other factors, such as differences among countries and scientific fields, the scientific research productivity of the university influences both

\footnotetext{
${ }^{37}$ For evidences on the phenomena in the UK context see Pike and Charles (1995; pp. 20-21)

3* Other more detailed specifications thave also been estimated. The coefficients of the institutions focused on medicine was sometimes significant and negative, indicating the presence of a overestimation of the scientific research productivity of these institutions. Also due to the small number of institutions with this characteristics, the test for the restricted against unrestricted specification did not allow to reject the null hypothesis. Thus, the 9 dummies specification have been chosen..
} 
the probability of taking part in an EU-funded R\&D co-operative project and the number of times a university participated in these projects, while the size is only significant when used to explain the latter.

Among other reasons, the different frequency in participation seems to be effected by the characteristics and behaviour of the universities, the behaviour of the funding agency, and the unintended consequences of the selection mechanisms. A possible interpretation of the results of the estimations points to the existence of a set of factors that seems to have a significant influence on the frequency of participation. First, as the large universities tend to have more research groups and, consequently, tend to have more participation in EU R\&D co-operative projects, the size distribution of the total population of European universities may influence the skewness of the distribution of participation. Second, the existence of important differences in scientific research productivity and the presence of cumulative and self-reinforcement mechanisms could explain why only a small number of universities have a high level of participation. Third, the differences in the national systems of higher education may have created different incentives for participating in EU R\&D projects. Fourth, the priorities of the EU research and development policy. especially as it concerns cohesion policy and technology orientation, may influence the frequency of the distribution of participation. Finally, the localisation and information advantage enjoyed by some institutions may have enabled the creation of barriers to entry, permitting them a higher participation rate.

\subsection{Conclusions}

A growing share of the income of universities in the $\mathbb{E U}$ countries is generated through research grants and contracts from both national agencies and the EU. In a context of increasing internationalisation of the research process and of rising importance of the research network, the participation in EU R\&D co-operative projects becomes an issue of crucial importance. 
This chapter has examined the determinants of university participation in $\mathrm{EU}$ R\&D projects. The analysis focused primarily on the selection process. Assuming that the process is driven by the "quality" principle and acknowledging the fact that "quality" is not observable, an interpretatiwe framework has been put forward. At its heart lies the importance of signalling mechanisms and the fact that the "quality" principle is intrinsically linked with various types of cumulative and selfreinforcement nechamisms. An econometric model has been developed to test for the relevance of different factors on both the probability of joining a EU-funded R\&D COoperative project and the actual number of times a university participated in these projects.

Evidence has been found to support the idea that scientific research productivity influences both the probability of joining a EU-funded R\&D cooperative project and the number of times an institution has participated in these projects, while the research size has a positive influence only on the latter. Given the size and scientific research productivity of the university, other factors are important to explain the different frequency in participation. Among many others, the following three seem to be consistent with the results of the estimations. First, the bureancratisation and the lack of practice in competitive found raising of the university system may have a negative influence on the propensity to take part in EU R\&D co-operative projects. Second, the existence of techno-economic convergence aims for the Framework Programmes tends to advantage the participation of institutions localised in less-favoured regions. Third, due to the winintended consequences of the selection mechanisms the early entrants in the system tend to have advantages in the repeated participation.

The estimations suggest that the scientific research performance is important in the EU decision process, but some evidence of the influence of the cohesion policy has been found too. The relevance given to the scientific research productivity originates, through the effect of cumulatiwe and self-reinforcement mechanisms, a repeated selection of a minority of high research quality institutions. This tends to 
maximise short-term research outcomes. Nonetheless, longer term goals are pursued when, following the guidelines of cohesion policy, uniwersities in less-favoured regions have at some advantage in participation. ${ }^{39}$ In this way, especially in the case of university research, positive knowledge spillovers may increase the research capabilities of those regions.

Finally, if the consequences of a selection based on the "quality principle" are reinforced by what has been called the first entry advantage, another short-term versus long-term trade-off should be considered. On the one hand, the characteristic of repeated selection may tend to reinforce the dominant research strategies (scientific paradigms and research programs), limiting research variety, and consequently decreasing the probability of scientific innovation. ${ }^{40}$ On the other hand, the standardisation of scientific knowledge enables an increase communication, and consequently a rise in the value of current science.

In the context of a policy perspective, a better understanding of the two tradeoffs and of the interactions between them is needed. Further analysis is needed to evaluate the implications for the university funding structure of an increasing reliance on EU funding. In particular, improved indicators of scientific research activity, such as publication by scientific fields, publications weighted by their impact factor, and more detailed information on the universities participating in EU-funded R\&D cooperative projects, for example at the level of the department, should be used.

\footnotetext{
${ }^{39}$ For the developinent of this problematique in the case of the BRITE-EURAM programme see Gambardella and Garcia-Fontes (1996).

to For the discussion of sclentific paradigms and research programs see respectively Kuhn (1970) and Lakatos (1970).
} 


\section{EU and National University Research Funding: The BRITE-EURAM Programme}

In the last chapter, emphasis was placed on university participation in Community Framework Programmes. As revealed, $88 \%$ of European universities have taken part at least once in a $R \& D$ project financed by the EU. In a context of national university research funding stagnation or reduction the advancement in budgetary scope of EU's research and development policy made this source of university research funding increasingly important. Although the incomes from EU contracts and services are small compared to total university funding, they represent an important share of the research funds due to specific services. In this chapter the relationships between EU and national university research funding will be analysed.

The expansion in budgetary scope of the EU's research and technological development policy has increased the need for a better understanding of the consistency between Community and national policies. Although the need for a closer integration of the RTD activities in Europe is clearly stated in the $4^{\text {th }}$ Framework Programme, ${ }^{2}$ no clear guidelines have been defined. The most common approach to the understanding of the relationships between $\mathrm{EU}$ and nationai science and technology policies has been based on the definition of boundaries between Community and member state RTD activities. The definition of the respective

\footnotetext{
See Chapter 5, Section 5.1.1 Table 1 for the figures in the UK case.

${ }^{2}$ For an analysis of current co-ordination actions see Commission of the European Communities (1994c)
} 


\section{EU and National University Research Funding}

domains is given by the principle of subsidiarity" that dictates that "the Community should take action on research only if the objectives can be better achieved by the Community than by the Member States acting on their own." To apply this principle, the objectives that can be better achieved by the Community, need to be clearly defined. One attempt to define the categories by which to restrict Commission funding activities has been done by the House of Lords, Select Committee on the European Communities (1990). Nonetheless, Dawid, Geuna and Steinmueller (1995), discussing the proposed categories, point out that one of the criteria for Commission actions requires that there would be added value in performing them at the Community rather than at the national level. However, the concept of 'added vallue" may carry a large set of meanings, leaving the definition of the limits of Community action unclear. Consequently, David, Geuna and Steinmueller, acknowledging that rigid boundaries between Community and member states research objectives cannot be drawn, highlight that the Community RTD policy can be better viewed as a political outcome. If research objectives of $\mathrm{EU}$ and national actions cannot be clearly separated, the funding priorities of EU RTD policies might diverge from the national funding priorities. This situation gives rise to a complex set of interactions between EU and national initiatives. For example, member states favouring different technological priorities can modify a funding initiative undertaken by the Community augmenting or subtracting national funds to specific technological fields. At the extreme is the case in which the member states substitutes EU funding for their owni.e. they subtract national funds from fields that have received EU funds.

The analysis of the interactions between EU and national research funding can be developed either at the country, technology or institution level. For the purpose of this chapter, the focus is on the latter. The relationships between EU and national university research funding are studied considering both the deliberate action of government in response to EU funding, and the unintended consequences related to the existence of two overlapping sources of research funds. The analysis is carried

\footnotetext{
${ }^{3}$ See, among others, Commission of the European Communities (1994b) and EIPA (1991) for a discussion of the subsidiarity principle.
} 
out at the level of the university department mainly because it allows one to capture the micro-mechanisms that can explain the conduct of the complete institution.

To obtain the required level of detail, a specific EU RTD programme (BRTTEEURAM) and a single country (in this case, the UK) had to be chosen. With regard to the EU programme selected, BRTTE-EURAM was chosen for the following reasons. First, the continuity present in the programme's aims and structure in the successive Framework Programmes allows a sufficiently long period of time to observe effects. Second, considering both the level of participation and funding for shared cost actions, BRITE-EURAM is the second most important EU programme. Third, as pointed out in Chapter 6, BRITE-EURAM is an extremely important source of HEIs funding. Finally, its sectoral orientation involves not only applied and development work, but also more basic research with industrial apphicability allowing for substantial contributions from universities. With regards to the country selection, the UK was chosen for two main reasons. First, as pointed out in Chapter 5 , the ratification of the Education Act (1988) led to profound modification within the university funding system in United Kingdom. Due to these changes, EU funding plays a larger and more important role, both directly -i.e. through an increase of the EU share of total HEIs research funding, and indirectly -i.e. through a series of cumulative and self-reinforcing mechanisms. Second, the new UK "market oriented" approach could be used as a blueprint by other continental systems, raising the importance of understanding its development and consequences.

The chapter is organised as follows. The first section describes the BRITEEURAM innovation system and examines the evolution of the its research programmes. Section 7.2 discusses university participation in BRITE-EURAM shared-cost projects. The study of the relationships between $\mathrm{EU}$ and national university research funding in the $U K$ for the institutions involved in the BRITEEURAM programmes is presented in Section 7.3. 
Table 1: Share of R\&D Expenditures by aims, $1992 .{ }^{4}$

\begin{tabular}{|l|c|c|c|c|}
\hline Aims & \multicolumn{2}{|c|}{ National } & \multicolumn{2}{c|}{ EU Frameworks } \\
\hline & Col $\%$ & Row $\%$ & Col \% & Row $\%$ \\
\hline Fundantental Research & 53,0 & 94,9 & 8,9 & 1,2 \\
\hline Support to Public Policy & 21,3 & 92,3 & 24,5 & 7,7 \\
\hline Industrial Innowation & 7,9 & 81,0 & 15,3 & 11,3 \\
\hline Spatial & 8,4 & 52,3 & 0,0 & 0,0 \\
\hline Aeronautic & 2,5 & 97,2 & 1,0 & 2,8 \\
\hline Telecommunications & 3,7 & 51,0 & 38,1 & 38,7 \\
\hline Nuclear & 3,1 & 77,8 & 12,2 & 22,2 \\
\hline Total & 100 & 84,3 & 100 & 6.1 \\
\hline MECUs & \multicolumn{2}{|c|}{38,653} & \multicolumn{3}{|c}{2,812} \\
\hline
\end{tabular}

Source: OST (1996).

The row of does not sum to 100 due to the exclusion of the other 3 European modalities of R\&D co-operation

\subsection{The BRITE-EURAM Innovation System}

In 1992 non-military $R \& D$ expenditures in the EU countries accounted for 45,866 MECUs. Of these, 38,653 were realised at the national level and 7,213 at the European level. Four institutional modalities exist for $R \& D$ co-operation at the European level: the EU Framework Programme (2,812 MECUs), the EUREKA programme (704 MECUs), the European Space Agency (2,967 MECUs) and the large scientific research institutions for basic research such as CERN and ESRF (856 MECUs). ${ }^{5}$ Table 1 illustrates the break down by aims of national and EU R\&D expenditures. It shows that the EU Framework Programmes are responsible for $6.1 \%$ of total non-military R\&D expenditures and for $11.3 \%$ of the expenditures in support of Industrial Innovation. The BRITE-EURAM programme is the source of almost the totality of these funds.

4 Environment, agriculture, transport and infrastructure are included in Support to Public Policy. Nuclear research tinanced by the EU Frameworks is mainly carried out in the Joint research Centres.

s The source of these figures are estimations made by the OST (1996). 


\section{EU and National University Research Funding}

Since 1989 three BRTTE-EURAM programmes have been financed by the Commission of the European Communities. ${ }^{6}$ The overall objective of these programmes is the improvement of the competitiveness of European manufacturing

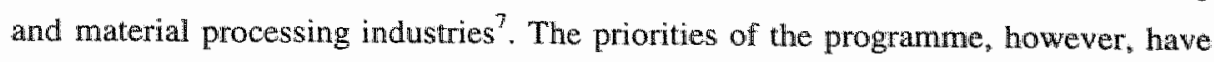
evolved according to the European economic situation. The passage from the First to the Third Framework Programme saw the relevance of materials-related technologies diminished and the importance of the technologies for transport mean angmented. The BRITE-EURAM programmes apply a transwersal approach to the innovation process. Rather than focusing their support on a specific type of technology or on a specific industrial sector, they concentrate their intervention at the level of the production technologies in the broad area of material processing and manufacturing technologies. For example, among the projects financed there are some carrying on research on chemical process but not on chemical products or, alternatively, on electrical materials but not electrical equipment. The European economic situation in the 1980s can explain why this approach has been chosen. On the one hand, to reach a higher level of technological cohesion between the less favoured regions of the EU, such as Greece and Portugal, and the more advanced, such as Germany and the UK, the Community action had to focus not only on edge technologies but also on more traditional ones. Moreover, the focus on production technologies allows a general upgrading of the industrial structure of less developed regions through the development of knowledge that can be transferred to the production of other products. On the other hand, the large penetration of Japanese and, to a lesser extent, American products during the 1980s was interpreted as an evidence of the existence of lower cost production processes. Hence, there was a need to stimulate process innovations able to lower European manufacturing production costs.

\footnotetext{
6 See Section 7. I. If for the description of their structure and ains.

Pixarmaceuticals and electronics are excluded because the research in these sectors is the focus of other Community programmes.
} 
Looking at the projects financed, ${ }^{8}$ it is possible to highlight the participation of firms from most industrial sectors. Nonetheless, automobile, machine tool/mechanical engineering, materials processing, aeronautics, electrical materials and civil engineering can be considered the core sectors. At the technology level, particular emphasis has been put on automatism and informatics, design, structural material technologies, and functional material technologies. One must also bear in mind that the most important disciplines are applied mathematics and informatics, applied physics, and material science.

An heterogeneous set of participants took part into the BRITE-EURAM shared-cost projects. In the first and second programmes, big companies are the largest single type of institution in terms of both participation and funding. Small and medium enterprises have level of participation similar to the one of big companies, but their funding is lower, although higher than the one for the total of the Frameworks Programmes. The large participation of SMEs owes much to the special incentives to their participation present in the BRITE-EURAM programmes and to the large presence of SMEs in sectors like textile/clothing and material processing. As discussed below in Section 7.2, even if the BRITE-EURAM programmes have a strong industrial orientation, HEIs are playing a relatively important role accounting for about one quarter of the total participation and one fifth of total funding. Their contribution to the projects has been mainly in terms of basic research with industrial applicability.

Given the technological and sectoral foci of the BRITE-EURAM programmes, the distribution of participation by countries mirrors the industrial strengths in manufacturing and materials processing of the European countries. Germany is the country with the highest level of participation, followed by France

\footnotetext{
\$ For a detalled ewaluation of the progrmmmes BRTIE, EURAM, and BRITE-EURAM I see Commission of the European Communities (1997b, 1996.1993d).

Sae Table 2, Chapter 6 for the distribution of participation and funding by organisational type in the two Frameworlik Programmes.
} 
and the UK. In particular, Germany tend to have a strong involvement in automobile, machine tools and chemistry; France appear to have an edge in automobile, aeronautics and instruments; the UK is especially present in civil engineering and electricity/electronics.

\subsection{The BRITE-EURAM Research Programmes}

The first BRITE-EURAM programme was built upon the experience and achievements of both BRTTE (Basic Research in Industrial Technologies for Europe) and EURAM (European Research on Advanced Moterials) programmes. Under BRTTE (1985-1988), 215 shared-cost research projects have been developed. The Commission of the European Communities allocated to it public funds of about 180 MECUs. The most relevant aim of the programme was to develop the applications of new technologies and new materials in traditional industrial sectors During the same span of time under the EURAM (1986-1989) programme, the Commission of the European Communities approved 91 projects, totalling $30 \mathrm{MECU}$. The programme was supported with the goal of stimulating the development of research in new materials (Commission of the European Communitios, 1992c: p.65).

The BRITE-EURAM I (1989-1992) programme (henceforth B-E I) is hence the aggregation and extension of these two programmes. It was approved by the Council of Ministers on 14 Murch 1989 and budgeted in the Second Framework Programme for about $500 \mathrm{MECUs.} \mathrm{The} \mathrm{main} \mathrm{aim} \mathrm{of} \mathrm{this} 4$-year programme was to improve the competitiveness of European manufacturing and material processing industries in the world market. Also relevant were the following strategic objectives: (i) to foster trans-frontier collaboration in strategic industrial research, (ii) to support the transfer of technology across Community frontiers and between sectors, particularly those with many SMEs, and (iii) to underpin the process of European cohesion (Commission of the European Communities, 1993c: pp.9-16). Even if the programme was devoted to pre competitive research, it was characterised, more than the previous two, by a market-oriented activity. The Programme covered five R\&D areas: (1) Advanced Materials Technology; (2) Design Methodology and Assurance 


\section{EU and National University Research Funding}

for Products and Processes; (3) Application of Manufacturing Technologies; (4) Technologies for Manufacturing Processes; (5) Aeronautics. To assist SMEs the programme included not only shared-cost research contracts, but also concerted actions and feasibility awards. ${ }^{10}$ The emphasis on SMEs and the more marketoriented kind of research supported distinguish the B-E I programme from the two previous one. In the four years life span of the B-E I programme, about 1000 different institutions took part in at least one of the 350 shared-costs collaborative R\&D projects which have been financed by the Commission of the European Communities."

On 9 September 1991 the Industrial and Material Technology programme -BRITE-EURAM II-- (henceforth B-E II) was approved, within the Third Framework Programme, for the period 1991-1994 by the Council of Ministers. The operating budget of the programme was approximately 670 MECUs. This programme resulted from the merging of the two programmes B-E I and Raw Materials and Recycling (1990-1992). ${ }^{12}$ Following the previous programme, the basis of B-E III was the revitalisation of European manufacturing industry. Its main aims were: (i) to increase the competitiveness of European industry in the face of strong international challenges, particularly in strategic sectors of advanced technology; (ii) to strengthen European economic and social cohesion consistent with the pursuit of scientific and technical excellence; (iii) to increase the implementation of advanced technologies by SMEs; (iv) to increase the involvement of manufacturing SMEs in European RTD thereby developing links with other enterprises (Commission of the European

\footnotetext{
1* Concerted Actions are projects to support the co-ordination of broad-based, pan-European collaborative research activities in promising new technologies with the benefit of real added value as a result of cross-border collaboration. "The Commission supports the co-ordination costs, but not the research cost. Feasibility Award is a special type of contracts, available only to SMEs, that covers up to $75 \%$ of the costs of research undertaken within nine months (subject to a maximum of 30,000 ECU) to establish the feasibility of a concept, process or material for a collaborative BRITE-EURAM project.
}

"See Appendix l: Network Formation and the Main Hub for the analysis of participation.

12 During the two years of life of the RAW programme, 69 shared-cost research projects for about 23 MECUs were financed. 
Communities, $1992 \mathrm{~d}$ : pp.7-11). Eventually, the programme was characterised by the focus on advanced technology, the relevance given to the process of European economic and social cohesion and by the particular support for the SMEs' participation. $^{13}$

The programme included three main R\&D areas they are: (1) Materials and Raw Materials with the two sub-areas of Raw Materials and Recycling, and New and Improved Materials and their Processing; (2) Design and Manufacturing with the wo sub-areas of Design, and Manufacturing and Engineering; (3) Aeronautics. Industrial enterprises, universities, research organisations and other institutions have taken part into the programme through five schemes of support. They are: (1) Shared-cost collaborative research projects. In particular, about $90 \%$ of the available Community research budget was ascribed to the two sub-categories Industrial Research ( $80 \%$ ) and Focused Fundamental Research (10\%); (2) Concerted Actions already implemented in B-E I; (3) Accompanying Measures, among which the previously mentioned Feasibility Awards were particularly important; (4) Co-operative Research Action for Technology; and (5) Targeted Research Actions." Up to March 1994, about 1050 different institutions took part in at least one of the 323 shared-cost collaborative R\&D project financed by the Commission of the European Communities. ${ }^{15}$

Of particular note from the previous description is the continuity present between the two BRITE-EURAM programmes. Indeed, B-E II can be seen as a further step in the process of definition of a European programme. Due also to the Maastricht Treaty and to the feed-back from the previous programme, B-E II turned

13 The Co-operative Research Action for Technology (CRAFT) was designed to provide enterprises, especially SMEs not having their own research facilities, with the possibility to contract outside research institutes to carry out research on their behalf (ibidem: p.13).

14 Targeted Research Actions were focused to specific subjects of common interest - a.g. environmentally friendly technologies and flexible and clean manufacturing. They supported industrial research projects that may be grouped together and be subject to special co-ordiration to ensure synergy between the separate projects.

Is See Appendix I: Network Formation and the Main Hub for the analysis of participation. 
out to be a programme with a clearer stiategic orientation and an improved and enlarged variety of schemes of support.

The current research and technological development programme in the field of industrial and materialls technologies BRITE-EURAM III (1994-1998) (henceforth B-E III) was approved by the Council of Ministers on 27 July 1994. The operating budget of the programme was set at about 1,500 MECUs. As with other programmes, the concern with the competitive position of the European manufacturing industry is at the heart of the programme. In particular, competitiveness is seen as the most effective means of maintaining and even increasing employment. Confronted with economic recession and the increased level of pollution, the programme hopes to stimulate the industry's capacity to "develop technology for human-centred production system taking account of human factors and based on clean technologies" (Commission of the European Communities, 1994d: p.7). Three specific objectives are identified: (i) "in the short term, priority should be assigned to research for the adaptation of existing technologies, or for the development of new technologies ... particularly in sectors where the level of technology is lower; SMEs in these sectors account for a large proportion of European industry"; (ii) "in the medium term, research will focus on industries which are already developing innovative technologies and strategies allowing better use of human resources while endeawouring to reduce the adverse environmental impact of production"; (iii) "in the long term, research will focus on new technologies for the production and the desigm of products which allow new industries or markets to be created in a context of sustainable growth" (ibidem: p.8).

As for B-E T, the programme is subdivided into three main R\&D areas: (1) Production Technologies for Future Industries; (2) Technologies for Product Innovation; (3) Technologies for Transport Means. While the first two technical areas, with different name and different sub-classes, are similar to the first two areas of B-E II, the third one has been broadened to include not only aeronautics but also other technologies for transport means. The programme is implemented through the 


\section{EU and National University Research Funding}

same schemes of support used in B-E $\mathbb{A}$. The only new tool is the Pre-Normative Research Project, which is linked to the fulfiment of the general goal of the Fourth Framework Programme of supporting the other Community policies through prenormative research. Finally, the observation made above for the evolution of B-E II in comparison with B-E $I$, can be also made for the new programme versus the previous one. The various BRTTE-EURAM programmes are the result of a process. of evolution driven by the change of external economic and non-economic factors. The various modifications, however, take place without affecting a group of consolidated features of what can be defined as the BRITE-EURAM system of innovation.

\subsection{University Participation in BRITE-EURAM}

The following analysis focuses on the contracts which have been signed between 1989 and $1^{\text {st }}$ March 1994 in the BRTTE-EURAM I and BRITE-EURAM I (henceforth in general $B-E$ ) programmes. ${ }^{16}$ The data regarding the contract signed in the B-E programmes have been provided by the DG XII (Directorate-Gencral Science, Research and Development) of the Commission of the European Communities." The contract signed were respectively 352 , with 1783 participants, in the Second Framework (SF) and 703, with 2056 participants, 18 in the Third Framework (TF). For each contract available information includted the title of the project, the duration of the contract, the cost and EU contribution, the participants names and locations, and the participants position in the network (main contractor, secondary contractor, etc.). Unfortunately, information such as the type of institution

\footnotetext{
If In Appendix it an analysis of the metwork characteristics of the BRTEE-EURAM programmes is presented. For an analysis of the dynamics of research network in BRITE-EURAM see Garcia-Fontes and Geuna (1998).

${ }^{17}$ The contracts signed under RAW and AERONAUTTCS are not included.

"Here the participants" mumber account for any type of contractor including also instilutions involved in time/contribution amendments. Instead, in the statistics presented in the following analysis only contractors involved in shared-cosi actions are considered as participants.
} 
(large enterprise, small-medium enterprise, unversify, research organisation, etc.) and. its size were not released. Besides, due to their peculiarities, contracts such feasibility award, first step CRAFT, concerted action; other "Iike-grant' action, and time amendments have been excluded from the data-set, while the institutions involved in contribution amendments have been considered as normal contractors taking part in the network. The data-set constructed in this way takes into account about $90 \%$ of the contracts (of those involving shared-cost actions) signed during the SF and the $80 \%$ of the ones signed during the $\mathrm{TF}{ }^{19}$

Table 1. Participants in the two frameworks by organisational type.

\begin{tabular}{|l|c|c|c|}
\hline Organisational Type & $2^{\text {nd }}$ Framework & $3^{\text {rd }}$ Framework & Total \\
\hline InE Is & $47626.8 \%$ & $44126.5 \%$ & $91626.7 \%$ \\
\hline Other Insthtutions & $130273.2 \%$ & $122173.5 \%$ & $252373.3 \%$ \\
\hline TOTAL & 1778 & 1662 & 3440 \\
\hline
\end{tabular}

Source: Elaboration of CEC data.

In relation to the rype of cost reimbursement, the participants can be classified into two organisational type. The community reimburses up to $50 \%$ of the project actual costs to companies or institutes that operate a project costing system. Universities, higher education establishments and similar non-commercial bodies receive up to $100 \%$ of the additional costs.

Table 2: Main contractor figure by organisational type.

\begin{tabular}{|c|c|c|c|}
\hline Organicational Type & $2^{\text {nat }}$ Framework & $3^{\text {trd }}$ Framework & Total \\
\hline HEIS & $7220.6 \%$ & $60 \quad 18.6 \%$ & $132 \quad 19.6 \%$ \\
\hline Other Ingtitutons & $27879.4 \%$ & $26381.4 \%$ & $54180.4 \%$ \\
\hline TOTAL & 350 & 323 & 673 \\
\hline
\end{tabular}

Sounce: Elaboration of $\mathrm{CEC}$ data.

As shown in Table 1 and Table 2 , the total population of 3,440 participants is distributed among 637 contracts, with 350 contracts in the SF and 323 in the TF. If

\footnotetext{
${ }^{19}$ The data for the Third Framework where only available up to the 1 march 1994, the $80 \%$ represent an estimate of the contracts signed up to that date.
} 


\section{EU and National University Research Funding}

one looks at the total population, HEIs, with a bit more than one fourth of the participation, play quite a relevant role both in the SF and in the TF. While, examining the main contractor figure, their relevance is less evident and their share decreases from the SF to the TF, indicating that industry plays a more important trole in establishing the research effort. Table 3 shows the data concerning the EU contribution. While in the SF the share of EU contribution to HEIs and the share of their participation are about the same value, in the TF they are different due to a decrease in the EU contribution of about 4 points.

Table 3: EU contribution in the two frameworks by organisational type. (in ECU)

\begin{tabular}{|l|c|c|c|}
\hline Organisational Type & $2^{\text {in }}$ Framework & $3^{\text {ra }}$ Framework & Total \\
\hline HEIs & $101,431,83527 \%$ & $87,581,446,23 \%$ & $189,013,28126 \%$ \\
\hline Other Institutions & $275,379,91473 \%$ & $292,722,066 \quad 77 \%$ & $568,101,98074 \%$ \\
\hline TOTAL & $376,811,749$ & $380,303,512$ & $757,276,261$ \\
\hline
\end{tabular}

Source: Elaboration of CEC data.

To better understand the role

Figute i

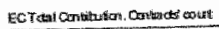

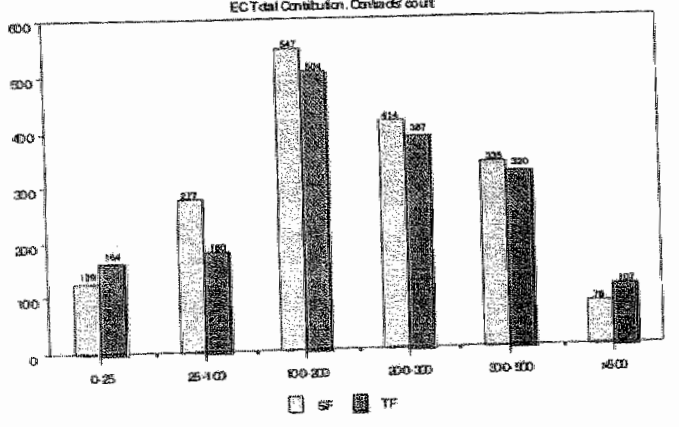
played by HEIs in the B-E programmes, the EU contribution structure is analysed in more detail. First, the variable EU contribution has been subdivided into six categories: (1) $[0-25,000] \mathrm{ECU} ;$ (2) 125,000 $\begin{array}{lll}100,000] \quad \text { ECU; } & \text { (3) } & 1100,000 \\ 200,000] \mathrm{ECU} & \text { (4) } & {[200,000} \\ 300,000] \mathrm{ECU} ; & \text { (5) } & {[300,000-}\end{array}$ $500,0001 \mathrm{ECU}$; (6) $>500,000$ ECU. Then, the contracts (in this case one each participant) have been classified in relation to these classes. Figure 1 shows the allocation of $\mathbb{E}$ Total contribution, with each bar representing the number of contracts present in that class. The distribution is very similar in the two frameworks. 


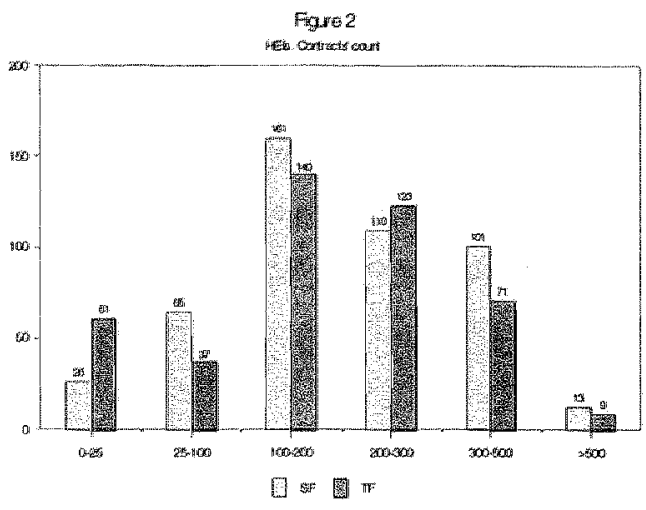

As expected, the TF usually exhibits lower values than the SF; only in the first and last category the TF has more contracts.

Turning to Figure 2 (allocation of EU contribution to HEIs), one can attest that, going from the SF to the TF, a much larger number of HEIs have participated in projects with a contribution smaller than $25,000 \mathrm{ECU}$. The number of contracts in the first category is more than double. Minor changes have also append in other categories: HEIs decreased their presence in the fifth and sixth categories of contracts and increased their participation in project of the fourth class. Figure 3

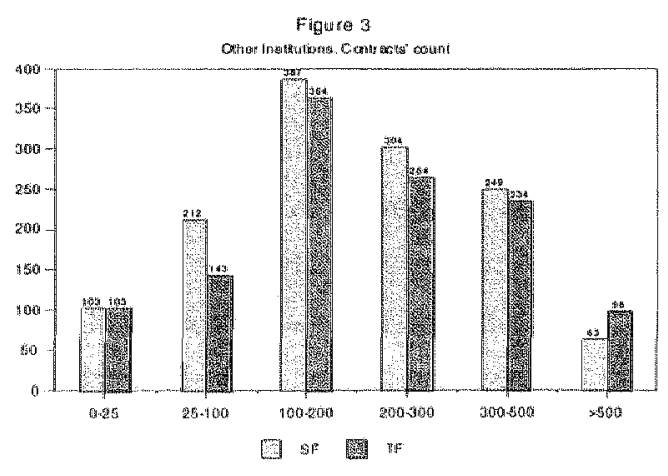

presents the allocation of EU contribution to institutions different from HEIs. Enterprises and research organisations have decreased their participation in low budget contract (class 2 has lost a relewant number of contracts) and they have increased their presence in the top class. Overall, comparing the participation in contracts of HEIs and other institutions, it can be underscored that, although HEIs had a lower level of participation in the high categories, their presence in contracts with a EU contribution higher than 200,000 ECU (classes 4,5 and 6) sitayed about unchanged, $47 \%$ and $46 \%$ respectively in the Second and in the Third Framework Programmes. 
Comparing participation and funding figures for HEIs in B-E with the total distribution of participation and funding in the second and third framework programmes, ${ }^{20}$ it can be pointed out that the B-E programmes are characterised by a lower level of HEIs participation than the total of all Framework programmes. Nonetheless, the share of HEI funding in B-E remains above the HEIs' share in the total of all Framework programmes. Furthernore, there is a smaller gap between the share of participation by number (Table 1) and by funding (Table 3) in B-E relative to overall EU funding of research programmes. Therefore, even if HEIs have lost share, they remained strong players in the B-E programmes compared to the other programmes.

\subsection{The Participation of UK Universities in BRITE-EURAM}

To analyse the relationships between EU and national university research funding the case of the United Kingdom is considered. ${ }^{21}$ The total participation of UK institutions was respectively $17.5 \%$ in the $\mathrm{SF}$ and $15.1 \%$ in the $\mathrm{TF}_{\text {. }}$ Table 4 shows the participation of UK institutions in the B-E programmes. The share of HEls participation, almost equal in the two Frameworks $(35.7 \%-35.8 \%)$, is about 9 points higher than the aggregate value. ${ }^{22}$ Only a sub-set of the 133 institutions of higher education in the UK (International Handbook of Universities, 1993) has taken part in the B-E programmes. Forty-nine different institutions account for the 201 times UK HEIs participated in projects. Moreover, only four new institutions appear on the roster of HEIs supported by the TF, while fourteen institutions that were in the $\mathrm{SF}$ did not participate in the TF, leaving 31 institutions that took part in both Framework

\footnotetext{
${ }^{2 *}$ See Table 2, Chapter 6 for the distribution of participation and funding by organisationat type in the two Framework Programmes.

"For a broad analysis of the impact of European Community policies upon science and technology in the United Kingdom see Georghiou er at. (1993). For the analysis of the additionality issue in the UK context see David, Geuna and Steinmueller (1995).
}

${ }^{22}$ See Table 1 HEIs share. 
Programmes. Of the 49 different HEls patticipating in either Framework, 40 are "old" universities. In other words, ex-polytechnics and other higher education institutions rarely succeeded in getting funds from the EU. ${ }^{23}$ of the 40 'old' universities, 26 took part in both frameworks, while 11 participated only to the SF and 3 to the TF. In total, they account for 174 participation. Finally, if one considers the University of London, rather than the different colleges which form it, one can find 36 "old" university participants in at least one of the B-E programmes, representing $68 \%$ of the total population of "old' UK unversities.

Table 4: Participation of UK instifutions.

\begin{tabular}{|l|c|c|c|}
\hline & $2^{\text {nd }}$ Framework & $3^{\text {rd }}$ Framework & Total \\
\hline Tot. Participation & 311 & 251 & 562 \\
\hline HEIs Participation & 111 & 90 & 201 \\
\hline Number of HEIs & 45 & 35 & 49 \\
\hline "Old" Uniwersities & 37 & 29 & 40 \\
\hline
\end{tabular}

Source: Elaboration of CEC datat.

To understand the possible relationships between the EU and the national university research funding, a field study has been carried out. In particular, due to the new market oriented internal structure of the university, it is most relevant to focus the analysis on the department/research centre. Indeed, to shed light on the interaction among different funding sources, the mechanisms at work at the department level have to be studied. Nevertheless, the university as a whole remains the main actor, the behaviour of which is explained here. The focus on the research centre is then justified, not by the interest of explaining the functioning of the department itself, but by the need to identify the micro-mechanisms that can explain the conduct of the complete institution.

\footnotetext{
2. An intriguing question is to understand if these institutions do not bave the competence/quality for applying to the BU or if they "strategically" decide not to apply"
} 


\section{EU and National University Research Funding}

The following analysis focuses on those departments involved in the two B-E programmes. Only Materials Technology, Material Science and Engineering departments have been considered. ${ }^{24}$ It can be maintained that each university has only one of the three departments. Thus, the number of 'old' universities can be considered as the population of reference. A subusample of 20 departments has been contacted, the heads of the departments have been interviewed via telephone, and asked to fill in a questionnaire. ${ }^{25}$ Of these 20 departments, 16 have responded to both the telephone interview and the written survey, representing the $40 \%$ of the "old" universities present in the B-E programmes and accounting for $55 \%$ of the times 'old' universities (95) have participated into a contract. It is thus a meaningfully large sample. The original sample of 20 departments has been selected according to the financial dimension of their university (11 Large, 6 Medium and 3 Small) and their regional location (15 England, 3 Scotland and 2 Wales). The 16 departments that have responded belong to 8 Large, 6 Medium and $2 \mathrm{Small}$ universities; 13 of them are located in England, 2 in Wales and 1 in Scotland.

The survey addresses the changes in the funding structure of the department in the period 1990-1993 and the situation in 1994. The questions require to rate on a scale of different importance (from 1: Unimportant to 5: Extremely Important) a predefined set of alternatives. The questionnaire is structured in a way that allows to classify the various departments in relation to their type of research involvement (Question 1) and to their financial dimension (Question 5). All the departments have high research intensity. The funds from Research Council, EU contracts and services and Industry contracts and services tend to be always extremely important, the are valued on average, $4.9,4.5$ and 4.2 respectively. Only one department assesses the three sources of funds at a medium importance. The relevance of Fees for the total funding of the department can be used as a proxy for teaching orientation. On average, Fees reports a value of about 3.7 , that is to say, of medium importance. $50 \%$

24 These are the three research units that have taken part most frequently into B-E programmes.

2s See the arnexed telephone questions and questionmaire (Appendix 2). 
of the departments regard Fees as medium or less important for the total funding of the department, confirming the strong research orientation of the sample considered. The average budget of the respondents was about $12.4 \mathrm{M}$ with a lowest extreme of

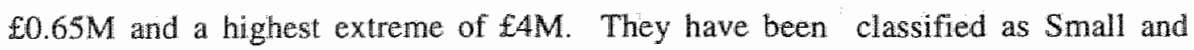
Medium Departments (SMDs) if their annual budget was below than $£ 2.9 \mathrm{M}$ and as Large Deparment (IDs) otherwise.

The aim of the survey is to assess the existence of relationships between $\mathrm{EU}$ and national university research funding. In particular, the telephone interviews and the second, third and fourth questions of the questionnaire try to identify the presence of positive or negative dependence between the two sources of funds in terms of cumulative and serf-reinforcement phenomena and substitution effect. The following observations are based on the responses of these 16 surveyed departments.

First, the presence of cumulative and self-reinforcenent phenomena in the process of funds raising emerges clearly from both interviews and questionnaires. These are due to the so-called Matthew effect. ${ }^{26}$ Research groups that are successful in finding external funding for their research have a higher probability of producing publishable research, which improves their probability of getting funds in the future. When this concept is applied to the EU funding process, it is possible to highlight the presence of a specific "path dependent" additional mechanism at work. Success in obtaining funds from the EU enhances the ability to raise research funds in the future from both EU and Government sounces. This is due to four micro-mechanisms:

1. The level of equipment funding that the department receives from the central administration of the university depends in part upon the value of their

\footnotetext{
${ }^{26}$ For un economic analysis of the Mathew effect and its implications for resource allocation see Arots. David and Gambardellin (1995). Dasgupa and David (1987, 1994) and David (1994). For the original delinition in the sociology of science see Merton (1968). For an early aralysis on the relationships between scientific productivity and cumulative effect see De Solla Price (1963, 1976). In Chapter 6. Section 6.2 has been introduced an interpret ative framework in which cumulative and selfresuforoment phenomena anfluencing the alocation of funds to universities at the European level.
} 


\section{EU and National University Reseanch Fuding}

external research contracts. EU contracts have a particularly significant weight.

2. The ability to obtain EU funds is regarded as critical for the assignment of high rank in the UK's Research Assessment Exercise. Thus, it affects the share of funds for research received by the university from the Exchequer Grant and the Research Council.

3. The international character of the competition for EU funds, and therefore the high quality of the participants, improves the reputation of the wimners. Obtaining EU funds is thus reputation-building, which increases the probability that winning institutions will receive future funding both from the EU and Research Council.

4. Network creation via EU co-operative projects enables the department/university to form a stable co-operation with industrial partners. which provides a means to generate projects which increase future funding

The relevance of these micro-mechanisms is confirmed by the results of the survey. Specifically, EU funds receipts were judged to have a positive infuence on EU sources by $79 \%$ of the respondents, while $57 \%$ of the respondents also found a positive effect on receipts from industrial funding. In the case of Government Funds the impact is generally a bit less important. It is perhaps because the Research Assessment Exercise is a relatively novel enterprise, as are the intemal universily negotiations about the departmental distribution of funds received by the university. Thus only $36 \%$ of the responses note a positive influence, while $64 \%$ clam there was no influence on UK Government funding.

Second, when the existence of substitution effects - $-i . \%$ an increase of funds from one source is linked to a decrease of funds from another-is studied, $63 \%$ of all the responses indicate no such substitution. However, if one breaks down the responses by university and by department size, it can be shown that: 


\section{EU and National University Research Funding}

- $57 \%$ of the SMDs in small and medium universities observe some form of substitution;

- $71 \%$ of the LDs in lange universities do not notice any form of substitution.

Thus, the funding policy followed by the government appears to be influenced by the size of the department and university, implying the selective application of substitution in a manner that favours the already major research performers.

Third, the impact of government funding policy, and its interaction with the EU funding system, can be better understood when the process of diversification -i.e. moving from fewer main sources of funds to more and different funding sources-is considered. In particular the finding of the survey allow the following observations:

- Overall, $56 \%$ of the answers indicate an increase in its annual budget, while no one indicates a decrease. However, a somewhat smaller number of the SMDs indicates increases rather than no change.

- There has been an increase of EU funds in all the departments surveyed. Its growth is particularly important for SMDs.

- The Research Council funds have generally tended to decrease, but the effect: is more notable among SMDs.

- Industry funds have only undergone minor changes or have decreased mainly in SMDs in small and medium universities.

- The Exchequer Grant has been cut in all the departments without distinction as to the dimension of the department budgets.

If the department budget size and university budget size are respectively taken as proxy for "quality' and political power, it can be maintained that, on the one hand, UK government university research funding tends to be additional to EU funding mainly for a small group of high quality/politically strong departments/universities. On the other hand, SMDs, especially when located in small and medium universities, rely, for their research money, to a larger extent on EU funds which, although highly 
concentrated, are more broadly distributed across universities. Furthermore, due to the recent economic recession, business enterprises have reduced external funds for research, and high quality deparments or universities with long lasting industrial relationships have strengthened their advantage in obtaining contract and grants from industry.

\subsection{Conclusions}

The research and development policy of the EU appear to increasingly affect the implementation of national policies. Given the partial overlapping of EU and national actions, a better understanding of their interactions is needed. The analysis of the relationships between $\mathrm{EU}$ and national research funding can be developed at different: levels of aggregation. Here the interactions between the two sources of funds have been analysed at the level of the university. Although the income from EU contracts and services accounts only for a small portion of total university funding, their relevance becomes much more evident when compared with a similar source of funds $-e . g$. research grants and contracts of the Research Councils. ${ }^{27}$

Three main conclusions can be drawn from the analysis of the relationships between EU and national university research funding in the UK context. First, the group of universities involved in the B-E programmes tend to be quite large in comparison to the total population of "old" universities, although it is small compared to the number of HEIs. Second, the analysis at the department level has highlighted a set of mechanisms that, by their intrinsic nature, reinforce the research and grantservicing capabilities of the players that are in the game. They also increase the cost $-i . e$. the required quality - that a potential new entrant has to pay to gain access to funding. Third, some evidence has been found to support the view that small and

\footnotetext{
27 In the UK EU funds are, on average, $21 \%$ of Research Councill funds, and for about $10 \%$ of the institutions they represent more than $50 \%$. One head of department interviewed pointed out that if EU funds had to be cut down the department would have run the risk of closing down.
} 
medium sized departments, mainly when they are part of a small or medium university, suffer funding substitution, while for large departments EU funds seem to be accompanied by substantial funds from the UK government.

Whether or not the owerall impact of UK government research policies regarding unversities gives rise to a substitution of EU funds for national resources, depends not only on the consequence of conscious, deliberate government policy directions but also on the outcome of criteria applied in pursuit of other objectives. The promotion of greater stratification among universities with regard to the conduct of research may cause the addition of the two sources of funds as an outcome of strengthening the already llarge and elite research institutions. Or, by further handicapping the smaller institutions and weakening them in their ability to compete for funding from government and industry, it might produce such a contraction as to yield, over time, wrambiguous evidences of substitution.

Further research evaluating different programmes and countries is required to support the results of this analysis. Nonetheless, the outcomes of this study point to the relevance that unintended consequences play in policy analysis. Particularly in the case in which there is a lack or only partial co-ordination between various policy actions, such as in the case of EU and national research funding, the final outcomes of these actions will be determined by their interactions. Hence, the existence of diversified non co-ordinated competitive funding sources may give rise to effects that were not unintended by policy makers. 


\section{Appendix 1: Network Formation and the Main Hub.}

This appendix presents the analysis of the network structure of B-E programmes. Table 5 shows the distribution of participation according to the position in the network. Going from the Second to the Third Framework two main changes in the network structure can be highlighted. First there has been an important increase in the number of sub-contractors. ${ }^{28}$ Networks have become more branched in small components. Therefore, the number of network linkages with different priority level has increased. On the one extreme there are the relationships among contractors at the international level, on the other extreme there are the linkages between contractors and sub-contractors at the local level which were pre-existing to the RTD project. The increase in sub-contractors implies an increased probability of having newworks composed by parts of already pre-existing networks. Therefore, networks of the "TF are characterised by less genuine novelty.

Table 5: Distribution of participation type

\begin{tabular}{|l|c|c|c|}
\hline Participation Type & 2nd Framework & 3rd framework & Total \\
\hline Main Contractor & $350-19.7 \%$ & $323-19.4 \%$ & $673-19.5 \%$ \\
\hline Second Contractor & $337-19.9 \%$ & $312-18.8 \%$ & $649-18.9 \%$ \\
\hline Third Contractor & $305-17.1 \%$ & $296-17.8 \%$ & $601-17.5 \%$ \\
\hline Fourth Contractor & $258-155 \%$ & $196-11.8 \%$ & $454-13.2 \%$ \\
\hline Fifth Contractor & $178-10.0 \%$ & $135-8.1 \%$ & $313-9.1 \%$ \\
\hline Other Contractors & $130-7.3 \%$ & $1.2-8.5 \%$ & $272-7.9 \%$ \\
\hline Sub Contractors & $220-12.4 \%$ & $258-15.6 \%$ & $478-139 \%$ \\
\hline Total & 1778 & 1662 & 3440 \\
\hline
\end{tabular}

Source: Elaboration of CEC data.

Second, up to the third contractor there are no big differences between the two frameworks. Instead, the share of participants identified as fourth contractor has strongly decreased in the TF. Hence, in the last framework the networks are composed by a smaller number of contractors. Typically in the TF there are three

\footnotetext{
${ }^{28}$ Each contractor is entitled to sub-contract part of her research to other institutions that become her specific sub-contractor.
} 
contractors and a certain number of sub-contractors. In general, the TF's networks. are then characterised by a lower number of contractors and a larger number of subcontractors.

When one takes into account the average network size, the distinction between contractors and sub-contractors becomes less important. Table 6 illustrates the networks" distribution by size (number of partners) in the two frameworks. While the mean number of partners is about five for both frameworks, in the TF slightly less than $50 \%$ of the projects are carried out by networks with four or less participants. This is due to the fact that an extremely high number of networks (91) has only three participants. In the SF the networks with five participants are the ones with the highest share. Going from the second to the third framework the size of the network witnesses a contraction, with a polarisation of projects within the three-participants network structure.

Table 6: Network by number of participants.

\begin{tabular}{|l|c|c|c|}
\hline Number of Participant & $2^{\text {nd }}$ Framework & 3rd framework & Total \\
\hline $\mathbf{1 . 0 0}$ & $7(2.0 \%)$ & $3(0.9 \%)$ & $10(1.5 \%)$ \\
\hline $\mathbf{2 . 0 0}$ & $22(6.3 \%)$ & $7(2.2 \%)$ & $29(4.3 \%)$ \\
\hline $\mathbf{3 . 0 0}$ & $44(12.6 \%)$ & $91(28.2 \%)$ & $135(20.1 \%)$ \\
\hline $\mathbf{4 . 0 0}$ & $58(16.6 \%)$ & $52(16.1 \%)$ & $110(16.3 \%)$ \\
\hline $\mathbf{5 . 0 0}$ & $94(26.9 \%)$ & $54(16.7 \%)$ & $148(22.0 \%)$ \\
\hline $\mathbf{6 . 0 0}$ & $61(17.4 \%)$ & $42(13 \%)$ & $103(15.3 \%)$ \\
\hline$>6$ & $64(18.3 \%)$ & $74(22.9 \%)$ & $138(20.5 \%)$ \\
\hline TOTAL & 350.00 & 323.00 & 673.00 \\
\hline
\end{tabular}

Source: Blaboration of CEC data.

"The number of participants is given by the sum of co-ordinator, contractors, sub-contractors and contribution amendments contractors.

In general, without taking into account the participants' position in the network, the most recent B-E programme is characterised by networks of smaller size. Moreover, when the type of participants is considered too, the networks of the TF are not only smaller but they are also characterised by a larger amount of subcontractors, then by an increasing number of, probably pre-existing, one-to-one relations. 
To shed more light on the structure of participation in the B-E programmes the concentration in the participation is analysed. A name has been assigned to the various participating institutions and they have been identified in the different projects in both frameworks. The result is shown in Table 7. An institution can be involved in RTD projects only one time (single participation), or more times (repeated participation). For the latter type of organisation it is possible to calculate how many times, included the first, it has taken part into a project (expanded participation). The analysis of these variables allows to highlight the following observations.

Table 7: Concentration in the participation.

\begin{tabular}{|c|c|c|c|c|c|c|}
\hline & \multicolumn{2}{|c|}{$2^{\text {nd }}$ Framework } & \multicolumn{2}{|c|}{ 3rd framework } & \multicolumn{2}{|l|}{ Total } \\
\hline $\begin{array}{l}\text { Single Participation } \\
\text { (A) }\end{array}$ & $\begin{array}{l}711 \\
(40 \%)\end{array}$ & $71.2 \%$ & $\begin{array}{l}780 \\
(47 \%)\end{array}$ & $75.3 \%$ & $\begin{array}{l}1184 \\
(34.4 \%) \\
\end{array}$ & $69.6 \%$ \\
\hline $\begin{array}{l}\text { Repeated } \\
\text { Partieipation } \\
\text { (B) }\end{array}$ & 287 & $28.8 \%$ & 256 & $24.7 \%$ & 516 & $30.4 \%$ \\
\hline $\begin{array}{l}\text { Total Number of } \\
\text { Institutions } \\
\text { (C) }=(\mathrm{A})+\text { (B) }\end{array}$ & 998 & & 1036 & & 1700 & \\
\hline $\begin{array}{l}\text { Expanded } \\
\text { participation } \\
\text { (D) }\end{array}$ & $\begin{array}{l}1067 \\
(60 \%)\end{array}$ & & $\begin{array}{l}882 \\
(53 \%)\end{array}$ & & $\begin{array}{l}2256 \\
(65.6 \%)\end{array}$ & \\
\hline $\begin{array}{l}\text { Total Participation } \\
(\mathrm{E})=(\mathrm{A})+\text { (D) }\end{array}$ & 1778 & & 1662 & & 3440 & \\
\hline
\end{tabular}

Source: Elaboration of CEC data.

First, the average level of participation for the institutions with repeated participation (B) is dlecreasing. From 3.7 participation in the 2 nd Framework to 3.4 in the 3rd. In other words the institutions with only one participation obtained a higher share of contacts (from $40 \%$ to $47 \%$ ). Second, when one considers the two frameworks together an increase of the average level of participation (4.4 projects per institutiony can be highlighted. That is due to the presence of institutions that are both in the 2 nd and in the 3 rd framework. Third, there are 334 institutions present at least one time in both frameworks. This group of institutions is characterised by an 
average level of participation equal to 5.4. Moreover, these 334 institutions, after the first participation, are involved other 1474 times in a project. Considering that in the two frameworks there are 1740 contract with institutions that already had a participation $(\mathrm{D}-\mathrm{B}=2256-516)$, that means that the 334 institutions are responsible of the $85 \%$ of the repetitions $(147.4=85 \% 1740)$. They represent only the $19.6 \%$ of the population, but they account for 1808 contracts, that to say the $52.6 \%$ of the total contracts signed during the two frameworks. Fourth, the 516 institutions with repeated participation $(B)$ in both the frameworks can be divided in two groups. The previous one formed by the 334 institutions with a mean participation of 5.41 and a second group of 182 institutions with an average level of participation equal to 1.46 $(266 / 182$, where $266=1740-1474)$. Finally, the 1700 institutions present in the two frameworks can be characterised as follow:

- The "singles" formed by 1187 institutions that got only one contract;

- The "networkers" formed by 182 institutions that got more contracts, but only in one framework;

- The "main hub" constituted by 334 institutions that got more contracts in both frameworks.

To conclude, the analysis of the network structure of the B-E programmes highlights an effort of the Commission for enlarging the population of institutions involved in the R\&D projects. In the TF there is, indeed, a larger variety, there are more institutions with at single participation. Nonetheless, is extremely important to stress the relevance of the main hub. If $19 \%$ of the institutions succeeded in getting $52 \%$ of the contracts it means that more than a half of the $\mathrm{EU}$ funds is directed to the same group of institutions. Assuming that these organisations have an extremely high research quality, then excluding every kind of bureaucratic inertia and all type of lobbying, this implies that the distribution of funds is heavily shaped by the merit criterion and then strongly influenced by cumulative and self reinforcement mechanisms. 


\section{Appendix 2: Telephone Interviews and Questionnaire.}

Telephone interview, four questions:

First, How have the sources of funds for research changed over time in your department?

Second, Is there some kind of positive or negative interrelation among the various sources of funds?

Third, What type of research expenditure have been most influenced by recent funding patterns.

Fourth, Can you say something specific on the role played by the EU funds?

\section{Questionnaire:}

\section{QUESTION I}

"The annual survey on university financing, published by the Universities" Statistical Record, identifies a certain number of income sources. Al the most aggregate level the break down is among the seven clussers we use below

How important are the following sources/classes for the total funding of your department this year? (Circle your choice)

\section{Unimportanut:}

\section{Exchequer Gratit}

2. Research Councill

3. Government contracts and services

4. Eu contracts and services

5. Industry contracts and services

6. Fees

7. Others

$\begin{array}{lllll}1 & 2 & 3 & 4 & 5 \\ 1 & 2 & 3 & 4 & 5 \\ 1 & 2 & 3 & 4 & 5 \\ 1 & 2 & 3 & 4 & 5 \\ 1 & 2 & 3 & 4 & 5 \\ 1 & 2 & 3 & 4 & 5 \\ 1 & 2 & 3 & 4 & 5\end{array}$




\section{EU and National University Research Funding}

\section{QUESTION 2}

Do you think that in recent years (1990-1993) the funding structure of the department has undergone a process of diversification (Diversification: moving from fewer main sources of funds to more and different funding sources)? (Circle your choice)

$$
\text { YES NO }
$$

If yes, how important was the change (growth or contraction) of the following classes in the years 1990-1993? (Circle positive (t) or negative (-) to indicate diversification change)

Unimportant

Extremely

Important

1. Exchequer Grant

2. Research Councill

3. Government contracts and services

4. EU contracts and services

5. Industry contracts and services

6. Fees

7. Others

$\begin{array}{lllllll}+ & - & 1 & 2 & 3 & 4 & 5 \\ + & - & 1 & 2 & 3 & 4 & 5 \\ + & - & 1 & 2 & 3 & 4 & 5 \\ + & - & 1 & 2 & 3 & 4 & 5 \\ + & - & 1 & 2 & 3 & 4 & 5 \\ + & - & 1 & 2 & 3 & 4 & 5 \\ + & - & 1 & 2 & 3 & 4 & 5\end{array}$

\section{QUESTION 3}

Have you noted some form of substitution (Substitution: an increase of funds from one source is linked to a decrease of funds from another) among the various form of funding in your department in recent years (1990-1993)? (Circle your choice)

\section{YES}

NO

If yes, do you agreetdisagree that the following forms of substitutions have occurred?

\section{Strongly Agree}

1. Fees have substimted Exchequer Grant

$\begin{array}{lllll}1 & 2 & 3 & 4 & 5\end{array}$

2. EU contract and services hawe substituted Research Council $1 \quad 2 \quad 3 \quad 4 \quad 5$

3. EU contract and services have substituted Government contract and services

$\begin{array}{lllll}1 & 2 & 3 & 4 & 5\end{array}$

4. Industry contract and services have substituted

Reseatroh Council

$12 \quad 3 \quad 4 \quad 5$

5. Industry contract and services have substituted Government contract and services

$\begin{array}{lllll}1 & 2 & 3 & 4 & 5 \\ 1 & 2 & 3 & 4 & 5\end{array}$

6. Research Council has substituted Exchequer Grant

7. Others. (Specify which and how important) 


\section{EU and National University Research Funding}

\section{QUESTION 4}

Do you think that EU funds receip has had either a positive or a negative influence on the following funding sources? (Circle your choice)

1. Exchequer Grant

\section{Strongly \\ Positive}

2. Research Council

3. Government contracts and services

4. EU contracts and services

5. Industry contracts and services

6. Fees

7. Others

1
1
1
1
1
1
1

$\begin{array}{cccc} & \text { No Influence } & & \begin{array}{c}\text { Strongly } \\ \text { Negative }\end{array} \\ 2 & 3 & 4 & 5 \\ 2 & 3 & 4 & 5 \\ 2 & 3 & 4 & 5 \\ 2 & 3 & 4 & 5 \\ 2 & 3 & 4 & 5 \\ 2 & 3 & 4 & 5 \\ 2 & 3 & 4 & 5\end{array}$

\section{QUESTION 5}

Could you please give us an estimate of the annual budget of your department including total salaries and other costs?

$$
\text { E }
$$

Has this wallue changed in the last four to five years? (Circle your choice)
a) Increased
b) Decreased
c) No Change

Could you please tell us the number of BRTE-EURAM projects in which your department has been invol vied? 
EU and National University Research Funding 


\section{PART IV}

Summary and Conclusions 



\section{Conclusions}

This thesis has focused on the economics of European universities and, in particular, on the issue of how the changing structure of research funding influences university research behaviour. Its overall objective has been to evaluate the presence and importance of the unintended consequences of recent changes in the rationale for allocating society's resources to the support of university research and related training activities. In Part One this issue has been examined from a theoretical perspective, introducing an economic approach to university research behaviour that allows one to take into account and evaluate the indirect consequences of the new competitive approach to university behaviour and funding. On the basis of this and an evolutionary account of European universities which defined the unit of analysis of the thesis, empirical modelling has been used to test some of the behavioural hypotheses in Part Two and Part Three. This concluding chapter gives an overview of the results of this thesis and presents some possible directions for further research.

Before turning to review the principal findings, a reminder of the disciplinary perspective on the subject-matter and the methodology of this thesis may be called for. The economics of university research behaviour has been approached in this dissertation not only within the langer framework of public economics complementary to the economics of science, but also it has been related explicitly to the literature on industrial knowledge production and innovation processes. This work therefore may be seen as an effort to provide one necessary building block for the economics of knowledge production and distribution, interpreting the latter to 


\section{Conclusions}

comprise the study of all the various public and private components of the system upon which the modern knowledge-based economy has come to depend.

\section{Summary of the Rerults}

Part One presents European Universities as the units of analysis of the thesis, and develops both a theoretical framework and an historical characterisation of certain functions of these institutions. Chapter Two introduces an economic approach to the analysis of university research behaviour, which motivates and guides all of the empirical analysis carried out in this thesis. After showing that the utility-maximising approach to university behaviour is an unsatisfactory framework to study the current changes underway in the university system, an alternative framework is proposed. This seeks to explain university research behaviour as a result of the relevant incentives and constraints. The examination of the impacts, in terms of incentives and constraints, of a diversified funding structure for university research lies at the core of this analysis. Chapter Two not only yields an analysis of university research behaviour but, linking this to the changes in the rationale for resource allocation to the university, puts forward behavioural hypotheses that are tested in the empirical studies of Part Two and Part Three. In particular, the presence of unintended consequences of the competitive rationale for resource allocation is examined in relation to the following four problematiques: 1) excessive concentration of resources; 2) disproportionate incentives for a short-term foresecable research endeavour;"3) conflicting incentive structures; and 4) exacerbation of the impact of cumulative and self reinforcement phenomena present in the process of scientific production.

An evolutionary account of European universities is presented in Chapter Three. The historical analysis of the development of the institutions of higher education and, only after the eighteenth century, research in Europe reveals that, althongh important national idiosyncrasies are present, a set of common attributes characterise European universities. Highly diversified modern European universities are the result of a process of incremental institutional innovation. 'Their governance 


\section{Conchusions}

and organisation derive from the medieval tradition, the approach to scientific discovery developed by the scientific societies, the Humboldtian ideal of university and the post-war rationale of the 'endless frontier." Hence, contemporary university behaviour is based on operating and decision-making rules that have developed in the adjustment to changes in the environment all along the history of the university.

Since the Second World War a process of rapid growth and diversification has characterised the national university systems of all the EU countries. This process was paralleled by a rise in society"s expectations of economic returns from the funding of university research. Chapter Three examines the impact of these phenomena, discussing the modifications taking place in the university systems of the various EU countries. It suggests that one of the possible outcomes of the ongoing changes is the polarisation of the university system with, on the one extreme, a small group of dynamic research oriented universities, and, on the other extreme, a large group of mainly teaching oriented institutions.

Part Two begins by presenting a statistical analysis of contemporary European universities. The first section of Chapter Four examines the level and changes in university reseatch funding and publication output at the national level in 1982-1993. Then, on the basis of an originall database, it presents a detailed analysis of the total population of universities for eleven $\mathrm{U}$ countries in 1992. Circa two-fifths of the active European universities have been founded within the past 50 years. The tolal population of universities is characterised by a large number of small-medium sized institutions, with low scientific research orientation and low scientific research productivity.

The second section of Chapter Four develops a methodology to describe the university system in terms of its main features. The modelling approach used here aims at analysing whether it is possible to identify well-defined clusters of institutions with similar size, research output and foundation period. The results provide robust support for the hypothesis of a stratification (polarisation) of the university system at 
the European level. In fact, two clearly distinct clusters of institutions have been identified. The furst comprises a small group of dynamic research oriented universities of large size, founded almost exclusiwely before the Second World war, with a high international scientific reputation and an international networks of public and private research partners. The second is composed by a large group of small-sized institutions, mainly founded in the post-war period, which are either involved in technological research or teaching, with a national or local focus. These results suggest that the policies aimed at a more directed allocation of the research effort, and at the creation of quasi-market incentive structures developed during the 1980 s early 1990s, have already produced an extremely high level of concentration of university research.

To better understand the possible consequences of the competitive approach to university behaviour and funding, a still more detailed analysis of the relationships between funding and research output has been carried out in Chapter Five. Firstly, the evolution of the funding structure of 'old' UK universities in the period 1989-1993 is examined, showing how the growth of Specific Incones has not been sufficient to cover the diminishing of General Funds for research.' Then, the econometric modelling developed in Chapter Four is applied at the start and at the end of the period considered to evaluate the impact on the scientific publication rate of the changes in the research funding structure, and, specifically, of the increased reliance on industrial funding of certain universities. The results of the analysis at the static level (at the start and at the end of the period) indicate that the universities with smaller scientific faculties and with lower scientific research productivity tend to depend more heavily on industrially funded research. Besides, the analysis at the dynamic level (changes between the two periods) shows that the universities which were pushed to rely more heavily on industrial funding $-i$.e the ones for whom the cuts in the general public support were not offset by an increase of public specific

\footnotetext{
1 In particular, while EU funding receipts have risen throughout the period. UK Industry funding receipts, after snall increase, have shown negative growh rates.
} 


\section{Conclusions}

funds-have further lowered their average scientific publication rate. The findings confirm the view that, on the one hand, the leading research-intensive UK universities are the most important recipients of industrial support and that, on the other hand, they are among the less dependent on industrial funding. ${ }^{2}$ In addition, evidence has been found supporting the hypothesis that the universities which have sustained significant cuts in public funding were pushed to do routine contract research for industry, resulting in low publications output (and spillovers) and knowledge that does not lay a basis for further scientific and technological innovations.

Overail, the two chapters in Part Two present robust evidence supporting the view that the competitive approach to university behaviour and funding is resulting in the polarisation of the university system with a high concentration of research resources in a few institutions. This process goes with an increased dependence on industrial funding of the financially weaker universities. In Chapter Five some evidence validate the hypothesis that the routine contract research carried out for industry by these weaker institutions produces mainly private returns to the firms that support only a part of total cost. Hence it represents a form of public subsidy for particular industries for a kind of research that firms can and have to pay for itself.

In Part Three the analysis focuses on a particular type of competitive funding mechanism, the EU contract for R\&D co-operative projects, and its interactions with other sources of funding. Chapter Six examines university participation in EU-funded R\&D co-operative projects. First, it presents a descriptive analysis at the aggregate level of the participation of higher education institutions in the three Frameworks Programmes of the European Commission. HEIs are the largest single type of institution in term of the number of times they participated into a project. They have taken part in networks including a large majority of research institutions, but they have also collaborated. with industrial partners. Finally, although they are the dominant players in a few programmes such as Step/Epoch and Environment, they

\footnotetext{
${ }^{2}$ A similar observation is also rute for US universities (Baldwin, 1996).
} 


\section{Conclusions}

also participated in a respectable number of projects in the industrially-oriented programmes.

In the second section of Chapter Six an interpretative framework explains the different level of university participation in EU-funded R\&D co-operative projects in terms of information signalling, and cumulative and self-reinforcement mechanisms. These phenomena may yield a lock-in situation in which a restricted group of institutions are repetitively granted support from the European Commission. On the basis of this framework and a detailed statistical description of the participation of the 379 European universities in shared-cost actions funded by the DG XII of the European Commission, an empirical model is developed. The aim of the twoequation regression model is to test the relevance of size, scientific research productivity, and other fixed factors on both the probability of joining an EU-funded R\&D co-operative project and the actual number of times aniversity participated in these projects. The results of the estimations indicate that scientific research productivity influences both the probability and the level of participation, whille research size has a positive influence only on the latter. Among the other results, the analysis of the fixed factors shows that in the case of Jrish and Greek universities, the cohesion policy followed by the European Commission exerts some influence on the selection process. Overall, these results suggest that, on the one hand, the relevance given to scientific research productivity in the selection process, through the effect of cumulative and self-reinforcement mechanisms, favours the selection of a minority of high research intensive institutions. This is efficient in the short term as it maximises current research output, but it may have negative long-term effects. On the other hand, the European Commission pursues long-term objectives attributing advantages in participation to the less-favoured regions (Gambardella and Garcia Fontes, 1996).

The second chapter of Section Three, Chapter Seven, is one of the first attermpts to analyse the possible effects of competitive, non co-ordinated university research funding from EU and national sources. To obtain the level of detail needed to carry out this type of examination, a specific progtamme funded by the European 


\section{Conclusions}

Commission --BRTTE-EURAM- and a single country -the UK-- had to be chosen. Firstly, the chapter presents an analysis of the BRITE-EURAM innovation system, as well as of the institutional participation and network structure of the BRITE-EURAM programmes funded in the Second and Third Framework Programme. It then studies the relationships between EU and national university research funding for the departments of Material Technology, Material Science and Engineering of the "old" UK universities. The analysis considers both the unintended consequences resulting from the existence of two non co-ordinated sources of funds, and the deliberate action of the government in response to EU funding. Specifically, a survey and interviews have been made to evaluate the dependence between EU and national sources of research funds in terms of cumulative and self-reinforcement phenomena and substitution effects. The results of this empirical study underscore the presence of micro-mechanisms that unintentionally support a 'path dependent' funding process: success in obtaining funds from the EU enhances the probability of raising research funds in the future from both EU and government sources. These mechanisms not only reinforce the capabilities of the game-players, but also increase the research 'quality' required by a potential new entrant in order to be granted the support. Furthermore, some evidence attests to the presence of a selective application of substitution of funds from the government which favour the already major research performers.

In general, the results of the studies carried out in the two chapters of Part Three indicate that, in a diversified funding structure, the criteria applied in granting a source of funds have indirect effects on the allocation of other resources. Given the existence of cumulative and self-reinforcement phenomena, these effects tend to give a disproportionate advantage to the high research-intensive universities.

\section{Overall Conclusions}

Building upon the conclusions emerging from the separate chapters, more general observations and questions are suggested. First, the results of the various studies carried out in this thesis indicate that universities, rather than presenting an 


\section{Conclusions}

homogeneous behavioural response to the modifications in the uniwersity research funding system, react according to their specific chatacteristics. Moreover, the competitive approach to university behaviour and funding increases differences within the university system. This augmented diversity, in turn, implies an increasingly diversified response to policy actions which leads to important unintended effects. As a result, there is the need for a rethinking of policy action reflecting the diversity present in the system. Policy initiatives should dewelop an approach that accounts for the heterogeneity of institutional response. In the light of these considerations, the studies developed by the new economics of science (some of them cited in this thesis) and this thesis itself can be seen as an attempt to provide a theoretical and empirical framework for understanding university research behawiour that opens the way for further researcher aimed at the redefinition of policy actions.

Second although this thesis does not supply at definitive answer to the question of whether or not the competitive approach to university behaviour and funding causes a shift of university research away from fundamental research, some indications in support of this view have been found. If this is the case, as it seems, it is highly likely that, due to the diversion of money from the funding of exploratory research to the financing of a more applied type of research, the stock of fundamental knowledge will probably increase at a slowing growth rate. With continuously shrinking government funding for fundamental research and increasing public and private spending on applied research, the stock of basic knowledge available as at foundation or enabler of applied research will become smaller relative to the demands for its use. To the extent that applied and development research draw from the stock of basic knowledge, and if the stock of knowledge follows the law of diminishing returns, the marginal productivity of applied and development research will tend to decline (Aranson, 1995). Moreover, the increasing propensity in funding research with a clear and predictable output will tend to reinforce the dominant science, limiting research variety and consequently decreasing the probability of scientific innovation (Kuhn, 1970; Lakatos, 1970). This, in turn, is likely to reduce the new knowledge base from which new technological innovations can flow. Both 


\section{Conclusions}

phenomena are reinforced by a competitive research allocation of resources based on ex-post evaluation of university research performance. In fact, should publications be used as a primary signal of professional ability, the incentive structure would bias research decisions toward orthodox, low-risk projects (Garner, 1979).

Third, it is widely recognised that the flow of knowledge among the warious sites where scientific and technological knowledge is produced, most notably between university and industry, increases social welfare because it allows a wider and more effective exploitation of the knowledge produced. Nonetheless, tighter linkages between university and industry with the am of increasing the transfer of knowledge may produce unintended negative effects. In fact, the evidence presented in this thesis suggests that further government push towards a closer interaction between university and industry may cause counterproductive effects. This is particularly true for those universities in a weak financial situation. Constrained to accept industrial funds for developing routine contract research, and faced with the impossibility of charging the real cost of the research, ${ }^{3}$ their collaboration with industry results not in a contribution of university to the wealth of society, but in an exploitation for private profit of a public investment. This observation has to be pondered over the diverse level of industrial and government funding of the various EU countries. Whereas some countries such as the UK exhibit a high degree of university involvement in industrial reseanch, others such as Ifaly, may have still space for further development. Noiwithstanding these different national situations, government policies for the development of university-industry relationships should be shaped taking into account the general point that an advan agcous co-operation for both university and industry requires the existence of scientific, technological and cultural complementarities. Different capabilities are present in the various unversities; policy actions should encourage university-industry collaborations that enable the building up and further develop of these capabilities. A myopic push for

\footnotetext{
3 This is oue both to the organisational structure of the unversity, and to the wse of the results of research funded with public funds to develop private research.
} 


\section{Conclusions}

short-term economic return may induce changes in the social organisation of the university that could damage either the university's capabilities for knowledge production or its abilities to transmit knowledge.

Finally, this thesis has examined the unintended consequences of the competitive approach to university research behaviour and funding, leaving the andysis of the benefits of the competitive system in the background. The implicit assumption made is that the use of a competitive funding system can generate positive effects, mainly in terms of efficiency improvements. The evidence presented in the thesis, however, indicates that the competitive approach also may give rise to important negative effects. Therefore, what is advocated here is balance between competitive allocation mechanisms that can improve the short-term efficiency of the system, and non-competitive ones that support longer-term societal objectives.

\section{Divections for Further Research}

The above discussion underscores a number of interesting results emerging from the economic approach to university research behaviour developed in this thesis. These are not conclusive, but, on the contrary, they open the way for further research. Different research paths can be followed, a number of them have already been discussed in the various chapters of this thesis. Two broad issues for further research

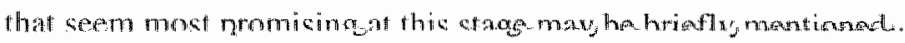

First, at deeper understanding of the operation of the university as an economic and social instiution is needed. Although Chapter Two acknowledges the need for a general theory of university behaviour, it has only focused on university research behaviour and, specifically, on its response to changes in the extermal enviromment. For that reason, a general system theory of the operation of 'the university' which takes into accotint the multi-product character of the institution and considers both the intermal university behwviour and the response of the university to external changes would greatly contribute to the understanding of the process of knowledge production and distribution. Currently, this research path is hindered by the lack of reliable 


\section{Conchusions}

statistics for the implementation of empirical studies to test alternative behavioural bypotheses, and the difficulties posed by the recognised heterogeneity of the population of institutions of higher education.

A second important research path would seek a better understanding of the implications of the collaboration between university and industry. Although a large body of literature has been produced on university-industry collaboration, clear answers have yet to be given to questions such as: What are the economic and social returns of the substitution of industrial funding for public sector support? What are the trade-off, if indeed any exist? Is there an optimal share of university's total research budgets that are financed by industry? Having said this, there is the need for both theoretical and empirical studies analysing university-industry collaboration and its implications from the perspective of the university." This research would contribute not only to the rethinking and reassessment of the science and technology framework, but it may allow the idlentification of a "best practice" which could be more widely diffused for implementation through internal university procedures and externall regulatory action.

\footnotetext{
4 A closely related topic, rarely discussed in the fiterature, is the understanding of the amplications for the university structure of different industrial-funds raising capabilities of the warious disciplines.
} 
Conclusions

214 


\section{Annex A: Data Sources}

EU Participation: DGXI, Directorate-General Science, Research and Development, Commission of the European Communities

INDRE:

University Statistics. Volume Three: Finance, Universities' Statistical Record, 1991, 1994.

NEWOLD: International Handbook of Universities, Intemational Association of Universities, $1991,1993$.

No. Researchers: International Handbook of Universities, International Association of Universities, 1991, 1993; different national reports on higher education.

No. Students:

International Handbook of Universities, International Association of Universities, 1991, 1993; different national reports on higher education.

NSCIRES:

University Statistics. Volume Three: Finance, Universities' Statistical Record, 1991, 1994.

Publications: $\quad$ Science Citation Index, CD-ROM version, ISI, 1993.

SPRUPUBS:

J.S. Katz and D. Hicks, B.E.S.S. Database, SPRU, 1996.

RETOT:

University Statistics. Volume Three: Finance, Universities" Statistical Record, 1991, 1994. 
Annex A: Data Source 


\section{Bibliography}

Adams, J.D. and Z. Griliches, 1996, Research Productivity in a System of Universities, NBER Working Papers Series, No. 5833.

Aldenderfer, M.S., and R.K. Blashfield, 1984, Cluster Analysis, Sage Publications, London

Antonelli, C., 1995, The Economics of Localized Technological Change and Industrial Dynamics, Kluwer Academic Publishers, Dordrecht.

Aranson, P.H., 1995, Normative and Positive Theories of Science and Technology Policy, in J.W. Sommer, (ed.), The Academy in Crisis, The Independent Institute, Oakland, California.

Arora, A., David, P.A. and A. Gambardella, 1998, Reputation and Competence in Publicly-Funded Science, Les Annales d"Economie et de Siatistiques, numéro exceptionnel: "The Economics and Econometrics of Innovation," edited by Jacques Mairesse et al. Forthcoming.

Arora, A. and A. Gambardella, 1997, Public Policy towards Science: Picking Stars or Spreading Wealth?, Revue d'Economie Industrielle, N. 79, $1^{\text {er }}$ Trimestre, pp.63-76.

Arora, A. and A. Gambardella, 1990, Complementarity and External Linkages: The Strategies of Large Firms in Biotechnology, Jounal of Industrial Economics, Vol.38, pp. $361-379$.

Arrow, K.l. et al. (eds), 1996, Education in a Research University, Stanford Uniwersity Press, Stanford.

Arrow, K.J., 1962, Economic Welfare and the Allocation of Resources for Inventions, in R. Nelson (ed.), The Rate and Direction of inventive Activity: Economic and Social Factors, Princeton University Press, Princeton.

Arthur, W.B., 1988, Competing Technologies: An Overview, in G. Dosi et. al. (eds.), Technical Change and Economic Theory, Pinter, London. 


\section{Bibliography}

Arundel, A., G. van de Pall and L. Soete, 1995, Innovatiom Strategies of Europe's Largest Industrial Firms, PACE Report prepared for the SPRINT Programme.

AXION, 1995, The Impact of EC R\&D Policy on the European Science and Technology Community 1987-1991 $2^{\text {mid }}$ Framework Programme. National Impact Studies Synthesis, Study conducted on behalf of the European Commission, Interim Report.

Backhaus, J.G. (ed.), 1993, The Economics of Science Policy: An Analysis of the Althoff System, Special issue of Jowmal of Economic Studies, Vol.20, No. 4/5.

Baldwin, W.L., 1996, The US Research University and the Joint Venture: Evolution of an Institution, Review of Industrial Organization, Vol. L, pp.629-653.

Ball, R. and R. Wilkinson, 1994, The Use and Abuse of Performance Indicators in UK Higher Education, Higher Education, Vol.27, pp.417-427.

Bania, N., Eberts,R.W. and M.S. Fogarty, 1993, Universities and the Startup of New Companies: Can We Generalize from Route 128 and Silicon Valley?, The Review of Economics and Statistics, Vol 75, pp.761-764.

Baumol, W.I., Panzar, J.C. and D.G. Willig, 1982, Contestable Markets and the Theory of Industrial Structure, Harcourt Brace Jovanovich, New York.

Beasley, J.E., 1990, Comparing University Departments, Omega, Vol.18, pp.171-183.

Becker, G.S., 1975, Human Capital. A Theoretical and Empirical Analysis, with Special Reference to Education, Second Edition, The University of Chicago Press [Midway Reprint, 1983], Chicago.

Becker, G.S., 1962a, Investment in Human Capital: A Theoretical Analysis, Joumal of Political Economy, Vol.70, pp, $9-49$.

Becker, G.S., 1962 b, Irrational Behaviour and Economic Theory, Journal of Political Economy, Vol.70, pp. 1-13.

Bell, D., 1976, The Coming of post-industrial Society. A Venture in Soctal Forecasting, Harper Collins Publishers.

Bird, G., 1992, The Economics of Managing a University, Studies in Higher Education, Vol. 17, pp.265-280.

Blaug. M, 1970, An Introduction to the Economics of Education, Allen Lane The Penguin Press, reprinted Penguin Books 1976. 


\section{Bibliography}

Blume, S., 1990, Transfer Sciences. Their Conceptualisation, Futuctions and Assessment, presented to the conference "Consequences of the Technology Economy" Programme for the Development of Indicators", Paris, $2^{\text {nd }}-5^{\text {th }} \mathrm{J}$ July.

Blume, S., 1987, The Theoretical Significance of Co-operative research, in S. Blume et al. (eds.), The Social Direction of the Public Sciences, Sociology of the Sciences Yearbook, Vol XI.

Borden, V.M.H. and T.W. Banta, 1994, Using Performance Indicators to Guide Strategic Decision Making, New Direction for Institutional Research, Jossey-Bass Publisher, San Francisco.

Borden, V.M.H. and K.V. Bottrill, 1994, Performance Indicators: History, Definitions, and Methods, in V.M.H. Borden and T.W. Banta, Using Performance Indicators to Guide Strategic Decision Making. New Direction for Institutional Research, Jossey-Bass Publisher, San Francisco.

Bossard Consultant, 1989, Contract Research Organizations in the EEC, Study and Directory carried out for the SPRINT Programme, Luxembourg.

Braxton, J.M. (ed.), 1996, Faculty Teaching and Research: Is There a Conflict?, New Direction for Institutional Research, Jossey-Bass Publishers, San Francisco.

Brierty Me, V., 1993, The University-Industry Interface: From the Lab to the Market, Higher Education Management, Vol.5, pp.75-94.

Brinkman, P.T., 1990, Higher Education Cost Functions, in S.A. Hoenack and E.L. Collins (eds.), The Economics of American Universities. Management, Operations. and Fiscal Environment, State University of New York Press, Albany, NY.

Brinkman, P.T, and L.L. Leslie, 1986, Economies of Scale in Higher Education: Sixty Years of Research, The Review of Higher Education, Vol. 10, pp.1-28.

Brizzi, G.P. and J. Verger (eds.), 1993, Le Universita dell'Europa: Gli Vominite Liooghi, Amilcare Pizzi Editore, Milano.

Brizzi, G.P. and J. Verger (eds.),1992, Le Universizà dell Europa: Dal Rinnowamento Scientifico all'Età dei Lumi, Amilcare Pizzi Editore, Milano.

Brizzi, G.P. and J. Verger (eds.), 1991, Le Università dell'Europa: Dal Rinascimento alle Riforme Religiose. Amilcare Pizzi Editore, Milano.

Brizzi, G.P. and J. Verger (eds.),1990, Le Universita dell Europa: La Nascita delle Università, Amilcare Pizzi Editore, Milano. 


\section{Bibliography}

Broadbent, $J$ and R. Laughlin, 1997, Contracts and Competition? A Reflection on the nature and Effects of recent Legislation on Modes of Control in Schools, Cambridge Joumal of Economics, Vol.21; pp.277-290.

Brocke vom, B., 1991, Friedrich Althoff: A Great Figure in High Education Policy in Germany, Minerva, Vol.29, pp.269-293.

Buchbinder, H. 1993, The market Oriented University and the Changing Role of Knowledge, Higher Education, Vol.26, pp.331-3.47.

Bush, V., 1945, Science the Endless Frontier, United States Govermment Printing Office, www.physic.uiuc.edu/ysn/docs/html_articles/vBush 1945.html

Callon, M., 1994, Is Science a Public Good? Fifth Mullins Lecture, Virginia Polytechinic Institute, 23 March 1993, Science, Technology \& Human Values, Vol. 19 , pp.395-424.

Callon, M., 1991, Techno-economic networks and Irrewersibility, in J. Law (ed.), A Sociology of Mansters; Essays on Power, Technology and Domination, Routledge, London.

Callon, M. and D. Foray, (eds.), 1997, L'Economie Industrielle de la Science, Numéro Spécial of the Revue d'Economie Industrielle, Vol. 79.

Carnoy, M. and D. Marenbach, 1975, The Return to Schooling in the U.S., 19391969. Journal of human Resources, Vol.10, pp.213-332.

Carpenter, M.P. et al, Bibliometric Profiles for British Academic Institutions: An Experiment to Develop Research Output Indicators, Scientometrics, Vol.14, pp.213233.

Catalano et al. 1993, Chi Paga l'istruzione Universilaria? Dall"esperienza Europea una Nuova Politica di Sostegno agit Studenti in Italia, Franco Angeli, Milano.

Cave, M., et al. 1997. The Use of Performance Indicators in Higher Education, Jessica Kingsley Publisher, London.

Cave, M., Dodsworth, R. and D. Thompson, 1992, Regulatory reform in Higher Education in the UK: Incentives for Efficiency and Product Quality, Oxford review of Economic Policy, Vol.8, pp.79-102.

Cave, M. and M. Weale, 1992, The Assessment: Higher Education: The State of Play, Oxford Review of economic Policy, Vol.8, pp.1-18. 


\section{Bibliography}

Chapman, $\mathbb{B} ., 1997$, Conceptual Issues and the Australian Experience with Income Contingent Charges for Higher Education, The Economic Joumal, Vol.107, pp.738751.

Charle, C. And J. Verger, 1994, Histoire des Universites, Presses Universitames de France, Paris.

Clark, B.R. (ed.), 1984, Perspectives on Higher Education. Eight Disciplinary and Comparative Views, University of California Press, Berkeley.

Clark, B.R. and G. Neave (eds.), 1992, The Encyclopedia of Higher Education, Pergamon Press, Oxford.

Cobban, A.B., 1975, The Medieval Universities: Their Development and Orgamization, Methuen \& Co Ltd, London.

Cohen, W. And D. Levinthal, 1989, Innovation and Learning: The Two Faces of $\mathrm{R} \& \mathrm{D}$, Economic Joumal, Vol.99, pp.569-596.

Cohen, W., and R. Florida, 1996, For Knowledge and Profit: University-industry Research Centers in the United States, Oxford University Press, New York.

Cohen, W., Florida, R. and R. Goe, 1992, University-Industry Research Centres in the United States, Report to the Ford Foundation, Center for Economic Development, Carnegie Mellon University, Pittsburgh.

Cohendet, P, Ledoux, M. and E. Zuscovitch, 1988, New Advanced Materials, Springer-Verlag, Berlin.

Cohn, E., Rhine, S.L.W. and M.C. Santos, 1989, Institutions of Higher Education as Multi-product Firms: Economies of Scale and Scope, The Review of Economics and Statistics, Vol 71 , pp.284-290.

Cole, J. and S. Cole, 1973, Social Stratification in Science, Chicago University Press, Chicago.

Cole, $J$ and S. Cole, 1972, The Ortega Hypothesis, Science, Vol.178, pp.368-375.

Commission of the European Communities, 1997a, Fifh Framework Prograwme for Reseanch and Technological Development (1998-2002). Commission Working Paper on the Specific Programmes: Starting Points for Discassion, COM (97) 553.

Commission of the European Communities, 1997b, Evaluation and Analysis of the Technological Transfer Generated by the Programmes EURAM, BRITE and BRITEEURAM I, Report EUR 16878, EN. 
Commission of the European Communities, 1996, Evaluation of the Economic Effects of the Programmes EURAM, BRITE and BRITE-EURAM I, Report EUR 16877 EN.

Commission of the European Communities, 1994a, The European Report on Science and Technology Indicators 1994, Report EUR 15897 EN.

Commission of the European Communities, 1994b, Report to the European Council on the Application of the Subsidiarity Principle, COM (94), 533.

Commission of the European Communities, 1994c, Research and Technological Development Achieving Co-ordination Through Co-operation, COM (94), 438.

Commission of the European Communities, 1994d, Proposal for a Council Decision Adopting a Specific Research and Technological Development Programme in the Field of Materials Technologies.

Commission of the European Communities, 1993a, Catalogue of Research Projects in the Third Framework, Report EUR 14937 EN.

Commission of the European Communities, 1993b, Working Document of the Commission Concerning the S\&T content of the Specific Programmes Implementing the 4th Framework Programme for Community Research and Technological Development (1994-1998) and the Framework Programme for Community Research and Training for the European Afomic Energy Community (1994-1998), COM (93) 459.

Commission of the European Communities, 1993c, Evaluation of the BRITE/EURAM Programme (1989 - 1992) - (areas I to 4), Report EUR 15070 EN.

Commission of the European Communities, 1993d, Economic Evaluation of the Effects of the BRITE/EURAM Programmes on the European Industry, Report EUR $15171 \mathrm{EN}$.

Commission of the European Communities, 1993e, Second Commission Working Document Concerning RTD Policy in the Community and the Fourth Franework Programme (1994-1998) of Community RTD Activities, COM (93) 158.

Commission of the European Communities, 1992a, EC Research Funding. A Guide for Applicants.

Commission of the European Communities, 1992b, Evaluation of the Second Framework Programme for Research and Technological Development, SEC (92) 675. 


\section{Bibliography}

Commission of the European Communities, 1992c, BRITE \& EURAM: Evaluation Study of Finished Projects. Projects Completed by December 1991. Report EUR 14541 .

Commission of the European Communities, 1992d, A Universe of Possibilities: Industrial and Material Technologies, Information package

Contzen, J., 1991, European Integration and University Research: an Overview, Higher Education Management, Vol.3 No. 2, pp. 137-144.

Cox, A., 1994, Derogation, Subsidiarity and the Single Market. The Case of Energy Exploration and Extraction under the EU Utilities Procurement Rules, Joumal of Common Market Studies, Vol.32, No. 2, pp. 126-147.

Cozzens, S., 1989, What Do Citations Count? The Rhetoric-first Model, Scientometrics, Vol.15, pp.437-447.

Cragg, J., 1971, Some Statistical models for Limited Dependent Variables with Application to the Demand for Durable Goods, Ecomometrica, Vol.39, pp.829-844.

Culyer, A.J., 1970, A Utility-Maximising View of University, Scottish Joumal of Political Economy, Vol.17, pp.349-368.

Cyert, R.M. and J.G. March, 1963, A Behavioral Theory of the Firm, Englewood Cliffs.

Daalder, H. and E. Shils (eds.), 1982, Universities, Politicians and Bureaucrats: Europe and the United States, Cambridge University Press, Cambridge.

Dasgupta, P. and P.A. David, 1994, Toward a New Economics of Science, Research Policy, Vol.23, pp.487-521.

Dasgupta, P. and P.A. David, 1987, Information Disclosure and the Economics of Science and Techmology, Chap.16, in Arrow and the Ascent of Modern Economic Theory, G. Feiwel (ed.), New York University Press, New York.

David, P.A., 1997a, Reputation and Agency in the Historical Emergence of the Institutions of 'Open' Science. University of Oxford Discussion Papers in Economic and Social History.

David, P.A., 1997b, From Market Magic to Calypso Science Policy. A Review of Terence Kealey's The Economic Laws of Scientific Research, Research Policy, vol.26, pp.229-255. 
David, P.A., 1994, Positive Feedbacks and Research Productivity in Sicience: Reopening Another Black Bor, in O. Granstand (ed.). The Economics of Technology, Elsevier Science Publisher, Amsterdam.

David, P.A., 1985, Clio and the Economics of QUERTY, American Economic Review, Vol.75, pp.332-337

David, P.A. and D. Fordy, 1994, Accessing and Expanding the Science and Technology Knowledge base, Working Group on Innovation and Technology Policy, DSTI/STP/TIP 94(4), OECD, Paris.

David, P.A. Foray, D. and W. E. Steinmueller, 1998, The Research Network and the new Economics of Science: From Metaphors to Organisational Bahaviour, in A. Gambardella and F. Malerba (eds.), The Organisation of Inventive Activity in Europe, forthcoming from Cambridge University Press

David, P.A., Geuna, A. and W. E. Steinmueller, 1995, Additionality as a Principle of European R\&D Funding. A Study carried out for the STOA Programme of the European Parliament, MERTT's Research Memoranda 2/95-012.

Dawid, P.A., Mowery, D.C. and W.E. Steinmueller, 1994, University-Industry Research Collaborations: managing Missions in Conflict, presented at the conference CEPR/AAAS "University Goals, Institutional Mechanisms, and the Industrial Transferability" of Research", 18-20 March, University of Stanford.

David, P.A. and W.E. Steinmueller, 1995, A Productive Tension: University-Industry Research Collaboration in the Age of Knowledge-Based Economic Development, Stanford University Press, Stanford, CA, forthcoming.

Diamond Jr. A.M. 1996. The Economics of Science, Special Issue of The International Journal of Knowledge Transfer and Utilization, Vol.9, pp.3-49.

Dill, D.D., 1997, Higher Education Markets and Public Policy, Higher Education Polloy, Vol.10, pp.167-185.

Dolton, P.J., Greenaway, D. and A.. Vignoles, 1997, 'Whither Higher Education?' An Economic Perspective for the Dearing Committee of Inquiry, The Economic Joumal, Vol.107, pp.710-724.

Dosi, G., 1996, The Contribution of Economic Theory to the Understanding of a Knowledge-based Economy, in OECD, 1996, Employment and Growth in the Knowledge-based Economy, Paris.

Dosi, G. at. (eds.), 1988, Technical Change and Economic Theory, Pinter Publisher, London. 


\section{Bibliography}

Dresch, S.P., 1995, The Economics of Fundamental Research, in J.W. Sommer (ed.), The Academy in Crisis, The Independent Institute, Oakland, California.

Dunteman, G. H., 1989, Principal Component Analysis, Sage Publications, London.

Edquist, C. (ed.), 1997, System of Innovation. Technologies, Institutions and Organizations, Pinter, London.

EIPA, Subsidiarity: The Challenge of Change, Proceedings of the Jacques Delors Colloquium, European Institute of Public Administration, Maastricht.

Elliason, G., et al., 1990, The Knowledge-based Information Economy, Almquist \& Wiksell, Stockholm.

Etzkowitz, H., 1997, The Entrepreneurial University and the Emergence of Democratic Corporatism, in H. Etzkowitz and L. Leydesdorff (eds.), Universities and the Global Knowledge Economy, Pinter, London.

Etzkowitz, H., 1993, Enterprises from Science: The Origins of Science-based Regional Economic Development, Minerva, Vol.XXXI, No.3, pp.326-360.

Etzkowitz, H., 1993, Redesigning "Solomon's House": The University and the Internationalization of Science and Business, in Crawford, E. et. al., Denationalizing Science, Kluwer Academic Publishers, pp. 263-288.

Evans, R., 1990, Le Università di Oxford e Cambridge, in Brizzi, G.P. and I. Verger (eds.), 1990, Le Università dell'Europa: La Nascita delle Università, Amilcare Pizzi Editore, Milano.

Fairweather, J., 1988, Reputational Quality of Academic Programs: The Institutional Halo, Research in Higher Education, Vol.28, pp.345-355.

Faulkner, W. and J. Senker, 1995, Knowledge Frontiers. Public Sector Research and Industrial Innovation in Biotechnology, Engineering ceramics, and parallel Computing, Oxford University Press, Oxford.

Feller, 1., 1990, Universities as Engines of R\&D-Based Economic Growth: They Think They Can, Research Policy, Vol.19, pp.335-348.

Ferrone, V., 1992, Le Accademie Scientifiche, in Brizzi, G.P. and I. Verger (eds.),1992, Le Università dell'Europa: Dal Rinnovamento Scientifico all'Età dei Lumi, Amilcare Pizzi Editore, Milano.

Flam, F., 1992, Japan Bids for US Basic Research, Science, Vol.258, pp. 1428-1430. 
Foray, D., 1994, University-Industry Research Relations: Institutional Problems, Organization and Contractual Tools in France, presented at The CEPR/AAAS conference "University Goals, Institutional Mechanisms, and the "Industrial Transferability' of Research", Stanford University, March 18-20.

Foray, D. and B. Lundavall, 1996, The knowledge-based Economy: From the Economics of Knowledge to the Learning Economy, in OECD, 1996, Employment and Growth in the Knowledge-based Economy, Paris.

Frank, R.H. and P.J. Cook, 1995, The Winner-Take-All Society, Martin Kessler Books, The Free Press, New York.

Freeman, C. and L. Soete, 1997, The Economics of Industrial Innovation, Pinter Publisher, London.

Frijhoff, W., 1992, Universities: 1500-1900, in B.R. Clark and G. Neave, The Encyclopedia of Higher Educarion, Pergamon Press, Oxford.

Gambardella. A and W. Garcia-Fontes, 1996, Regional Linkages through European Research Funding, Economics of Innovation and New Technologies, Vol.4, pp.123138.

GarciamFontes, W. and A. Geuna, 1998, The Dynamics of Network in BRITE/EURAM, in A. Gambardella and F. Malerba (eds.), The Organisation of Inventive Activity in Europe, forthcoming from Cambridge University Press.

Garner, C.A., 1979, Academic Publication, Market Signalling, and Scientific Research Decisions, Economic Inquiry, Voll.XVII, pp. 575-584.

Garvin, D.A., 1980, The Economics of University Behaviour, Academic Press, New York.

Geiger, R.L., 1993, Research and Relevant Knowledge. American Research Universities Since World War II, Oxford University Press, Oxford.

Geiger, R.L., 1985, The Home of Sicientists: A Perspective on University, in Wittrock, B. and A. Elzinga (eds.), 1985, The University Research System. The Public Policies of the Home of Scientists, Almquist \& Wiksell International.

Gellert, C. (ed.), 1993, Higher Education in Europe, Jessica Kingsley Publishers, London.

Georghiou, L. et al. 1993, The Impact of European Community Policies for Research. and Technological Development Upon Science and Technology in the United Kingdom, Report prepared for the DGXII of the Commission of the European Communities and for the Office of Science \& Technology, HMSO, London. 
Geuna, A., 1998a, Determinants of University Participation in EU-Funded R\&D Cooperative Projects, Research Policy, Vol. 26, pp.677-687.

Geuna, A., 1998b, The Internationalisation of European Universities: A Return to Medieval Roots, Minerva A Review of Science, Learning and Policy, forthcoming.

Geuna, A., 1997, Allocation of Funds and Research Output: The Case of UK Universities, Revue d'Économie Industrielle, N. 79, $1^{\text {er }}$ Trimestre, pp. 143-162.

Geuna, A., 1996. The Participation of Higher Education Institutions in Community Framework Programmes, Science and Public Policy, Vol.23, pp.287-296

Gez, M., Siegfried, J.J. and Hao Zhang, Estimating Economies of Scale in Higher Education, Economics Letters, Vol.37, pp.203-208.

Gibbons, A., 1992, Bioteclnnology, Japanese in for American Expertise, Science, Vol.258, November 27, pp. 1431-1433.

Gibbons, M. et al., 1994, The New Production of Knowledge. The Dynamics of Science and Research in Contemporary Societies, Sage Publications, London.

Gibbons, M. and B. Wittrock (eds.), 1985, Science as a Commodity: Threats to the Open Community of Scholars, Longman, Harlow.

Gieysztor, A., 1992, Management and Resources, in Rüegg, W. (ed.), 1992, A History of the University in Europe. Vol.I Universities in the Middle Ages, Cambridge University Press, Cambridge.

Gimore, J.L. and D. To, 1992, Evaluating Acadenic Productivity and Quality, in C.S. Hollins, Containing Costs and Improving Productivity in Higher Education, New Directions for Institutional Research, Jossey-Bass Publishers.

Giorello, G., Regge, T. and S. Veca, 1993, Europa Universitas, Feltrinelli, Milano.

Glass, J.C., McKillop, D.G. and N. Hyndman, 1995, Efficiency in the Provision of University Teaching and Research: An Empirical Analysis of UK Universities, Journal of Applied Econometrics, Vol.10, pp.61-72.

Glennerster, H., 1991, Quasi-markets for Education?, The Economic Journal, Vol.101, pp. 1268-1276.

Goff Le, J., 1990, Introduzione, in Brizzi, G.P. and J. Verger (eds.), 1990, Le Università dell'Europa: La nascita delle Università, Amilcare Pizzi Editore, Milano.

Goudriaan, R. and H. de Groot, 1993, State regulation and University Behavior, Journat of Economic Behavior and Organization, Vol.20, pp.309-318. 


\section{Bibliography}

Griliches, Z, 1996, Education, Human Capital, and Growth: A personal Perspective, NBER, Working Paper 5426.

Groot de, H., McMahon, W.W. and J.F. Volkwein, 1991, The Cost Structure of American Research Universities, The Review of Economics and Statistics, Voll.73. pp.424-431.

Guston, H. and K. Keniston (eds.), 1994a, The Fragile Comtract, The MIT Press, Cambridge, $\mathrm{MA}$.

Guston, $\mathbb{H}$ and $\mathrm{K}$ Keniston, 1994b, Introduction: The Social Contract for Science, in H. Guston and K. Keniston (eds.), The Fragile Contract, The MIT Press, Cambridge, MA.

Hague, D., 1991, Beyond Universities. A New Republic of the Intellect, Hobart Paper 115, IEA London.

Hall, A.R., 1983, The Revolution in Science. 1500 1750, Longman, London.

Hanham. H.J., 1991, The Funding of University Research. The Rolle of Overheads, Higher Education Management, Vol.3, pp.107-113.

Hansen, W.L., 1970, Income Distribution Effects of Higher Education, American Economic Review, Vol.60, pp.335-341.

Hare, P. and G. Wyatt, 1992, Economics of Academic Research and Its Implications for Higher Education, Oxford review of economic Policy, Vol.8, pp.48-66.

Hare, P. and G. Wyatt, 1988, Modelling the Determination of Research Output in British Universities, Research Policy, Vol.17, pp.315-328.

Harris, G. and G. Kaine, 1994, The Determinants of Research Performance: A Study of Australian University Economists, Higher Education, Vol.27, pp.191-201.

HEFCE, The Impact of the 1992 Research Assessment Exercise on Higher Education Institutions in England, Ref M 6/97, http:/www.niss.ac.uk/education/hefce/ pub97/

HEFCE, Anmual Report 1992-93, 1993.94.

Hicks, D., 1995, Published Papers. Tacit Competencies and Corporate Management of the Public/Private Character of Knowledge."Industrial and Corporate Change, Vol.4. pp.401-424.

Hildenbrand, W., 1989, Facts and Ideas in Microeconomics Theory, European Economic Review, Vol.33, pp.251-276. 
Hippel, E, von, 1988, The Source of Innovation, Oxford University Press, Oxford.

HMSO, 1993, Realising our potential. A strategy for Science, Engimeering and Technology.

HMSO, 1991, Higher Education. A New Framework.

HMSO, 1988, Education Reform Act 1988 Chapter 40, (Reprinted 1989).

Hoare, A.G., 1995, Scale Economies in Academic Excellence: An Exploratory Analysis of the United Kingdom's 1992 Research Selectivity Exercise, Higher Education, Vol.29: pp.241-260.

Hoare, A.G., 1991, Reviewing the Review: The Geography of University Rationalisation, Higher Education Quarterly, Vol.45, pp.234-253.

Hoenack, S.A., 1990, An Economist's Perspective on Costs Within Higher Education Institutions, in S.A. Hoenack and E.L. Collins (eds.), The Economics of American Universities. Management, Operations, and Fiscai Environment. State University of New York Press, Albany, NY.

Hoenack, S.A. and E.L. Collins (eds.), 1990, The Economics of American Universities. Management, Operations, and Fiscal Environment, State University of New York Press, Albany, NY.

Hopkins, D.S.P., 1990, The Higher Education Production Function: The Theoretical Foundations and Empirical Findings, in S.A. Hoenack and E.L. Collins (eds.), The Economics of American Universities. Management, Operations, and Fiscal Environment, State University of New York Press, Albany, NY.

House of Lords, Selected Committee on the European Communities, 1990 . A Community Framework for $R \& D, \mathrm{HMSO}$, London.

Hughes, D., Griffiths, L. and J.V. McHale, 1997, Do Quasi-markets Evolve'? Institutional Analysis and the NHS, Cambridge Journal of Economics, Vol,21, pp. $259-276$.

Hurst, E.R., 1991, Cost Calculation and Cost Management of Multinational Research Projects, Higher Education Management, Vol.3, pp. 114-127.

International Association of Universities, 1993, Intemational Handbook of Universities, Stockton Press, New York.

International Association of Universities, 1991, International Handbook of Universities, Stockton Press, New York. 


\section{Bibliography}

Jaffe, A, 1989, Real Effects of Academic Research, American Economic Review, Vol.79, pp.957-970.

James, E. 1990, Decision Processes and Priority in Higher Education, in S.A. Hoenack and E.L. Collins (eds.), The Economics of American Universities. Management, Operations, and Fiscal Environment, State University of New York Press, Albany, NY.

James, E., 1986, The Private Nonprofit Provision of Education: A Theoretical Model and Application to Japan, Journal of Comparative Economics, Vol.10, pp.255-276.

James, E., 1978, Product Mix and Cost Disaggregation: A Reinterpretation of the Economics of Higher Education, The Journal of Human Resources, Vol.13, pp. 157186.

James, E. And E. Neuberger, 1981, The University Department as a Non-profit Labor Cooperative, Public Choice, Vol.36, pp.585-612.

James, E. and S. Rose-Ackerman, 1986. The Nonprofit Enterprise in market Economics, Fundamentals of Pure and Applied Economics, Harwood Academic Publisher, Chur.

Jílek L. (ed.), 1984, Historical Compendium of European Universities, CRE, Geneve.

Johnes, G., 1997, Costs and Industrial Structure in Contemporary British Higher Education, The Economic Journal, Vol.107, pp.727-737.

Johnes, G., 1992, Performance Indicators in Higher Education: A Survey of Recent Work, Oxford Review of Economic Policy, Vol.8, pp.19-34.

Johnes, G., 1988, Determinants of Research Output in Economics Departments in British Universities, Research Policy, Vol.17, pp.171-178.

Johnes, G. and J. Johnes, 1993, Measuring the Research Performance of UK Economics Departments: An Application of Data Envelopment Analysis, Oxford Economic Papers, Vol.45, pp.332-347.

Johnston, R., 1994, Effects of Resource Concentration on Research Performance, Higher Education, Vol.28, pp.25-37.

Jorgenson, D.W., 1986, Econometric Methods for Modelling Producer Behavior, Chapter 31 in Griliches, Z. and M.D. Intriligator (eds.), Handbook of Econometrics, North-Holland, Amsterdam.

Jongbloed, B.W.A. and D.F. Westerheijden, 1994, Performance Indicators and Quality Assessment in European Higher Education, in V.M.H. Borden and T.W. 


\section{Bibliography}

Banta, Using Performance Indicators to Gülde Strategic Decision Making. New Direction for Institutional Research, Jossey-Bass Publisher, San Francisco.

Kaiser, F. et al. 1992, Public Expenditure on Higher Education: a Comparative Study in the EC-Member States, 1975-1990, Higher Education in Europe, Vol. 17, pp.33-64.

Karady, V., 1986, Les Université de la Troisième République, in Verger, J. (ed.), 1986, Historie des Universités en France, Bibliothéque Historique Privat, Toulouse.

Katz, J.S., Hicks, D., Sharp, M. and Ben R. Martin, 1995, The Changing Shape of British Science, STEEP Special Report No 3, SPRU.

Katz, J.S., and B.R. Martin., 1997, What Is Research Collaboration?, Research Policy, Vol.26, pp.1-18.

Kells, H. (ed.), 1993, The Development of Performance Indicators for Higher Education: A Compendium for Twelve Countries, Programme on Institutional Management in Higher Education, OECD, Paris.

Kerr, C., 1995, The Uses of the University, Harvard University Press, Cambridge, MA.

Kesselring, R.G. and C.T. Strein, 1986, A Test of The Williamson Hypothesis for Universities, The Journal of Behavioral Economics, Vol. 15, pp.103-112.

Kersbergen van, K. and B. Verbeek, 1994, The Policy of Subsidiarity in the European Union, Joumal of Common Market Studies, Vol.32, pp.215-236.

Kirman, A.P., 1992, Whom or What Does the Representative Individual Represent? Jowrnal of Economic Perspectives, Vol.6, pp. 117-136.

Kuhn, T.S., 1970, The structure of Scientific Revolutions, 2nd ed., University of Chicago Press, Chicago.

Kuznets, S., 1966, Modern Economic Growth: Rate, Stracture and Spread. Yale University Press, New Haven.

Kyvik, S., 1995a, Are Big Departments Better than Small Ones? Higher Edwcation, Voll.30, pp.295-304.

Kyvik, S, 1995b, Department Size and Resources for Administration, Tertiary Education and Management, Vol.1, pp.107-108.

Lakatos, 1., 1970, Falsification and the Methodology of Scientific Research Programmes, in 1. Lakatos and A. Musgrave (eds.), Criticism and the Growth of Knowledge, Cambridge University Press, Cambridge. 
Lambert, G. and Willinger, M., 1994, Status quo presentation and organisational inertia, presented at the EUNETIC conference "Evolutionary Economics of Technological Change" European Parliament, Strasbourg, October 6-7.8.

Larédo, P., 1995, The Impact of Community Research Programmes in France, Press Ecole des Mines de Paris.

Larédo, P., 1994, Les politiques européennes de R\&D au milieu de guế, in F. Sachwald (ed.), Les defis de la mondialisation innovation et concurrence, Masson, Paris.

Lee, Y.S., 1996, 'Technology Transfer' and the Research University: A Search for the Boundaries of University-industry Collaboration, Research Policy, Vol.25, PP. 843-863.

Le Grand, J.L, 1991, Quasi-markets and Social Policy. The Economic Joumal, Vol.101, pp 1256-1267.

Leydesdorff, L., 1992, The Impact of EC Science Policies on the Transnational Publication System, Technology Analysis \& Strategic Management, Vol.4, pp.279. 298.

Lloyd, P.J., Morgan, M.H. and R. A. Williams, 1993, Amalgamations of Universities: Are There Economies of Scale or Scope?, Applied Economics, Vol.25, pp.10811092.

Lotka, A.J., 1926. The Frequency Distribution of Scientific Productivity, Joumal of the Washington Academy of Sciences, Vol. 16, pp.317-323.

Lowe, J., 1993, Commercialization of University Research: A Policy Perspective, Technology Analysis \& Strategic Managenent, Vol.5, pp.27-37.

Lundvall, B.-A. (ed.), 1992, National System of Innovation: Towards a Theory of Innovarion and Interactive Learning. Pinter Publishers, London.

Laukkonen, T., O. Persson and G. Sivertsen, 1992, Understanding Patterns of International Scientific Collaboration, Science, technology \& Human Values, Vol. 17, pp. $101-126$.

Maassen. A.M., Goedegebuture, C.J., and D.F. Westerheijden, 1993, Social and Political Conditions for Changing Higher Education Structures in the Netherlands, in C. Geller (ed.), Higher Education in Europe, Jessica Kingsley Publishers, London.

Maclulup, F., 1982, Knowledge: Its Creation, Distribution, and Economic Significance, Vol. 1-3, Princeton University Press. 


\section{Bibliography}

Malerba, F. et ah., 1991, The Nascent Globalization of Universities and Public and Quasi-Public Research Organisations, FAST Research in the framework of the MONITOR Programme.

Mansfield, E., 1995, Academic Research Underlying Industrial Innovations: Sources, Characteristics, and Financing. The Review of Economics and Siatistics, Vol.LXXVII, pp.55-65.

Mansfield, E., 1991, Academic Research and Industrial Innovation, Research Policy, Vol.20, pp. 1-12.

Mansfield, E. and J.Y. Lee, 1996, The Modern University: Contributor to Industrial Innovation and Recipient of Industrial R\&D Support, Research Policy, Vol.25, pp. $1047-1058$

Mantovani, A., 1991, Accademie Scientifiche e Letterarie, in Brizzi, G.P. and J. Verger (eds.),1991, Le Università dell'Europa: Dal Rinascimento alle Riforme Religiose, Amilcare Pizzi Editore, Milano.

Martin, B.R., 1994, British Science in the 1980s - Has the Relative Declime Continued?, Scientomernics, Vol.29, pp.27-56.

Martin, B. R. et al., 1993, The Effect of Size and Other Factors on the Research Performance of University Departments, SPRU, University of Sussex.

Martin, B.R., and J. Irvine, 1983, Assessing Basic Research: Some Partial Indicators of Scientific Progress in Radio-Astronomy, Research Policy, Vol.12, pp.61-90.

Martino, J.P., 1992, Science Funding. Politics \& Porkbarrel, Transaction Publishers, New Brunswick.

Massit-Follé, F. and F. Epinette, 1992, L'Europe des Universitess. LEnseignement Supérieur en Mutation, La Documentation Française, Paris.

Massy, W.F. (ed.), 1996, Resource Allocation in Higher Education, The University of Michigan Press.

Masten, S.E., 1997. The Internal Organization of Higher Education; Or Why Universities, Like Leguslatures, Are nor Organized as Markets, mimeo University of Michigan Business School.

Matteucci, N. (ed.), 1991. L'Universita nel Mondo Contenporaneo, Bompiani, Milano.

McClellan, J.E. III, 1985, Science Reorganised: Scientific Societies in the Eighteenth Century, Columbia Lniversity Press, New York. 


\section{Bibliography}

Meek, V.L. and F.Q. Wood, 1997, The Market as at New Steering Strategy for Australian Higher Education, Higher Education Policy, Vol. 10, pp.253-274.

Merton, R.K., 1973, The Sociology of Science: Theoretical and Empirical Investigations, Chicago University Press, Chicago.

Merton, R.K., 1968, The Matthew Effect in Science, Science, Vol.159, pp.56-63.

Miller, H.D.R, 1995, The Management of Change in Universities, SRHE and Open University Press, Buckingham.

Moed, H.F. et al., 1985, The Use of Bibliometric Data for the Measurement of University Research Data, Research Policy, Vol.14, pp.131-149.

Murphy, P.S., 1995, Benchmarking Academic Research Output in Australia, Assessment \& Evaluation in Higher Education, Vol.20, pp.45-57.

National Committee of Inquiry into Higher Education, 1997, Higher Education in the Learning Society: Report of the National Committee, HMSO, Norwich.

National Science Board, 1982, Industry-University Research Relationships, 14th report of the NSB, Washington D.C.

Neave, G. and F. Van Vught (eds.), 1991, Prometheus Bound. The Changing Relationship Between Government and Higher Education in Western Europe, Pergamon Press.

Nederhof, A.J. and A.F.J. van Raan, 1993, A Bibliometric Analysis of Six Economics Research Groups: A Comparison with Peer Review, Research Policy, Vol.22, pp.353368.

Nederhof, A.J. and E.C.M. Noyons, 1992, Assessment of the International Standing of University Departments' Research: A Comparison of Bibliometric Methods, Scientometrics, Vol.24, pp.393-404.

Nelson, R.R., 1959, The Simple Economics of Basic Scientific Research, Joumal of Political Economy, Vol.67, pp.297-306.

Nelson, R.R. (ed.), 1993, National Innowation System: A Comparative Analysis, Oxford University Press, Oxford.

Nelson, R.R. and N. Rosemberg, 1994, American Universities and Technical Advance in Industry, Research Policy, Vol.23, pp.323-348.

Nerlove. M., 1972, On Tuition and Costs of Higher Education: Prolegomena to a Conceptual Framework, Journal of Political Economy, Vol.80, pp.s178-s218. 


\section{Bibliography}

OECD, 1996. Employment and Growth in the Knowledge-based Economy, Paris.

OECD, 1995, Education at a Glance, Paris.

OECD, 1992, Pubiic Educational Expenditure, Costs and Financing: An Analysis of Trends 1970-1988, Paris.

OECD, 1990a, University-Enterprises Relations in OECD Member Countries, Paris.

OECD, 1990b, Financing Higher Education. Current Patterns, Paris.

OECD, 1987, Universities under Scrutiny, Paris.

OECD, 1984, Industry and University: New Forms of Co-operation and Communication, Paris.

OECD, 1981, The Measurement of Scientific and Technological Activities. R\&D Statistics and Output Measurement in the Higher Education Sector, Paris.

OST, 1996, Science \& Technologie Indicateurs 1996. Economica, Paris.

OST, 1994, Science \& Technologie Indicateurs 1994, Economica, Paris.

Palombara, J., 1991, Gli Usi Strumentali dell'Università: Riflessioni sull'Esperienza degli Stati Uniti, in N. Matteucci, L univeristà nel Mondo Contemporaneo, Bompiani, Milano.

Pavitt, K., 1995, Academic Research, Technical Change and Government Policy, in J. Krige and D. Pestre (eds.), Science in the 20 $0^{\text {th }}$ Cenfury, Harwood Academic Publishers.

Pavit, K, 1993, What do Firms Learn from Basic Research?, in D. Foray and C. Freeman (eds.), Technology and the Wealth of Nations." The Dynamics of Constructed Advantage, Pinter Publishers, London.

Pavitt, K, 1991, What Makes basic Research Economically Useful?, Research Policy, Vol. $20, \mathrm{pp} .109-119$.

Peacock, A., 1991, Economics, Cultural Values and Cultural Policies, Joumat of Cultural Economics, Vol.15, pp.1-18.

Perkin, H., 1984, The Historical Perspective, in B.R. Clark (ed.), Perspectives on Higher Education, University Califomia Press, Berkeley. 


\section{Bibliography}

Pestre, D., 1997, La Production des Savoir Entre Académies et Marché - Une Relecture Historique du Livre: "The Production of Knowledge", Édité par M. Gibbons, Revue d'Economie Industrielle, No.79, $1^{\text {er }}$ Trimestre, pp. 163-174.

Peters, M., 1992, Performance and Accountability in 'Post-industrial Society': The Crisis of British universities, Studies in Higher Education, Vol.17, pp. 123-139.

Phillimore, A.J., 1989, University Research Performance Indicators in Practice: The University Grants Committee's Evaluation of British Universities, 1985-1986, Research Policy, Vol.18, pp.255-271.

Pike, A. And D. Charles, 1995, The impact of International Collaboration on UK University-Industry Links, Industry and Higher Education, Vol.9, pp.264-276.

Price de Solla, D.J., 1963, Little Science, Big Science, Columbia University Press, New York.

Price de Solla, D.J., 1976, A General Theory of Bibliometric and Other Cumulative Advantage Process, Journal of the American Society of Information Science, Vol.27, pp.292-306.

Ramsden, P., 1994, Describing and Explaining Research Productivity, Higher Education, Vol.28, pp.207-226.

Raan, R.T.H wan (ed.), 1988, Handbook of Quantitative Studies of Science and Technology, North Holland, Amsterdam.

Rashdall, H., 1936, The Universities of Europe in the Middle Ages, Oxford University Press, Oxford.

Robbins Report, 1963, Higher Education, HMSO.

Rose-Ackerman, S. (ed.), 1986, The Economics of Nonprofit Instifutions, Oxford University Press, New York.

Rosemberg, N., 1994, Science-Technology-Economy Interactions, in O. Granstrand (ed.). Economics of Technology, Elsevier Science, Amsterdam.

Rothblatt, S. and B. Wittrock (eds.), 1993, The European and American University since 1800, Cambridge University Press, Cambridge.

Rothblatt, S., 1976, Tradition and Change in English Liberal Education, Faber and Faber, London.

Rothschild, M. and L.J. White, 1991, The University in the Marketplace: Some lnsights and Some Puzzles, NBER Working Papers Series, No. 3853. 


\section{Bibliography}

Rudy, W., 1984, The Universities of Europe, 1100-1914. A History, Associated Universily Press, Cranbury.

Rüegg, W. (ed.), 1992, A History of the University in Europe. Voll I Universities in the Middle Ages, Cambridge University Press, Cambridge.

Ruiegg, W., 1992. Themes, in W. Rüegg (ed.), 1992, A History of the University in Europe. Voll Universities in the Middle Ages, Cambridge University Press, Cambridge.

Sanderson, W., 1974, Does the Theory of Demand Need a Maximum Principle?, in P.A. David and M.W. Reder (eds.), Households and Nations in Economic Growth, Academic Press.

Senker, J., Senker P. and M. Grossman, 1995, Effects of TCS on Academia, SPRU Report, University of Sussex, Falmer.

Samuelson, W. and R. Zeckhauser, 1988, Status Quo Bias in Decision Making, Journal of Risk and Uncertainty, Vol.1, pp. 1-59.

Santambrogio, M. 1997. Chi Ha Paura del Numero Chisso?. Laterza Roma.

Schmitt, C. (ed.), 1985 1994, History of University, Vol.V-XIII, Oxford University Press, Oxford.

Schultz, T.W., 1960, Capital Formation by Education, Joumal of Political Economy, Vol.68, pp.571-583.

Scott, P., 1997. The Changing Role of the University in the Production of New Knowledge, Tertiary Education and Management, Vol.3, pp.5-14.

Scott, P., 1984, The Crisis of the Uniwersity, Croom Helm, London.

Shapley, D. and R. Roy, 1985, Lost at the Fronier. US Science and Technology Policy Adrift, ISI Press, Philadelphia.

Simon, H.A., 1955, A Behavional Model of Rational Choice, Quarterly Jommal of Economics, Vol.69, pp.99-118.

Simone, R., 1993, L'Università dei Tre Tradimenti, Saggi Tascabili Laterza, Roma.

Slaughter, S. and $\mathrm{G}$. Rhoades, 1996, The Emergence of a Competitiveness Research and Development Policy Coalition and the Commercialization of Academic Science and Technology, Science, Technology, \& Haman Values, Vol 21, pp.303-339. 


\section{Bibliography}

Smith. A. 1976, An Inquiry into the Nature and Causes of the Wealth of Nations, Oxford University Press [1 ${ }^{\text {st }} \mathrm{ed.}$ 1776], London.

Soete, L. and A. Arundel (eds.), 1993, An Integrated Approach to European Imnovation and Technology Diffusion Policy: A Maastricht Memorandum, SPRINT, Commission of the European Communities, Publication no. EUR 15090, Bruxelles.

Sommer, JW. (ed.), 1995, The Academy in Crisis, The Independent Institute, Oakland, California.

Spence, A.M., 1974, Market Signalling. Information Transfer in Hiring and Related Screening Processe: Harvard University Press, Cambridge, Massachusetts.

Spinner, H.F., 1993, Althoff and the Changing Constitution of Science: Bureaucratic, Economical or Cognitive?, Jounal of Economic Studies, Vol.20, pp.134-166.

Stahler, G.J. and W.R. Tash, 1994, Centers and Institutes in the Research University, Journal of Higher Education, Vol.65, pp.540-554.

Stankiewicz, R., 1986, Academics and Entrepreneurs: Developing University. Industry Relations, Frances Printer, London.

Staropoli, A. et al, 1995, Modelli di Universita' in Europa e la Questione dell'Autonomia, Fondazione Giovanni Agnelli, Torino.

SteindI, J., 1965, Random Processes and the Growth of Firms, Griffin \& Company Limited, London.

Steinmueller, W.E., 1994, Basic Research and Industrial Innovation, Chapter 5 in M. Dodgson and R. Rothwell (eds.), The Handbook of Industrial Innovation, Edward Elgar, Aldershot.

Stephan P.E., 1996, The Economics of Science, Joumal of Economic Literature, Vol.34, pp.1199-1235.

Stiglitz, J.E., 1988, Economics of the Public Sector, W.W. Norton \& Company, New York.

Sutton, J., 1997, Gibrat's Legacy, Joumal of Economic Literature, Vol. XXXV, pp. $40-59$.

Tapper, E.R. and B. G. Salter, 1995, The Changing Idea of University Autonomy, Studies in Higher Education, Vol.20, pp.59-71.

Teichler, U., 1988, Changing Patterns of the Higher Education System.: The Experience of Three Decades, Jessica Kingsley Publishers, London. 


\section{Bibliography}

The Economist, 1997, The Knowledge Factory, October $4^{\text {th }}$.

The Times Higher Education Supplement, Various issues.

Tornquist, K.M. and L.A. Kallsen, 1994, Ont of the Ivory Tower, Characteristics of Institutions Meeting the Research Needs of Industry, Journal of Higher Education. Vol.65, pp.523-539.

Trow, M.A., 1984, The Analysis of Status, in B.R. Clark (ed.), Perspectives on Higher Education, University California Press, Berkeley.

Turner, S., 1996, Comments on The Economics of Science, Special Issue The Economics of Science, The International Joumal of Knowledge Transfer and Utilization, Summer/Fall, Vol.9, pp.99-105.

Tversky, A. and Kahneman, D., 1991, Loss Aversion and Riskless Choice: A Reference-Dependent Model, Quarterly Joumal of Economics, Vol.106, pp. 10391061.

Unesco Statistical Yearbook, various editions.

Universities' Statistical Record, University Statistics. Vol.1 Students and Staff, Various issues.

Universities' Statistical Record, University Statistics. Vol.3 Finance, Various issues.

Valigra, L., 1994, Academic Biotech Deals Offer More Promise Than Product, Science, Vol.263, pp.168-169.

Vavakova, B., 1998, The New Social Contract: Governments, Universities, and Society. Has the Old One Failed?, Minerva A Review of Science, Learning and Policy, forthcoming

Veblen., T., 1918, The Higher Learning In America. A Memorandum on the Conduct of Universities by Business Men, reprinted 1994 Routledge/Thoemmes Press, London.

Vereeck, L.M.C., 1992. The Economics of Science and Scholarship: An Analysis of the Althoff System, Universitaire Pers Maastricht, Maastricht.

Verger, J., 1992a, Patterns, in W. Ruiegg (ed.), 1992, A History of the University in Europe. Voll Universities in the Middle Ages, Cambridge University Press. Cambridge. 
Verger, J., 1992b, Teachers, in Ruiegg, W. (ed.), 1992, A History of the University in Europe. Voll Universities in the Middle Ages, Cambridge University Press, Cambridge.

Verger, J. (ed.), 1986, Histoire des Universités en France, Bibliothéque Historique Privat, Toulouse.

Vught van, F.A., 1997, Cornbining Planning and the Market: An Analysis of the Government Strategy towards. Higher Education in The Netherlands, Higher Education. Policy, Vol.10, pp.211-224.

Vught van, F.A., 1991, The Netherlands: From Corrective to Facilitative Governmental Policies, in G. Neave and F. Van Vught, 1991, Prometheus Bound. The Changing Relationship Between Govemment and Higher Education in Western Europe, Pergamon Press.

Weale, M.., 1992, The Benefits of Higher Education: A Comparison of Universities and Polytechnics, Oxford Review of Economic Policy, Vol.8, pp.35-47.

Webster, A., 1994, UK Government's White Paper (1993): A Critical Commentary on Measures of Exploitation of Scientific Research, Technology Analysis \& Strategic Management, Vol.6, pp.189-201.

Weghtman, P., 1991, Collaborative Scientific Research in a European Context. A University of Liverpool Case Study, Higher Education Management, Vol.3, pp. 145153.

Williams, G., 1992, An Evaluation of the New Funding Mechanisms in British Higher Education: Some Micro-Economic and Institutional Management Issues, Higher Education in Europe, Vol.17, pp.64-85.

Williams, G., 1992, Changing Patterns of Finance in Higher Education, SRHE and Open University Press, Buckingham.

Williams, G., 1984, The Econornic Approach, in B.R. Clark (ed.), Perspectives on Higher Education, University California Press, Berkeley.

Williamson, O.E., 1967, The Economics of Discretionary Behaviour: Managerial Objectives in a Theory of the Firm, Markham Publishing Company, Chicago.

Wittrock, B., 1993, The Modern University: The Three Transformations, in S. Rothblatt, and B. Wittrock (eds.), 1993, The European and American University since 1800, Cambridge University Press, Cambridge.

Wittrock, B. and A. Elzinga (eds.), 1985, The University Research System. The Public Policies of the Home of Scientists, Almqvist \& Wiksell International. 


\section{Bibliography}

Wood, F.Q. 1997, The Peer Review Process, National Board of Employment. Education and training, Australian Research Council, Commissioned Report No.54.

Wood, F.Q., 1995, Issues and Problems in the Public Funding of University Basic Research, Ph.D. Thesis, University of New England, Armidale NSW.

Wood, P., 1994, Science, the Universities, and the Public Sphere in the EighteenthCentury Scotland, in History of University, VolXII, Oxford University Press, Oxford.

World of Learning, 1995, Europa Publications, London.

Ziman, J., 1994, Prometheus Bound. Science in a Dynamic Steady State, Cambridge University Press, Cambridge.

Zuckerman, H., 1977, The Scientific Elite: Nobel laureates in the United States, The Free Press, New York. 
Bibliography 


\section{Nederlandse Samenvatting (Dutch Summary)}

Dit proefschrift gaat over de universiteiten in de landen van de Europese Unie aan het begin van de jaren negentig. Het is vooral gericht op de invloed van gewijzigde grondslagen voor universiteitssubsidies op wetenschappelijk onderzoek en op de structuur van het universiteitsstelsel. Aan de orde komen daarnaast de steeds wisselende mogelijkheden en beperkingen waarmee universiteiten in de EU te maken krijgen. In deel 1 van het proefschrift wordt een gedragsaanpak geschetst ten aanzien van wetenschappelijk onderzoek, en wordt een historische beschrijwing gegeven van de "Europese universiteit" als kenmerkende eenheid van analyse. Op basis hiervan wordt in deel 2 de samenhang geanalyseerd tussen de toekenning van subsidiex enerzijds en de organisatie en ontwikkeling van wetenschappelijk onderzoek anderzijds. In deel 3 wordt ten slotte het door de EU gefinancierd wetenschappelijk onderzoek grondig bestudeerd.

De globale doelstelling van dit proefschrift is inzicht te krijgen in de onbedoelde gevolgen van de veranderde grondslagen voor subsidietoekenning aan universiteiten, meer in het bijzonder het bestaan van die gevolgen en de invloed daarvan op het beleid en de prioriteiten van universiteiten. Hierbij komen wee andere specifieke onderwerpen aan bod. In de eerste plats, de samenhang tussen het toekennen van subsidies en de productiviteit van wetenschappelijk onderzoek. Deze analyse heef betrekking op de totale universiteitspopulatie in de EU-landen en meer specifiek op de "oude" uniwersiteiten van het Verenigd Koninkrijk. Daarbij komt vooral de invloed van financiering vanuit het bedrijfsleven aan de orde waarop universiteiten steeds meer lijken te zijn aangewezen voor hun onderzoek. In de tweede plats worden zogenaamde 'competitieve' subsidies voor wetenschappelijk onderzoek beinvloed 
door cumulatieve en zichzelf versterkende verschijnselen, en in het bijzonder door het zogeheten 'Mathew-effect'. Nagegaan wordt wat de invloed hiervan is op de deelname van universiteiten in door de EU gefinancierde samenwerkingsverbanden op het gebied van $\mathrm{R} \& \mathrm{D}$. 


\section{Curriculum Vitae}

Aldo Geuna is a Research Fellow at BETA, Universite Louis Pasteur (Strasbourg 1), financed by a post doctoral Marie Curie Fellowship of the European Commission. He studied at the Politecuico di Milano, Universita di Torino and Maastricht University. His research interests includes Industrial Organisation, Economics of Innovation and Technological Change, Economics of Knowledge Production, Science and Technology Policy, Economics of Information and Communication Technologies, Internet Economics. 